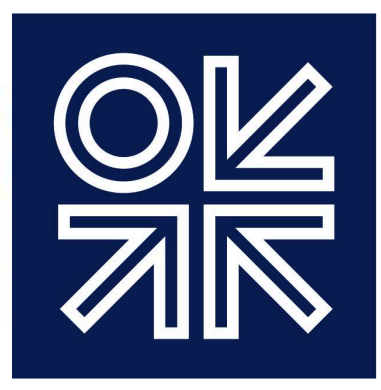

THE OXFORD

INSTITUTE

FOR ENERGY

STUDIES

December 2015

\title{
The evolution of European traded gas hubs
}

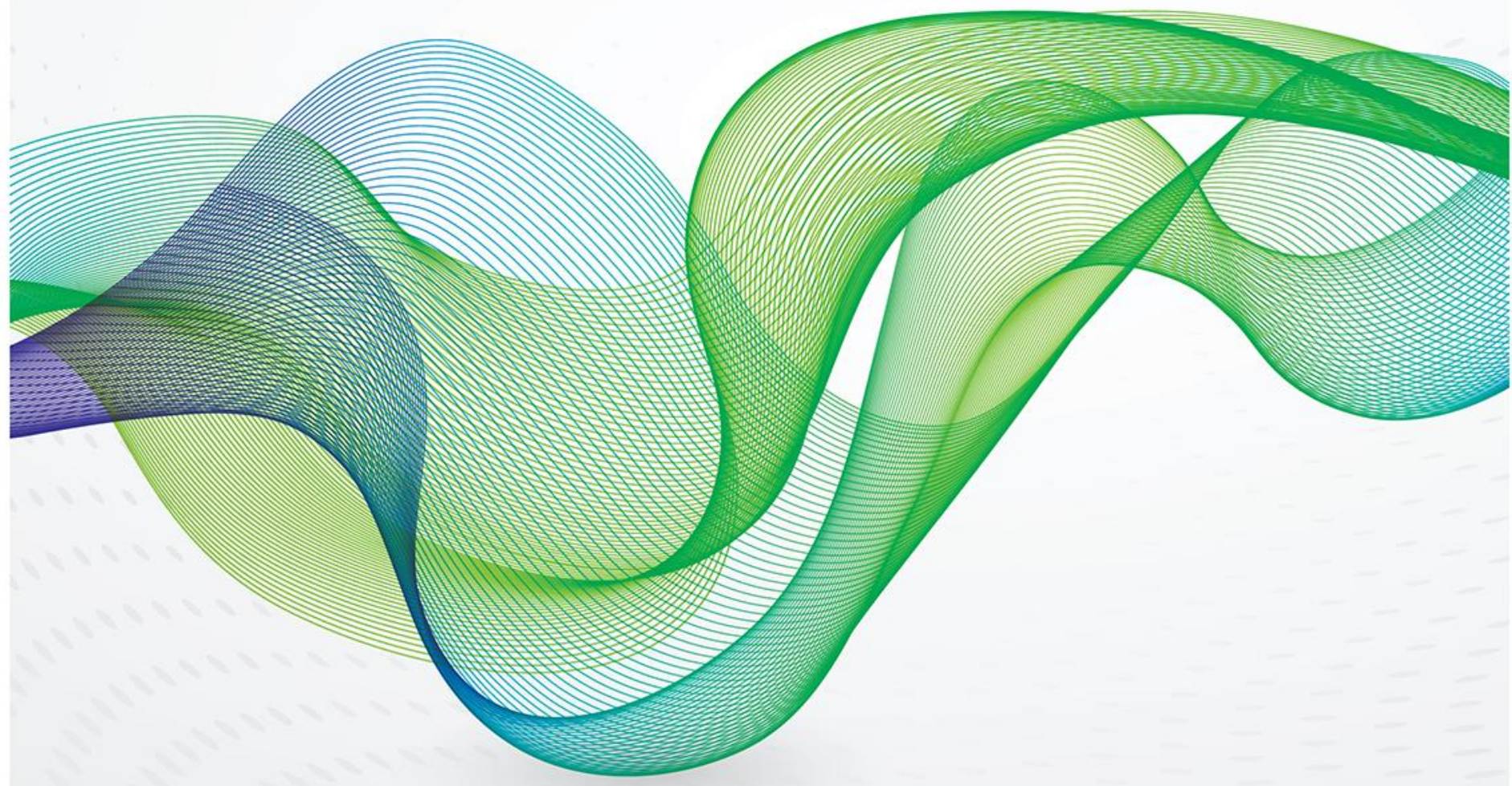



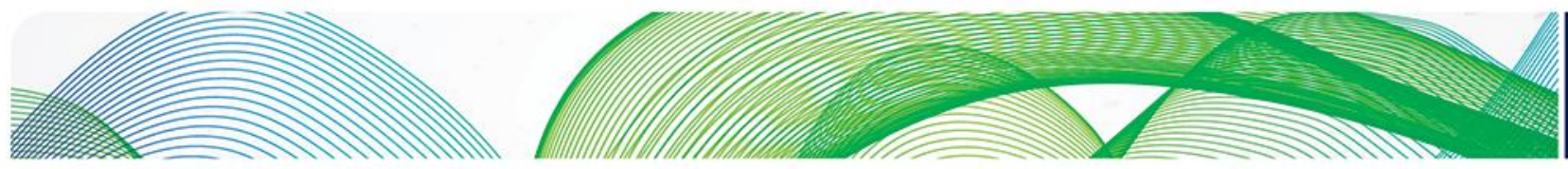

\section{O는}

The contents of this paper are the authors' sole responsibility. They do not necessarily represent the views of the Oxford Institute for Energy Studies or any of its members.

Copyright $\odot 2015$

Oxford Institute for Energy Studies

(Registered Charity, No. 286084)

This publication may be reproduced in part for educational or non-profit purposes without special permission from the copyright holder, provided acknowledgment of the source is made. No use of this publication may be made for resale or for any other commercial purpose whatsoever without prior permission in writing from the Oxford Institute for Energy Studies.

ISBN 978-1-78467-046-7 

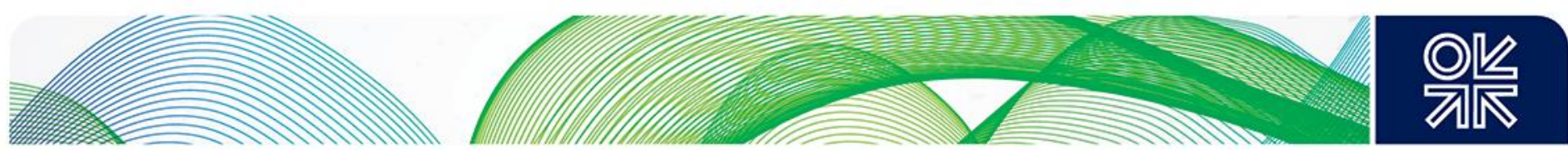

\section{Preface}

In following the process of the transition of continental European gas pricing over the past decade, research papers published by the OIES Gas Programme have increasingly observed that the move from oil-indexed to hub or market pricing is a clear secular trend, strongest in northwest Europe but spreading southwards and eastwards. Certainly at an overview level, such a statement appears to be supported by the measurable levels of trading volumes and liquidity. The annual surveys on pricing of wholesale gas undertaken by the IGU also lend quantitative evidence of these trends.

So if gas hub development dynamics in Europe are analogous to 'ripples in a pond' spreading outwards from the UK and Dutch 'epicentre', what evidence do we have that national markets and planned or nascent hubs at the periphery are responding? This is more than an academic question. The EC's Third Package and Gas Target model requires all member states to comply with its very prescriptive provisions for market opening.

In this his third paper on the development of European traded gas hubs, Patrick Heather in addition to charting the progress of the established hubs has undertaken extensive field research: interviewing a range of market participants from regulators, TSOs, traders and government officials - from Spain to the Balkans to the Baltics and many points in between. In addition to comparing national aspirations with EC goals and deadlines he has noted not just the infrastructure projects required to create the connectivity for traded market development, but equally importantly the political will, cultural acceptance of traded markets and the commercial appetite. Clearly to achieve the vision of the Gas Target Model there is certainly 'much left to do'.

In terms of assessing the stage of development of the various hubs, Patrick presents not only an update of his own quantitative and subjective measures but also incorporates the work of other relevant surveys and academic analyses. Based on this substantial synthesis, the results, both intuitively and analytically compelling, highlight the limited progress made by other hubs in 'catching up with' the Dutch and British hubs.

Whether a third, liquid regional hub will emerge in Europe is a moot point. Italy could in time become the Mediterranean or South European hub but 'there must be a commercial imperative for such hubs to develop, usually driven by the diverse, sizeable import flows into a market of material scale giving rise to different dynamics to those in the other already liquid hubs, thereby creating the possibility of arbitrage in response to price signals having, at their root, different causes.'

The OIES Gas Programme has and will continue to undertake research on European market price evolution. This paper represents a powerful contribution to this body of work, in terms of the comprehensiveness of its scope, the strength of its analytical conclusions and in the searching questions it raises on the slow progress being made in several member states.

Howard Rogers

Oxford, December 2015 

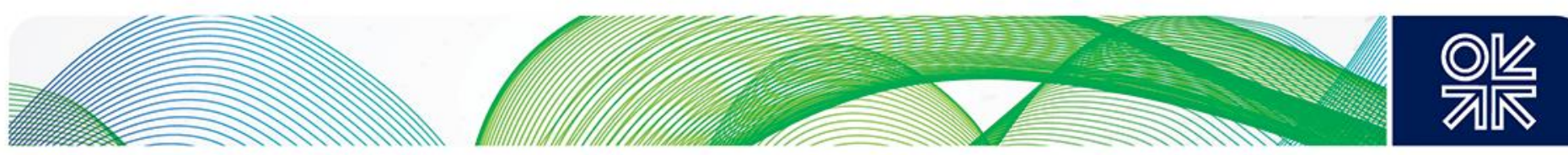

\section{Acknowledgements}

This is a much longer list of acknowledgements than you would normally see but over the past two and a half years I have made many visits, had many meetings and asked many questions; these are just some of those without whom I would not have been able to collect the reams of information used in the writing of this Paper.

These are just some of the many people who answered my questions, helped me plan and arrange my visits, or gave presentations to help me understand the current situation in the traded gas hubs across Europe:

Ambassador Eitvydas Bajarūnas, Thierry Bros, Peter Crilly, Dr Athanasios Dagoumas, Ronald Farmer, Alvaro Franco, Tassos Giamouridis, Horen Grama, Pierros Hadjiyiannis, Gregory Heloir, Bert Hoven, Jan Ingwersen, Katarina Johnsson, Sybren de Jong, Mariusz Kawnik, Michael Kehr, Wouter de Klein, Markus Krug, Javier Lara Villafranca, Adam Marzecki, Otilia Nutu, Spiros Paleoyannis, Jason Pegley, Paweł Pikus, Michael Pleijeff, Rodica Popa, Lucie Roux, Joanna Rycerz, Egbert-Jan Schutte-Hiemstra, Maria Sicilia Salvadores, Nicoleta.Simionescu, Nigel Sisman, Gottfried Steiner, Dr. Michael Thomadakis, Arta Turcanu, Andy Williamson, Roland Wolk, Rocío Prieto González, and if I have omitted anyone I sincerely apologise but thank you all the same!

The enormous task of collecting all the relevant trading data for all of the hubs since 2011 was made a little easier by the help and assistance I received from several companies, in particular:

My thanks to ICIS for having provided the underlying trading data for most of the tables and figures; thanks to Argus Media, ICIS-Heren and Platts for providing background information and news items; thanks to CEGH, EEX and ICE for supplying data files of their exchange trades; thanks to the various brokers and market participants who advised, informed and helped me during the long data collection process.

Lastly, but by no means least, I would like to thank my colleagues at the OIES for their help, guidance and encouragement, in particular:

Anouk Honoré, Beatrice Petrovitch, Jonathan Stern, Katja Yafimava, and a special thank you to Howard Rogers for his support and patience! Many thanks also to Kate Teasdale and John Elkins for their help in preparing the Paper for publication. 


\section{Contents}

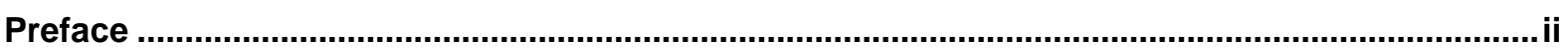

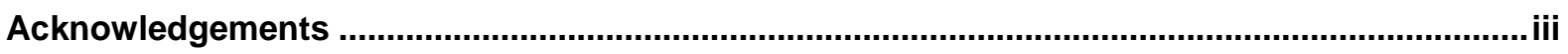

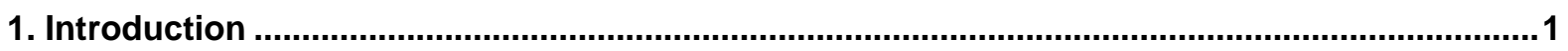

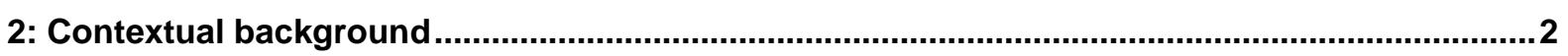

2.1: Findings from the 2012 paper on Continental European gas hubs ........................................... 2

2.2: The impact of changes in gas price formation and the Gas Target Model ................................ 3

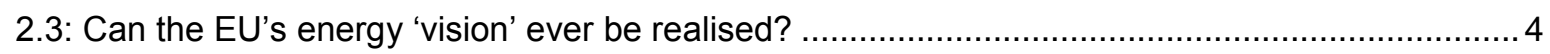

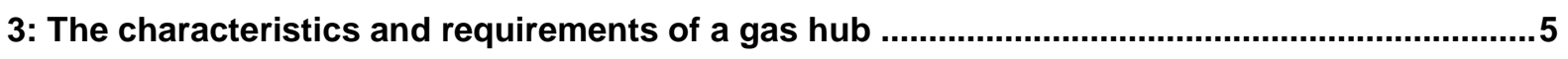

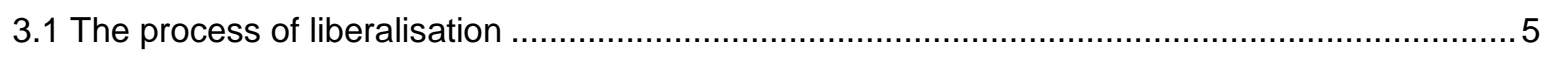

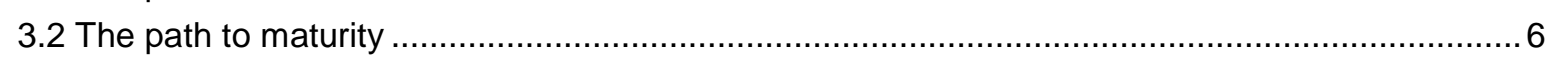

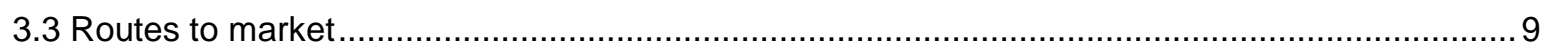

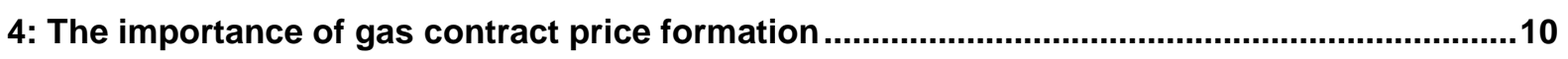

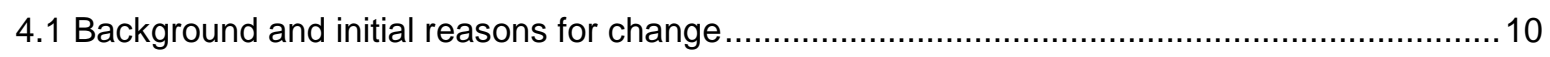

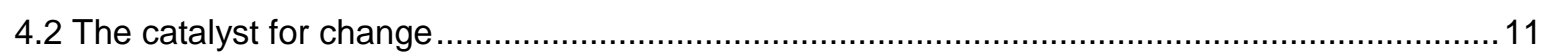

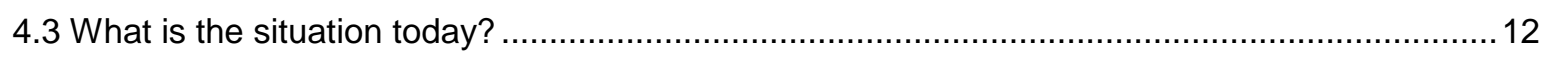

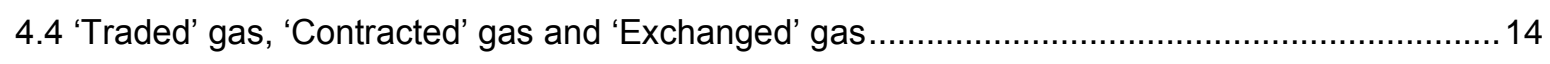

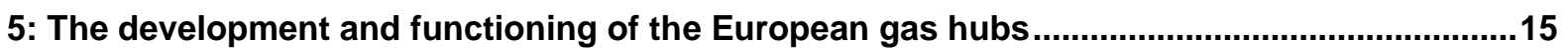

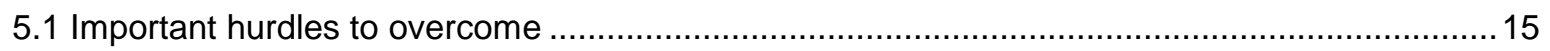

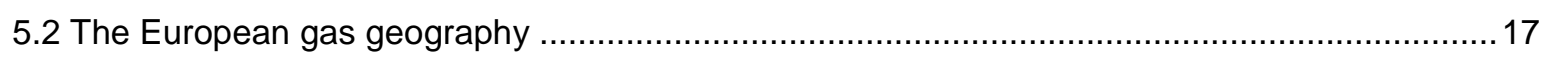

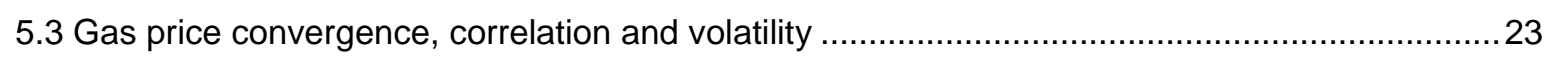

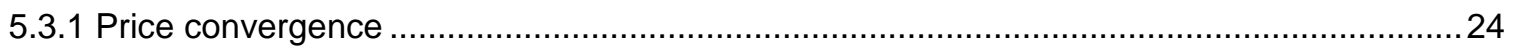

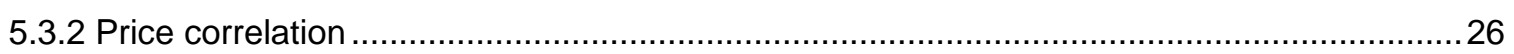

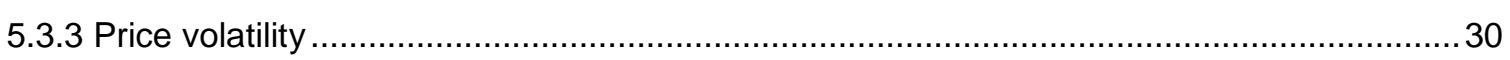

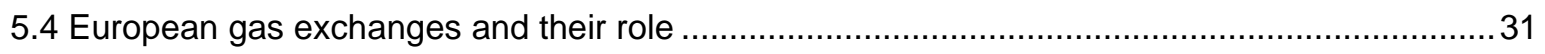

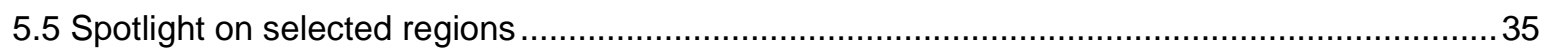

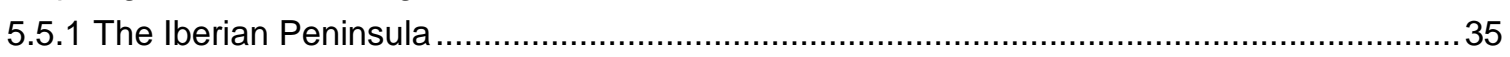

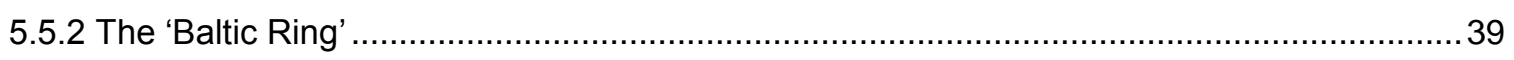

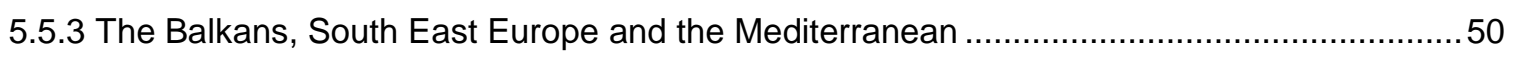

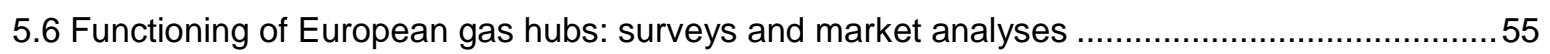

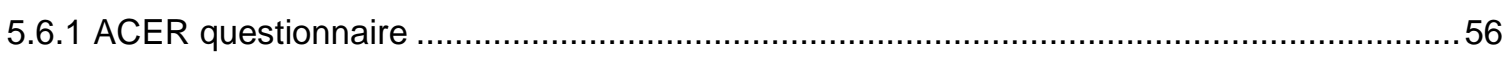

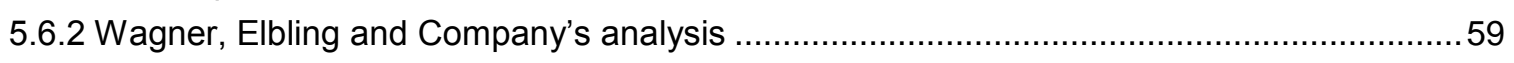

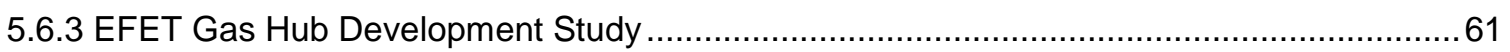

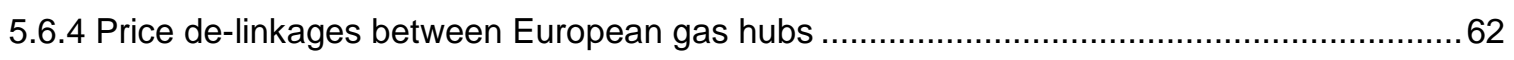

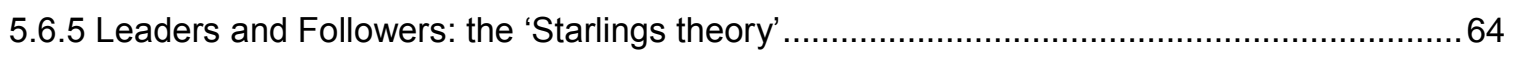

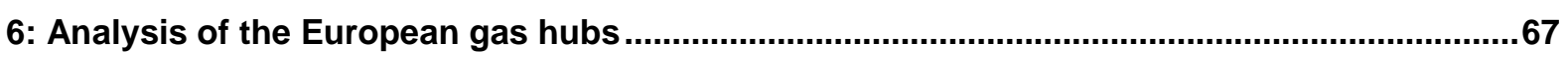

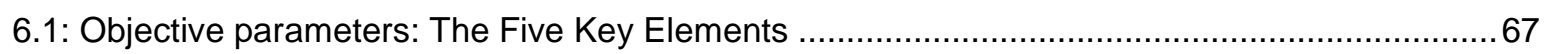

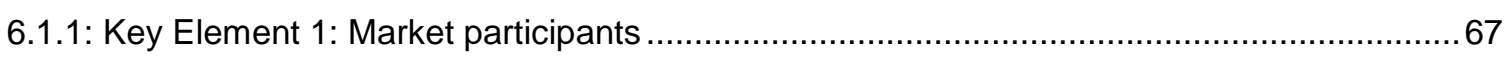

6.1.2: Key Element 2: Traded products ….................................................................... 70

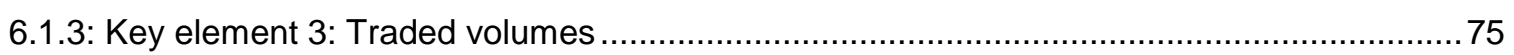



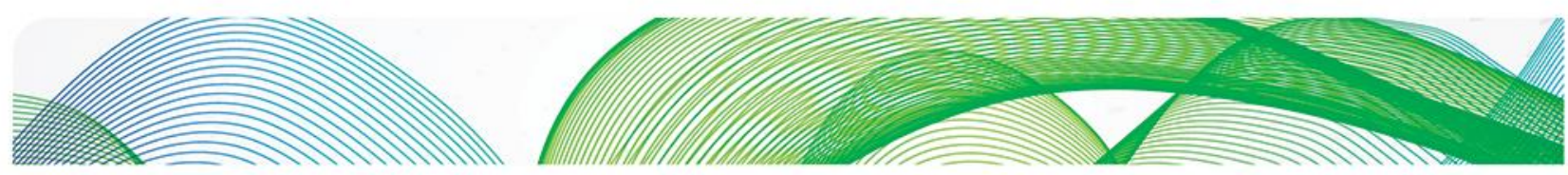

6.1.4: Key element 4: Tradability Index .78

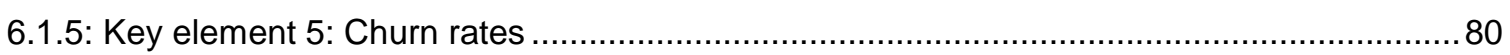

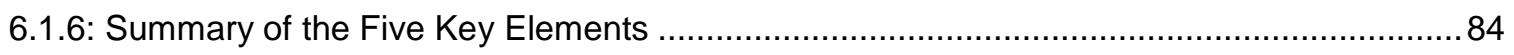

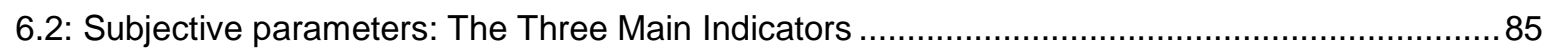

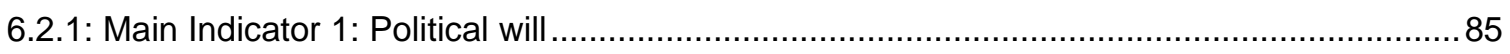

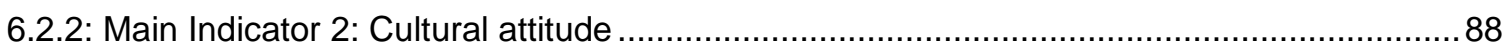

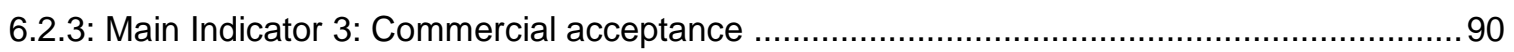

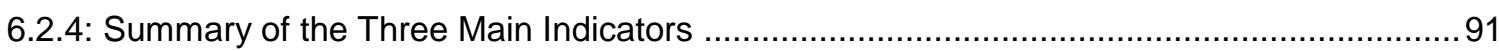

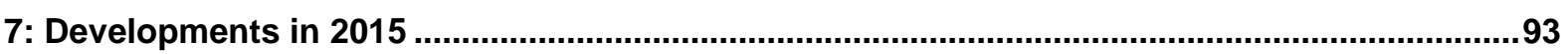

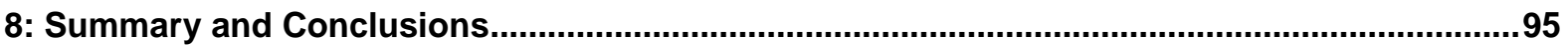

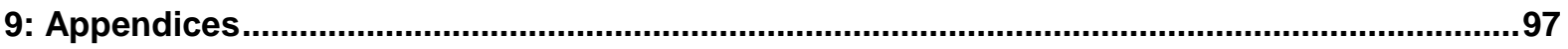

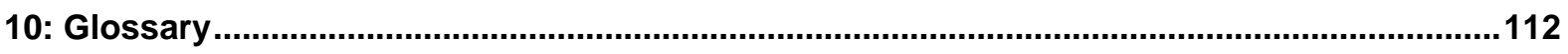

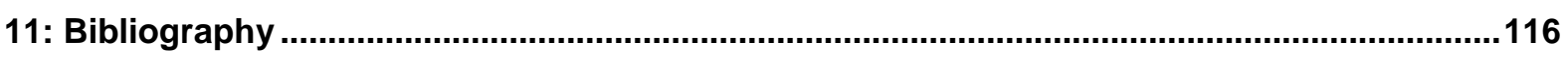

\section{Figures}

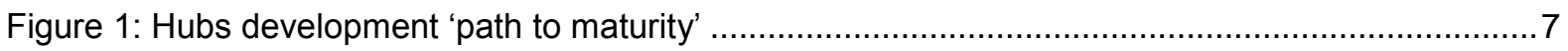

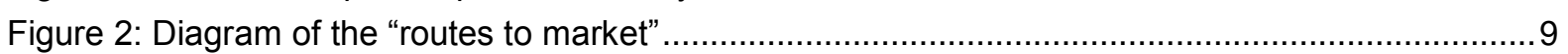

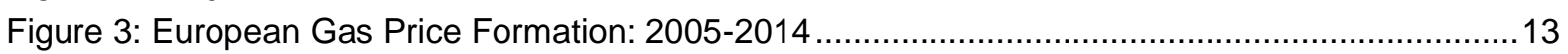

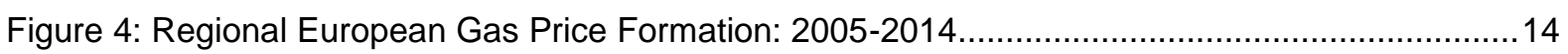

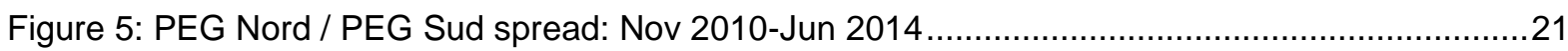

Figure 6: Best four hubs price convergence, Month Ahead contracts: 2012-2014.............................24

Figure 7: Best five hubs price convergence, Month Ahead contracts: 2012-2014 …......................25

Figure 8: Best six hubs price convergence, Month Ahead contracts: 2012-2014 .............................25

Figure 9: Gas hubs price correlation, Month Ahead contracts: 2007-2011 ….................................26

Figure 10: Gas hubs price correlation, Month Ahead contracts: 2012-2014 ….............................27

Figure 11: Gas hubs price correlation, Day Ahead contracts: 2013-2014 …................................28

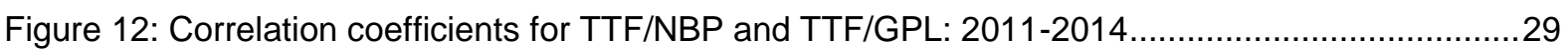

Figure 13: Correlation coefficients: TTF/PEGN, PEGN/PEGS and TTF/PEGS: 2011-2014 ...............30

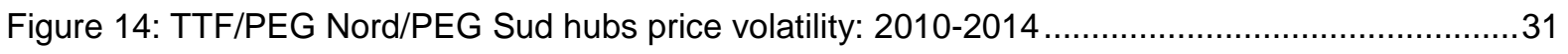

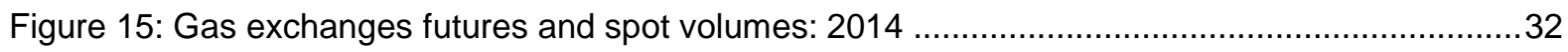

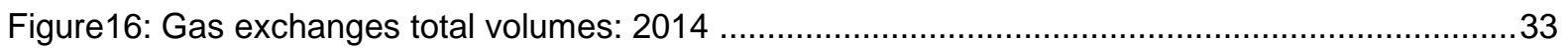

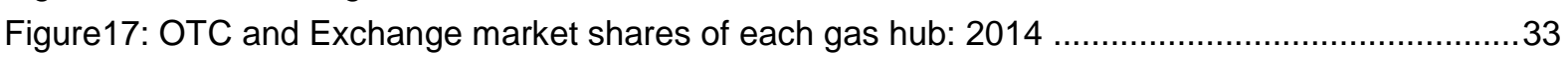

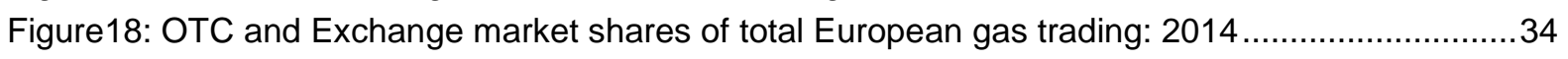

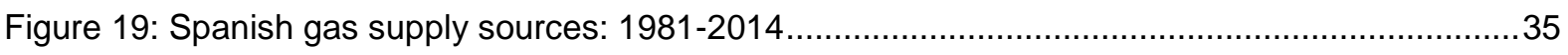

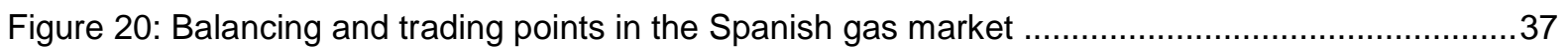

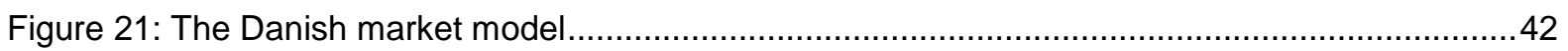

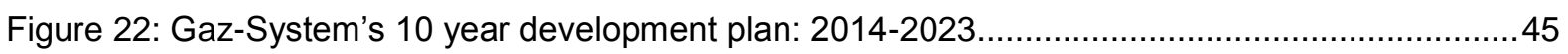

Figure 23: Market access: ease and difficulty of finding trading partners .........................................56

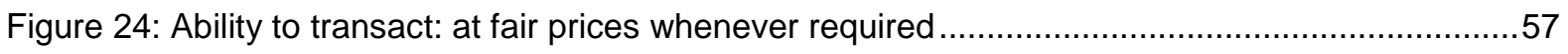

Figure 25: Traded market concentration: of top three sellers in each hub ......................................58

Figure 26: Demand of respondents on deal frequency, liquidity and liquid trading horizons ...............58

Figure 27: Price discovery: deal count per day vs. trading horizon .................................................59

Figure 28: Availability of gas: offered volumes vs. trading horizon .................................................60

Figure 29: Cross correlations between OTC day ahead daily prices (Pearson coefficients \%) ...........63 

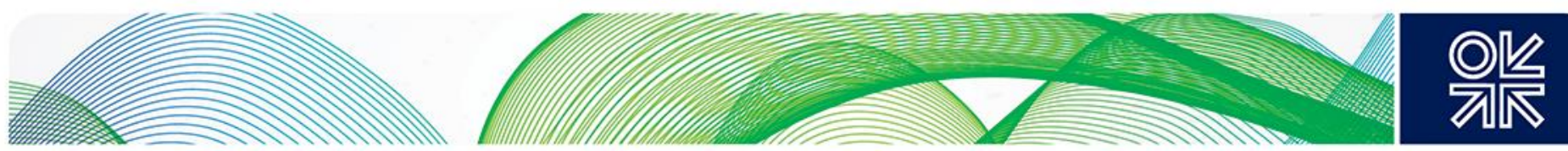

Figure 30: The influence of one hub on another: graphical representation ...................................65

Figure 31: The influence of one hub on another: bar chart...................................................66

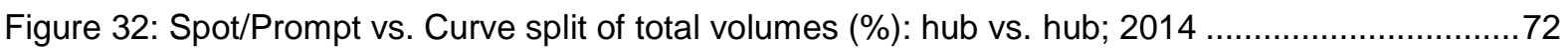

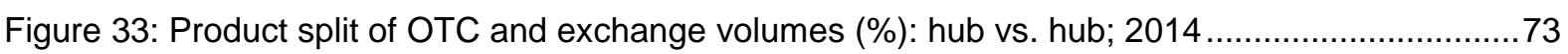

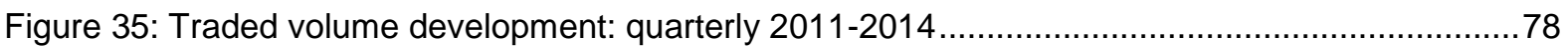

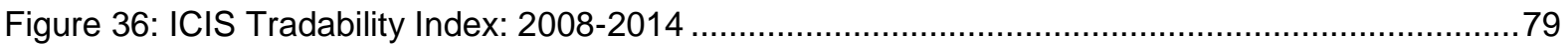

\section{Tables}

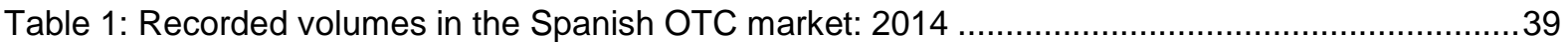

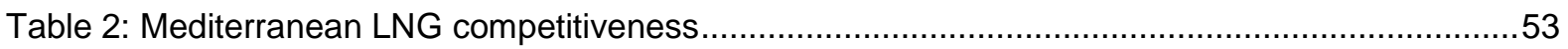

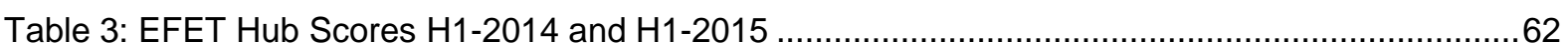

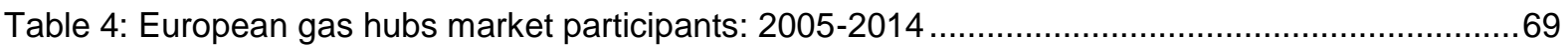

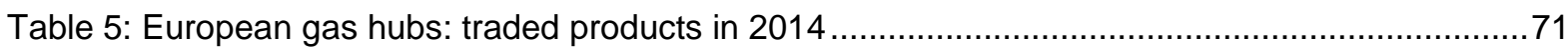

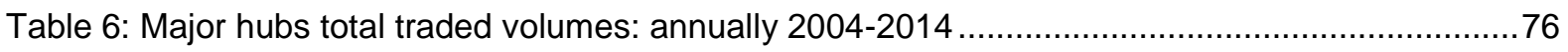

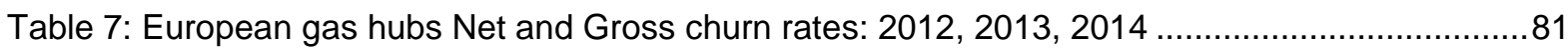

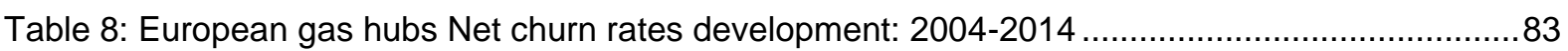

Table 9: European traded gas hubs development based on the 5 Key Elements...........................84

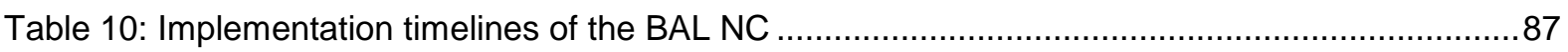

Table 11: EFET Hub Scores categorised as mature/active, poor and inactive ...............................92

\section{Maps}

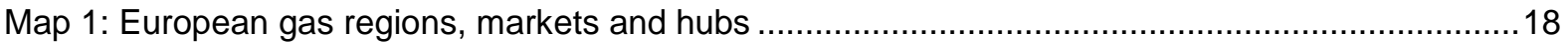

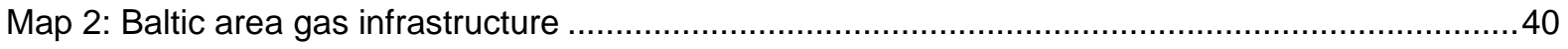

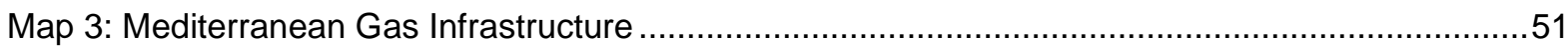

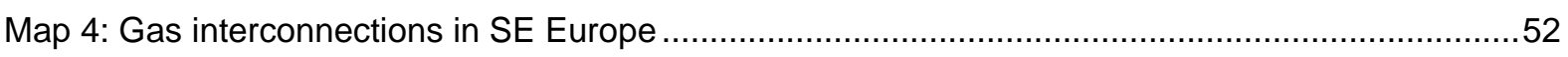

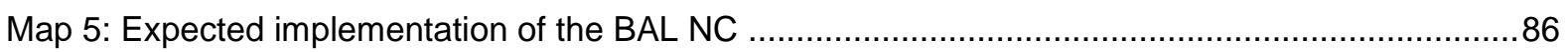



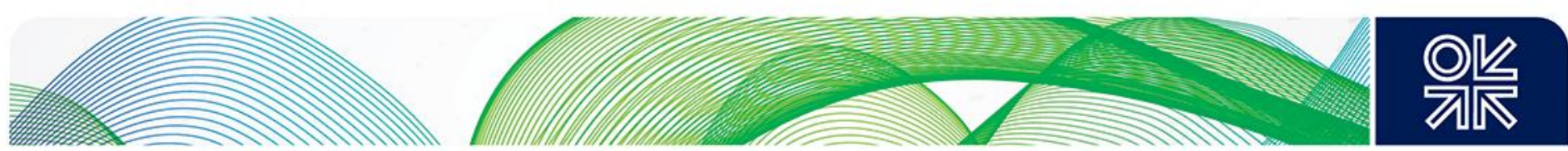

\section{Introduction}

This is the third paper by the Author that explores the development of traded gas hubs in Europe. The first 'The Evolution and Functioning of the Traded Gas Market in Britain'1 explained how a traded market operates, as well as charting the sometimes rocky path taken by the British NBP to becoming a successful, mature traded gas market used for physical deliveries and balancing transactions but also, and more significantly, for risk management trades. The second 'Continental European Gas Hubs: Are they fit for purpose?'2 posed the question whether the Continental European ${ }^{3}$ gas hubs were ready to offer credible price creation, discovery and reference points, which could be used to provide a price index on which to base medium and long-term gas contractual pricing terms.

This third paper was initially intended to be a simple 'update' but so much has happened in Europe regarding gas trading generally and gas hubs in particular, that a more comprehensive approach was needed. Following the start-up of new gas hubs and the promise of yet more in the near future, it was clear that a review of the whole of Europe was necessary in order to provide a full overview; this particularly in the context of the European Commission's vision for a single energy market (in gas) ${ }^{4}$. The vision includes the establishment of gas hubs in each Market Area ${ }^{5}$ as well as regional hubs ${ }^{6}$ at which it is intended all gas will be delivered for sale and purchase - whether under long term contract or traded.

The research and subsequent analysis in this paper will broadly follow the Entsog ${ }^{7}$ Gas Regional Investment Plan areas: North West Europe, Iberian Peninsula, Central Europe, Southern Europe, North East Europe and South East Europe. In order to evaluate the structure and effectiveness of the gas hubs in each country and to assess the development of gas trading, a number of quantitative and qualitative/subjective metrics have been reviewed which facilitate a comparison and provide conclusions as to the individual 'ranking' of each hub ${ }^{8}$ relating to its stage of development. Finally, the paper will review the various projects to create regional gas hubs and whether any of these could one day become significant in helping the EU's vision become a reality.

This is therefore a comprehensive report on the status of the existing traded gas hubs as well as the nascent hubs and those that are still be at an aspirational stage. The two current 'leaders', the British NBP and the Dutch TTF, are now established benchmark hubs; the paper will analyse the reasons why they have become dominant whilst other north west European (NWE) hubs have struggled to gain traction. The paper will also compare and contrast the varying levels of transparency and liquidity in the different hubs as well as the different levels of political willingness, different cultural attitudes and varying levels of commercial acceptance. Having established what the prerequisites are for a successful gas hub, the paper assesses how the emerging hubs might fare and their likelihood of becoming simply balancing physical hubs or whether they have the potential to become liquid, financial risk management hubs. In addition, some adjacent hubs might merge to form larger Market Areas with a single regional hub.

\footnotetext{
Heather (2010).

${ }^{2}$ Heather (2012)

${ }^{3}$ Specifically: Austria, Belgium, France, Germany, Holland, and Italy.

${ }^{4}$ More properly called the Internal Energy Market, which covers both gas and electricity; the latest "Report on the progress towards completing the Internal Energy Market [COM(2014) 634]" can be accessed at: https://ec.europa.eu/energy/sites/ener/files/documents/2014 iem communication 0.pdf

5 The Gas Target Model (GTM, see 2.2) defines a Market Area (MA) as a single Entry/Exit zone with a traded virtual hub.

${ }^{6}$ The GTM envisages that in time two or more MAs could merge to form one larger MA or Regional Hub.

European Network of Transmission System Operators for Gas.

${ }^{8}$ All data and analysis in the main body of the Paper will be up to the end of 2014 .
} 

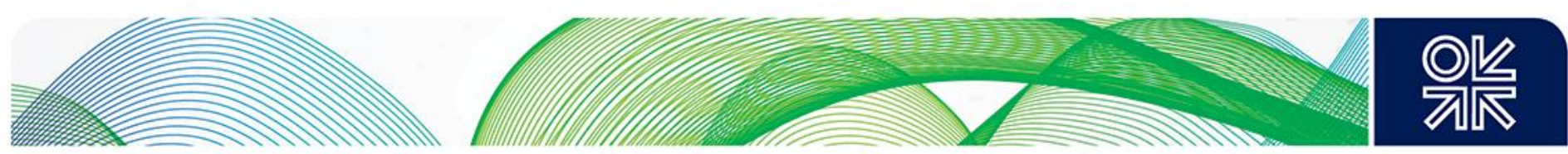

The paper comprises five further chapters. Chapter Two provides context and poses the research questions to be addressed; Chapter Three addresses the characteristics and requirements of different gas hub models and the 'path to maturity'; Chapter Four discusses the importance of gas contract price formation; and Chapter Five the development and functioning of the European gas hubs and their ability to provide a reliable price reference for contracted gas; finally Chapter Six contains an indepth analysis of the European gas hubs, using both quantitative and qualitative frameworks, following which the paper's conclusions are set out.

In order to research this Paper, the Author travelled extensively across Europe, to gain an understanding of where specific hubs stood in the evolutionary process of change towards liberalised gas markets. Meetings were held with energy Ministries, Regulators, $\mathrm{TSO}^{9}$, exchanges and, perhaps most importantly, with market participants. This provided the insight to be able to present the findings to a wider public and to assess the level of preparedness and willingness of different European Member States to strive towards the Gas Target Model ${ }^{10}$, which in turn will determine whether the European Commission can ultimately fulfil its vision for a single energy market (in gas).

\section{2: Contextual background}

\section{1: Findings from the $\mathbf{2 0 1 2}$ paper on Continental European gas hubs}

Having explored whether the traded gas hubs in Europe (which at that time numbered just 10 hubs in 7 countries) were sufficiently developed to be able to provide reference prices for wholesale physical gas contracts, the 2012 paper uncovered significant variations between the hubs. The wide range of individual hub development even at that time cast doubts as to whether the aspirations of the strongly worded Directives from the EU ${ }^{11}$ and the 'Gas Target Model' (see 3.2 below), which were aimed at facilitating the liberalisation process and setting out operational guidelines, were based on realistic timescales.

The general development of continental European hubs dates broadly from 2009, with the wave of LNG supply at a time of low demand in 2010 and 2011 serving to catalyse hub liquidity and development. The main conclusion from the 2012 Paper was that in Europe as a whole, the British NBP hub was at the forefront of gas market development, with a liberalised, fully mature traded market, offering reliable marker prices. In Continental Europe the Dutch TTF had already emerged as the pre-eminent hub.

By 2012 Britain's physical gas supplies were by and large all market priced whereas Continental Europe had lagged behind, with most of its supplies still on Long Term Contracts (LTCs) which had oil indexation formulae as their pricing mechanism. Oil-indexed pricing had not reflected market fundamentals for some time but the economic recession and a period of gas oversupply had made the situation untenable; the conclusion was that the existing Long Term Contracts for gas would have to change to reflect the changes that were being observed in the market. In order for this transition to be successful, there would need to be reliable 'marker prices' to establish a new price formation reference for LTC's and to allow for both physical balancing and financial risk management on liquid trading hubs.

As to the question in the 2012 paper "Are the European gas hubs fit for purpose?" the general answer was an emphatic 'yes', although they might not all serve the same purpose in the future. The NBP

\footnotetext{
${ }^{9}$ See Transmission System Operator (TSO) in Glossary.

${ }^{10}$ See Gas Target Model (GTM) in Glossary.

${ }^{11}$ For a fuller explanation, see Heather (2012): 4.1 Legislation and Regulation, pp.22-25.
} 

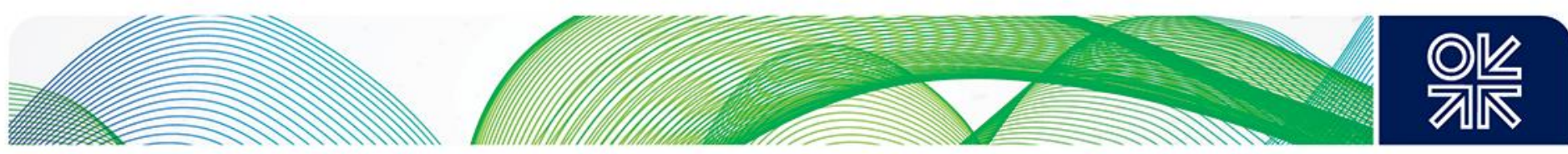

would probably remain the Sterling benchmark and TTF would become the Euro benchmark, for gas in north western Europe, with the CEGH a strong contender for Central European supplies and possibly, the PSV at a later stage, for gas supplies from the south. The final conclusion then was that other hubs would probably not be price markers but would still be used for the balancing of physical portfolios. This said, all the hubs would have closely correlated prices.

It remained to be seen whether the same degree of development was likely to occur across eastern and south eastern Europe in line with the Commission's wishes but, my contention was that (a few) gas hubs in western Continental Europe were sufficient to provide a true reference point in a market priced environment.

This Paper will examine whether those findings still hold true in 2014, whether the new gas hubs being created across Europe will develop in the same way and whether they are likely to become 'balancing' or 'financial' hubs. In turn this will help determine whether the EU's vision of a single gas market for Europe is likely to become a reality, and over what timescale.

\section{2: The impact of changes in gas price formation and the Gas Target Model}

Much had already happened in the move towards hub pricing prior to the 2012 Paper and this process of transformation has continued since ${ }^{12}$; however, the ultimate requirement of successfully moving to market pricing is the need for reliable, transparent, liquid traded gas markets on which companies can risk manage their trading portfolios. As more and more wholesale contracts are priced against a reference (often today a Month Ahead Index or Day Ahead Index at the NBP or TTF), it is essential that newly formed gas hubs across Europe are able to at the very least perform the role of a balancing hub and, potentially, perform the function of a risk management hub.

The EU Network Codes and Guidelines are instruments to achieve the main goals set out in the Gas Regulation ${ }^{13}$ for a single energy market, namely: market integration, non-discriminatory infrastructure access, effective competition, and efficient market functioning. The Gas Target Model (GTM) ${ }^{14}$ stated that the implementation of the codes should be achieved by October 2014 but it did not make clear in the documentation exactly how the individual Network Codes were to be implemented. This quite naturally led to a deadline which was impossible to achieve: when each code needs to be conceived, elaborated, discussed, amended, approved, reviewed, finalised and eventually ratified by each Member State, the process is very lengthy and it is difficult, and in practice almost impossible, to make subsequent amendments after implementation

The EU approach has therefore, due to multiple parallel processes, been far more cumbersome than it was in GB, which has one network code covering all aspects of market transformation. It has also meant that the October 2014 deadline has passed and a modified Gas Target Model II ${ }^{15}$ was published in January 2015. This has simplified or abolished some of the conditions that had previously been set out as being necessary to meet the goal of achieving a pan-European liberalised, competitive gas market. It also effectively acknowledged that some Member States might not meet the criteria ${ }^{16}$ in the GTM and that they could delay the implementation of the Network Codes. Interestingly, it does not detail the process for coping with such delays or for establishing revised target dates for completion.

\footnotetext{
12 The situation today is described in chapter four.

${ }^{13}$ Regulation (EC) No 715/2009 (the "Gas Regulation").

${ }^{14}$ A full account of the GTM is described in: "A vision for the EU target model: the MECO-S Model", J.-M. Glachant, Florence School of Regulation, EUI Working Papers, RSCAS 2011/38, June 2011: http://cadmus.eui.eu//handle/1814/17974

15 Properly called the "Gas Target Model revue and update": http://www.acer.europa.eu/Events/Presentation-of-ACER-GasTarget-Model-/Documents/European\%20Gas\%20Target\%20Model\%20Review\%20and\%20Update.pdf

${ }^{16}$ Gas Target Model revue and update: “Unable to meet GTM 2014 criteria": section 4.5, pp.26-27.
} 

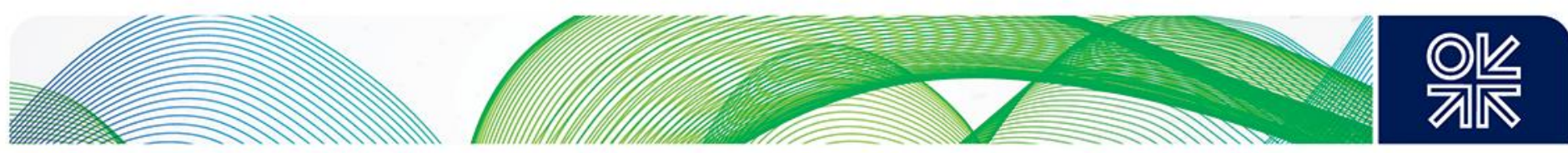

The suite of Codes and Guidelines includes: the Congestion Management Procedures (CMP) Guideline ${ }^{17}$, the Capacity Allocation Mechanisms in Gas Transmission Systems (CAM) Network Code $^{18}$, the Gas Balancing of Transmission Networks (BAL) Network Code ${ }^{19}$. Codes still pending at the end of 2014 were the Interoperability (INT) Network Code ${ }^{20}$, the Incremental and New Capacity (INC) Network Code ${ }^{21}$, the Harmonised Transmission Tariff Structures for Gas (TAR) Network Code 22.

The BAL and the CAM cite dates from which Member States are expected to implement and comply with these codes, specifically $1^{\text {st }}$ October 2015 and $1^{\text {st }}$ November 2015 respectively. However, it remains to be seen how many Member States will be in a position to implement and abide by the Codes, even though these dates are one year after the original GTM target implementation date (see section 6.2.1 for detailed information).

The Commission has acknowledged that certain Member States will have difficulty in meeting these deadlines and the BAL code in particular has provision within it for late implementation. Article $45^{23}$ describes interim measures for the implementation of the Code and clause 4 states that "The report shall foresee the termination of the interim measures no later than five years as from the entry into force of this Regulation", taking the effective implementation deadline to October 2020. Furthermore, Article $47^{24}$ regarding the balancing platforms states in clause 3 that "In case the situation described under paragraph 1 has not fundamentally changed after five years the national regulatory authority may, without prejudice to Article 45(4) and after submitting the appropriate amendment of the report, decide to continue the operation of the balancing platform for another period of no more than five years". This means that theoretically, some Member States could wait until as late as October 2025 to implement the BAL Network Code!

\section{3: Can the EU's energy 'vision' ever be realised?}

The EU's political ambition to create a fair market for all consumers was instigated through Directives, which were part of 'Energy Packages' that also included reforms to the electricity markets. We will analyse later in this paper the situation at the end of 2014 with regards to gas hub development and observe that the process of transformation towards liberalised gas markets is not progressing at the same rate across Europe and that there is yet much to do, especially in eastern Europe.

\footnotetext{
${ }^{17}$ Essentially 'Use It Or Lose It' requirements to reduce congestion in gas pipelines. "Commission Staff Working Document: Guidance on best practices for congestion management procedures in natural gas transmission networks": https://ec.europa.eu/energy/sites/ener/files/documents/20140711 guidance congestion management ngtn.pdf

${ }^{18}$ Requires gas grid operators to use harmonised auctions when selling access to pipelines. "Commission Regulation (EU) No 984/2013 of 14 October 2013 establishing a Network Code on Capacity Allocation Mechanisms in Gas Transmission Systems and supplementing Regulation (EC) No 715/2009 of the European Parliament and of the Council”: http://eurlex.europa.eu/legal-content/EN/TXT/PDF/?uri=CELEX:32013R0984\&from=EN

${ }^{19}$ Sets out gas balancing rules including the responsibilities of transmission system operators and users. "Commission Regulation (EU) No 312/2014 of 26 March 2014 establishing a Network Code on Gas Balancing of Transmission Networks (Text with EEA relevance)": http://eur-lex.europa.eu/legal-content/EN/TXT/PDF/?uri=CELEX:32014R0312\&from=EN

${ }^{20}$ Since approved in April 2015: Aligns the complex technical procedures used by network operators within the EU, and possibly with network operators in the Energy Community and other countries neighbouring the EU: "Commission Regulation (EU) 2015/703 of 30 April 2015 establishing a network code on interoperability and data exchange rules (Text with EEA relevance)": http://eur-lex.europa.eu/legal-content/EN/TXT/PDF/?uri=CELEX:32015R0703\&qid=1448894405871\&from=EN ${ }^{21}$ Strictly speaking, an amendment to the CAM to provide the framework for the offer of incremental capacity to satisfy demand beyond the offer of existing capacity in a market-based manner, and ensure the necessary investments are efficient and financially viable. Submitted by Entsog to ACER on $26^{\text {th }}$ December 2014 and still awaiting approval.

${ }^{22}$ Intended to establish rules that would define a set of common parameters for tariff setting and set requirements on the publication of tariff setting data. Submitted by Entsog to ACER on 26th December 2014 and still awaiting approval.

${ }^{23}$ BAL NC, p.32: "CHAPTER X-INTERIM MEASURES-Article 45-Interim measures: general provisions". The full Article is reproduced in Appendix A.

${ }^{24}$ BAL NC, 33: "CHAPTER X-INTERIM MEASURES-Article 47-Balancing platform". The full Article is reproduced in Appendix B.
} 

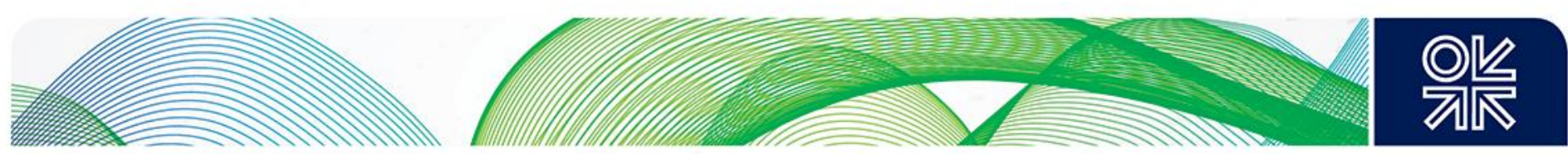

Entsog, as the federation of European TSOs, has been tasked with creating the framework network codes which, when formulated, it submits as proposals to ACER for approval, before the codes are sent out to the Member States for ratification. The Commission has been putting pressure on Entsog to deliver completed codes that will create the Single Market in short order, and indeed Entsog has responsibilities imposed upon it to monitor the progress. However, it has no statutory authority to enforce them, which creates a fundamental tension between Entsog, the Commission, the many TSOs and the Member States.

That the process of creating the network codes and getting them approved can take up to 3 years, plus a further year to 18 months to get them ratified, makes one wonder how long exactly it will take to achieve completion. Even when the codes are ratified and become operational, there are clauses that allow for delaying their introduction; as seen above, the Balancing Code has provisions that could mean some Member States do not comply before 2025.

In reality, it is more likely that there will be further reviews of the GTM and possibly of the Commission's vision on a Single Energy Market also, in order that as many Member States as possible commit to the implementation and adherence to the provisions of the gas market Guidelines and Codes. From a political point of view it is more acceptable to promote full inclusion, even if at the expense of rigour, rather than to adhere to tough legislation that may compromise the original vision. Some might conclude that, as we see the situation in 2015, the EU's energy 'vision' for gas markets may never be entirely realised, or may at least be phased in region by region over time

\section{3: The characteristics and requirements of a gas hub}

\subsection{The process of liberalisation}

Despite nearly 20 years passing since the British gas market liberalised and some 15 years since the EU published its first Gas Directives, there is still confusion in some parts of Europe as to what a 'gas hub' actually is. Confusion exists over whether a hub is an actual geographical location (terminal, flange, processing plant, compressor station etc.), or a virtual location often, but not always, within a country's gas grid network. This is what is also often referred to as an Entry/Exit zone or Market Area.

These Market Areas will serve an important role under the Gas Target Model, as places to both balance the physical volumes of gas and to price those volumes, as well as being places to simply 'trade' gas. This report will focus on the commercial or financial, virtual, and trading aspects of the hubs.

The first prerequisite for the development of a liberalised wholesale market and a successful traded hub is to ensure that the industrial, commercial and residential sectors are fully liberalised; this creates competition between suppliers and encourages the end-user to demand more competitive pricing. This in turn will lead to the wholesale sector requiring and using traded hubs in order to satisfy the risk management of their portfolios, ultimately leading to market suppliers also participating in the traded market via hubs.

The contracts used in the traded gas market tend to be standardised, meaning that terms and conditions are harmonised apart from the delivery period, quantity and of course price. They can be traded bilaterally or on exchanges but they are all essentially of the same format. This is important because standardisation concentrates liquidity, liquidity attracts volume, volume attracts traders and together they help create a successful hub.

In Britain, the NBP is a notional point, effectively the whole NTS (National Transmission System) and was 'invented' to permit the balancing mechanism of the Network Code, where Shippers nominate 

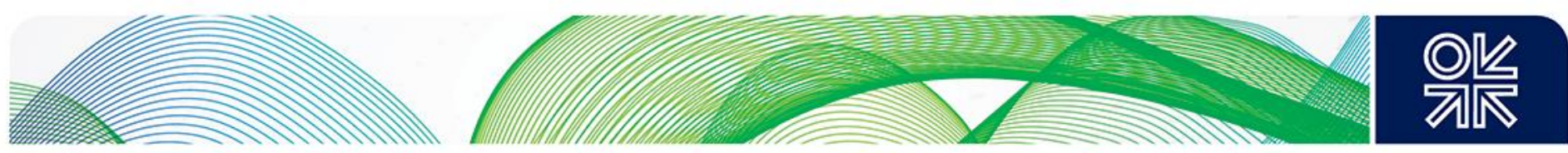

their buy and sell trades and where the Transmission System Operator (TSO) can balance the system on a daily basis. This was the first system of its kind and was also the first virtual trading point for gas in Europe. Several years later, the Italian PSV and the Dutch TTF virtual hubs were closely modelled on the NBP.

The NBP rapidly evolved as traders had confidence in buying and selling gas on a standardised basis at the most liquid point, namely the UK's high-pressure transmission system, (the NTS). This is in stark contrast to the 'old world', where gas was mostly traded at the Entry Points. The NBP was the focal point for the standardised "NBP'97" 25 trading document, the cornerstone of the UK OTC traded market and subsequently became the delivery point for the ICE futures exchange natural gas contract. In Continental Europe, the EFET contract has become the standard trading contract in traded gas markets.

The principal features of trading gas at the NBP are that deliveries are for 'flat' ${ }^{26}$ gas, that participants are 'kept whole'27, that in practice there is no Force Majeure (FM) ${ }^{28}$ and that there are standardised billing and payment terms. Some but not always all of these features are also included in some of the European hubs. The only FM permissible would be an event beyond the control of the affected party resulting in the inability to get a trade nomination into or accepted by Gemini, the TSO's nominations system. These features were key to the success of the NBP as a traded gas hub.

All of the gas hubs in Europe are 'balancing' hubs: used by Shippers to balance their portfolios near to maturity and at delivery and by the TSO to physically balance the gas grid, usually on a daily basis; the 'trading' hubs are additionally used by Shippers to risk manage their portfolios, often up to 3 or more years in advance. The more mature and successful hubs are both balancing and trading hubs.

\subsection{The path to maturity}

We can describe the process leading to such mature and successful hubs as being a "path to maturity' as shown in Figure 1. The development of a liquid hub takes time, commitment and, as history has shown us in North America, Britain and now north-west Europe, can result in disruption and financial cost to (particularly) the incumbent players who dominated the pre-liberalisation landscape.

Based on the North American and British markets' transition experience, the process can take 10-15 years and this is now proving to be the case in Continental Europe. It also requires the commitment of governments, suppliers and system operators to achieve a smooth transition; furthermore, a market that has indigenous production and/or is well supplied by competing sources of gas, is likely to achieve the goal more quickly and establish a more successful, liquid trading hub.

The process usually starts with a move to Third Party Access (TPA) to the network infrastructure, often requiring legislative changes to force incumbents to release infrastructure capacity and gas supply volumes thus incentivising independents to enter the market. There is a requirement for the adoption of rules and regulations governing the physical side of the business, whilst the emergence of standardised contracts will favour the commercial aspects. This will then be followed by bilateral trading, often aided by the first brokers, helping to create trading opportunities between counterparties. These trades start to be reported in the trade press, thus creating the beginnings of a transparent market. With price disclosure comes price discovery which in turn attracts more players to

\footnotetext{
25 Updated as the "NBP'15", introduced on $1^{\text {st }}$ October 2015.

${ }^{26}$ Flat gas: 'Flat' meaning that the volumes traded are delivered at a constant 'flow rate' during the whole of the delivery period, without any re-nomination rights.

${ }^{27}$ Kept whole: meaning that the volumes delivered are guaranteed to equal the volumes traded: there is no interruption or volume tolerance permitted.

${ }^{28}$ Limited Force Majeure: There is no relief of the obligation to deliver/take gas at the NTS; even an upstream Field failure, or a downstream exit point shutdown, does not constitute FM.
} 

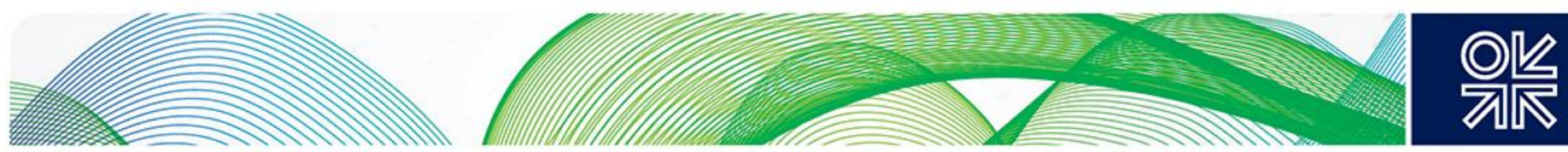

the market, often at this stage smaller physical traders and the first tentative moves by financial players too. The creation of exchange products (futures), based on the underlying physical contracts, offers greater access to the market, especially by non-physical players (who will always close out their trading positions before maturity).

Gradually, as increasing numbers of varied participants come to trade in a particular market, a forward curve will develop and this will be used for risk management purposes. The final stage of maturity is when the hub develops sufficient liquidity for traders to use specific traded products (such as the Day Ahead or the Month Ahead) as indices on which to price their physical transactions.

\section{Figure 1: Hubs development 'path to maturity'}

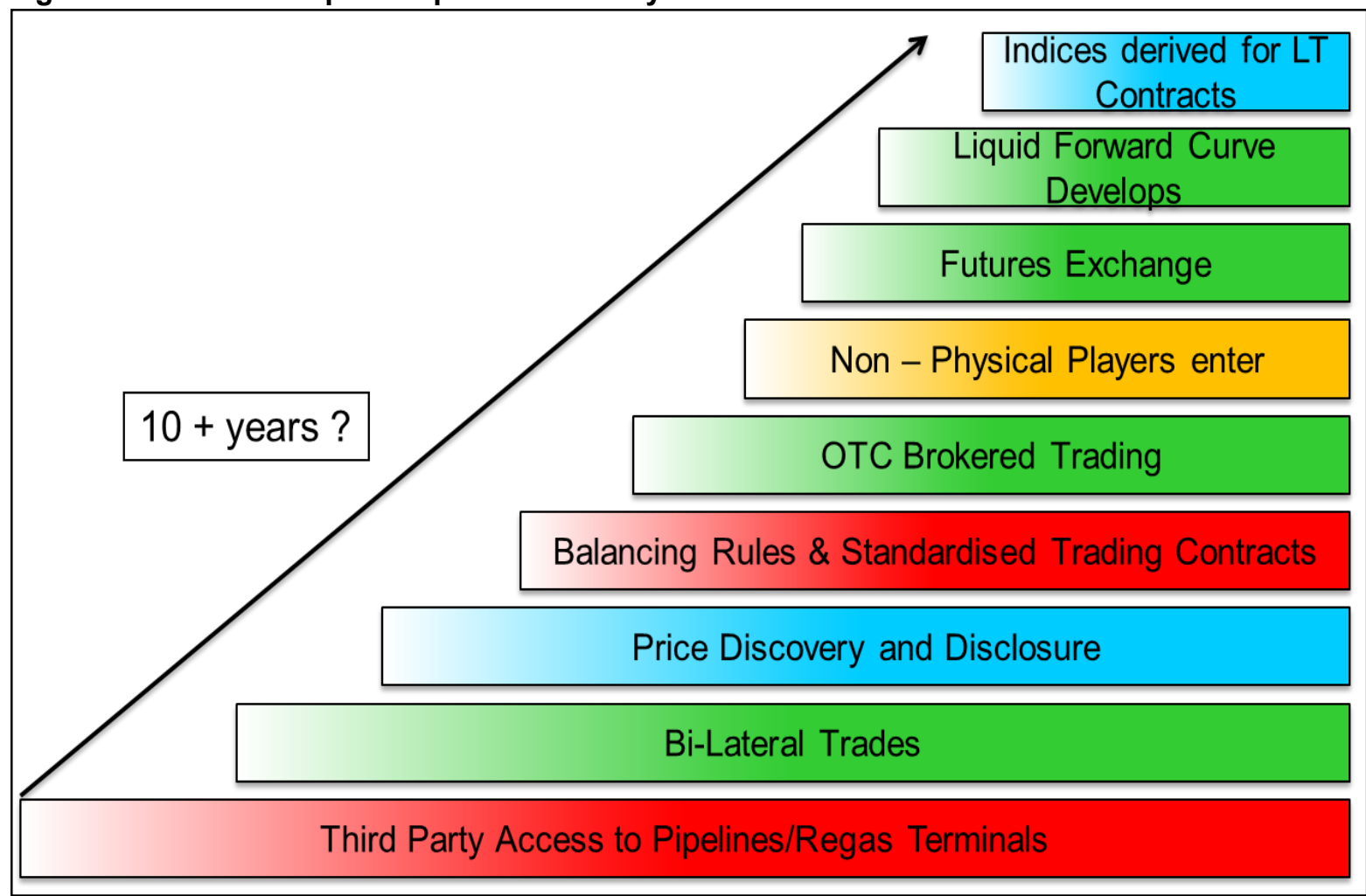

Source: H.Rogers (OIES)

There are five main requirements that lead to successful trading: they are liquidity, volatility, anonymity, transparency and traded volumes.

- Liquidity is a measure of how easy it is to trade volume at a given price without 'moving' the market. Standardisation of traded contract terms and conditions tends to concentrate liquidity.

- Volatility is a measure of price movement in relation to market activity. Historically, financial markets have high liquidity and fairly low and consistent volatility, whereas energy markets are typically very volatile yet may also be very liquid. They are particularly sensitive to external information.

- Anonymity is the 'corner stone' of futures trading. The Clearing House is the counterparty to all trades and this allows both 'big' and 'small' participants to trade alongside each other.

- Market transparency is very important in the development of a successful traded market. It means that traded volumes and prices are quickly disseminated in the public arena and this openness gives traders added confidence in the market in which they are trading. Indeed, the importance of accurate, reliable and timely market data cannot be understated, whether this is official government statistics on energy consumption, TSO data on physical flows or capacity auctions, or 

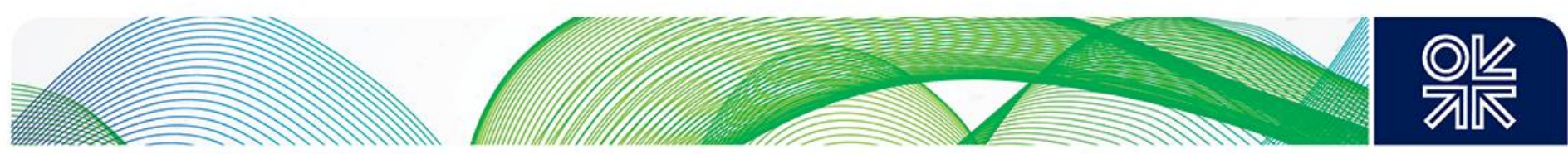

broker or exchange information on volumes and prices. There is very good data availability in Britain and the Netherlands but many of the other European countries still lag behind, although there are signs of improvement.

- Traded volumes simply relates to the total actual volume traded in any given market; this could be the OTC volume or the exchange volume or the split between spot and curve but in all cases refers to the total traded in each category.

Now let us look at trading activity. The usual reason for trading in the spot and prompt contracts ${ }^{29}$ is to physically optimise or balance a portfolio at, or just ahead of, physical delivery. The forward curve is usually used to financially optimise a trading portfolio for hedging or speculative purposes. Most trading activity takes place in the prompt and near curve, with the most popular contracts being WD, $\mathrm{DA}, \mathrm{MA}^{30}$ and the front two seasons. There is activity too in the mid-curve, especially because of price spreads between seasons, although beyond three years trading activity is much lower, primarily for credit reasons.

The length of time forward that it is possible to trade is known as the 'curve'. This traded curve covers the spot, the prompt, the near, mid and far curves:

- Spot refers to today or tomorrow;

- Prompt refers to all other periods within the month;

- The near curve covers from the front month to the first two seasons;

- The mid curve covers out to about two years forward;

- The far curve is everything beyond that, currently up to about five years forward, although it is possible to get quotes as far out as 10 years $^{31}$ in some European gas markets (mainly NBP and TTF).

The spot and prompt contracts cover days or groups of days such as Within Day (WD), Day Ahead (DA), Balance of Week (BOW), Weekend (WE), and the Balance of Month (BOM) contract. The 'curve' trades in months, quarters, seasons and years (both calendar and gas year).

There are some other differences between OTC and Exchange trading:

The OTC market has evolved in a standardised way in which trades are conducted in 'clips' or multiples (of 25,000 therms per day on NBP and ZEE; or $20 \mathrm{MWh}$ per day on the Continent) in one of several clearly defined time periods (as detailed above). This allows for ease of trading, greater transparency and inevitably greater liquidity. These standard trading contracts form the backbone of the brokered market today. These deals can be traded over the phone or, more commonly nowadays, by electronic media. Despite the standardisation of these contracts and their popularity, it must be remembered that these are still bilateral contracts and therefore still hold counterparty credit and performance risk.

The Exchanges are regulated markets where traders are secure in the knowledge that they are governed by the relevant financial regulator in each country and that the clearing house also financially guarantees all of the trades executed. Exchange trading has gained in popularity since the financial crash of 2008, although market penetration varies from country to country. The European Exchanges that offer gas contracts are: ICE, ICE-Endex, EEX, Powernext, CEGH and GME.

\footnotetext{
${ }^{29}$ Spot refers to today or tomorrow; Prompt refers to all other contracts within the first month.

${ }^{30} \mathrm{WD}=$ Within Day; DA = Day Ahead; MA = Month Ahead.

${ }^{31}$ Although these far out periods rarely trade today following the tightening of capital adequacy requirements.
} 

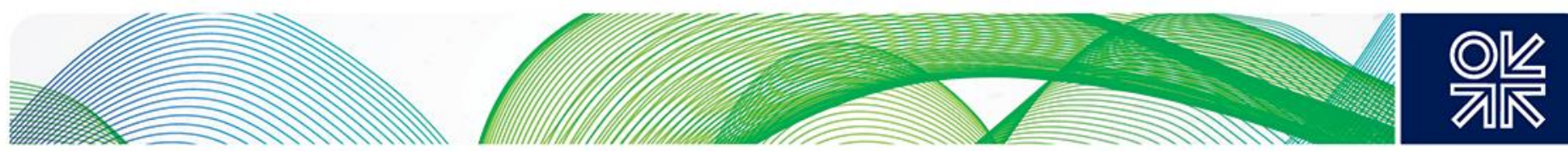

\subsection{Routes to market}

Having described the evolutionary path to hub maturity, it is also necessary to understand why one would need or indeed want to trade. A company will engage in trading for one or more of the following reasons: to buy or sell gas to balance a physical portfolio; as a financial hedge; or as speculation.

As shown in the flow chart in Figure 2, the reason for trading will determine which route to follow 32 : through the regulated or non-regulated markets; through the "paper" market or the physical market; using a bilateral contract or a cleared contract. The instruments of trading vary from the bilaterally negotiated traded contracts to the OTC standardised physical deals; from the futures market and other cleared transactions to financial trades such as swaps; finally there is the possibility on some markets of trading options, either cleared or bilateral, physical or financial.

Figure 2: Diagram of the "routes to market"

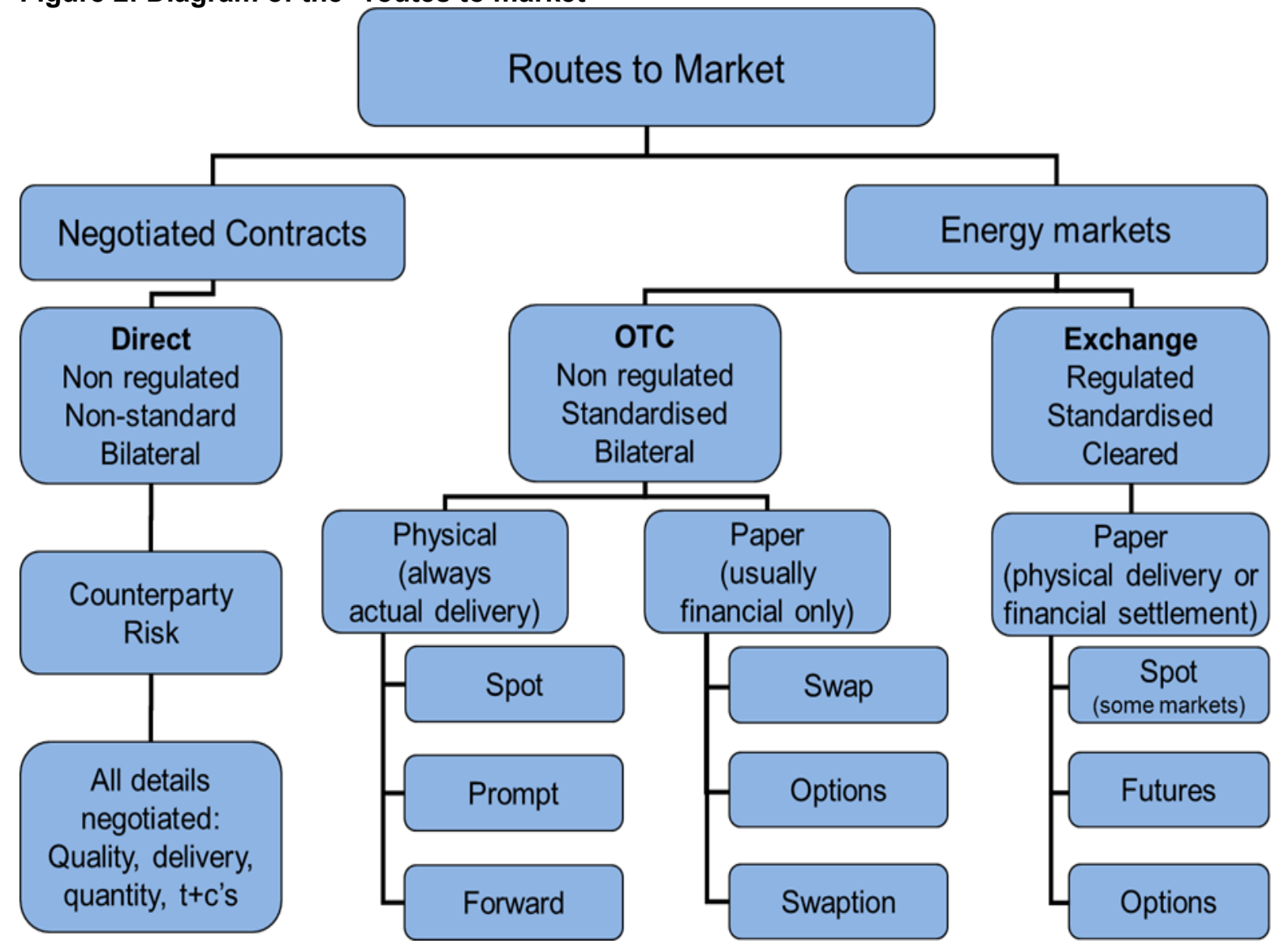

Source: Heather (2010) 

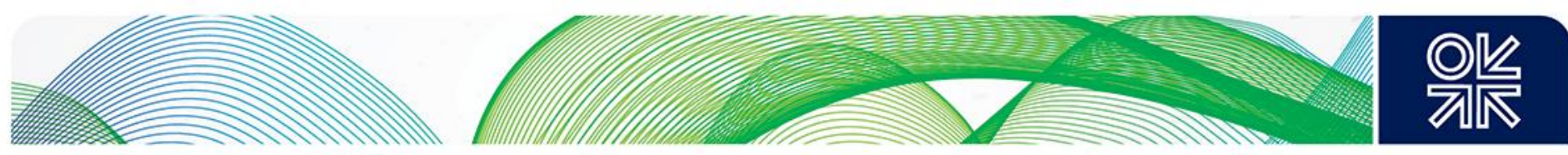

\section{4: The importance of gas contract price formation}

\subsection{Background and initial reasons for change}

The development of natural gas and its introduction into the energy mix faced a number of challenges, which ultimately influenced the commercial and pricing framework under which it was sold. Having a low energy density compared to oil products and coal, gas is expensive to transport and store. Initially natural gas could be sold to local markets where it displaced Town gas ${ }^{33}$, and the cost of modifying infrastructure and appliances was modest. The development of the large onshore Groningen field in the Netherlands in the 1960s posed a problem however. A 'cost plus' approach would result in a low gas price and major disruption to the existing oil products markets of NW Continental Europe and a loss of revenues for the Dutch government and upstream investors. The solution was to price gas on a 'competing fuel price minus' basis. This approach was very successful and natural gas quickly gained market share. The advent of major European imports of gas from the then Soviet Union and North Africa required a major investment in long distance pipelines, distribution systems and storage facilities. This investment was underwritten by long term gas contracts with a 25 and sometimes 30 year duration, with take-or pay requirements and the gas price linked to that of gasoil and fuel oil. In this construct the 'buyer took the volume risk, and the seller took the price risk'.

The first sign of change in the established regional gas pricing structure occurred in North America when their gas market started to liberalise in the 1970s. 40 years later and despite having a very successful benchmark hub, Henry Hub, the overall gas market has a complicated structure: there are a total of 33 hubs $^{34}$ and traders have to 'wheel' gas shipments from hub to hub, sometimes as many as 5 or 6 or 8 , in order to get gas from a supply point to its final consumer market. The process of liberalisation took nearly 20 years to produce a competitive market, and then, only truly liberalised at the wholesale level. Most American wholesale gas supplies are priced against the Henry Hub marker (with regional basis differentials), although downstream there are still several States that operate regulated pricing structures (i.e. the gas utility is allowed to make a regulated return on its assets, taking into account the cost of gas acquired on the traded market).

In Europe, the process of change followed two very different courses: that of Britain's privatisation and Continental Europe's liberalisation. In Britain, the change from the old world to the new was primarily due to the need of Mrs Thatcher's government in the early 1980s to bring government spending into balance. Of a series of major privatisations of nationalised industries, British Gas was the second state-owned company to go through the process. This was a lengthy transformation which took 15 years and was 'painful and costly' to most participants ${ }^{35}$. However, today, Britain has a fully liberalised, established and successful traded gas market, which has reached maturity, and the NBP is a very successful marker hub for the British Isles and some LNG deliveries to the Channel ports. All of Britain's gas supplies are now priced against the NBP marker, whether they are contracted or traded supplies. The entire market is liberalised, both at the wholesale and retail level.

Continental Europe's liberalisation of the energy markets was driven by the EU's political ambitions to create a fair market for all consumers and this it instigated through Directives ${ }^{36}$ which were part of 'Energy Packages' 3738 that also included reforms to the electricity markets. The process of

\footnotetext{
${ }^{33}$ Manufactured gas, using coal, oil or naphtha as feedstock.

${ }^{34}$ Known as 'Market Centers'; see Appendix C for a map of the North American hubs.

${ }^{35}$ For a full account of the process, see Heather (2010).

${ }^{36}$ See EU Natural Gas Directives in Glossary.

37 See EU Energy Packages in Glossary.

${ }^{38}$ A full account of the issues relating to the Third Energy Package is given in Yafimava (2013).
} 

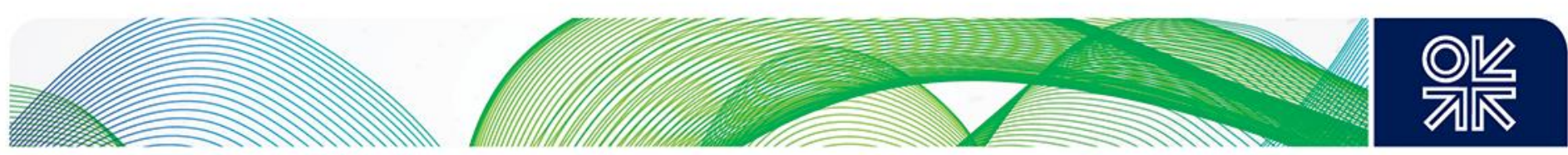

transformation started in the late 1990s although the first real signs of change were only apparent in the mid 2000s and then only in western Europe. There is still much to do, especially in eastern Europe, and it now looks likely that the whole process will also take, in total, some 15 or so years to complete, just as it did in both North America and in Great Britain. However, in western Europe, the Dutch TTF hub has now established itself as a marker hub for the north west European region and there are even plans for regional hubs in central Europe and south eastern Europe.

The pricing of Continental Europe's gas supplies is still undergoing the process of transformation. The historical Long Term gas Contracts (LTCs) are in turmoil and, in the words of the CEO of a major wholesaler ${ }^{39}$, need to be "re-engineered": oil-indexed pricing has not reflected market fundamentals for quite some time and the recession and a period of gas over-supply from 2009 to the present have made this situation untenable.

\subsection{The catalyst for change}

The real catalyst for change came in 2009/10: the recession of 2008-09 led very quickly to a major downturn in demand for gas across Europe ${ }^{40}$, followed in the autumn of 2009 by the commissioning of the two Qatari LNG import projects in Europe ${ }^{41}$ which then saw large volumes of LNG being imported, especially into the British South Hook terminal. Across the Atlantic, the shale 'revolution' in the US reduced North America's LNG import requirements, such that cargoes of LNG previously destined for the US were diverted, mainly to Europe. Also, in the same period, there were several other large LNG export projects coming to market such as the Tangguh, Yemen and Sakhalin liquefaction plants that added to the wave of surplus LNG. Combined, these four factors created a mini gas 'bubble' in Europe. At the same time, world oil prices were recovering from early 2009 , leading to a marked increase (from summer 2009 onwards) in the price of oil-indexed long term contract gas imported by Europe.

Finally, two significant German legal decisions galvanised the change in attitude towards traded gas markets in Continental Europe. Already in June 2006, the higher regional court of Dusseldorf had upheld a Federal Cartel Office decision declaring that long term contracts between E.On and its distributors were illegal and imposed limitations on the duration of any future supply contracts. Then, crucially, in March 2010, the German Federal Court of Justice ${ }^{42}$ declared that prices for natural gas for private clients were no longer allowed to be immediately linked to the price for heating oil 43 . These two pieces of legislation, along with vociferous complaints by industrial users and their ability to purchase spot gas at the hubs were key factors which caused the German end-user market to open up.

The change in attitude towards trading across Europe has been primarily a 'bottom up' demand for change, but there were signs that some sellers were also prepared to change. GasTerra publicly said ${ }^{44}$ that it was responding to its customers' demands for more market pricing and that it had therefore agreed with many of them to change the point of delivery from the 'factory gate' to the TTF hub. It went on to demonstrate this support by the role it played in helping make the TTF more

\footnotetext{
${ }^{39}$ Klaus Schäfer, CEO of Eon-Ruhrgas, at ONS 2010: "We have to re-engineer the Long Term Contacts to anticipate the future needs of the market: price levels, indexation and review mechanism".

${ }^{40}$ For greater detail see Honoré (2010).

${ }^{41}$ South Hook LNG, South Wales, capacity 21.5bcma; Adriatic LNG, off the Veneto coastline, capacity 8bcma.

${ }^{42}$ Bundesgerichtshof ("BGH").

${ }^{43}$ German Energy Blog, $24^{\text {th }}$ March 2010: "BGH Declares Oil Price Linkage Clause in Gas Contracts Void": see article at: http://www.germanenergyblog.de/?p=2278

BGH ruling 61/2010, can be accessed at: http://juris.bundesgerichtshof.de/cgi-

$\underline{\text { bin/rechtsprechung/document.py? Gericht=bgh\&Art=pm\&Datum }=2010 \& \text { Sort=3\&nr }=51371 \& \text { pos }=2 \& \text { anz }=63}$

${ }^{44}$ European Gas Hub Market conference, Frankfurt, 5th December 2011.
} 

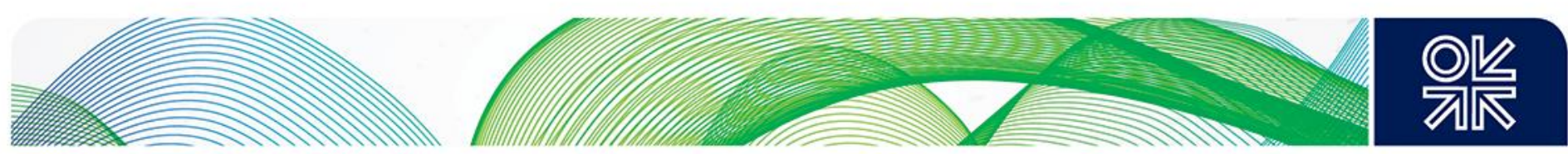

transparent and liquid. It did this by offering traded products on the TTF market where it also acted as a Market Maker ${ }^{45}$, as well as offering its customers products using TTF indexation.

This was a significant change in attitude towards gas trading, from a Dutch company selling Dutch gas. The Dutch were, of course, the first to market natural gas in the 1960s and the ones who 'invented' oil indexation as a means of marketing their new product ${ }^{46}$. This underlines the significance of GasTerra committing to sell its production on the TTF hub or on contracts priced at the TTF hub.

Of the other gas suppliers into Europe, Norway is already selling a large proportion of its gas at hub prices $^{47}$ and is well placed to embrace a pan-European market-priced environment as and when national markets achieve the transition. LNG is sold both at hub prices and on contracts with oil or oilproducts pricing formulae, depending on where it is landed and who the seller is, but will most probably migrate towards the 'norm' of hub pricing as and when hub pricing becomes established in a specific importing country. Russia has been arguing the merits of oil indexation but, in reality, has been willing to adjust its contracts to reflect hub prices, and the latest analysis shows that the average Russian selling price to European buyers is within $5 \%$ of hub prices ${ }^{48}$. The last stumbling block to moving fully towards a market priced situation in Europe is Algeria, which is for the time being holding out for the 'traditional' oil-indexed contracts.

The markets are changing and this is a consumer led change. To be successful, it will require robust and reliable marker prices. To be credible, a marker or benchmark hub must have good liquidity from spot to several years forward, as well as being fully transparent and fully open and accessible to a wide range of participants. There is strong evidence that the pricing structure of European gas markets has significantly changed over the past ten years as more LTCs are re-negotiated to include a greater portion of market pricing, or are the subject of arbitral decisions in favour of including a greater element of market pricing in the formula or simply in the out-turn price.

The tipping point from oil indexation to market pricing came in $2013^{49}$ and the trend has continued since: the latest IGU ${ }^{50}$ Wholesale Gas Price Survey (see Figures 3 and 4) shows that the share of market pricing across Europe as a whole reached 61\% in 2014, although there are great variances across the regions.

\subsection{What is the situation today?}

Across Europe as a whole the move from oil indexation to Gas-on-Gas pricing has been decisive over the past 10 years. Despite this, there are anomalies in the results from the 4 European regions that the IGU surveys: Figure 3 (IGU Table) and Figure 4 show that very different price formation mechanisms operate across European regions, and that the rate of change is also very different:

- North west Europe is clearly dominated by hub-pricing, with $88 \%$ of supplies sold on that basis, and the remaining $12 \%$ being the residual levels of oil indexation in the LTCs;

- Central Europe has just over half of its gas supplies priced at hubs but still $38 \%$ in relation to oil. It also has a quite significant $15 \%$ at regulated prices, a level which has barely changed in 10 years.

\footnotetext{
${ }^{45}$ Market Maker: where a market participant agrees to make bid/offer spreads, within certain agreed parameters, in order to increase liquidity for all other participants.

${ }^{46}$ For a history of oil indexation in gas contracts, see Stern (2007).

${ }^{47}$ All Norwegian gas sold to Britain is market priced and a percentage of European contracts is also indexed to hub prices.

${ }^{48}$ See Stern et al (2014), Fig.12, p.62.

49 The estimated split of European gas supply between oil indexed pricing and market pricing tipped over in favour of market pricing (51\% v 49\%) early in 2013 and by the end of that year had reached $57 \%$ v $43 \%$ in favour of market pricing. (Sources SocGen and IGU).

50 International Gas Union: North West Europe: Belgium, Denmark, France, Germany, Ireland, Netherlands, UK. Central Europe: Austria, Czech Rep, Hungary, Poland, Slovakia, Switzerland. Mediterranean Europe: Portugal, Spain, Italy, Greece, Turkey. South East Europe: Bosnia, Bulgaria, Croatia, Macedonia, Romania, Serbia, Slovenia.
} 

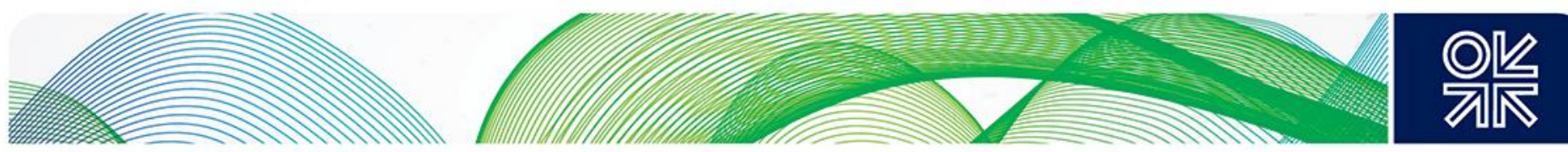

- In the Mediterranean region only $30 \%$ of gas is sold at hub prices (virtually all of which is in Italy), leaving a large $64 \%$ still oil-indexed, spread across the remaining countries of Spain, Portugal, Greece and Turkey;

- In south east Europe regulated prices dominate at $52 \%$, followed by oil indexation at $38 \%$ and almost no market priced gas (4\% accounts for small quantities in Croatia); in this region there has been virtually no change in these proportions over the past ten years.

Figure 3: European Gas Price Formation: 2005-2014

\section{Europe Price Formation: 2005-2014}

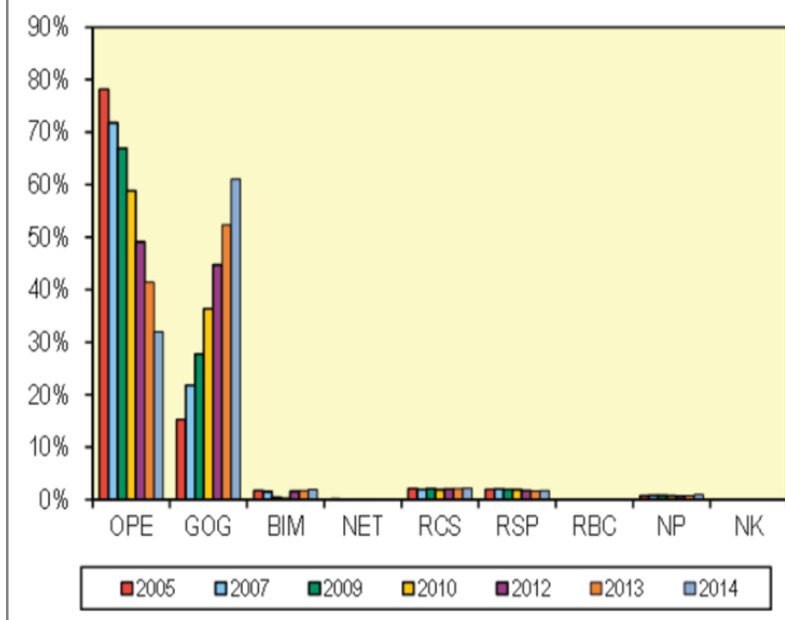

\section{Europe Gas Supply} by destination and pricing: Q4-2014

\begin{tabular}{|l|c|c|c|c|c|c|}
\hline $\begin{array}{l}\text { Region and approx. \% of } \\
\text { total European demand }\end{array}$ & O & G & R & R & B & N \\
\hline E & G & S & S & I & M & P \\
\hline North West Europe 50\% & 12 & 88 & & & \\
\hline Central Europe 15\% & 32 & 53 & & 15 & \\
\hline Med. Europe 30\% & 64 & 30 & & & 6 \\
\hline South East Europe 5\% & 38 & 4 & 52 & 4 & 2 \\
\hline & & & 3 & 2 & 2 \\
\hline
\end{tabular}

OPE: Oil Price Escalation GOG: Gas-on-Gas Competition RCS: Regulated Price (Cost of Service) RSP: Regulated Price (Social and Political) BIM: Bilateral Monopoly NP: No Price North West Europe: Belgium, Denmark, France, Germany, Ireland, Netherlands, UK.

Central Europe: Austria, Czech Rep, Hungary, Poland, Slovakia, Switzerland. Mediterranean Europe: Portugal, Spain, Italy, Greece, Turkey. South East Europe: Bosnia, Bulgaria, Croatia, Macedonia, Romania, Serbia, Slovenia.

Source: IGU Wholesale Gas Price Survey - 2015 Edition

There is further evidence that the move to market pricing has not yet spread across all of Europe to the same degree: in late 2013 the Financial Times newspaper ran an article ${ }^{51}$ on European gas pricing in which it quoted Statoil's Eldar Sætre ${ }^{52}$ on the company's response to market liberalisation. He explained that "all of its German contracts and nearly all its UK, Dutch and Belgian contracts now reference prices at regional gas hubs" and further explained that "progress has been slower in modifying contracts for supplies in to eastern and southern Europe, where hubs are less well developed". Statoil's changing approach to selling its gas to European consumers clearly follows the development of the hubs in each of its consumers' countries.

The situation at the end of 2014 is that European LTCs have become market priced, to a greater or lesser extent depending on the location of delivery. Britain now has essentially $100 \%{ }^{53}$ of its supplies market priced; Continental Europe is still 38\% oil-indexed but negotiations have meant lower final prices, $54 \%$ market priced with some contracts totally renegotiated and others with interim adjustments, leaving the remaining $8 \%$ at regulated prices. However, within Continental Europe, eastern and southern Europe are resisting change, mainly for historical political and infrastructure reasons.

\footnotetext{
${ }^{51}$ Financial Times, Wednesday 20th November 2013: "Hub-linked prices will not necessarily mean lower gas prices"

52 Executive vice-president for marketing.

${ }^{53}$ There are still a very few specific contracts that include oil indexation, maybe $1-2 \%$ of the total and declining.
} 

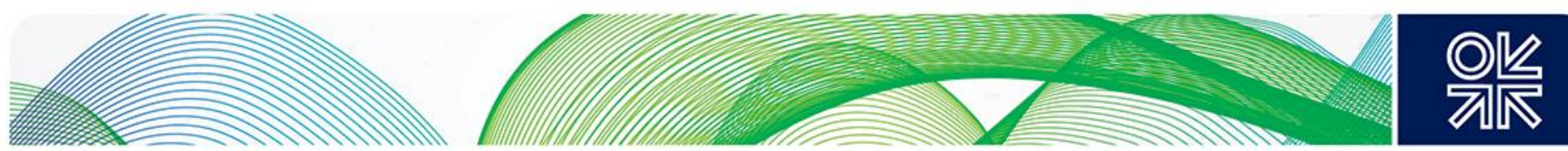

Figure 4: Regional European Gas Price Formation: 2005-2014

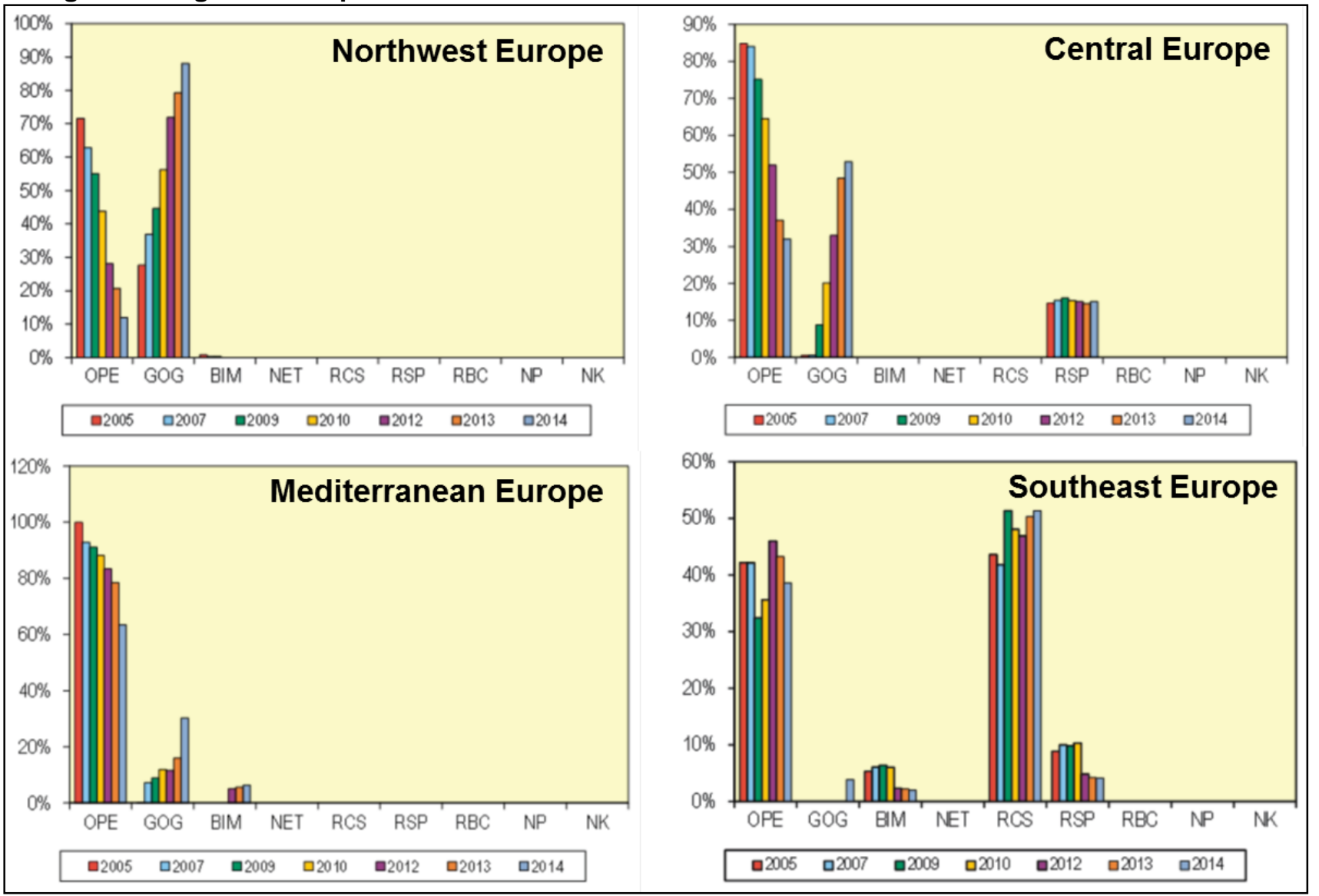

Source: IGU Wholesale Gas Price Survey - 2015 Edition

How long the transition to fully liberalised, commercial, hub-priced gas markets will take to complete is uncertain: it will take time and it will be costly for some players whose existing contractual commitments become 'out of the money', as it was in North America and in Britain, but competition will mean that gas-to-gas pricing will ultimately prevail.

\section{4 'Traded' gas, 'Contracted' gas and 'Exchanged' gas}

There has been much confusion over these terms as different countries view trading in varying ways, although over time a more consistent understanding appears to be developing, as follows:

'Traded' gas is gas that is bought and sold at the hubs, whether for physical delivery or for financial hedging or for speculative reasons. It is usually a 'standard' product, either OTC or exchange and mostly for spot, prompt or near to mid curve maturity. In Britain, about $50 \%$ of consumed gas is (net) 'traded'54 and about 20 times consumption is (gross) traded (i.e. the same molecule of gas is bought and sold many times prior to being consumed): this is the 'churn'. 

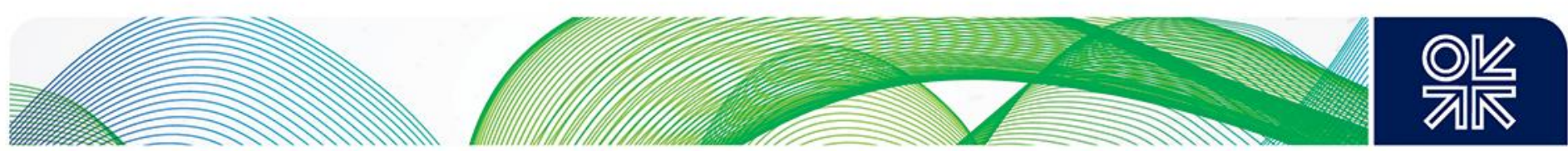

In Continental Europe, the share of gas 'traded'55 as part of the total consumption in each Market Area is much harder to establish than in Britain. The only country where there is enough market transparency (in the form of reliable and frequent data reporting) to make a credible assessment is Holland ${ }^{56}$; for the other countries, it is a case of relying on individual discussions with market participants. However, it can be noted that the scale of 'traded' supplies is broadly in line with the stage of development of each country's gas hub.

'Contracted' gas is gas that is traded or 'contracted' bilaterally for delivery at a hub and can be of a 'standard' product or bespoke, of any time duration, often medium to long term. In Britain, about $50 \%$ of consumed gas is 'contracted' but there is no 'churn' as the seller delivers to the buyer, either directly or through a hub.

'Contracted' gas includes the traditional Continental European LTCs as well as the 'new world' British contracts; they are concluded either directly between the seller and the buyer, or on the OTC market (through a broker or electronic platform). Whereas the Continental European LTCs typically have a duration of 20-30 years, the British 'long term' contracts are for 8-12 years and, in north America, a contract is deemed 'long term' if it is longer than one year.

Gas 'Exchanged' at a hub is a notion sometimes quoted by regulators and TSOs, although the practice is disappearing; it is essentially purely the gas that's physically nominated and delivered at, or taken from, a hub. This is the physical or volumetric part of gas contracts rather than the financial or pricing part.

\section{5: The development and functioning of the European gas hubs}

\subsection{Important hurdles to overcome}

There has been much progress in the development of the European gas hubs but there are still some very important hurdles to overcome before we can have efficient, successful and mature gas markets that can provide a reliable price reference for contracted gas supplies. The three main areas of concern are liquidity and data transparency; physical connectivity; political willingness and cultural attitudes.

In order to reassure traders and encourage them to participate in a market, which in turn will help develop market liquidity, there must be full transparency - i.e. key market data made available to all participants on a timely and reliable basis. This is a problem in the European gas markets in terms of the quality of available data and its timeliness: there is often a lack of common methodology, such as in the reporting of gas flows; some data is very easily accessible, such as British and Dutch physical flow volumes, some far more difficult, such as German physical flow volumes. Data can be had on a near real-time basis for both the British and Dutch markets, and on the TSO websites, but far less easily and with far greater time delay for say, France or Belgium or Germany and for most of the southern and eastern countries. Finally, there ought not to be any financial or administrative penalties in obtaining physical or trading data for the gas markets.

The physical infrastructure across Europe needs to be strengthened to allow for better physical transportation of gas but also to prevent constraints that in turn will distort prices. Each single entry/exit Market Area needs daily balancing and in order to provide this the infrastructure must be sufficiently resilient yet flexible enough to allow the balancing agent to fulfil its role. This may require

\footnotetext{
${ }_{55}^{55}$ Resulting from 'spot' trading rather than from Contracts.

${ }^{56}$ It is estimated that about $35 \%$ of Dutch consumption is 'traded' and $65 \%$ 'contracted', albeit increasingly at market prices.
} 

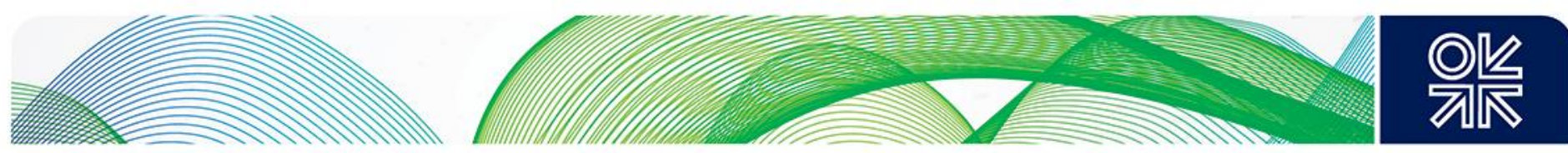

de-bottlenecking, which is a costly process ${ }^{57}$ and takes time. In some cases the cost/benefit analysis can be very poor, resulting in project delays or indeed projects not receiving financial approval. This is the major reason given for not merging the two German Market Areas into one ${ }^{58}$ but, inevitably, the result is a less than perfect system for both the consumer and also the gas market itself. There are nonetheless ways round this last hurdle, namely 'market coupling' where two adjacent Market Areas agree to combine the two areas financially but not necessarily physically. This has already been done between the Dutch grid and the German Gaspool grid, with the coupling being offered and managed by the GTS59 TSO in Holland and its sister company, the Gasunie Deutschland TSO in Germany.

Finally, graphs do not show the 'culture' behind the data. There are very differing political and commercial attitudes across Europe to both the liberalisation of the energy markets and to trading in particular. What is certain is that a political willingness to have liberalised markets only exists in two mature traded gas markets in Europe, Britain and the Netherlands, where a long history of trading exists and all the market participants have embraced the traded market. There is a general pattern going from a pro-liberalisation culture in north-west Europe to one of lower enthusiasm in the southeast.

Political willingness is a crucial factor in creating change in the structure of the gas markets. This was clearly demonstrated in Britain when the Thatcher government decided to implement a series of privatisations of nationalised industries and their effective implementation was critical for the policy to be successful. A different example is that of the Dutch government which decided in the mid-2000s to implement its "Gas Roundabout" 60 strategy. Despite the TTF having been established a few years previously it had not really attracted any significant trader interest, however, with the commitment of all key stakeholders it was effectively kick-started to become what is today Europe's second largest traded gas hub. As with the British example, it was the government that had a vision that it strongly wanted to implement. This involved passing laws to make sure that change was effected.

A further example is that of Austria. As in the Netherlands, the Austrian government and regulator pushed for reform of the network and for changes in commercial practices. After thorough consultation with industry, the parliament voted through a new Austrian Gas Act ${ }^{61}$ in October 2011. Since its implementation and the start of the new VTP hub in January 2013, there have been noticeable improvements in the liquidity of that hub.

Although other European countries have passed various laws, in line with EC 'Packages', to instigate a liberalised gas market, few have persevered to ensure effective implementation. In France and

\footnotetext{
${ }^{57}$ It has been estimated in a survey conducted for Entsog that it could cost $€ 200 \mathrm{bn}$ to create a single European gas market.

58 The 12 German TSOs submitted a cost-benefit analysis of a merger of the two German gas market areas to BNetzA in November 2012, as part of their obligations under the Gas Grid Access Ordinance. According to their calculations, the initial cost could be $€ 3 b n$ for additional capacity to be built, with a further $€ 300$ million additional costs in the first year. PWC was then asked to calculate the benefits to the consumer and arrived at a figure of just $€ 57 \mathrm{million} / \mathrm{a}$.

${ }^{59}$ Gas Transport Services.

${ }^{60}$ For more detailed information, see:

Foreest (2010).

Ministry of Economic Affairs: Economic Impact of the Dutch Gas Hub Strategy on the Netherlands; December 2010:

http://www.rijksoverheid.nl/documenten-en-publicaties/rapporten/2010/12/08/dutch-gas-hub-strategy-on-the-netherlands.html

Ministry of Economic Affairs: "The Dutch Gas Hub: Connecting Northwest Europe with the global gas market"; 2011:

https://www.government.nl/documents/leaflets/2011/12/07/the-dutch-gashub

Various references and information at the GTS website:

http://www.gastransportservices.nl/en/zoekpagina?q=gas+roundabout $\& x=7 \& y=8$

Oil and Gas Financial Journal report; The Netherlands: the energy hub of Europe; April 2010:

http://www.ogfi.com/articles/print/volume-7/issue-4/focus-reports/The-NETHERLANDS-the-energy-hub-of-Europe.html

${ }^{61}$ The "GasWirtschaftsGesetz 2011" (GWG-2011) was adopted by parliament on $19^{\text {th }}$ October 2011.

The original document can be accessed at: http://www.parlament.gv.at/PAKT/VHG/XXIV///I 01081/fname 208203.pdf

More detailed information, in English, can be found at: International Comparative Legal Guide:

http://www.iclg.co.uk/index.php?area $=4 \&$ country results=1\&kh publications id=228\&chapters $i d=5091$

E-Control Discussion paper, November 2011: http://www.e-

control.at/portal/page/portal/medienbibliothek/gas/dokumente/pdfs/Punktation Marktregeln v11 en.pdf
} 

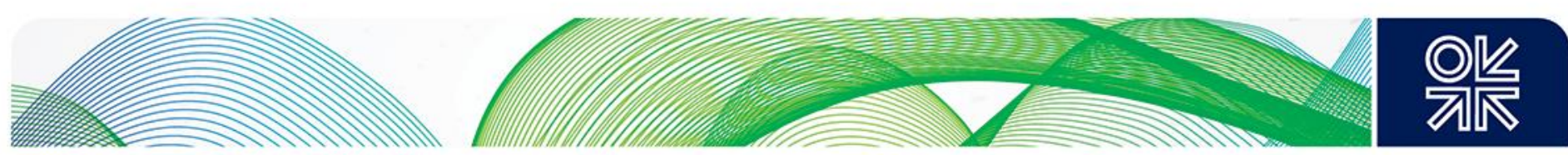

Belgium, very little change has actually happened in the gas market despite superficial changes in regulations. In Italy, there was no real desire for an effective commercial and liquid PSV gas hub until very recently, some ten years after the hub was first established in 2003.

In both France and Italy, the prevailing attitude is much in favour of strong national 'flag bearing' companies; this is part of the differing regional 'cultural attitudes' referred to above. In addition to political will to enact and enforce the relevant laws, it is very necessary that the market participants, from incumbent energy companies to wholesalers, to distributors and even the commercial and residential end users, 'want' to embrace the new commercial environment and take it to its logical conclusion. This is arguably why Britain and Holland succeeded because, once the incumbent supplier/energy company was forced to relinquish its dominant position, players in the rest of the value chain very quickly changed their approach to the market, having realised and accepted that it was in their interest to embrace trading.

It should also be noted that countries with indigenous production have been at a distinct advantage in making the change to liberalised, commercial markets. North America has always had a high level of gas production and is now self-sufficient since the expansion of shale gas recovery. Britain experienced a boom in gas production in the 1990s just as the internal market was going through its transformation. The Netherlands was Europe's first major natural gas producer and exporter and today still produces nearly double its demand. Romania has the potential to become the first country in eastern Europe to transition from a highly regulated national gas sector to a more liberalised one if its production, through the development of new discoveries, increases from $8 \mathrm{bcma}$ to $12 \mathrm{bcma}$ later this decade, against a demand of around 10bcma.

This does not preclude other countries achieving liberalisation, but the process may take longer. In Romania, the politicians have paid lip service to energy market reform for over 10 years but they are now declaring ${ }^{62}$ that change is timely. They are even contemplating creating a south east European gas hub with Bulgaria and Greece. Sometimes there needs to be a catalyst for the change in attitude and, in the case of Romania, it is probably the gas find in the Black Sea that could make the country not only self-sufficient by the end of the decade but even have a surplus for export. Another factor that could be a positive influence on developing a south east European hub is the abandonment by Russia of the South Stream project in favour of a new Turkish Stream ${ }^{63}$ which would, potentially, deliver upwards of 40bcm/year of gas at the Turkish/Greek Border after 2019.

In essence, therefore, government commitment and a willingness to embrace liberalisation by all stakeholders is a precondition for success in achieving a liquid traded gas hub. Where a country's demand is met substantially by domestic production, the government is in a strong position to influence, if not insist, on changing the commercial terms of its sale on the wholesale market from medium or long term oil-indexed contracts to market based pricing - whether as hub-traded gas or under 'new style' physical term contracts.

\subsection{The European gas geography}

There seems to be general consistency in today's language between 'west' and 'east', resulting from the political split in Europe dating from the Cold War period, and between 'north' and south', resulting from differing levels of economic development. However, there remains a wide inconsistency in the use of the terms 'North', 'South', 'East', 'West', 'Central', and 'Mediterranean', when it comes to describing the geographical areas in Europe in relation to gas hubs. The IGU has its own particular classification ${ }^{64}$, whereas Entsog the representative body of the EU's TSOs has overlapping

\footnotetext{
62 Presentation at the Aspen Institute 'Bucharest Forum Energy', $4^{\text {th }}-5^{\text {th }}$ June 2014

${ }^{63}$ See Appendix D for a map of the Turkish Stream project.

${ }^{64}$ Refer to Figure 3.
} 

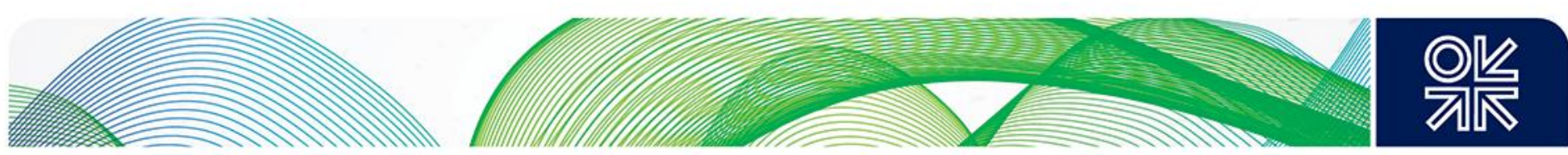

classifications when presenting its statutory documentation of the Gas Regional Investment Plans ${ }^{65}$ : whereas 15 countries are within one GRIP area, 12 countries are within two areas.

\section{Map 1: European gas regions, markets and hubs 66}

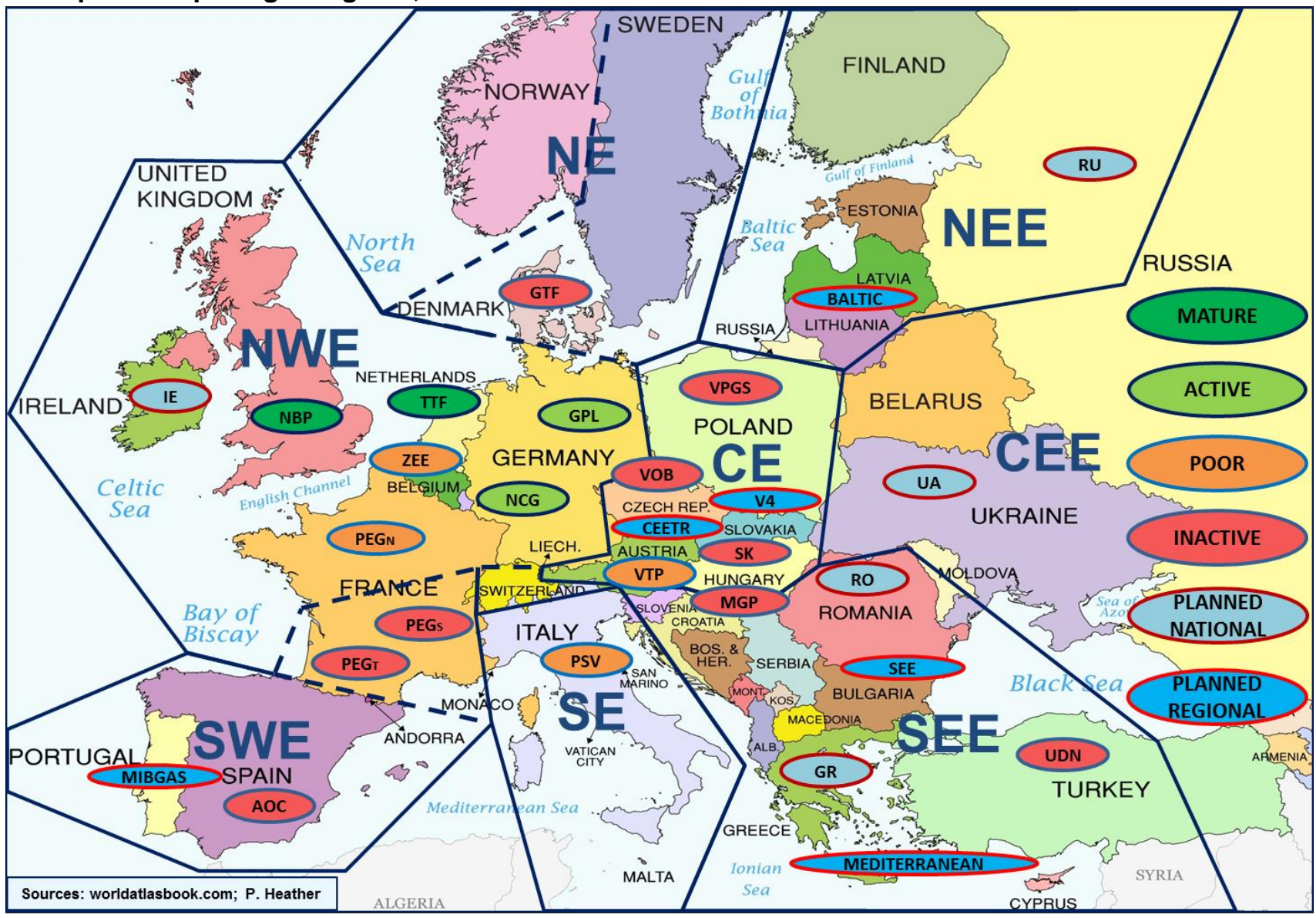

Map 1 shows the Author's representation of the European gas geography: it broadly follows the various levels of gas hub development ${ }^{67}$, although the gas geography of Europe and the development of each of the hubs also reflect in turn the different stages of evolution in gas price formation from oil indexation to market pricing. Furthermore, it must be stressed that Europe is not one homogenous gas market, neither in in terms of infrastructure nor in political desire to change, and that even within each area there can be many levels of development.

The most developed part of Europe in terms of liberalised gas hubs is the North-West. This is also the one with the most disparity between the 'mature', 'poor' and 'illiquid' hubs: from the fully mature British and Dutch hubs, to the 'middling' German, Belgian and northern French hubs, to the illiquid southern French hubs and, finally, to Ireland which has yet to create its gas hub. Even within each country there can be differences as is the case in France, which is effectively split north/south, with a 'poor' hub in the north of the country and two 'illiquid' hubs in the south; and Germany, which has two

\footnotetext{
${ }^{65}$ Baltic: Denmark, Estonia, Finland, Latvia, Lithuania, Poland, Sweden. North West: Belgium, Denmark, France, Germany, Ireland, Luxembourg, Netherlands, Sweden. UK. Central Eastern: Austria, Bulgaria, Croatia, Czech Rep., Germany, Hungary, Poland, Romania, Slovakia, Slovenia. South: France, Portugal, Spain. Southern Corridor: Austria, Bulgaria, Croatia, Cyprus, Hungary, Greece, Italy, Romania, Slovakia, Slovenia.

${ }^{66} \mathrm{~A}$ list of the hubs, with full names and dates of commencement can be found in Appendix $\mathrm{E}$.

${ }^{67}$ The attributions of 'Mature', 'Active', 'Poor' and 'Inactive' are taken from the Summary of the 5 Key Elements in section 6.1.6.
} 

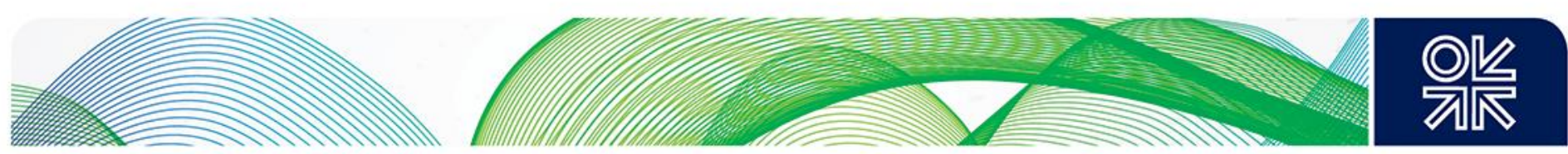

competing hubs limiting their potential for development as traded volumes (and hence liquidity) are shared between them.

The Central European region is the one showing promise for further development over the coming years, both in infrastructure and in market development. The Austrian traded market really only started in 2013 with the creation of a virtual hub but it is well placed at the centre of Europe and hopes to form part of a regional hub for Central Europe. Other countries in this region are still at varying levels of market development but there does seem to be a general desire for progress towards a fully liberalised gas market, with the possible exception of Hungary.

The Iberian Peninsula is essentially a separate market, heavily dependent on and linked to LNG. The Italian market was for a long time lagging in its development (although it is now catching up). The remaining countries, in the north and east are grouped in Northern and North East Europe (Denmark, Sweden, Finland and the Baltic States); and in Central Eastern and South East Europe (Ukraine, the Balkans, Romania, Bulgaria and Greece). Most of Eastern Europe is still heavily dependent on Russian gas supplies, arriving through the historic network of 'transit' pipelines: their local gas networks are generally poor and there is a major need for better north/south connectivity.

The following summarises the development of the existing European hubs:

The British NBP was the first European gas hub, which started trading in 1996 although significant activity commenced in the spring of 1997 . It soon attracted a variety of participants from producers to wholesalers to large consumers, as well as financial players. Within its first year, an exchange futures contract was established whose traded volumes grew rapidly. This market exceeded a 10x churn within just a few years and, by 2001, the churn had reached about 20x. Despite a trading lull in the mid-2000s, volumes have steadily grown on both the OTC and exchange markets and there are today a record number of participants, across both OTC and exchange, estimated at about 200, of which some 40 who are deemed to be 'active'. NBP is the predominant European gas hub with the following key attributes: full data transparency, easily accessible, with good liquidity and volume. It does occasionally 'suffer' in relation to its Continental neighbours, when linking pipeline infrastructure to The Netherlands and Belgium is offline or congested and also because it trades in Sterling (pence per therm). NBP was the first and still is the premier European gas benchmark hub.

The Dutch TTF started in 2003 but for several years did not trade very much. It was only when there was a real political commitment to develop the Netherlands as the 'Gas Roundabout' of Europe that this hub started to take off, slowly at first in around 2007 then with the first of several 'step changes' in 2009. Progress was firm from 2009 to 2011, with traded volumes rising by an average of over $62 \% /$ year, from an average of $28.5 \mathrm{bcm} / \mathrm{mth}$ in Gas Year 2009 , to $46.3 \mathrm{bcm} / \mathrm{mth}$ in Gas Year 2010 , to about $50 \mathrm{bcm} / \mathrm{mth}$ by the end of $2011^{68}$. After a second 'step change' increase in traded volumes in 2012 , and a third in 2014, the TTF today is about two-thirds the size of NBP in total traded volumes ${ }^{69}$. As with the NBP, the TTF has very good data transparency and accessibility, good liquidity and is attracting an ever greater number of participants, across both OTC and exchange, estimated at about 150, of which some 30 are said to be 'active'. The TTF is increasingly used by traders in other Continental European countries to financially hedge and risk manage their forward portfolios ${ }^{70}$, as well as serving as a balancing hub for the Netherlands. Since late 2013, it has become the second European benchmark hub and is priced in $€ / M W h$.

Germany has two Market Areas and two hubs: the NCG and the Gaspool (GPL) both of which started trading in 2009. The division of Germany into two areas has not always been the case: due to its historical gas structure, comprising originally 19 zones and two major pipeline systems, progress has been slow, even after a period of rationalisation from 2009 to 2011 . In 2010 the gas market areas in

\footnotetext{
68 Data from Gas Transport Services.

${ }^{69}$ In 2014, the total traded volumes were: NBP: 20,505TWh; TTF: 13,555TWh.

70 Timera Energy: "A quick check on gas hub liquidity", $3^{\text {rd }}$ November 2014, para. 4: http://www.timera-energy.com/a-quickcheck-on-gas-hub-liquidity/
} 

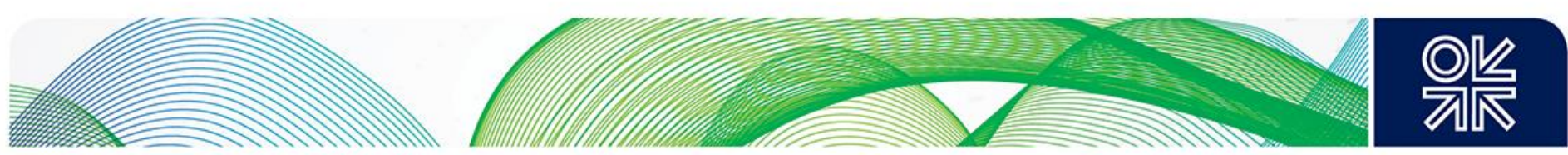

Germany were reduced to 3 high calorific gas and 3 low calorific gas zones. In 2011 there were two further changes: the first implemented on the $1^{\text {st }}$ April, reducing the number of zones to three, $2 \mathrm{H}$-cal and $1 \mathrm{~L}$-cal; the second on $1^{\text {st }}$ October when the last merger was effected, creating the current situation of a 2 Market Area system: Gaspool and NetConnect Germany. Each MA has both high and low calorific gas networks, which are still being balanced individually; the costs of energy conversion are expected to be 'socialised' by 2016 .

It is noteworthy that the German configuration is quite different to the rest of North West Europe, because the NCG and the GPL are each run by 6 TSOs. The proposed final merger, of NCG and GPL, has become a very political issue and the regulator, BNetzA ${ }^{71}$, has stated ${ }^{72}$ that it would see increased benefits in a unified system but is for now leaving it up to the TSOs to decide if/when to proceed - all 12 of them. If the German market cannot unite into one Market Area, this could be a major stumbling block preventing a German hub from developing further.

There are signs that trading volumes improved for these two hubs in 2014 but it is uncertain whether the trend will continue. The traded volumes are dominated by the spot/prompt trades, although there has been an increase recently in near and mid-curve trading. The increase in volumes and in curve trading in 2014 is in part due to large quantities of Russian gas now being 'traded' at the Gaspool hub and in spreads between GPL and either NCG or TTF.

The Belgian Zeebrugge (ZEE) hub is really a misnomer: it is actually a trading point, which started trading in 2000, the second gas hub in Europe. There has also been a virtual hub in parallel since 2012, the ZTP. Neither hub is particularly large although the Zeebrugge physical point is the one with the most trading, all OTC. Although volumes have grown a little they are mainly based on balancing needs of the shippers and/or spread trading between ZEE and either NBP or TTF. It has been and remains very much a 'mid-range' hub when compared to its neighbours. One very interesting point to note however, is that Belgium and its neighbour, Luxembourg are aiming at integrating their national market areas, which will be the first of its kind between two European Member States. This merger is expected to be in place by October $2015^{73}$.

France now has two Market Areas and two hubs: PEG Nord and TRS ${ }^{74}$; Nord has the majority of the traded volumes. The growth seen in late 2011 and 2012 has since slowed markedly and, despite a brief success in financially linking the Nord and Sud hubs through an exchange spread contract ${ }^{75}$, the price differential between the hubs has widened again (Figure 5). The market-coupling scheme by Powernext was backed by the TSO, GRTgaz, but could not address the fundamental problem of insufficient physical capacity in the connection between the two zones. PEG Nord is well connected to pipeline gas supplies as well as LNG imports; PEG Sud is dependent solely on LNG imports, which can be supplemented by pipeline supplies from PEG Nord.

\footnotetext{
${ }^{71}$ Bundesnetzagentur.

${ }^{72}$ BNetzA presentation at the European Gas Hub Market conference, Frankfurt, $5^{\text {th }}$ December 2011.

${ }^{73}$ On the 1st October 2015, Creos Luxembourg and Fluxys Belgium, merged the Luxembourg and Belgian gas markets in one cross-border integrated gas market: the BeLux area: http://www.fluxys.com/belgium/en/Services/Transmission/MarketConsultations/ /media/F21AC4C69555421393FB1B6C937A3 CC0.ashx

${ }^{74}$ Trading Region South created on $1^{\text {st }}$ April 2015 from the merger of the former PEG Sud and PEG TIGF.

${ }^{75}$ Explained in Heather (2012): 3.3.3 “The Points d'Exchange de Gaz", pp.18-20.
} 

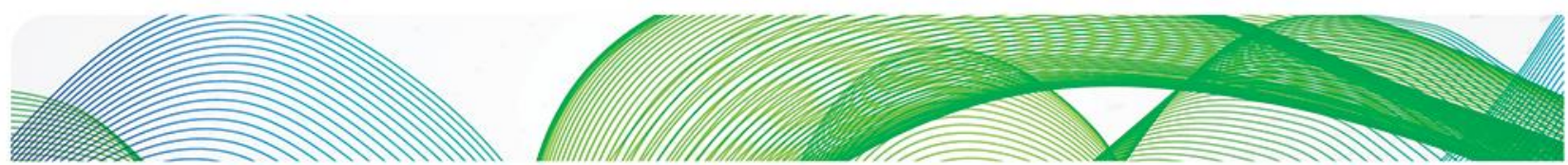

Figure 5: PEG Nord / PEG Sud spread: Nov 2010-Jun 2014

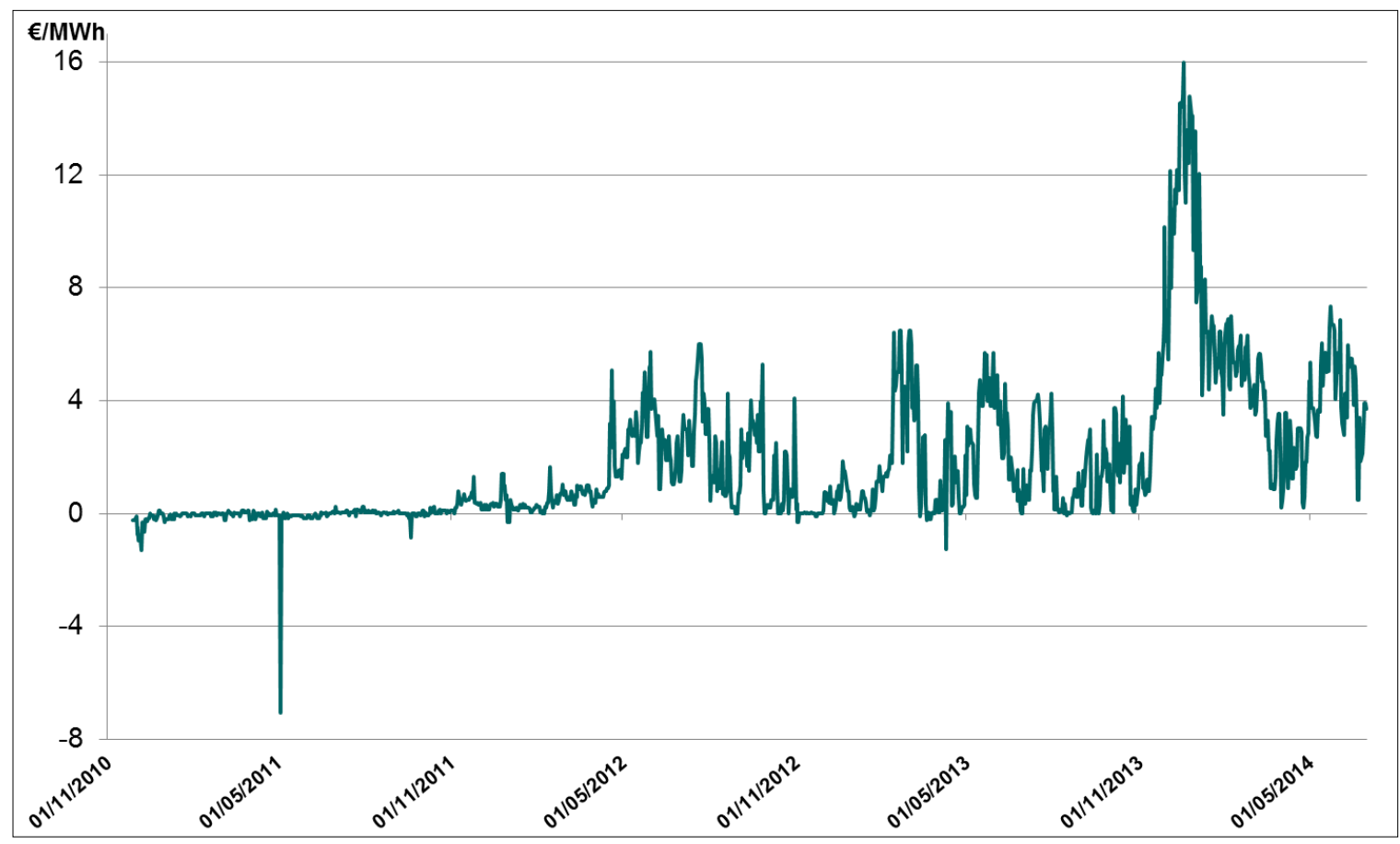

Sources: ICIS; P. Heather

The physical constraints became apparent in the volatility of the spread when, post-Fukushima, there was a pull of global LNG towards Japan and Asia more generally, resulting in fewer cargoes arriving in Europe, particularly at Fos in southern France, thereby causing an acute shortage of gas in the Sud zone. At that time, and since, the inadequate infrastructure capacity within France resulted in an increase in the price volatility between PEG Nord and PEG Sud as well as a large price differential.

Market coupling can work between two zones so long as there is a reasonably good physical infrastructure on both sides; otherwise it will fail as soon as the link is put under physical stress. PEG Sud started to de-correlate from PEG Nord as early as November 2011 and, since April 2012, the spread has been very volatile and has widened greatly, reaching a record $€ 16 / \mathrm{MWh}$ in December 2013.

There are plans approved by the French government to increase the N/S capacities thereby removing the physical constraint but this project has yet again been postponed ${ }^{76}$ due to the financial crisis. Of all the European hubs, the PEGs have clearly become 'balancing' hubs with any risk management being done at the TTF through spread trading.

Austria has a major trading point, Baumgarten, named after the village near to the import processing plant on the Austrian/Slovakian border. The import terminal itself is vast ${ }^{77}$ and is owned and operated by Gas Connect Austria ${ }^{78}$. Approximately one third of all Russian gas supplies to Western Europe come through Baumgarten for onward transportation to Germany, Italy, Slovenia and Hungary, as well as to supply the national market. The CEGH hub started trading in 2005 and in fact offered

\footnotetext{
${ }^{76}$ The project is now planned to be completed by 2019 and will probably include the merger of the Nord and TRS hubs to form one French Market Area.

77 Baumgarten Terminal has a total import capacity of $89 \mathrm{bcma}$.

${ }^{78}$ Known as OMV Gas GmbH prior to $14^{\text {th }}$ December 2011, the name change was part of the unbundling of the Austrian gas sector following the passing of the National Gas Act in October 2011.
} 

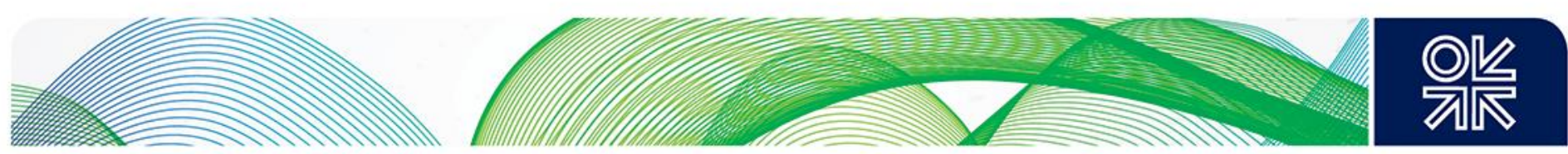

trading at 6 locations across Austria of which Baumgarten was by far the most important and the one that registered the most trades.

However, following the implementation of the Austrian Gas Act on $1^{\text {st }}$ January 2013, a virtual trading point was created, the VTP for the Eastern Market Area. (Austria's two other Market Areas are independent of each other and of the main Eastern Area and are each linked to and supplied by the German NCG grid). The VTP is showing signs of improvement, albeit slowly and most forward trading is the result of spreads with the TTF, NCG or PSV markets. Austria is also in discussions with two of its neighbours, Czech Republic and Slovakia, regarding the development of a Regional hub, the Central East European Trading Region (CEETR) ${ }^{79}$, although this project ${ }^{80}$ is currently on hold after Eustream ${ }^{81}$ withdrew in mid-2013.

There is also a parallel competing project, called Visegrad Four (or V4) ${ }^{82}$, to create a regional gas hub comprising the Czech Republic, Slovakia, Poland and Hungary. A roadmap ${ }^{83}$ was published in 2013 but, so far, progress has been slow and the milestones listed in the document have not been reached. There are suggestions that the countries do not share the same aims nor have the same appetite for the investment needed to achieve the project. The Slovak VTP and the Hungarian MGP ${ }^{84}$ are operational but very rarely trade and still have some problems: Slovakia has a 'hybrid' system of trading at physical points as well as a few trades at the domestic virtual trading point but the transit system is separate. In Hungary, there is also a 'hybrid' system as in Slovakia but there are actually two virtual trading points ${ }^{85}$ (MGP I and MGP II), depending on the shipper license held, diluting the already meagre liquidity.

When Italy announced the formation of the PSV, in 2003, there was great hope amongst the gas trading fraternity that this could be the beginning of truly pan-European trading. The Italian Network Code for gas is almost identical to the British one, although entry capacity is not as flexible. Storage is on an open access basis and all gas entering the system goes through the PSV. However, only a very small percentage of gas is actually traded at the hub and, until very recently, the national incumbent, $\mathrm{ENI}$, did not trade at the PSV at all. Furthermore, there has been a poor political and regulatory framework to encourage trading, all this on top of a national grid that was linked to its neighbours with both physical and contractual capacity constraints.

There have been noticeable improvements since 2012, partly spurred on by a new political willingness to see the PSV develop as a southern Europe market hub. The incumbent has been forced to 'trade' gas at the PSV and the Regulator has worked hard to encourage the dialogue between the Ministry, the TSO and major participants, to enable the continued growth of the hub. The results are clear to see, with a significant growth in OTC traded volumes, from 175TWh in 2012, to 282TWh in 2013 and 525TWh in 2014 (overtaking France by a small margin).

However, there do remain two crucial issues: the projected increase in south/north transit capacity needs to be realised; and the current situation regarding exchange trading and balancing needs to be resolved. The long discussed plans to increase gas flows from Italy northwards to Switzerland and onwards to France and Germany have recently received a major boost: the FID was taken by Fluxys in January $2015^{86}$ to make the Transitgas and TENP pipeline systems bidirectional from the end of

\footnotetext{
${ }^{79}$ Project CEETR was conducted by CEGH Central European Gas Hub AG, Energie-Control Austria; Eustream, A.S. and NET4GAS, s.r.o.

${ }^{80}$ Further details can be found in the GTMII Report, pp.39,40 (see Footnote 15 for the URL).

${ }^{81}$ Slovak gas TSO.

${ }^{82}$ Further details can be found in the GTMII Report, pp.41,42 (see Footnote 15 for the URL).

83 "Road Map towards the regional gas market among Visegrad 4 countries", June 2013:

http://www.visegradgroup.eu/documents/official-statements

${ }^{84}$ Magyar Gáz Ponton (Hungarian Gas Point).

85 This situation should change when a single shipper license/single vtp is created after the launch of SK-HU interconnector.

86 "Fluxys finances TENP, Transitgas reverse capacity": Argus Media, $28^{\text {th }}$ January 2015:

http://www.argusmedia.com/pages/NewsBody.aspx?id=984015\&menu=yes
} 

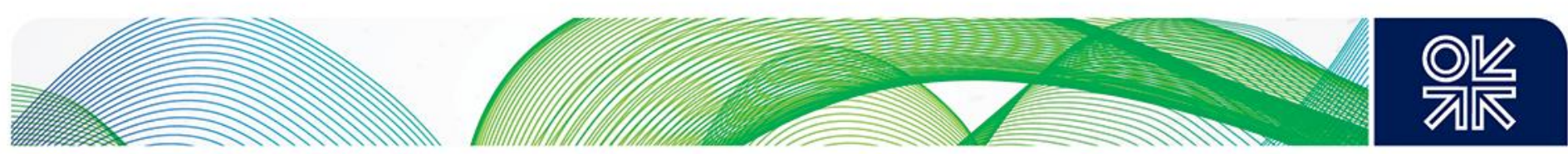

summer 2018. Fluxys cited the new supplies which are set to arrive in Italy, including through the TAP pipeline in 2020, as one of the reasons for going ahead with the project.

Although the OTC traded volumes have grown rapidly over the past three years, those on the GME trading platform ${ }^{87}$ have fared less well, with the notable exception of their PB-Gas product, essentially the trading of gas 'in storage' rather than 'at the PSV'. Indeed, the volumes of PB-Gas rose significantly from its beginnings in December 2011 following the introduction of the balancing regime in Italy, to reach 40.9TWh in 2013 and 41.6TWh in 2014. By contrast, bilateral exchange trading at the PSV (P-Gas) fell dramatically from an already low 3TWh in 2012, to 0.6TWh in 2013 and just 0.1TWh in 2014. There were no trades at all on the exchange futures contracts (MT-Gas) in 2014.

The Czech VOB ${ }^{88}$ hub is in the very early stages of trading but does already have OTC brokers and the Austrian CEGH exchange offers VOB futures contracts. In 2014, 33TWh traded OTC and 0.75TWh traded on the futures. Since 2013, the TSO, Net4Gas, no longer distinguishes between 'transit' and domestic gas but hub to hub trading will only take place after the implementation of the CAM arrangements (possibly in 2016). The Spanish AOC ${ }^{89}$, the Danish GTF ${ }^{90}$ and the Polish VPGS 91 barely trade. All other hubs in Europe are still at the planning stage.

Finally, there was news towards to end of 2014 regarding the often mentioned (in south east Europe) Vertical Corridor project to link Greece, Bulgaria and Romania. In an announcement made in December 2014" supplies [...] in that region [...] can be achieved by [...] improving interconnections [...] between Bulgaria and its neighbouring countries, and by improving North-South interconnections enabled with bi-directional flows. [...] In this context Member States and the Vice-President welcomed the joint statement signed today by Greece, Bulgaria and Romania on the natural gas "Vertical Corridor" connecting their countries".

If this infrastructure project does indeed go ahead, and in the light of the cancellation of the South Stream project and the announcement by Russia that it will deliver gas at the Turkish/Greek border after 2019, this could open the way for a regional hub in south east Europe, possibly including Turkey. In addition, the Black Sea discovery of gas could, according to ExxonMobili3, deliver up to $4 \mathrm{bcma}$ from 2019 and turn Romania into a net exporter of gas. A major obstacle to this remains, in that onward transportation from Romania will necessitate further infrastructure reinforcements and new pipelines to be built.

\subsection{Gas price convergence, correlation and volatility}

The EU's vision of a Single Energy Market implies a high degree of market integration across the Member States so that the differences in prices at different locations should only reflect transaction or transportation costs. This situation should also mean that prices in different Market Areas would respond to overall changes in supply and demand in the same way, at the same time.

\footnotetext{
${ }^{87}$ GME organises and manages the natural-gas balancing platform (PB-GAS), offers a trading platform for spot and forward bilateral trades (P-Gas), as well as being an exchange market for futures contracts (MT-Gas). For more information, see: http://www.mercatoelettrico.org/En/Mercati/MGas/MGas.aspx

${ }^{88}$ Virtuální obchodní bod ('virtual trading point' in Czech).

${ }^{89}$ Almacenamiento Operativo Comercial ('commercial operating storage' in Spanish, a misnomer resulting from using a historical term when the virtual trading point was created).

${ }^{90}$ Gas Transfer Facility, strictly speaking a physical bilateral trading point.

91 Virtual Point Gaz-System, formed in 2014.

92 Joint Press Statement by Ministers and Representatives of Austria, Bulgaria, Croatia, Greece, Italy, Romania and Slovenia and VP Šefčovič, $9^{\text {th }}$ December 2014: http://europa.eu/rapid/press-release STATEMENT-14-2520 en.htm

${ }_{93}$ Presentation at the Aspen Institute 'Bucharest Forum Energy', 4th-5th June 2014.
} 

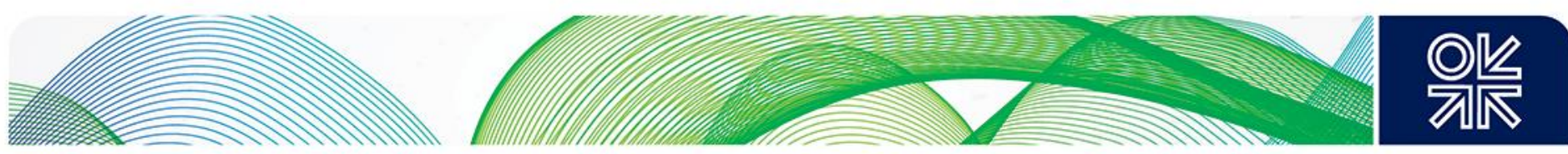

When comparing traded gas hubs, it is therefore useful to look at gas price convergence, the price correlations across the markets as well as the volatility of gas prices in the different markets. This provides an important additional tool in assessing the development of traded hubs ${ }^{94}$.

\subsubsection{Price convergence}

In order to have good price convergence between two or more hubs, there must be no restrictions in the ability to physically transport gas between them; it may not be necessary to actually physically transport the gas but it must simply be possible should the need arise. If that is the case then the traded markets will immediately 'arbitrage' any small price differences as they occur and bring the markets back in line with each other.

The price of gas at different hubs should theoretically reflect any cost of transportation between hubs, but in most instances this is not the case. This is because shippers often make locational swaps or trades, either with other shippers or from within their own portfolio. As an example: shipper A has a supply contract at Zeebrugge and intends to ship the gas to southern Germany and shipper B has a supply contract at Baumgarten and intends to ship the gas to Belgium. They agree to trade a locational swap with each other for an agreed price and the result is that each shipper has gas at its intended destination point, without having had to pay for the transportation.

Figure 6: Best four hubs price convergence, Month Ahead contracts: 2012-2014

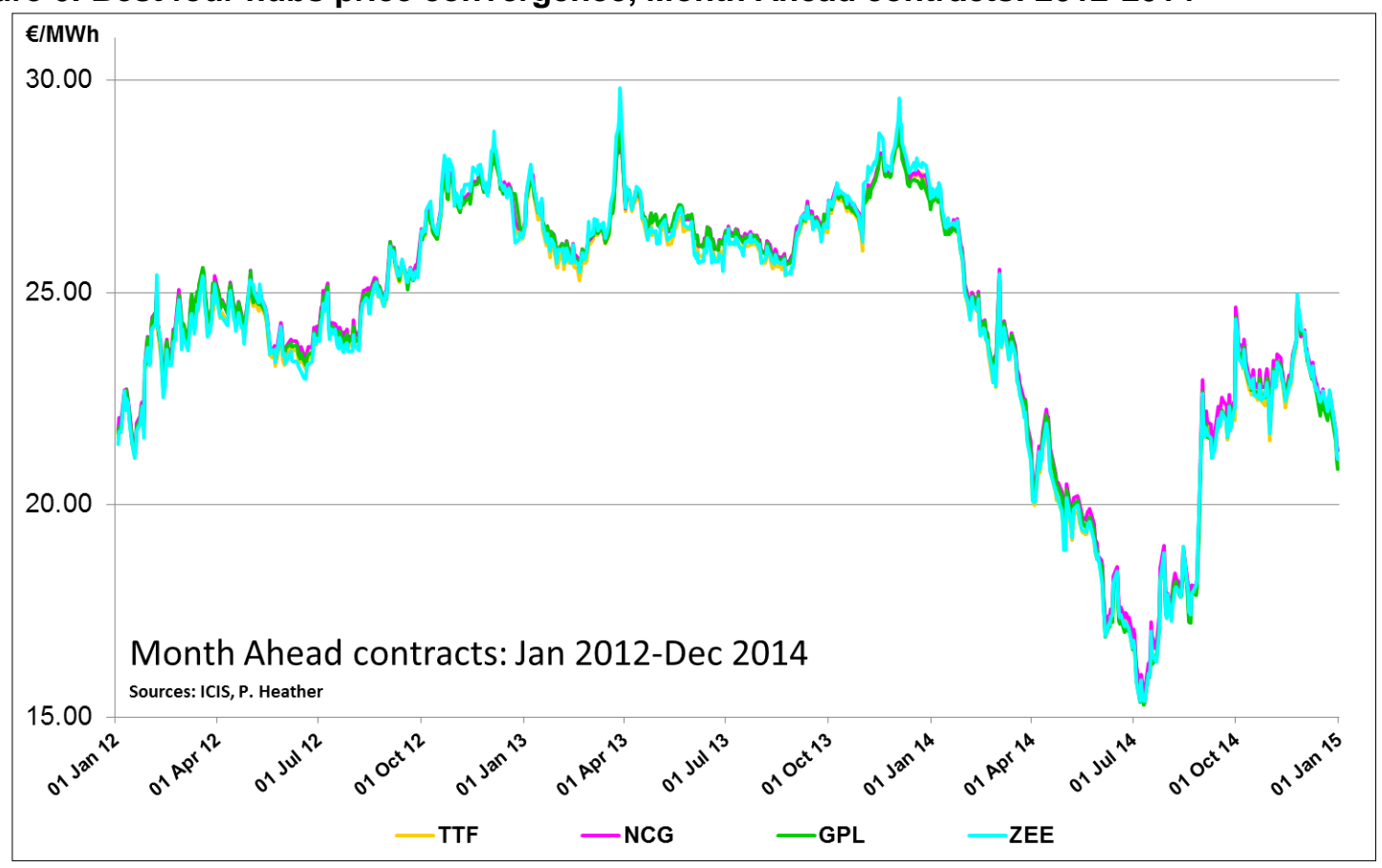

Sources: ICIS, P. Heather

Price convergence is a good indicator of market integration but it can be misleading as it is by no means an indicator of a hub being active or inactive, in absolute terms or in relation to other hubs.

There is the greatest price convergence between four neighbouring NWE hubs (Figure 6): TTF, NCG, GPL, ZEE. Over a three year period, the graph shows that the prices were almost always the same with very minor variances. This is unsurprising as there is very good physical infrastructure linking these four hubs.

\footnotetext{
${ }^{94}$ For a detailed analytical review of European hub price correlation, see Petrovich $(2013,2014,2015)$. A summary of the most recent analysis from this research is provided in this paper in section 5.6.4.
} 

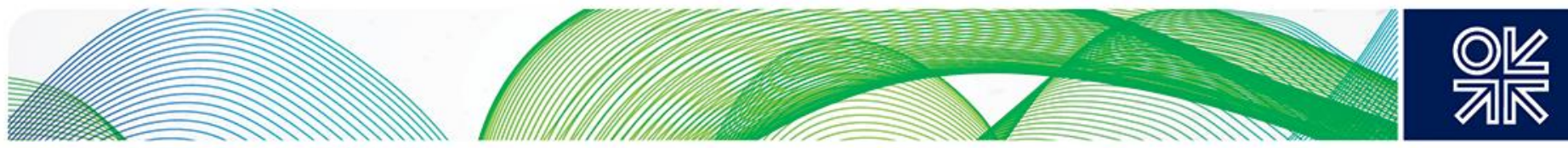

Figure 7: Best five hubs price convergence, Month Ahead contracts: 2012-2014

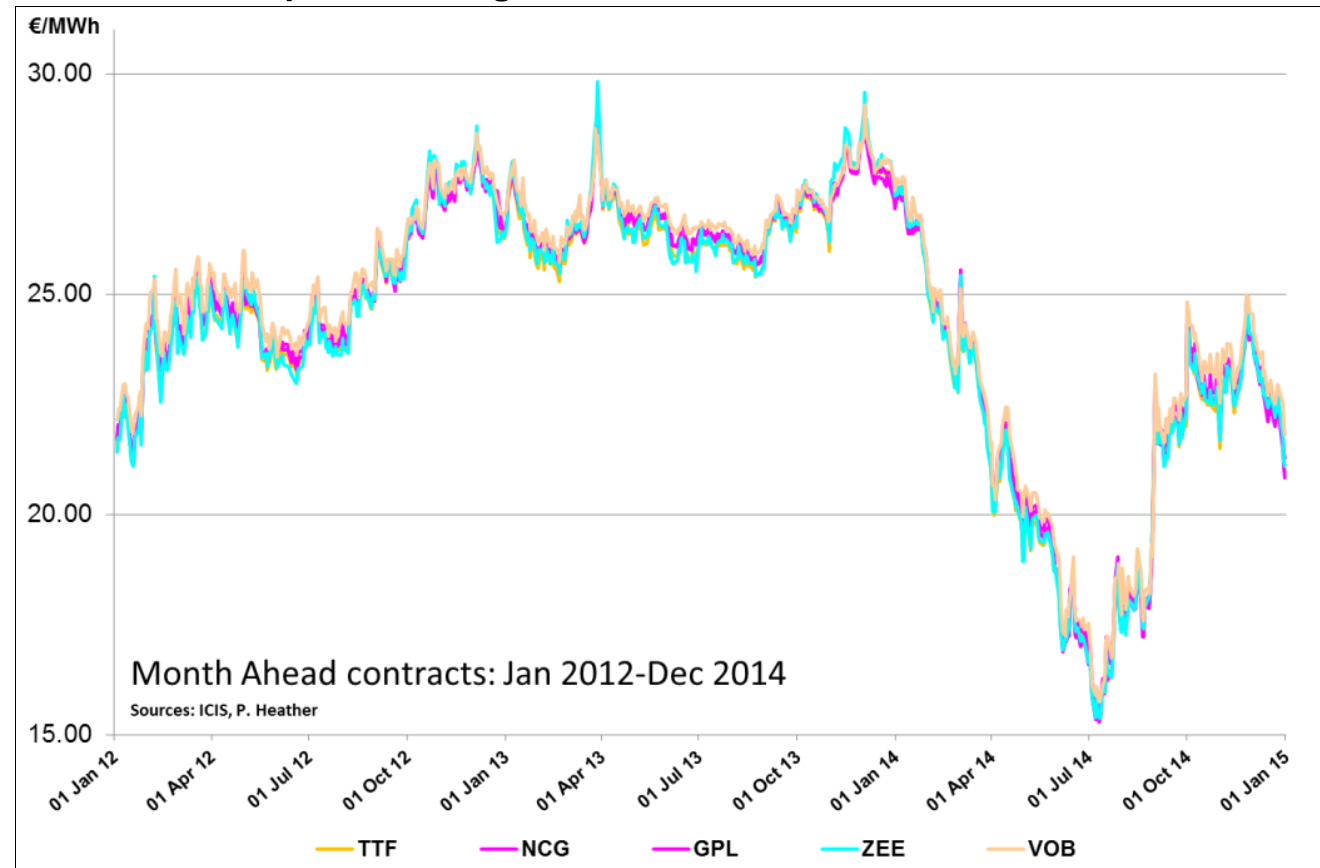

Sources: ICIS, P. Heather

If we add the Czech VOB (Figure 7), we see that it is very closely correlated and has very good price convergence also, showing just a few short periods when the price was slightly adrift from the other four hubs. Again, there is very good physical infrastructure linking the Czech Republic to Germany, so the slightly higher prices might be due to a less well developed traded market, with fewer market participants and less liquidity.

Figure 8: Best six hubs price convergence, Month Ahead contracts: 2012-2014

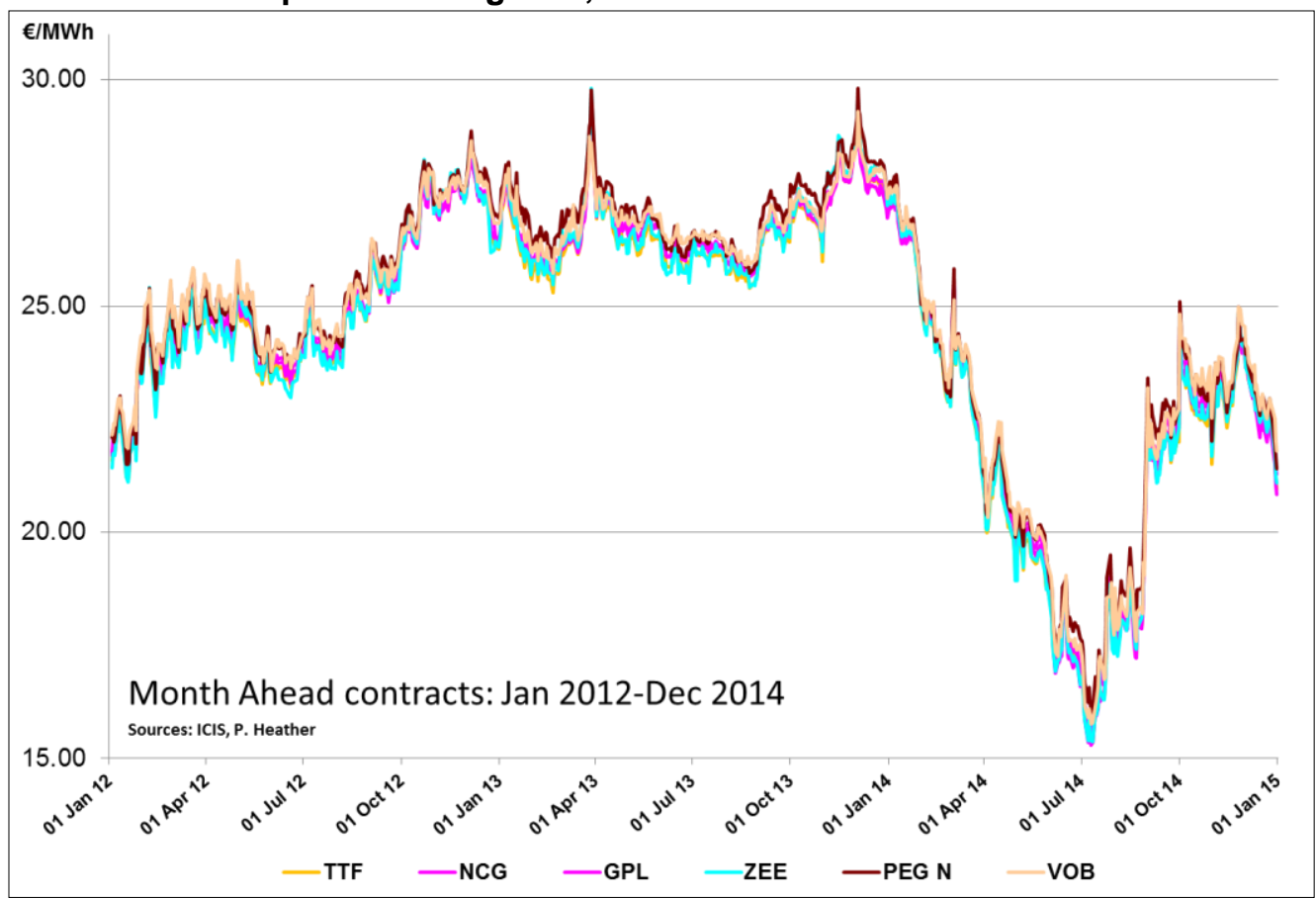

Sources: ICIS, P. Heather 

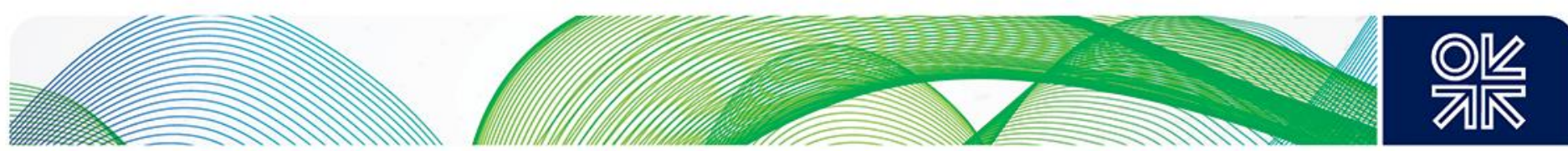

Finally, we add the French PEG Nord (Figure 8) and see that it has good price convergence most of the time but with more periods when its price does differ from the core four hubs. This is due to congested border connections with little additional spare capacity, as well as a slightly less liquid traded market.

Regarding the NBP hub: as can be seen in Figures 9,10,11, its price is most of the time very well correlated with, and has good convergence to, the other 'core' hubs with the exception of the summer months in some years. These periods of de-linkage have been found to correspond to IUK maintenance periods or, in 2010 and 2011, to the interconnector becoming congested in export mode due to high volumes of $L N G$ imported into the UK ${ }^{95}$.

\subsubsection{Price correlation}

Price convergence and price correlation requires careful analysis as two markets can be well correlated but at different price levels, with the spread potentially greater or less than the costs of transportation. Price correlation in itself does not conclusively prove market integration and is not an indicator of a hub being active or inactive. It must be noted that price correlation means prices move in the same direction at the same time by about the same amount; it does not mean 'same price' (as reflected in price convergence).

Price correlation shows whether or not adjoining markets are reacting to the same supply and demand factors but, analysis over a long time frame may be required to identify anomalies indicating potential physical or other constraints, or of excessive market dominance by one or a few players.

Figure 9: Gas hubs price correlation, Month Ahead contracts: 2007-2011

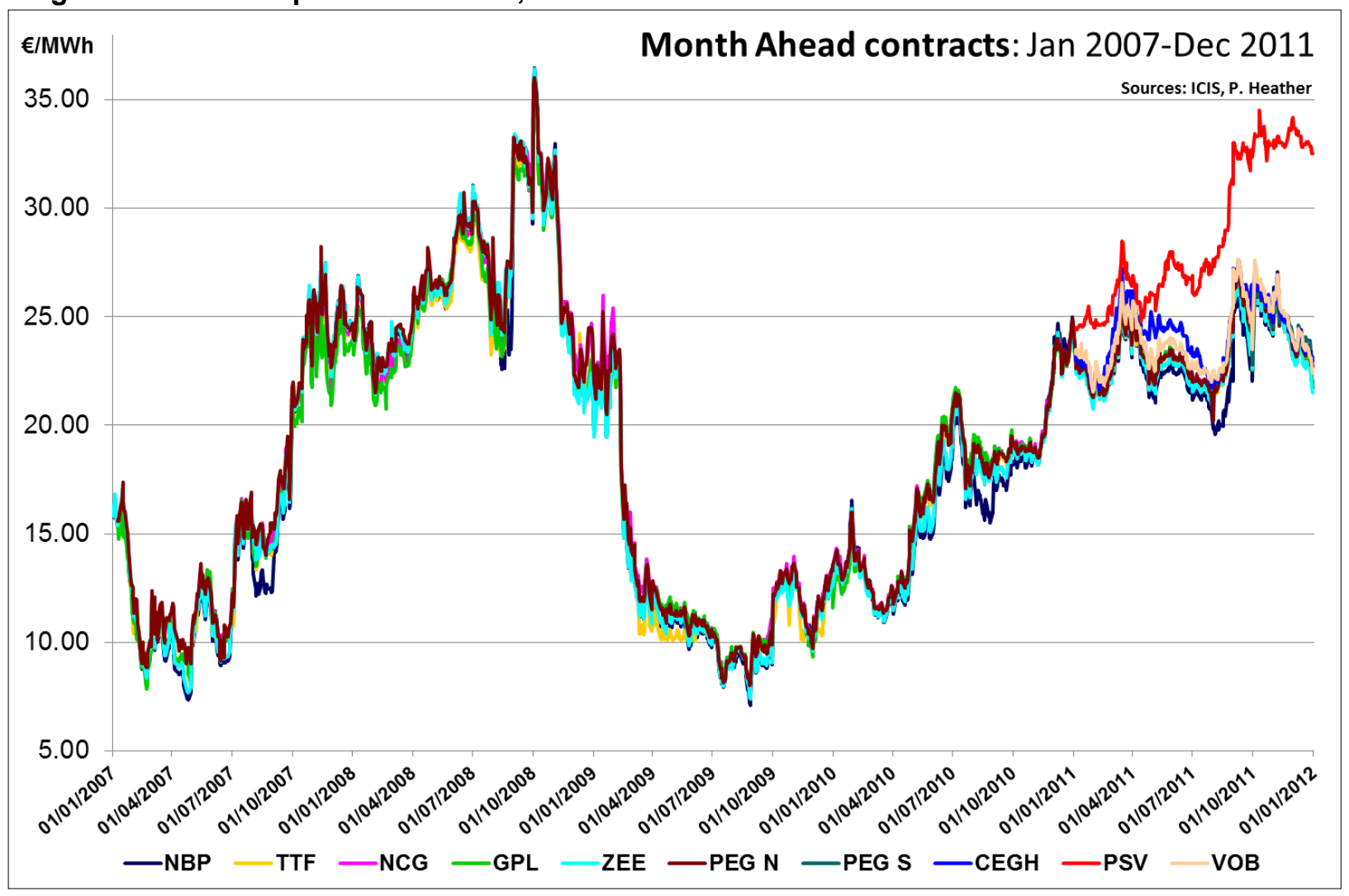

Sources: ICIS, P. Heather

${ }^{95}$ Petrovitch (2013): pp.40-44. 

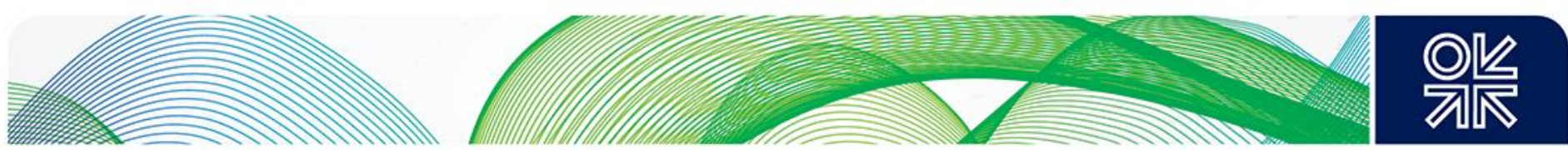

An important point is that close price correlation between two hubs may have no bearing on the liquidity of either. In North West Europe we may observe close correlation between several hubs - but what is likely to be happening is that most are 'taking their cue' from the highly liquid hubs such as NBP, or on the Continent, from TTF. Thus we may have hubs with low trading activity well correlated with TTF, provided there is sufficient physical transportation capacity between them.

Figure 9 shows the 'early' years, 2007 to 2011, when the wholesale gas markets were entirely dominated by the British NBP. The Belgian Zebrugge hub was generally closely correlated to NBP apart from the periods of IUK maintenance or congestion described above. The Continental markets proximate to Belgium were also well correlated with Zeebrugge despite low trading volumes.

From January 2011, data was available for the Austrian CEGH, Italian PSV and Czech VOB, with the French PEG Sud being added from late September of that year. The graph shows that despite starting more or less in line with the 'core' hubs, the PSV quickly traded at a significant premium and was clearly de-linked in terms of pricing. At this time, the other three 'new' hubs seemed to be well correlated.

Figure 10: Gas hubs price correlation, Month Ahead contracts: 2012-2014

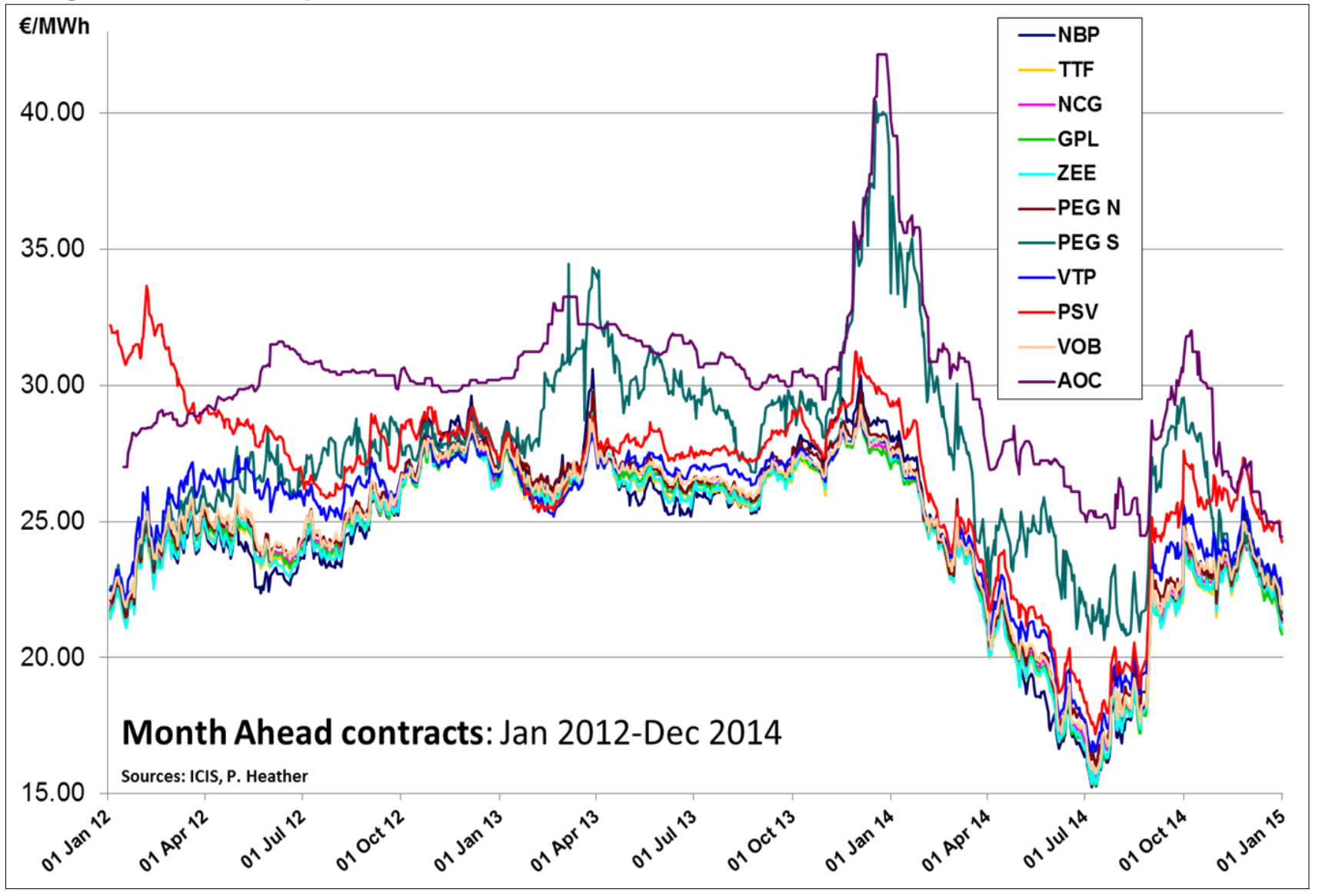

Sources: ICIS, P. Heather

Figure 10 shows the three years from 2012 to 2014, now with additional data showing the Spanish AOC. Traded volumes across all European gas hubs started to increase in 2010-2011 and this chart suggests that the correlation across the hubs has by and large remained, although less tightly than in the period 2007-2010 and with many more exceptions than in the previous period.

The Italian PSV prior to April 2012 had been as much as $€ 10 / \mathrm{MWh}$ dearer than TTF and poorly correlated. The spread narrowed to the European average after TAG pipeline capacity was made 

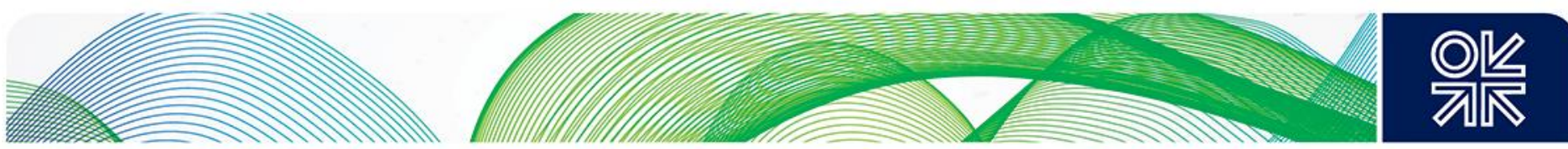

available in daily auctions but, since spring 2013 and more noticeably from the summer of 2014, its correlation to the 'core' hubs has been quite erratic. This has been due to physical and contractual congestion ${ }^{96}$.

The Austrian CEGH/VTP which is influenced by both its German and Italian neighbours, is subject to variances in physical flows from Russia, has over the four year period from 2011 to 2014 shown that it is mostly quite well correlated albeit usually at a higher absolute price. The exception was in Q2-2012.

The biggest differences are the Spanish AOC and the French southern PEG Sud and PEG TIGF hubs (shown in the Day Ahead data in Figure 11). This is due to these two markets being largely supplied by LNG as well as having poor connectivity with the northern European hubs. This situation results in higher absolute prices and quite a poor correlation.

Whereas there is no Month Ahead data for PEG TIGF, there is no Day Ahead data for the AOC; this is because that contract simply is not traded. Figure 11 shows that the Day Ahead prices are more volatile than the Month Ahead, which is a common feature of commodity markets. This graph clearly shows that the southern French hubs are well correlated to each other and have excellent price convergence to each other but no correlation with the other European hubs and no price convergence either.

Figure 11: Gas hubs price correlation, Day Ahead contracts: 2013-2014

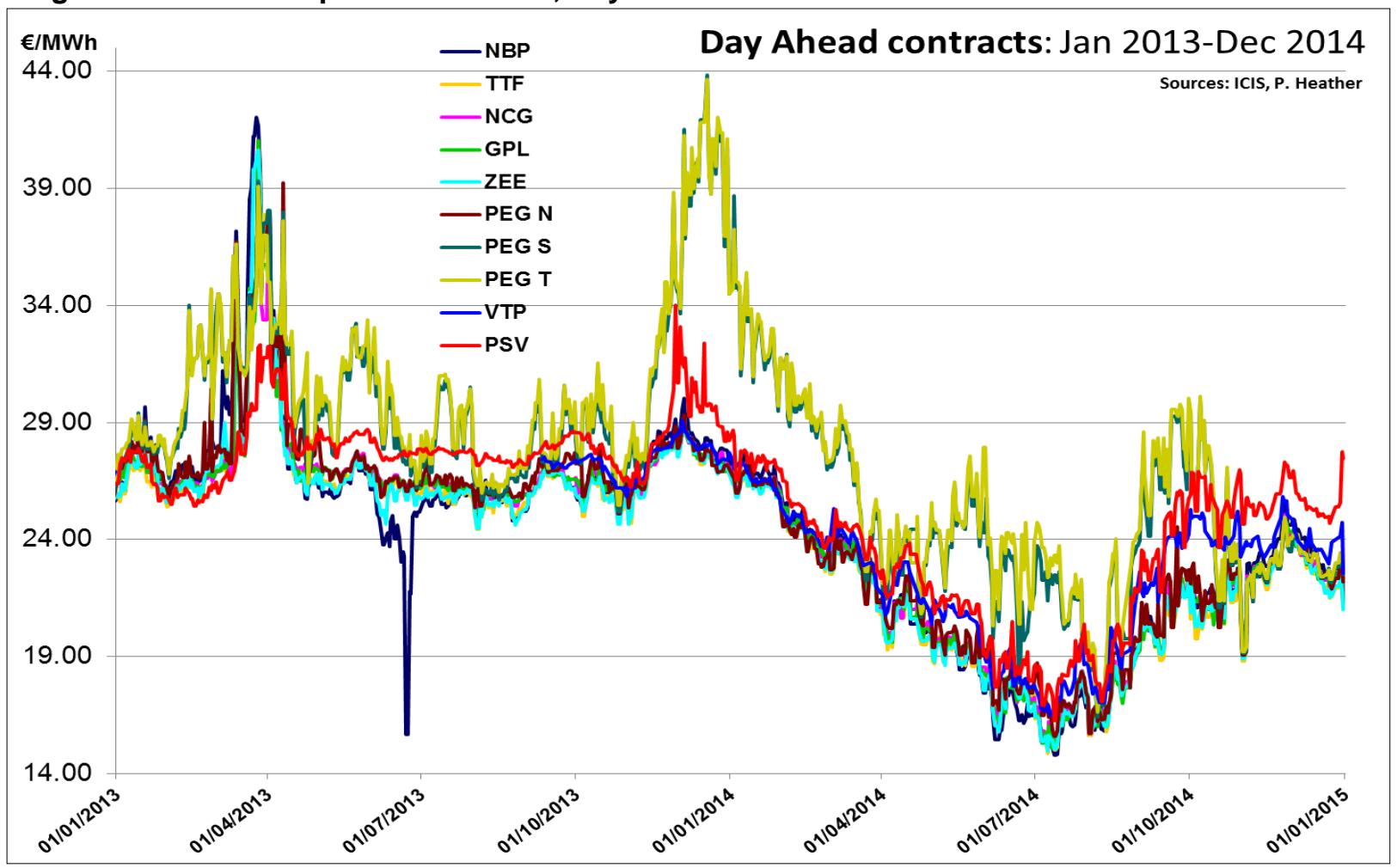

Sources: ICIS; P. Heather

Another way of assessing price correlation is to analyse the relationship between the prices of two hubs by using regression analysis. Regression analysis is used to model and analyse numerical data, consisting here of two sets of historical prices (May 2011 to August 2014)97 at some specific hubs: NBP, TTF, GPL, PEG Nord and PEG Sud.

\footnotetext{
${ }^{96}$ For a full analysis of the PSV price de-linkages, backed up with flow rate and capacity data, see Petrovitch (2015): pp.34-40.

${ }^{97}$ The data used in these analyses are the ICIS-Heren daily Day Ahead settlement mid-prices.
} 

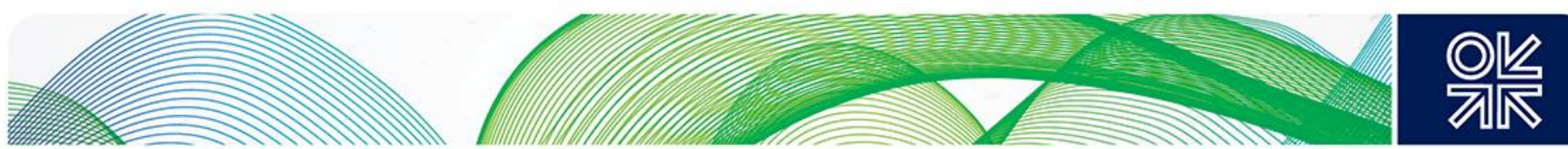

By using 'scatter diagrams' the degree of correlation can be visualised between, in this case, the prices at two hubs being compared: the higher the correlation, the closer the correlation coefficient (R2) 98 will be to 1 . Indeed a score of 1 indicates full correlation, a score of zero indicates no correlation and a score of around 0.4 to 0.6 indicates poor correlation.

Figure 12: Correlation coefficients for TTF/NBP and TTF/GPL: 2011-2014
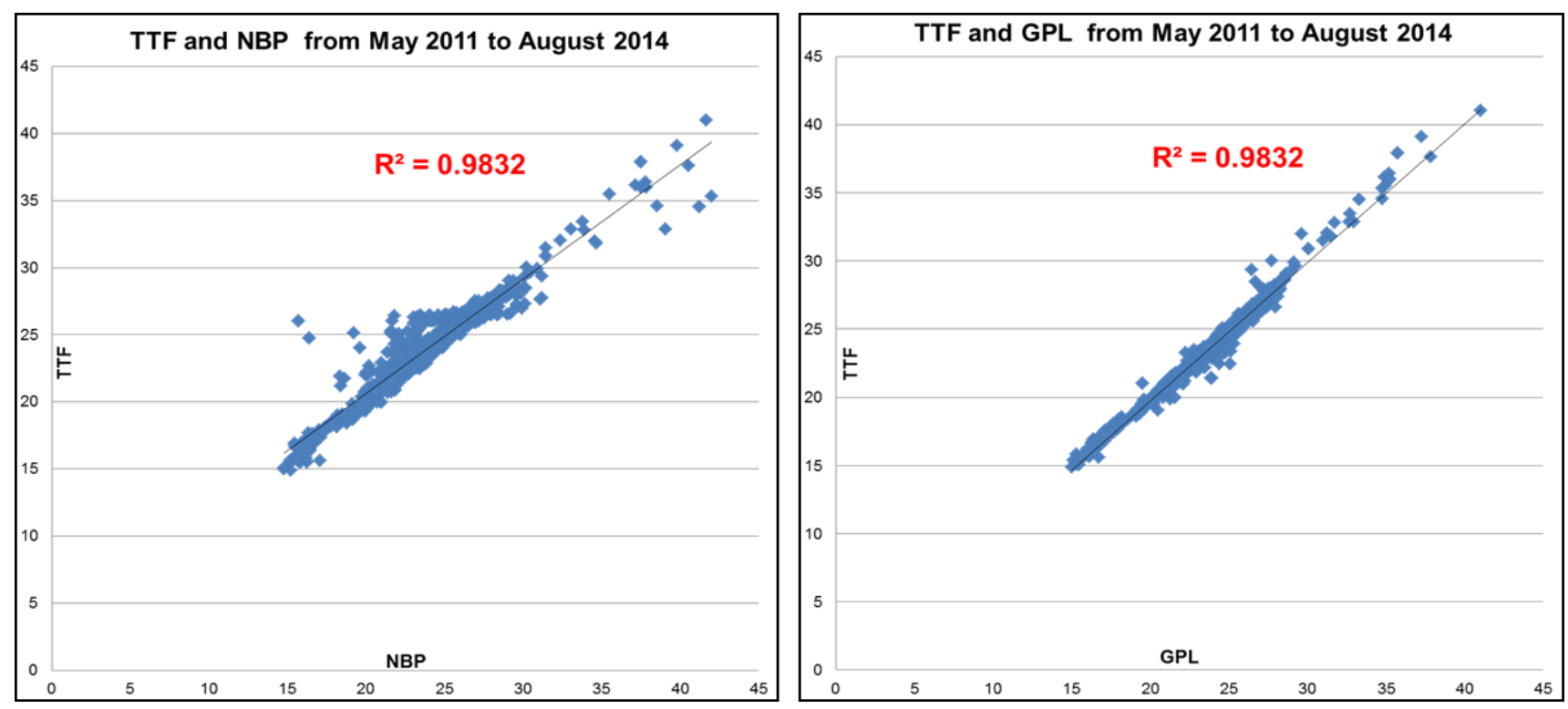

Sources: ICIS; P. Heather

The results show us several very interesting and important points: the two 'mature' gas hubs, as might be expected, are almost perfectly correlated, with a correlation coefficient of 0.9832 (Figure 12 left). Interestingly, the comparison between TTF and Gaspool gives the same correlation coefficient of 0.9832 (Figure 12 right). This is despite the Gaspool market having relatively low traded volumes. These trades are closely correlated to the price at the TTF.

The close correlation greatly assists the risk management trading through which market participants financially hedge their portfolios. Figure 13 shows the results for the French market, with its north south infrastructure constraint.

The correlation coefficient between TTF and PEG Nord (Figure 13 left) is very good (value 0.9567), which is corroborated by the results shown above in Figures 8,9,10 and 11. Industry intelligence that many French market participants use the TTF for the risk management of their portfolios is validated by this result.

However, when we look at the results comparing PEG Nord and PEG Sud (Figure 13 centre), the correlation coefficient falls to a poor 0.628 . It can be observed that this scatter plot is also much wider and more random in appearance; this reflects the extreme differences in volatility levels between the two markets (as can also be seen in Figure14). Not surprisingly, when comparing TTF and PEG Sud (Figure 13 right), the correlation coefficient is slightly lower still, at just 0.6274 .

\footnotetext{
${ }^{98} R^{2}$, more properly called the Coefficient of Determination, expresses how much of the variability in the price of one hub is explained by the variability of the price at another hub.
} 

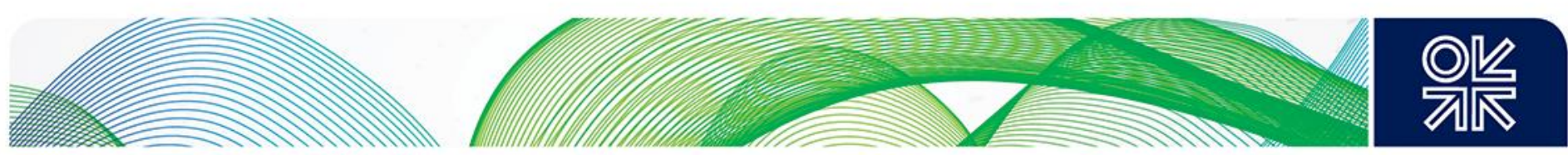

Figure 13: Correlation coefficients: TTF/PEGN, PEGN/PEGS and TTF/PEGS: 2011-2014
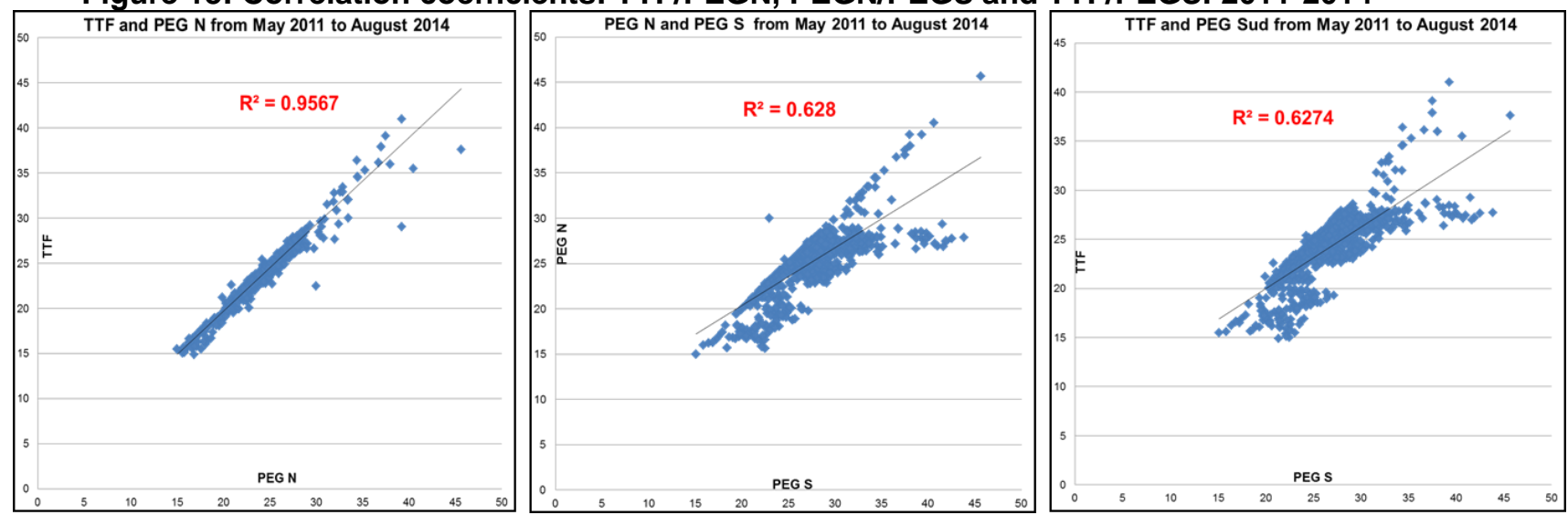

Sources: ICIS; P. Heather

The important commercial point is that when there is a high level or correlation, traders in one Market Area can financially hedge their physical positions at the hub in another Market Area. However, the lower the correlation, the greater the risk and, in the above examples, it is unlikely that traders in the south of France would use TTF to risk manage their positions.

\subsubsection{Price volatility}

A third important metric in this category is price volatility and its correlation between hubs. As with price correlation, price volatility in itself does not prove market integration and is no indicator of one hub being active or inactive, in absolute terms or in relation to the other hubs.

However, price volatility convergence between hubs is important for two reasons:

- This is what would be expected in an integrated European market, where adjoining hubs' prices would broadly move in line with each other whether the underlying price volatility of the gas markets was high or low.

- This is also the most representative metric of market risks ${ }^{99}$ and the difficulties involved in hedging. Different price volatility between hubs indicates that it would not be prudent to use one hub to financially hedge a physical position in the other.

We have established in the previous two sections that PEG Nord has good price convergence with TTF (a strong regression coefficient of 0.9567). We have also established that PEG Sud has poor price correlations with both TTF and PEG Nord (regression coefficients of 0.628 and 0.6274 respectively). We will examine the price volatility of these three hubs over a four year period (Figure 14) to see how these might influence a trader's decision whether to hedge a PEG Nord physical position at the TTF or a PEG Sud physical position at either the PEG Nord or the TTF.

Figure 14 shows four periods of extreme volatility spikes affecting all three hubs; however, in two of those spikes (June 2011 and May 2013), the PEG Nord spike extended much higher than both TTF and the PEG Sud. In the other two spikes (November 2011 and March 2012), both French hubs extended beyond the TTF. The graph also clearly shows that from May 2012, the PEG Sud price volatility is poorly correlated to both the PEG Nord and the TTF hubs. It is also clear that PEG Sud was very volatile throughout the remaining period of the chart.

\footnotetext{
${ }^{99}$ Market risk is defined as the potential risk of a loss in value or earnings as a result of changes in market factors underlying the portfolio or economic activity. Markets with differing levels of price volatility will be subject to different supply/demand factors; to different levels of trading activity; and to different price fluctuations at different times.
} 

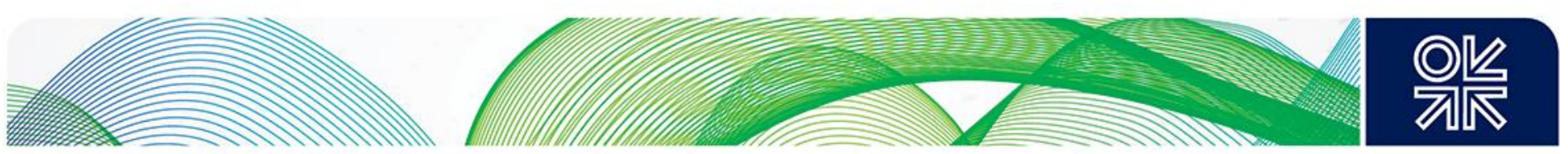

Figure 14: TTF/PEG Nord/PEG Sud hubs price volatility: 2010-2014

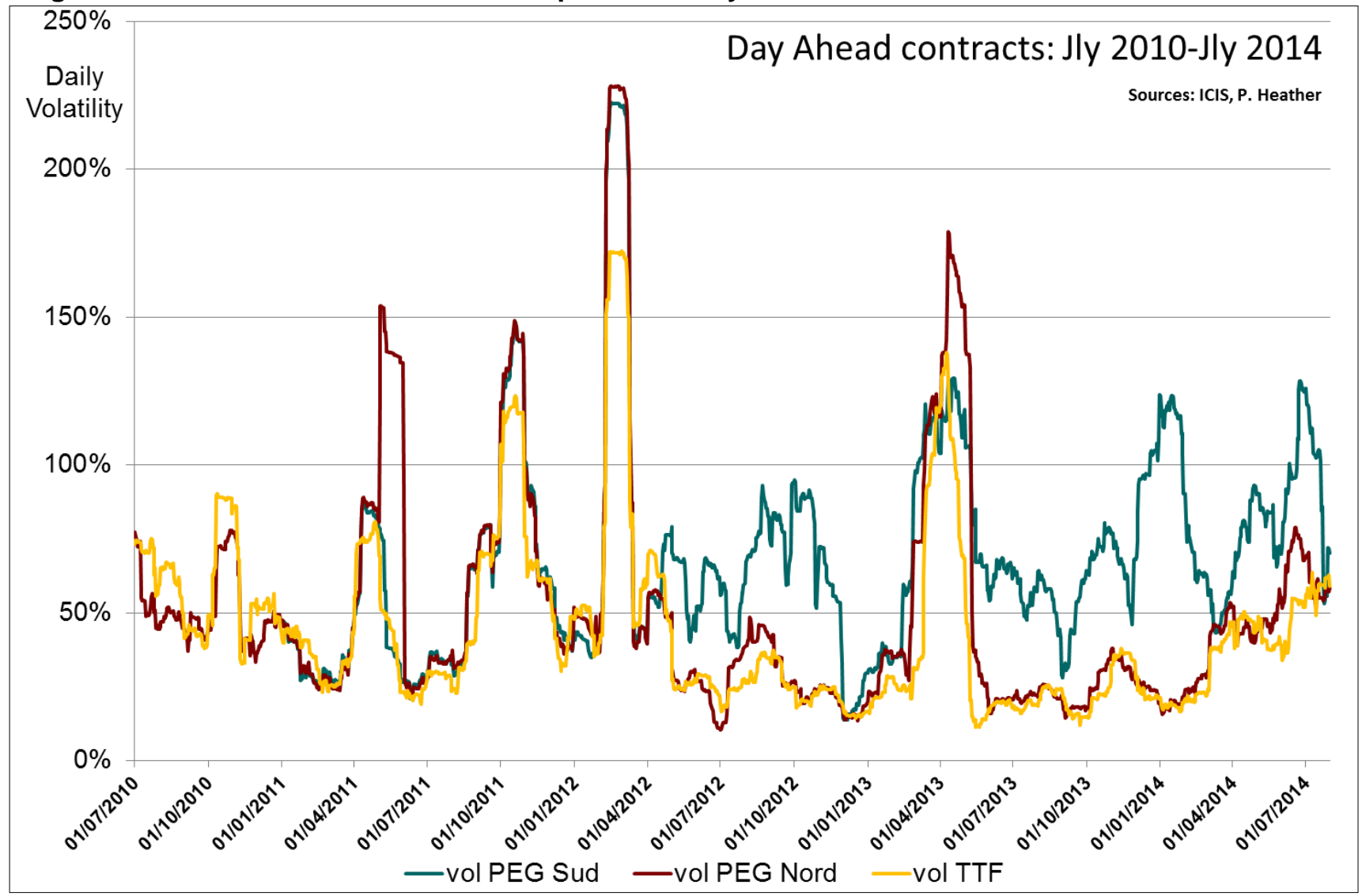

Sources: ICIS; P. Heather

In addition to volatility, traders will also take into account market access, data transparency, liquidity and depth, as well as external influences that may vary from hub to hub. However, the important commercial point here is that although TTF could be, and indeed in many cases is, used to financially hedge physical PEG Nord positions, TTF cannot be considered as a reliable financial hedge for physical PEG Sud or PEG TIGF positions. This is because it would leave traders exposed financially to the consequences of physical constraints between the Nord and Sud zones.

\subsection{European gas exchanges and their role}

Exchanges perform a vital role in the development of a traded commodity market and provide five important functions: price discovery, price transparency, supply/pricing flexibility, physical balancing, and financial risk management.

Generally, exchanges tend to provide futures contracts in a given commodity only once there is an established underlying physical market. This is because the contracts are futures 'derivatives' of that physical contract. However, once the OTC market is established, many participants will look to trade financial products as well as the underlying physical contracts, often for different purposes and especially for financial risk management of their portfolios.

Because exchanges are regulated marketplaces, they have an obligation to be fully transparent in everything they do: the products traded, the volumes traded and the prices at which they were traded. This enables all gas market participants and outside observers to know the price of gas now and in 

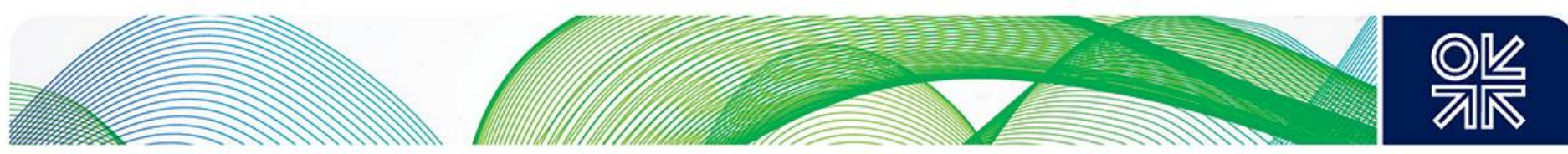

the future (e.g.: up to six years ahead on ICE NBP and five years for ICE-Endex TTF). The current traded price is visible usually in real time, or occasionally with a slight time delay.

Exchanges are sometimes used for actual physical transactions ${ }^{100}$ as a small percentage of the traded contracts do go to delivery at maturity. This provides a marketplace for the buying and selling of, usually, small quantities of physical gas. In some cases, exchanges are also used for the balancing of a gas Market Area, such as is the case with the NBP OCM ${ }^{101}$, traded on the ICE-Endex platform.

Perhaps the most important function of exchanges is to allow the separation of the financial from the physical (unlike traditional Continental European oil indexed LTCs which combine the two in a 'package'). In 'new style' contracts the physical volume is agreed for the duration of the contract, whereas the pricing of the gas will be determined at the time of delivery by reference to a market index, often an exchange published index. This then provides a facility for managing price risk through a secure and regulated market for hedging and trading.

There are six main exchanges offering gas contracts on the major European traded hubs. The International Petroleum Exchange (IPE), (later to become The ICE Exchange), was the first exchange in Europe to offer futures contracts in gas, on NBP in 1997. The NBP's balancing market, the OCM, traded on several platforms before being traded at the APX, later to be merged with Endex and today called ICE-Endex.

When analysing the volumes traded at the exchanges, it is useful to distinguish between the Spot ${ }^{102}$ contracts and the Futures ${ }^{103}$ contracts (Figure 15). Spot contracts are mostly used for final portfolio optimisation ahead of physical delivery and/or for balancing at maturity; Futures contracts are mostly used for medium term portfolio optimisation and for longer term risk management. In addition, most 'financial players' will trade Futures rather than Spot contracts. Analysing the volumes traded on different contracts can reveal interesting patterns of trade at different hubs.

Figure 15: Gas exchanges ${ }^{104}$ futures and spot volumes: 2014

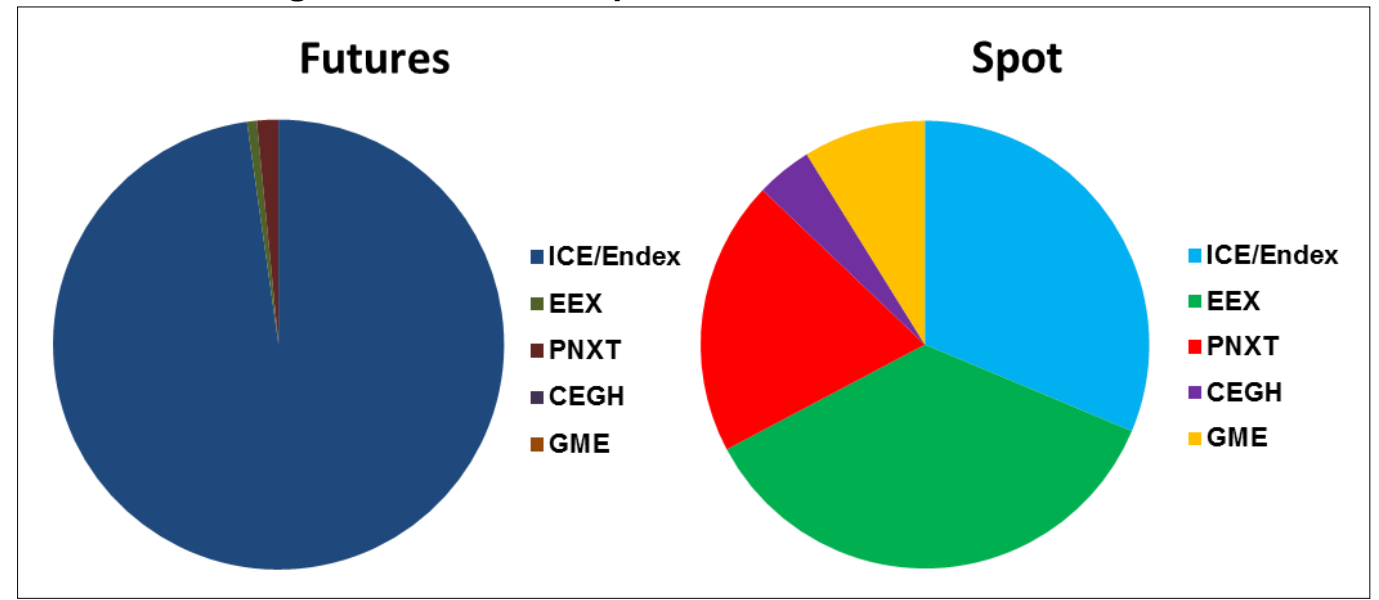

Sources: ICE, ICE-Endex, EEX, Powernext, CEGH, GME; P. Heather

From Figure 15, we see that the Spot contracts traded are quite evenly distributed across the top three exchanges: ICE/Endex, EEX and Powernext. These exchanges represent by and large the

\footnotetext{
100 This is only the case with physically delivery contracts (such as NBP gas) rather than financially settled ones (such as Brent oil).

101 'On-the-day Commodity Exchange'; the market used by shippers and the TSO to balance the NBP gas market.

102 Defined as contracts starting from Within Day and including all time periods up to the end of the current month.

103 Defined as contracts starting with Month Ahead and all time periods beyond that.

${ }^{104}$ See Appendix F for a list of the main gas exchanges and their contracts
} 

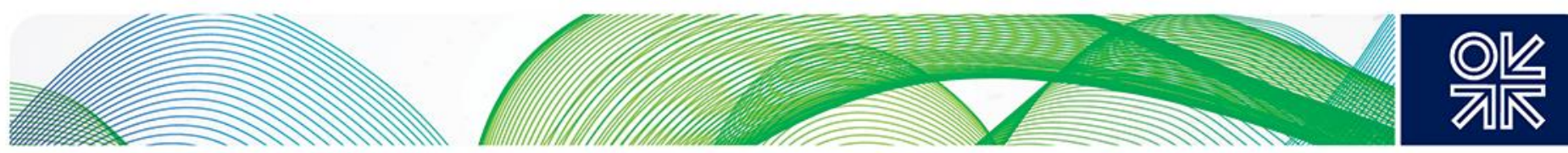

NBP/TTF, NCG/GPL and PEG hubs respectively, although in recent years some exchanges have started to offer spread contracts with adjoining hubs. There has also been a cross-market agreement between EEX and Powernext who now market each other's contracts on a shared platform ${ }^{105}$. The CEGH provides mainly VTP contracts and the GME only Italian ${ }^{106}$ ones.

Figure16: Gas exchanges total volumes: 2014

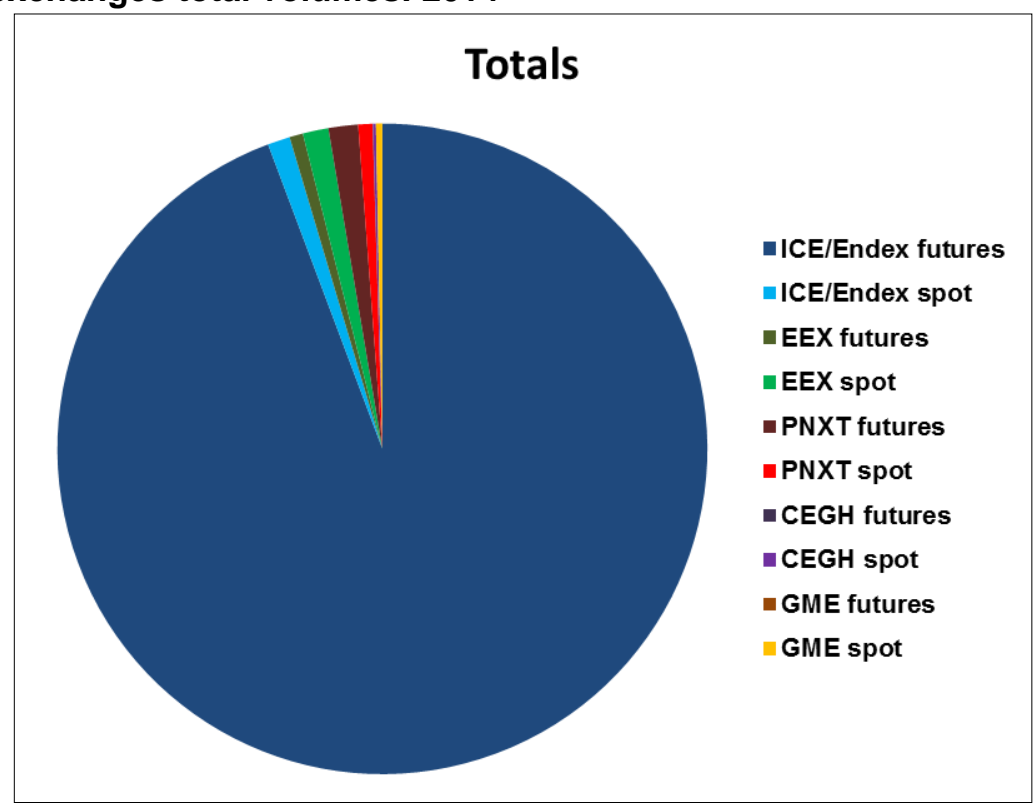

Sources: ICE, ICE-Endex, EEX, Powernext, CEGH, GME; P. Heather

Figure17: OTC and Exchange market shares of each gas hub: 2014

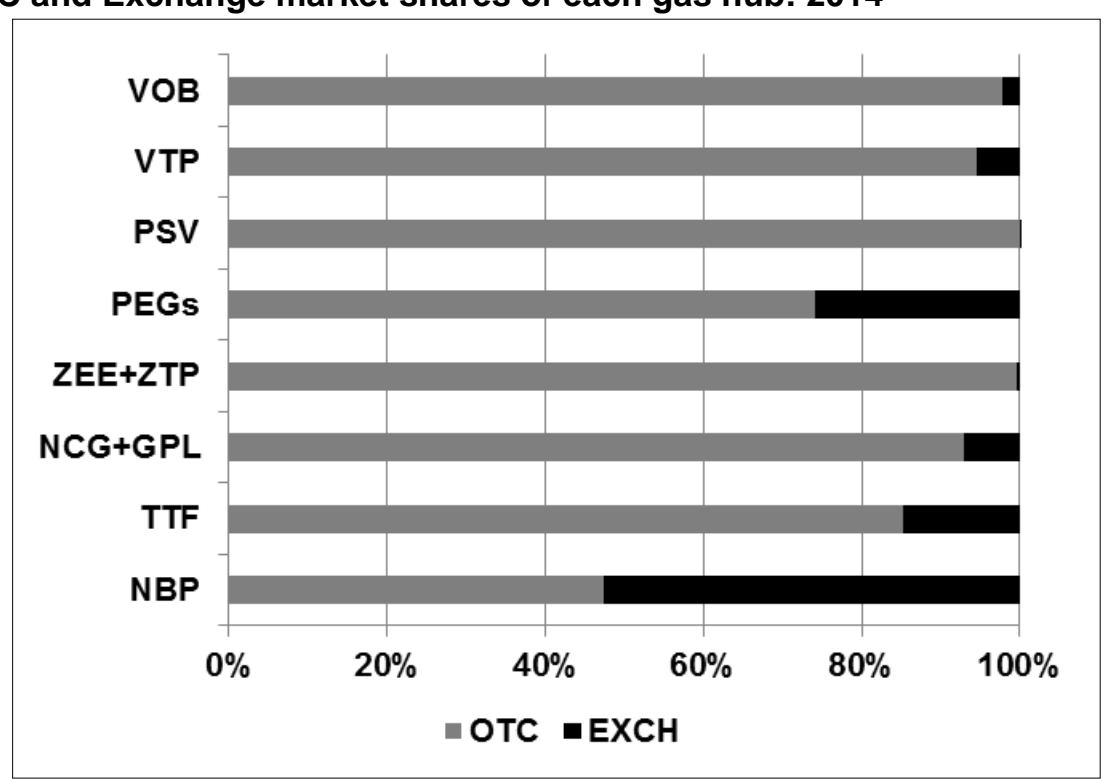

Sources: ICE, ICE-Endex, EEX, Powernext, CEGH, GME; LEBA, ICIS; P. Heather

\footnotetext{
${ }^{105}$ Called PEGAS, it became fully operational on $1^{\text {st }}$ January 2015. More information at: http://www.pegas-trading.com/en/ ${ }^{106}$ Its largest contract is the PB-Gas, to trade gas in storage (not at the PSV). The PSV contract volumes are very small.
} 

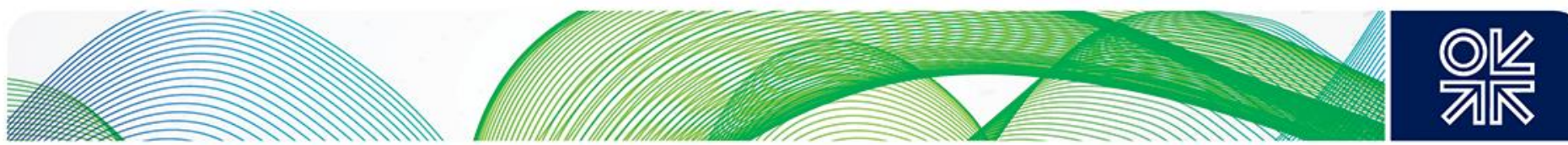

The Futures contracts volumes are almost entirely made up of ICE/Endex which is NBP and TTF, with just a tiny proportion traded on the EEX and Powernext and even less on CEGH and GME. This is a reflection of the OTC volumes for those markets ${ }^{107}$ but it is evident that the market share of Futures contracts at NBP, and also at TTF, is rising fast (Figure 17).

When combining both Spot and Futures contracts we can see (Figure 16) that the ICE/ICE-Endex dominates the exchange traded activity in gas across the major European hubs with $95 \%$ of the total in 2014.

Figure18: OTC and Exchange market shares of total European gas trading: 2014

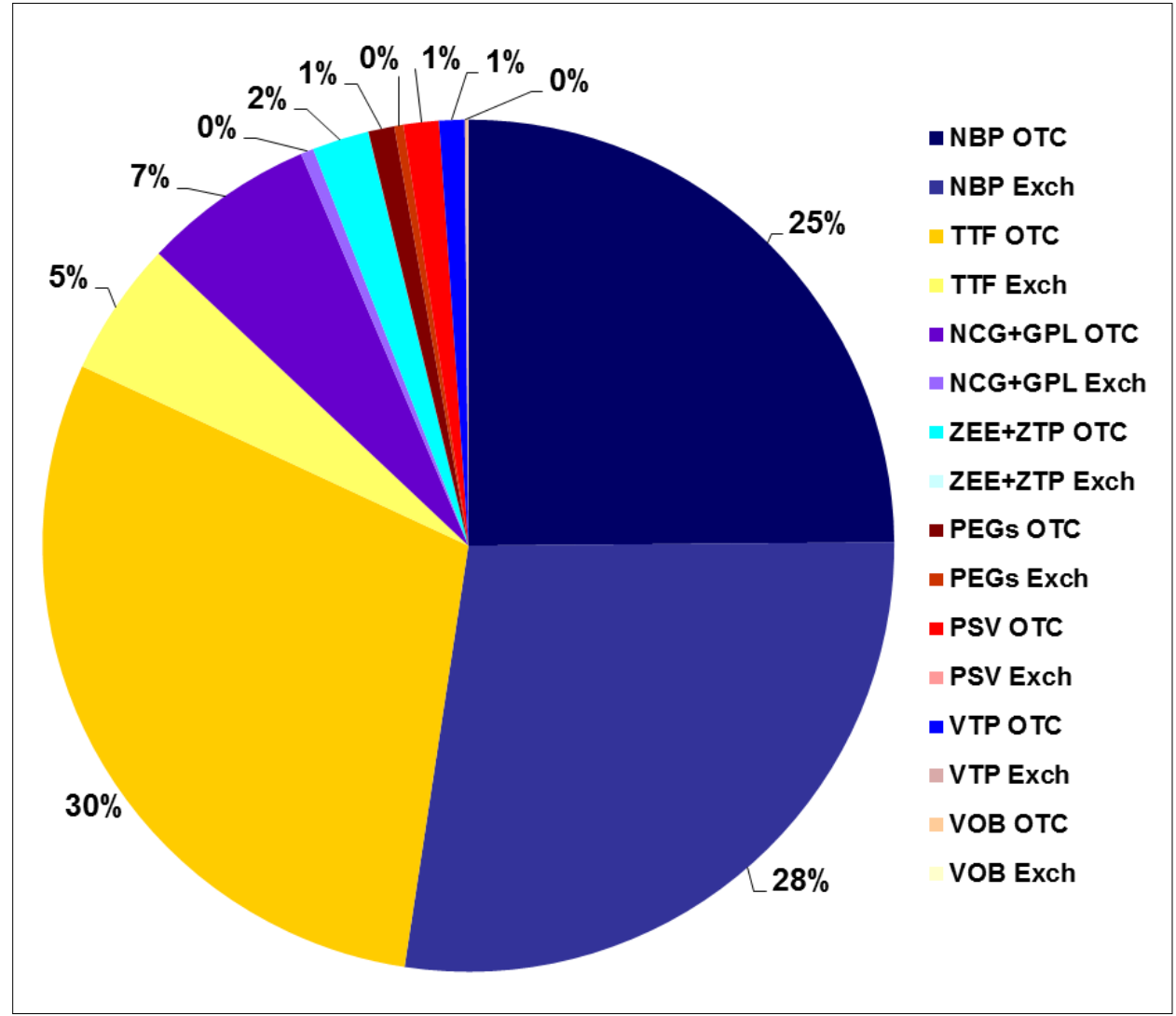

Sources: ICE, ICE-Endex, EEX, Powernext, CEGH, GME; LEBA, ICIS; P. Heather

Figure 17 shows the split between OTC and exchange volumes and shows how OTC still dominates across the main hubs, although at the NBP the exchange total now exceeds half the total traded volume: it has risen steadily from $\sim 30 \%$ in 2011 to $~ 52 \%$ in 2014 . By contrast the TTF, whose OTC volumes are rapidly catching up ${ }^{108}$ with those at the NBP, and whose exchange traded volumes have more than doubled in the last three years, has just $15 \%$ of the total traded on exchanges. However, the French PEGs show an exchange market share of $22 \%$ in 2014, which is mostly made up of Spot contracts and reflects the fact these exchange contracts are an efficient way for shippers to optimise and balance within month, ahead of delivery.

Finally, Figure 18 shows both the OTC and exchange market shares as a percentage of total European gas trading at the end of 2014. What is noticeable is that the NBP still accounts for over half $(53 \%)$ of all trading in Europe with TTF registering just over a third $(35 \%)$ and all the other hubs together, just $12 \%$.

\footnotetext{
${ }^{107}$ Full analysis of traded volumes is given in section 6.1.3.

${ }^{108}$ And have overtaken NBP during 2015.
} 

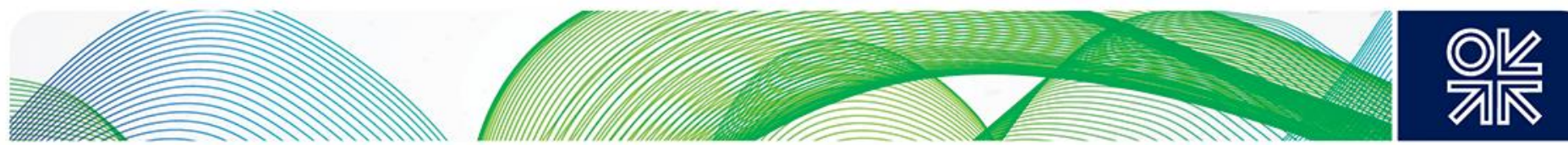

\subsection{Spotlight on selected regions}

\subsubsection{The Iberian Peninsula}

The Iberian Peninsula has long been a 'separate' gas market from the rest of Europe, being primarily fed by LNG and pipeline gas from Algeria. Despite Spain having two Interconnection Points with France ${ }^{109}$, there have been relatively limited flows of physical gas between the two countries, although this has increased over the past four years. About 13\% of Spain's gas imports in 2014 came through the IPs with France, and $40 \%$ came through the two southern IPs of Tarifa and Almeria delivering Algerian pipeline gas. By contrast, $47 \%$ of Spain's supply was in the form of LNG (Figure 19) arriving at its six regasification terminals, and sourced from seven countries. Of Spain's total supplies, Algeria was by far the country's largest single source of gas (comprising both LNG and pipeline gas), accounting for approximately $53 \%$. At $11.7 \mathrm{Mt}$, Spain's total LNG imports ${ }^{110}$ were the largest in Europe, accounting for just under $31 \%$ of the total. However, Spain was also Europe's, and the world's, largest re-exporter of LNG, reloading 3.84Mt which accounted for $60 \%$ of the world's reloaded LNG in 2014 .

Figure 19: Spanish gas supply sources: 1981-2014

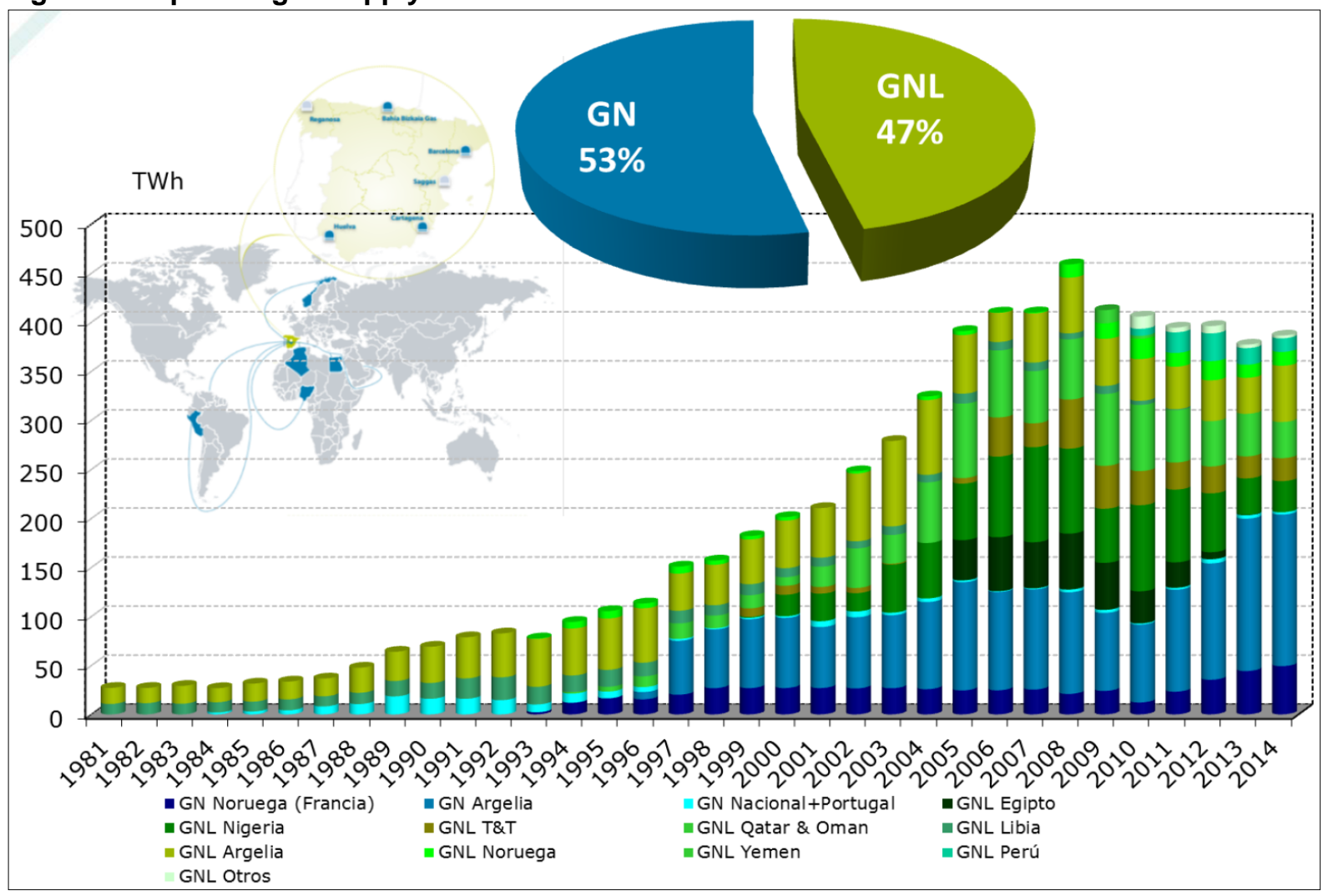

Source: Enagás

Following the 2008/09 financial crisis and subsequent recession Spain's demand for gas has fallen in each of the last 6 years, to $26.3 \mathrm{bcm}$ in 2014, the lowest level for 11 years ${ }^{111}$. Despite this (or indeed

\footnotetext{
109 See Appendix G for a map of the Spanish gas network.

110 GIIGNL (2015).

111 BP Statistical Review (2015).
} 

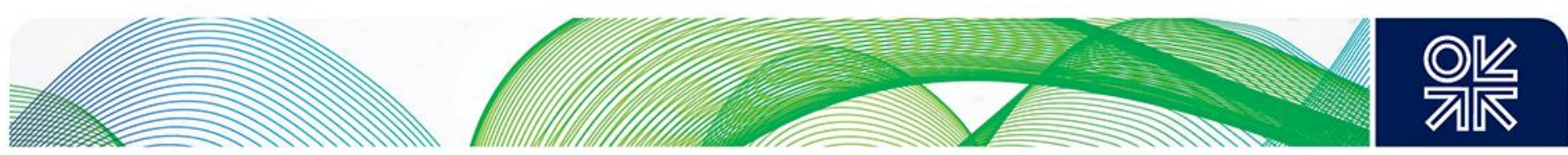

maybe because of the current situation where the country is over-contracted in gas), Spain has been pushing for the adoption by the EU of a Project of Common Interest, to build a new IP between Spain and France. In principle, Spain could export gas to northern Europe, thereby improving Europe's security of supply. However, this aim can only be achieved once the French grid is strengthened in the latter part of the 2010s.

Portugal is a much smaller gas market, which saw demand drop in 2014 for the $3^{\text {rd }}$ year in a row and, at just $3.8 \mathrm{bcm}$, is at the lowest level for ten years ${ }^{112}$. It consequently has a much smaller gas grid ${ }^{113}$ than Spain, which comprises a main north-south west coast line from the country's only LNG terminal in the south to one of the two IPs with Spain in the north. Additionally, there is a cross country pipeline leading to its second IP with Spain. Portugal receives about 2/3rds of its gas requirement by pipeline from Spain and one third by LNG, sourced in 2014 from seven countries ${ }^{114}$. There is a project involving the Portuguese TSO, REN, and its Spanish counterpart, Enagás, to build a third IP in the north east of the country, but this would require $162 \mathrm{~km}$ of new pipeline and $67 \mathrm{~km}$ of grid reinforcement just to get to the border. The project is unlikely to be granted $\mathrm{PCl}$ status in the current climate as it mainly strengthens the links between Spain and Portugal without achieving a wider European benefit.

Spain and Portugal have agreed for some time that a joint energy market would be beneficial to both their countries, as well as satisfying the EU's market integration objectives. Several high level meetings and project evaluations have been conducted by the main participants involved: the Energy Ministries, the regulators (CNMC, ERSE), the TSOs (Enagás, REN) and other stakeholders. These have concluded that they should aim to integrate the gas markets of Spain and Portugal into a single Iberian Gas Market (Mercado lbérico de gas, or Mibgas). Several possible integration models are being analysed, in order to evaluate their feasibility, taking into account the current market conditions and their advantages and drawbacks.

According to the Portuguese regulator, ERSE ${ }^{115}$, the creation of MIBGAS has the following objectives:

- to increase the security of supply through market integration and coordination of both systems of the natural gas sector and strengthening of interconnections;

- to increase the level of competition, reflecting the larger size of the market and the increase in the number of participants;

- to simplify and harmonize the regulatory framework in both countries; and

- to encourage the efficiency of regulated and liberalized activities as well as market transparency.

Mibgas should not, however, be confused with the Iberian Gas Hub, an independent company offering brokerage services in the Iberian OTC natural gas market since June 2013 and which operates an electronic trading platform (listing OTC physical products with delivery at the AOC and also OTC swaps with the two southern French balancing zones: TIGF/AOC and PEG Sud/AOC).

The origins of Mibgas (the hub) come from a 'Roadmap' published in April 2010 by the Spanish regulator, to develop a gas exchange in Spain. This followed CNMC's recognition ${ }^{116}$ that the Spanish wholesale market was facing problems regarding poor liquidity and a lack of transparency in pricing. The objective was to accelerate the creation of a gas hub in the Spanish Gas System in order to promote competitiveness and transparency, and reduce the lack of transparency of the then current OTC market. In 2014, the creation of a gas hub received a new impetus when the Ministry of Industry

\footnotetext{
112 BP Statistical Review (2015).

113 See Appendix $\mathrm{H}$ for a map of the Portuguese gas network.

114 GIIGNL (2015).

115 Entidade Reguladora dos Serviços Energéticos: http://www.erse.pt/eng/naturalgas/mibgas/Paginas/default.aspx

116 Comisión National de los Mercados y la Competencia: National Report to the European Commission 2015, "Roadmap to develop a gas exchange in Spain", p.65:

http://www.cnmc.es/Portals/0/Ficheros/Energia/Publicaciones Anuales/1509 National Report 2015 final.pdf
} 

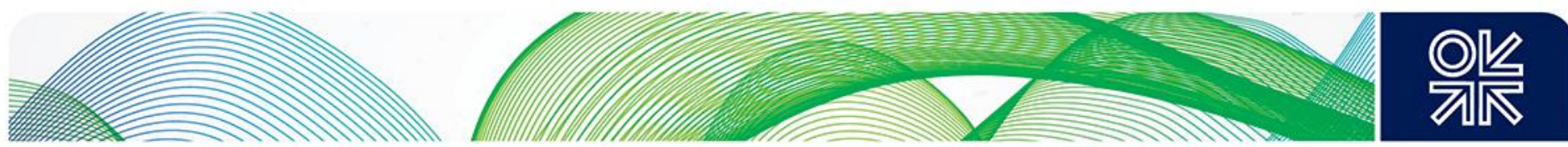

and Energy created a new working group in order to analyse and discuss the measures needed to remove all the regulatory barriers to develop such a hub in 2015. Furthermore, the amendment to the 1998 Hydrocarbons Law (Law 8/98) was passed in the Spanish parliament in the summer of 2015, thereby paving the way for, amongst other things, the implementation of an organised gas market and the creation of a gas exchange.

Disappointingly, progress on creating an open and transparent trading hub has been very slow: during June and July 2014, CNMC and ERSE organised a public consultation on the approach needed to achieve an integrated lberian gas market. The results were published in March $2015^{117}$ but without any real conclusion as to the chosen model for the integration of the two markets. To the contrary, they added a fourth model to the three previously identified options: Market Area Model, Trading Region Model, Market with Implicit Capacity Allocation and, the Satellite Model, as another possible tool for market integration and connection. At the time of writing this Paper ${ }^{118}$, there has not been any further progress made in establishing a more open traded gas market in Spain, let alone one that joins with Portugal, and the implementation of the new trading platform has yet again been delayed ${ }^{119}$.

\section{Figure 20: Balancing and trading points in the Spanish gas market}

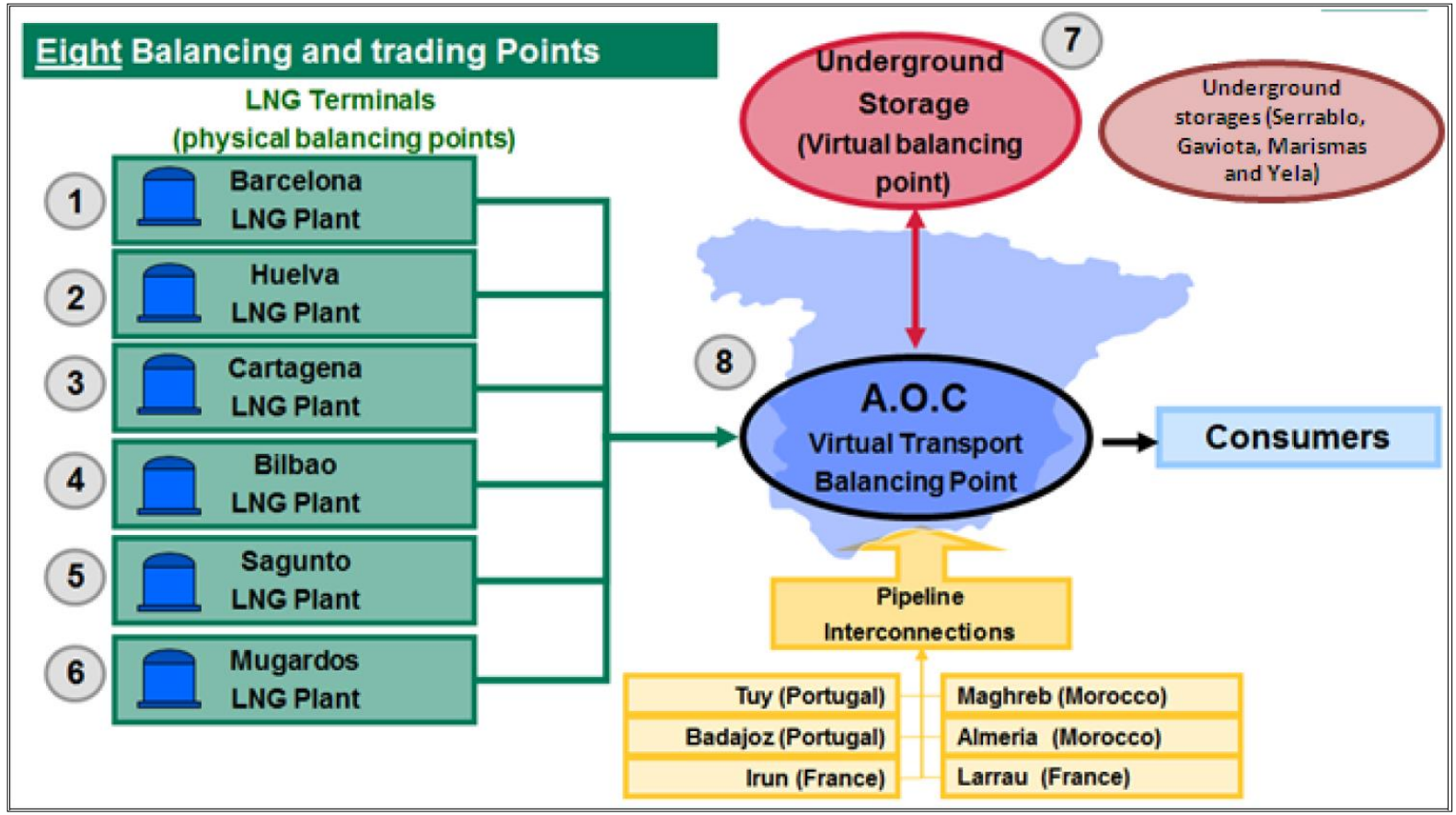

Source: CNMC Annual Report, p.62.

Turning to the wholesale markets, Spain's physical gas market can be compared to a 'spider's web', with LNG terminals and storage around the perimeter of the country, feeding the national distribution grid within. This allows for good flexibility to balance against the high installed capacity of renewables, in particular wind.

Companies operating in the lberian wholesale gas market include gas incumbents in Spain and Portugal, mainly with long-term upstream supply contracts, some new entrants and a few European traders without a customer base in Iberia. There are also LNG traders using the LNG storage infrastructures for flexibility and trading opportunities, including the reloading of LNG for export. There

${ }^{17}$ http://www.cnmc.es/Portals/0/Ficheros/Energia/ConsultasPublicas/gas mercado\%20iberico/MIBGAS\%20\%20Evaluation\%20of\%20responses\%202015-03-31.pdf

118 September 2015.

${ }^{119}$ Platts, $21^{\text {st }}$ September 2015: "Iberian MIBGAS hub to likely miss Sep 23 start". 

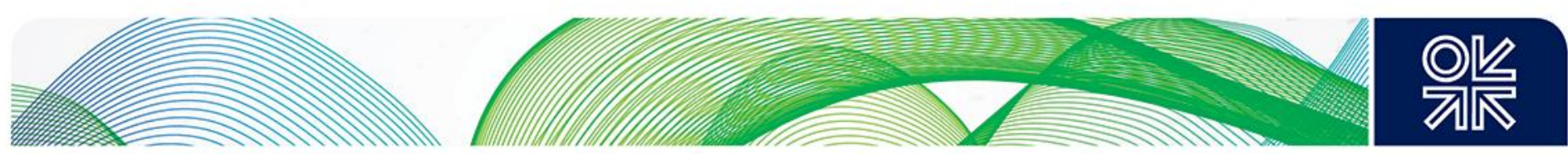

is very little or no OTC trading in Portugal and only a relatively small amount of 'real' trading at the Spanish virtual hub, the AOC.

According to CNMC, gas is "actively traded in Spain across eight balancing points: the six LNG terminals; the virtual balancing point (so called AOC) and the virtual storage point comprising the four Spanish underground storage sites in operation (Serrablo, Gaviota, Marismas and Yela)"; these are shown in Figure 20.

The majority of what is described as 'trading' is in reality merely volumes of gas 'swapped' between shippers at the AOC for balancing reasons (or LNG at the LNG terminals for operational reasons). Not only is it very difficult to determine what actual volumes may have traded (as opposed to being swapped), these 'trades' do not have any pricing data associated to them. The CNMC Annual Report states ${ }^{120}$ that "most of the gas traded in the Spanish market is negotiated in bilateral OTC transactions. The volume of gas traded on the OTC market is communicated to the system operator, in order to register the transfer of ownership, through the ENAGAS 'MS-ATR platform'. Given that the OTC platform MS-ATR allows free trading through direct gas exchanges (without a price) there is no public information available on OTC prices. Some gas price references are available from the auction mechanisms for the purchase of gas for TSO operations, cushion gas and last resort tariffs".

This makes data collection very difficult and the AOC has been omitted from most of the analysis in section 7. Indeed, one market new entrant stated that, despite there being "many deals done each day at the AOC, without a price attached to them, [when he wanted] to actually 'trade' some Day Ahead gas [(as you would at the NBP, TTF, etc.) he] could not get a quote from any other trader on that day; all they were interested in 'trading' were location or time swaps".

This point of view is supported by the regulator, which states ${ }^{121}$ that "the volume of gas traded stood at $533,000 \mathrm{GWh}$ in 2014 , a $33 \%$ of increase from 2013 , and is $77 \%$ higher than the demand for this year, with more than 7,000 transactions per month. Many of the trades are temporary swaps, as the OTC market is mainly used as a tool to manage the stocks of LNG and gas balance". Therefore, even when the regulator does quote volumes (Table 1) in its Annual Report, they are most likely 'nominated' volumes to the TSO on the Enagás platform, resulting mainly from swaps and not 'traded' volumes. Even given this point, the churn rate quoted is a very poor 1.77 on the total volumes, including at the LNG terminals, and a negligible 0.9 at the AOC (versus nominated physical volume); if this is compared to the national physical consumption ${ }^{122}$, the net churn reduces to 0.6 .

Another area which lacks clarity is the number of market participants. According to the CNMC, there are 125 companies that have a trading licence, but several of those are sister or subsidiary companies within the same group ${ }^{123}$. What is important in determining the trading activity on a hub is the number of active participants ${ }^{124}$. The regulator states that there were 70 'active' traders in 2014, up from 43 in 2013. However, it defines this category as traders who have traded at least once in the whole year. It says that the level of new entrants into the Spanish gas market is "very dynamic" with the number of registered traders "continuing to increase since liberalisation".

\footnotetext{
"Spanish OTC gas market (Enagas MS-ATR Platform)", pp..61, 65.

${ }^{1}$ CNMC Annual Report: "Spanish OTC gas market (Enagas MS-ATR Platform)", p.61.

122 BP (2015): Spanish consumption $26.3 \mathrm{bcm}$ which at a cv of 1040 is equivalent to $284 T W h$.

${ }^{123}$ This is the case at all the trading hubs.

${ }^{124}$ For a full explanation, see 6.1.1 'Key Element 1: Market participants'.
} 

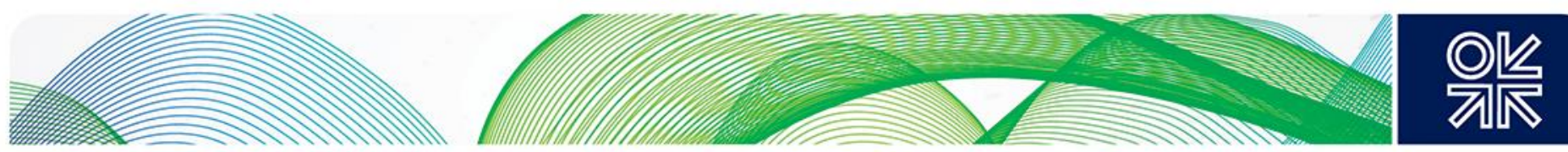

Table 1: Recorded volumes in the Spanish OTC market: 2014

\begin{tabular}{|l|r|r|r|r|c|}
\hline \multicolumn{1}{|c|}{ Balancing point } & \multicolumn{1}{c|}{$\begin{array}{c}\text { Traded gas } \\
\text { (TWh) }\end{array}$} & $\begin{array}{c}\text { Production } \\
(\text { TWh })\end{array}$ & $\begin{array}{c}\text { Churn } \\
\text { rate }\end{array}$ & $\begin{array}{c}\text { Number of } \\
\text { active } \\
\text { traders }\end{array}$ & $\begin{array}{c}\text { Market share } \\
\text { of } 3 \text { main } \\
\text { traders }\end{array}$ \\
\hline Barcelona LNG Terminal & 92.439 & 31.596 & 2,9 & 34 & $47 \%$ \\
\hline Huelva LNG Terminal & 105.675 & 20.146 & 5,2 & 39 & $39 \%$ \\
\hline Bilbao LNG Terminal & 36.639 & 17.026 & 2,2 & 19 & $58 \%$ \\
\hline Cartagena LNG Terminal & 42.973 & 11.795 & 3,6 & 28 & $61 \%$ \\
\hline Mugardos LNG Terminal & 11.940 & 13.183 & 0,9 & 16 & $75 \%$ \\
\hline Sagunto LNG Terminal & 75.622 & 17.051 & 4,4 & 29 & $44 \%$ \\
\hline Total LNG & 365.288 & 110.797 & 3,3 & 59 & $34 \%$ \\
\hline Underground storage & 5.567 & & & 17 & $72 \%$ \\
\hline Transmission balancing point & 162.847 & 190.703 & 0,9 & 45 & $37 \%$ \\
\hline Total Spain & 533.702 & 301.500 & 1,8 & 70 & $46 \%$ \\
\hline
\end{tabular}

Source: CNMC from Enagas

However, when talking to market participants and to brokers it appears that the number of traders active across the whole OTC market, including in-tank LNG swaps and 'nil price' AOC swaps, was probably in the region of $10-15$ in 2014 . If the criterion is narrowed to how many trade once per month at the AOC, the number drops to about 5-10; and, when using the same criterion as I have for all the other traded gas hubs, those who trade at least once per week, then the number is under 5 active participants. On an optimistic note, the CNMC lists those companies involved in international gas trading as Statoil, ENI, Vitol, Koch, Gunvor, Alpic, Gasela, Merrill Lynch, Morgan Stanley and, new in 2014, Gazprom. To have trading companies in the market augurs well for the future, even if the data for 2014 is poor.

As a final point, there are already four OTC brokers operating on the Spanish market (ICAP, CIMD, Prebon and IGH) and brokers are normally vital in encouraging development in an emerging market. With OTC presence, the changes brought in by the new Hydrocarbons Law, the promise of a new Iberian Gas Hub, the Spanish and Portuguese gas markets could develop to become an important entry point for physical gas to western Europe as well as a southern pricing hub.

\subsubsection{The 'Baltic Ring'}

The countries situated around the Baltic Sea accounted for just 6\% of total European gas demand in $2014^{125}$ and were dependent on Russian gas for nearly $65 \%$ of their requirements. This creates a high level of supply security concern for this region, especially given the current geopolitical tensions between the EU and Russia. Denmark and Sweden are the exception, having no Russian imports.

For several years now, the Baltic region governments have been working in cooperation with the European Union on projects to reinforce the gas (and electricity) infrastructure to improve connections with the rest of Europe. This in turn would help to improve security of supply, creating more varied sources of gas supply, and reducing dependency on Russia.

With these goals in mind, ministers from the Baltic nations signed an energy treaty ${ }^{126}$ in Riga on $13^{\text {th }}$ January 2015 to eventually create a common gas market. The Estonian Economy Minister Urve Palo stated that a free and transparent energy market in the Baltics is a priority for Estonia: "Together with

\footnotetext{
${ }^{125}$ BP (2015): 2014 demand in bcm: Europe 454; Baltic(exc. DE) 27.2; PL 16.3; DK 3.2; LT 2.6; FI 2.4; LV 1.3; SE 0.9; EE 0.5. ${ }^{126}$ Estonian Public Broadcasting, 14 ${ }^{\text {th }}$ January 2015: "Baltic nations sign energy treaty": http://news.err.ee/v/c58e65d8-9fba493b-a259-1f1ac852765d
} 

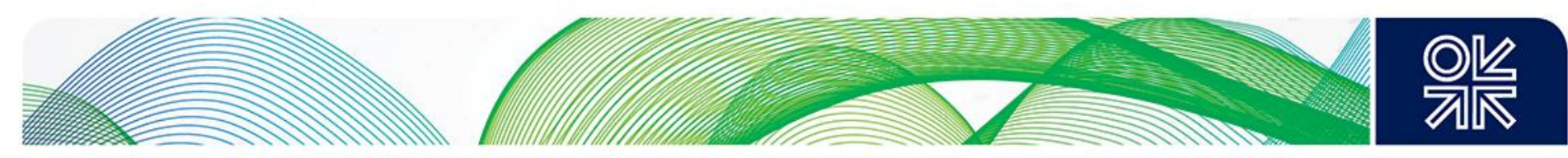

Latvia and Lithuania, we would like to guarantee a strong base for the functioning of the market, the development of infrastructure, and to guarantee supply".

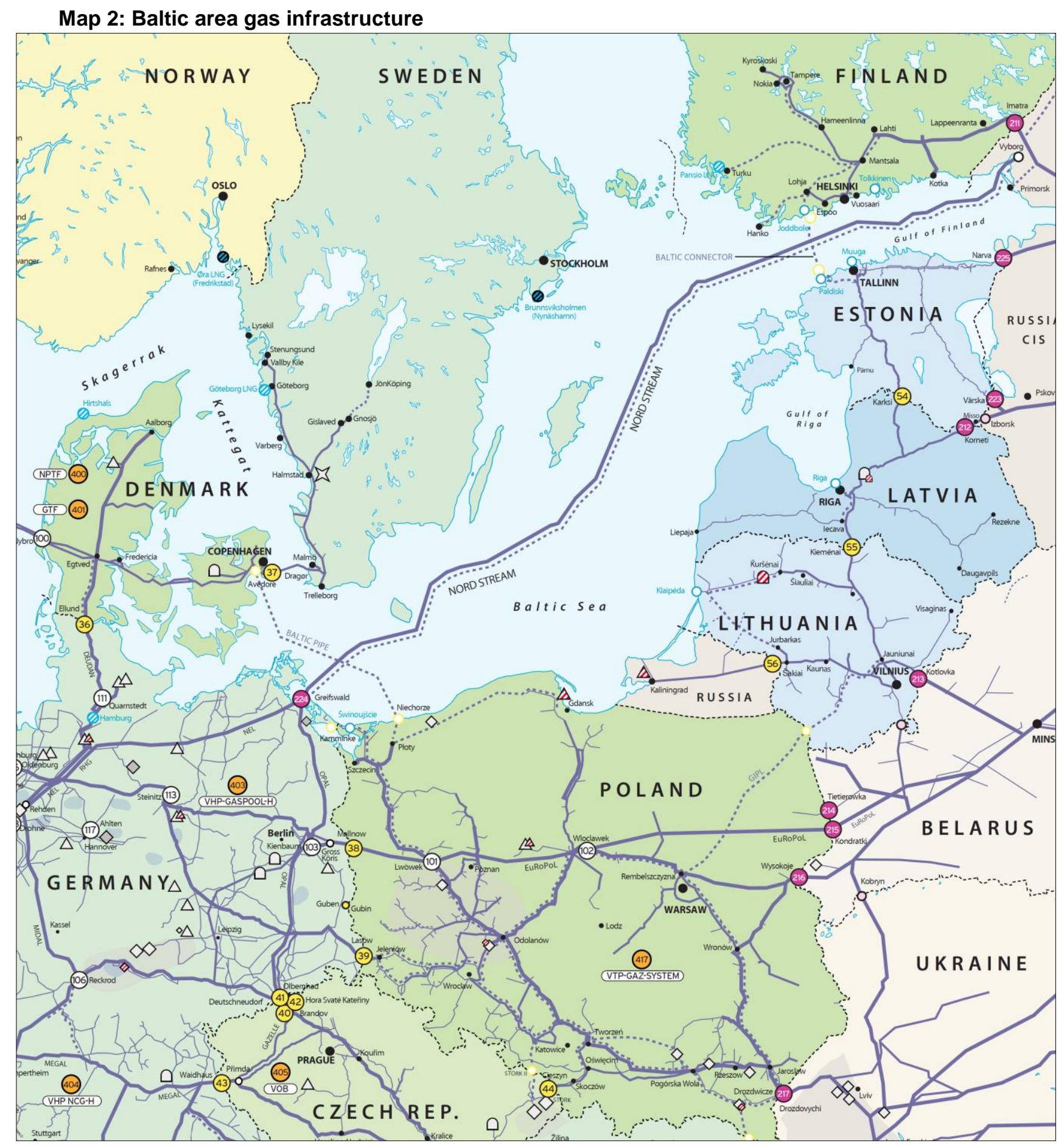

Source: ENTSOG European Natural Gas Network Map

Various enhancements have already been carried out, such as the reverse flow capacity on the Yamal pipeline, from Germany to Poland, as well as the increase in capacity from Germany to Denmark and on to Sweden. Further pipeline plans include the Baltic Pipe between Denmark and Poland, the Baltic Connector between Finland and Estonia and the Gas Interconnector Poland- 

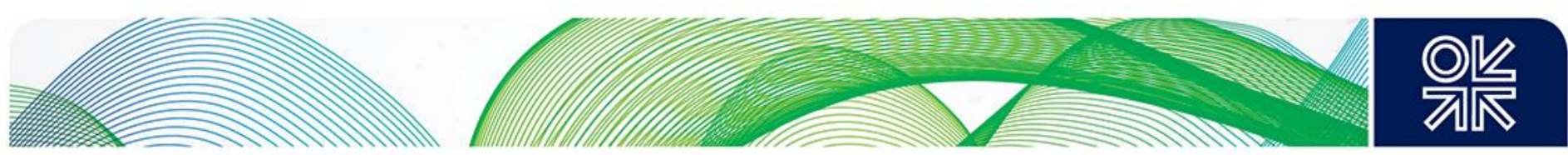

Lithuania (GIPL). However, plans for further interconnectors seem limited due to the uncertainty over future gas demand levels in these countries.

Having said that, Poland in particular recognises the part that gas can play in its de-carbonisation policy to reduce coal-fired power generation, and the potential for shale gas production that it hopes will add to the supply mix post 2020. In the light of this, Poland predicts a rise in its gas demand. Most other Baltic region countries, in their energy plans, expect the consumption of natural gas to fall, being either replaced or at least reduced by renewables.

Regardless of the future gas demand trends, commodity markets that have good physical infrastructure tend to be more resilient to both financial and physical shocks, and the greater the connectivity between neighbouring countries, the better they can balance their needs. Another very important attribute of adequate and flexible infrastructure is that it will make gas better able to balance the intermittency of renewable energy.

Given the large distances, sparse populations and low overall gas demand, it may prove more financially viable to develop LNG infrastructure rather than a pipeline grid in this region, and this appears to be happening.

A full account of the Baltic natural gas 'revolution' can be found in a report ${ }^{127}$ published by the Centrum Balticum in September 2015.

\subsubsection{Denmark}

In 2014 Danish domestic production was $4.6 \mathrm{bcm}$, the lowest level in recent years and less than half the 5-year average of $9.9 \mathrm{bcma}$ from 2005-2008. Exports amounted to $2 \mathrm{bcm}$ and were divided almost equally between Sweden and the Netherlands. Only $1 \%$ of Danish exports were allocated to Germany. In total Denmark imported $1.3 \mathrm{bcm}$, of which just under $1 \mathrm{bcm}$ came from Germany and the balance from Norway.

The TSO, Energinet, shows on its website the Danish Market Model (Figure 21). There are two natural gas pipeline entry points at Nybro (North Sea production) and Ellund (Germany), plus a virtual biogas entry point (BNG); there are two pipeline exit points at Ellund (Germany) and Dragør (Sweden); there are two storage facilities and one exit point to the national distribution network.

In addition to the physical flow points, there are two virtual trading points: the Exchange Transfer Facility (ETF) is the delivery point of all contracts at Gaspoint Nordic; the Gas Transfer Facility (GTF) is the delivery point of all OTC contracts.

The Danish gas market liberalised in 2002 and the road to full liberalisation is almost complete, except for part regulation of end user prices, to be phased out by October 2016. Dong is the incumbent producer but it is also present in energy distribution, in wholesale trading and in the retail markets. Danish consumers can choose their gas supplier from about 14 companies although the switching rate in 2014 was rather poor at $0.9 \%$.

A new balancing model was introduced in October 2014, where the shipper is responsible for balancing its deliveries and offtakes in the Danish gas transmission system; the commercial balancing model involves a daily full cash-out of the shippers' imbalances at the end of the day. 

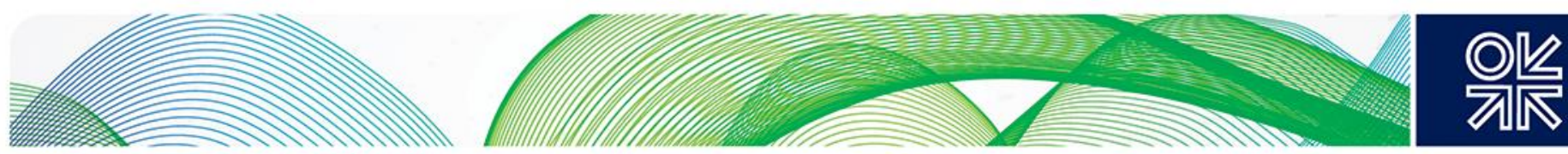

Figure 21: The Danish market model

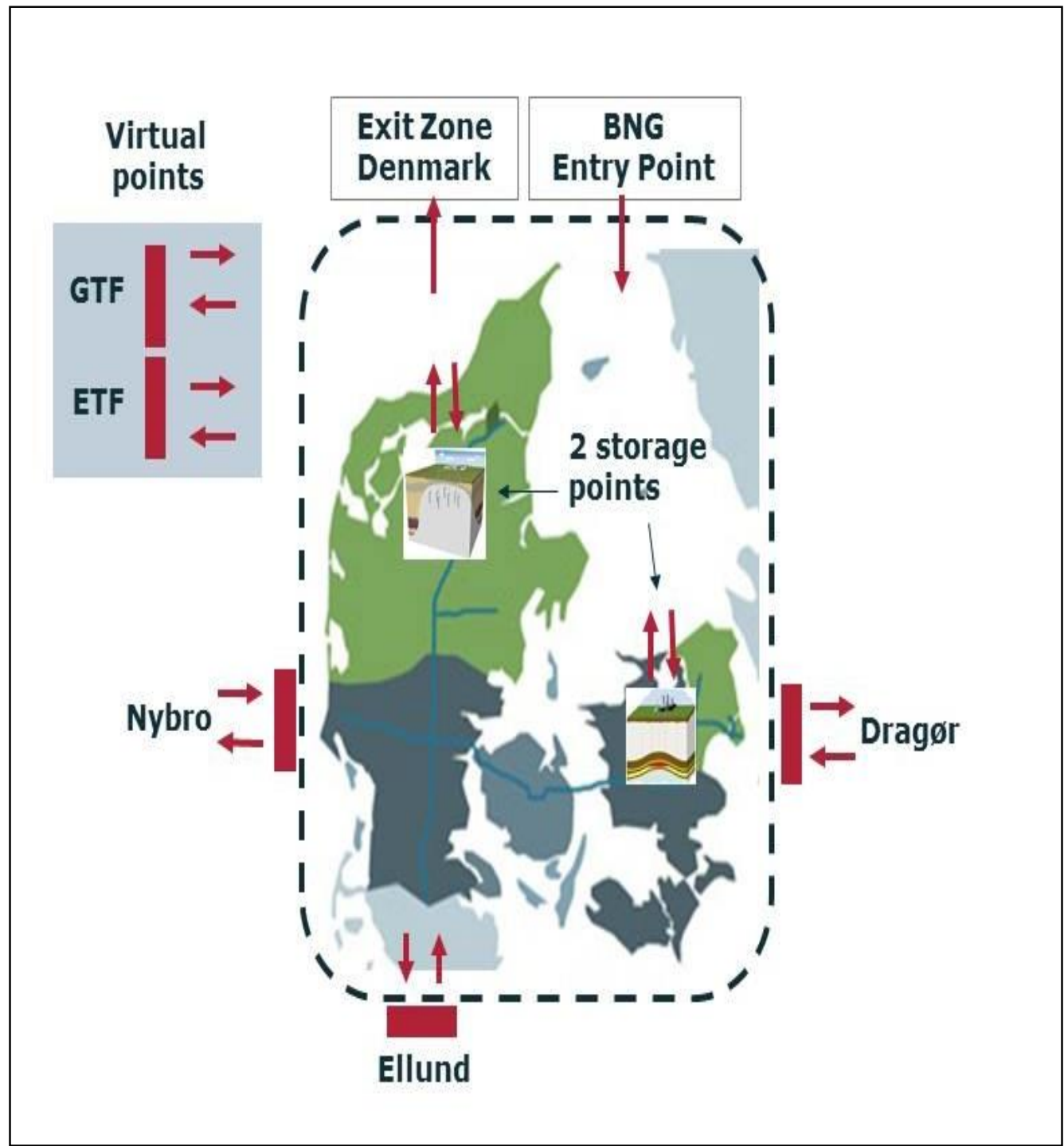

Source: Energinet.dk

The traded market was first established in 2004 with the creation of the Gas Transfer Facility (GTF). The wholesale market is mostly based on bilateral OTC trading. The exchange has progressively developed since it first opened in 2007 as the Nord Pool Gas, jointly owned by the power exchange Nord Pool Spot and the gas TSO, Energinet. The TSO took full control of the company in December 2012 before renaming it as Gaspoint Nordic the following summer. In a bid to try and increase trading volumes, Energinet joined forces at the start of 2015 with the German exchange EEX which bought $50 \%$ of the shares.

The Director of gas market, Energinet, Jeppe Danø has stated: 128 "Our commitment to the gas exchange has always been motivated by a desire to promote the gas market and ensure healthy competition, and we have now reached a point where it makes perfect sense to join forces with EEX. A partnership with EEX will provide gas market players with new and better opportunities in future".

\footnotetext{
${ }^{128} \mathrm{http} / / /$ www.energinet.dk/EN/GAS/Hvad-skete-der-i-2014/Sider/default.aspx
} 

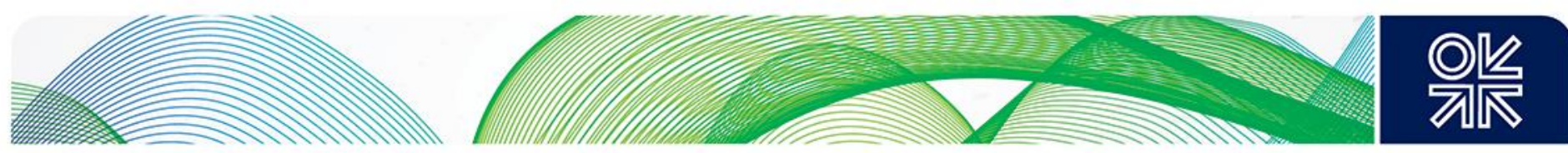

It remains to be seen whether this will indeed promote a more competitive marketplace in Denmark and if traded volumes will increase. The situation at the end of 2014 was less promising: according to the Danish regulator, Danish Energy Regulatory Authority (DERA),

"The Danish gas exchange is small and prices are not considered to be fully liquid" 129 . They show a churn rate of the ETF and GTF combined at 1.2; and, according to the Gaspoint Nordic website ${ }^{130}$, their exchange volumes alone equated to just $25 \%$ of the Danish consumption (a churn of 0.25 ). When taken individually or as a whole, these are very poor figures when compared to the other NorthWest European gas hubs.

\subsubsection{Sweden}

Sweden's gas grid is limited to the south western part of the country, along the coast between the main cities of Malmö and Göteborg, with a short spur inland. All of the country's pipeline gas supplies come from Denmark at the Dragør Interconnector Point. The TSO is Swedegas that was jointly bought ${ }^{131}$ by Fluxys and Enagás in March 2015. The natural gas market in Sweden (excluding the Stockholm area - see below) is very small with around 37,000 end-users, of whom approximately 3,600 are business customers and the remainder domestic.

There is a second, much smaller gas grid around the capital city, Stockholm, owned and operated by Stockholm Gas, and supplying about 70,000 customers. 'Town' gas has been produced and distributed in pipelines around Stockholm since 1853, originally from coal and, in the 1970s, from naphtha feedstock. In early 2011 Town gas was replaced by natural gas from LNG, delivered from Norway.

The Swedish Energy Agency is the regulator which oversees both grids. Due to Sweden's specific gas structure, there are no shippers and to gain access to the Swedish market a supplier needs to acquire transmission capacity on the Danish interconnector. E.On and Dong are the two major 'wholesalers' (although there is no wholesale market as such) and, along with five other distribution companies, the end user/customer. There is currently no congestion on the grid, either nationally or in the import link from Denmark. As there is no wholesale market, there is no gas trading in Sweden.

The Swedish government has for some time been ideologically opposed to gas in its quest to decarbonise; however, there seems to be an acceptance of biogas and its production has been growing rapidly ${ }^{132}$. Most of the production is used in the transport sector where Sweden has become a world leader in biogas as a fuel ${ }^{133}$. Only $1-2 \%$ of the natural gas distributed in the Swedish natural gas system ${ }^{134}$ consists of domestically produced biogas but this is set to grow in the coming years. The government is evaluating a scheme to produce biogas from forestry industry waste, and there is a long-term political ambition to completely replace natural gas with biogas.

\footnotetext{
${ }^{129}$ DERA 2014 National Report to the European Commission, p.36:

http://www.ceer.eu/portal/page/portal/EER HOME/EER PUBLICATIONS/NATIONAL REPORTS/National\%20Reporting\%202 014/NR En/C14 NR Denmark-EN.pdf

${ }^{130} \mathrm{http}: / /$ www.gaspointnordic.com/about-us/hjkoghl

131 "Fluxys and Enagás agree to acquire the Swedish operator Swedegas from EQT Infrastructure Limited":

http://www.fluxys.com/group/en/NewsAndPress/2015/150323 Swedegas

${ }_{132}$ Production of biogas in 2010 was 1.387TWh, rising to 1.7TWh in 2014

${ }_{133}^{1}$ IGU Biogas Report 2015: http://www.igu.org/sites/default/files/node-page-field file/IGU\%20Biogas\%20Report\%202015.pdf

${ }^{134}$ Biogas was first injected into the Swedish gas grid in October 2014: "Historic premiere for biogas in Sweden":

http://www.renewableenergyfocus.com/view/40196/historic-premiere-for-biogas-in-sweden/
} 

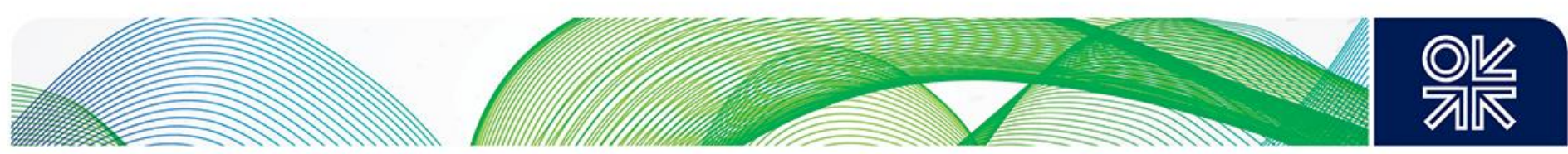

The retail market is fully liberalised, with non-regulated prices and open to competition. Swedish consumers can choose their gas supplier from seven companies and the switching rate is a poor $1.4 \%$.

\subsubsection{Poland}

Poland is the largest country in the region in terms of population and gas demand; it follows that its gas grid is also by far the most developed. It has its own production and is well connected by IPs to four neighbouring countries, and there are projects to increase this to seven within the next 5-7 years. There is one LNG terminal that is scheduled to commence commercial operations in 2016.

The country is still heavily dependent on Russian gas, which accounts for about $60 \%$ of its demand; its own production accounts for around $25 \%$ and the balance of some $15 \%$ comes from western Europe. Since 2009 gas demand has risen 13.2\% (compared to a small increase for coal of 1.9\%), although in 2014 there was a slight fall in gas demand year on year of $2.1 \%$.

This has led the government on a quest to reduce its dependence on Russian gas and Poland has pursued an intensive infrastructure development plan (Figure 22) to strengthen its national grid and increase transmission capacities on several lines to help it increase its security of supply.

Between 2009 and 2015 the TSO, Gaz-System implemented an investment plan covering the construction of more than $1,200 \mathrm{~km}$ of new gas transmission pipelines. The most significant projects were completed in north-west and central Poland. The expansion of the gas pipeline network is a major step in the development of the north-south Gas Corridor scheme to integrate the natural gas markets in central Europe. The projects already completed by Gaz-System and the virtual reverse flow services for the Yamal pipeline have enhanced the technical import capacities from non-Russian sources by a factor of 10, compared to 2011. 2014 saw the start of reverse flow from Germany (5.5bcm, rising to $10 \mathrm{bcm}$ by 2021$)$ and flows to Ukraine $(1.5 \mathrm{bcm})$.

New pipeline interconnections with Germany and the Czech Republic have helped to increase import options, but Poland has now turned to LNG as an alternative source of supply: Polskie LNG (a subsidiary of Gaz-System) was established to construct the LNG regas terminal in Świnoujście, northwestern Poland, near the border with Germany. The plant is due to commission in 2016 and has a send out capacity of $5 \mathrm{bcma}$. This will initially be supplied by a long term contract with Qatar but it is hoped that capacity enhancements will attract spot cargoes further down the line.

An important piece of the strategy for regional market integration is the Gas Interconnection Poland Lithuania (GIPL) project that has been heavily promoted by Poland but also supported by the Baltic States and the EU. The EC put GIPL on the strategic energy project list in October 2014, gave the project its financial backing in May $2015^{135}$ and helped the partners to achieve consensus on the pricing and technical details in September 2015, when Poland and Lithuania agreed ${ }^{136}$ the deal. The EC has since agreed to fund the project to $60 \%$, confirming the significance it has put on it providing energy security for the Baltic region.

GIPL construction works are planned to start in 2016 with first gas flow in 2019. When built, the gas link should become an important element of the Baltic Energy Market Interconnection Plan, BEMIP, which aims to integrate energy markets of all the states belonging to the Baltic Sea region. It will have an initial capacity of $2.3 \mathrm{bcm}$, with the option to expand to $4.5 \mathrm{bcm}$ in the future.

\footnotetext{
${ }^{135}$ Natural Gas Europe, $13^{\text {th }}$ May 2015: "EU Grants Maximum Assistance for Preparatory Work for Lithuania-Poland Pipeline": http://www.naturalgaseurope.com/eu-grants-maximum-assistance-for-preparatory-work-for-lithuania-poland-pipeline-23693

${ }^{136}$ Natural Gas Europe, 24 ${ }^{\text {th }}$ September 2015: "Lithuania and Poland Reach Accord on Gas Interconnection Poland-Lithuania": http://www.naturalgaseurope.com/lithuania-and-poland-reach-accord-gipl-25536
} 

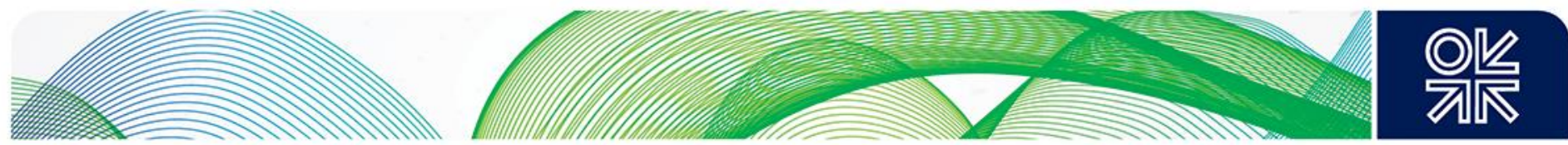

Figure 22: Gaz-System's 10 year development plan: 2014-2023

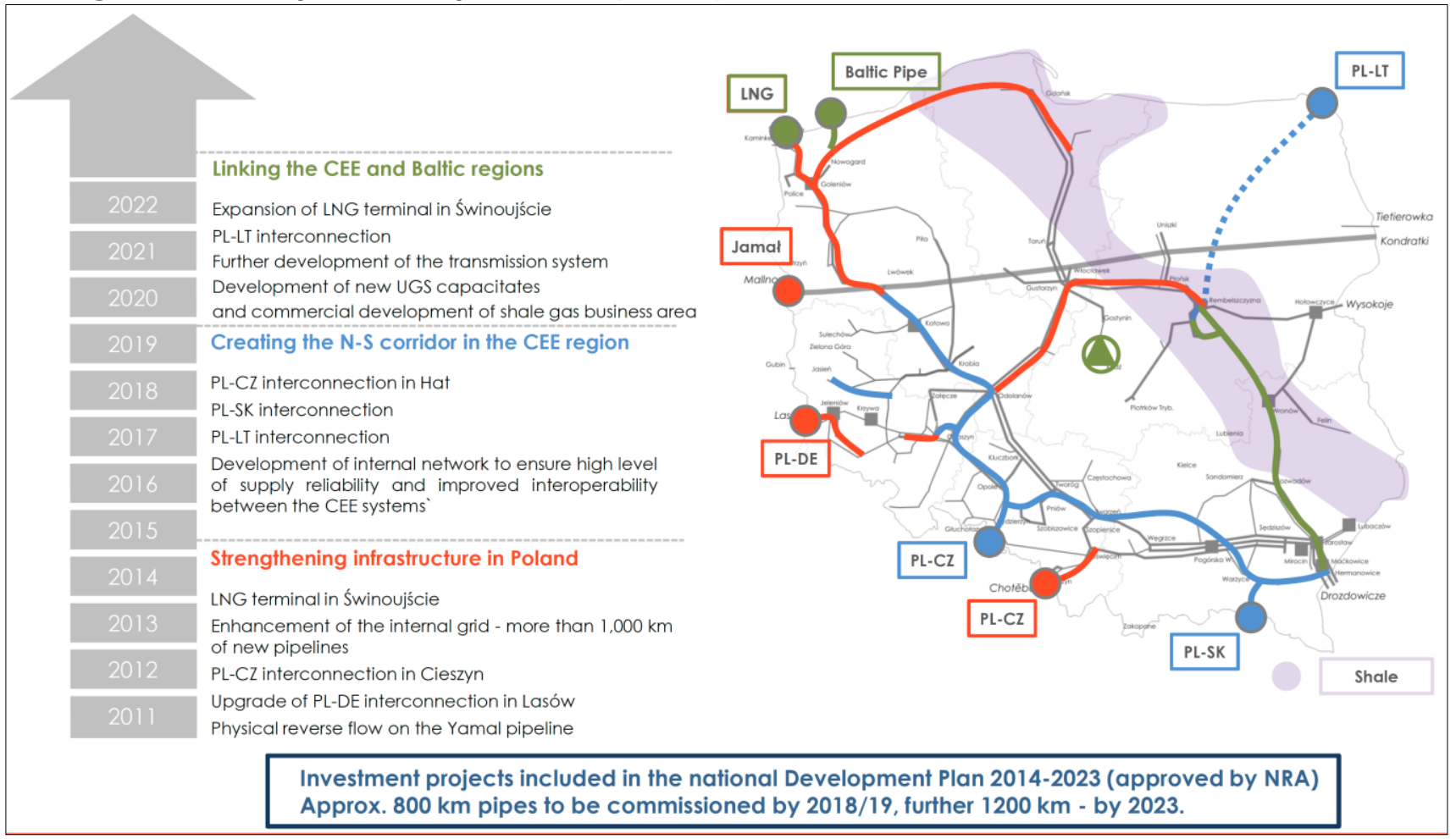

Source: Gaz-System

From the above plan, in the next phase (2015-19),

- the PL-LT interconnector is now agreed;

- the PL-CZ interconnector project cost split is agreed but FID is still to be taken, although there is a high probability of it going ahead;

- the PL-SK interconnector project is still subject to ongoing discussions as to the cost split but has a good probability of going ahead.

All the Polish internal improvements up to 2023 have already been approved by URE (the regulator).

In parallel with its aggressive infrastructure development plan, Poland has enacted political changes. The process of liberalisation has progressed and market conditions have improved but there is still far to go to completion. Progress so far includes implementation of the European Network Codes (in August 2014) with the introduction of the virtual trading point, pilot projects with bundled capacities, Gas-System's proprietary capacity auctioning platform, market-based balancing, and the launching of both virtual and subsequent physical reverse flow on the Yamal pipeline. In addition, a gas exchange (POLPX ${ }^{137}$ ) was established and an exchange trade obligation was put in place, but all these measures have proven to be insufficient so far to boost competition.

Poland still needs to phase out regulated prices in the gas sector and there needs to be better and 'fairer' regulation to help competition, not hinder it. The EC's "Energy Markets in the European Union 2014" states ${ }^{138}$ that "in some instance, the Regulator has released entities trading in natural gas from the obligation to submit tariffs for his approval". There is also a feeling that not enough is being done

\footnotetext{
137 POLish Power eXchange: http://www.tge.pl/en

${ }^{138}$ Footnote 340, p.127: http://ec.europa.eu/energy/sites/ener/files/documents/2014 energy market en.pdf
} 

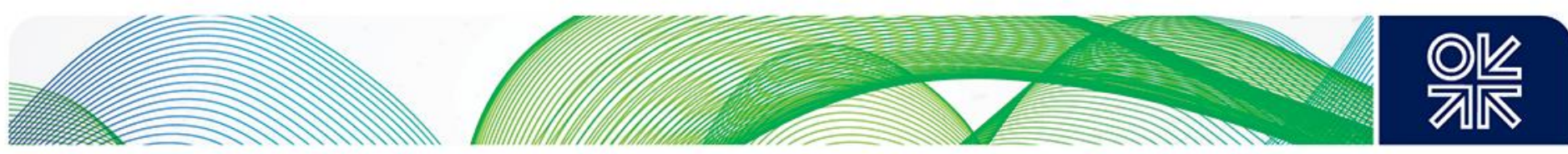

to break PGNiG's incumbent dominant position in all parts of the gas value chain. Since 2013, the company has been forced to deliver more of its gas supplies on to the gas exchange (POLPX) on a sliding scale, starting with $30 \%$ in 2013, rising to $40 \%$ in 2014 and 55\% in 2015 . PGNiG has also been split between Wholesale and Retail divisions, which has had the result that some large industrials have started to buy some of their gas needs from the hub, but only volumes above the ToP levels on their PGNiG supply contracts.

That PGNiG Capital Group held on to $95 \%$ of the wholesale and retail markets in 2012 and $2013^{139}$, with only a small reduction the following year, raises grave concerns that liberalisation may be stalled with the preservation of such a powerful monopoly position. The 70 shippers registered with GazSystem in 2014 shared a small proportion of the total volumes. At the retail end of the market, $94.5 \%$ of households were supplied with gas under regulated prices in 2013 (down from 99.5\% in 2012). The largest company in terms of gas sales volume, and not a part of the PGNiG Capital Group, was Egesa Grupa Energetyczna, with just a 1.17\% market share.

Compared with north-west Europe in general, Poland is lagging far behind on market liberalisation process. Rather than limiting itself only to actions absolutely required by the EU law, it needs to improve transparency, speed of data and information dissemination and, in a world where English speaking companies dominate gas trading, it should also increase the availability of information in English to facilitate new market entrants. There is much more to do before this country will have a properly functioning traded gas market.

The POLPX exchange started to offer gas products in early 2013. In order to be able to trade a market participant must first become a Member (either direct or through a broker), although this is changing in 2015. In 2014 there were 45 registered market participants, of which about 20 traded at least once per month. It is expected that PGNiG's customers will be allowed to trade with them on the exchange rather than directly, although initial evidence is that they did not do so in sufficient volumes for the incumbent to even fulfil its 'gas sales' requirement in 2013 and only just met it in 2014.

Trade volumes increased significantly during 2014, from a very low base, to a total volume of 111.69TWh ${ }^{140}$, which represents over 46 -times growth with respect to the aggregate gas market volume in 2013. The volume on the spot market (DAM\&IDM) was 6.57TWh, while on the forward market it reached 105.07TWh (including auctions).

\subsubsection{Baltic States}

The three Baltic States of Lithuania, Latvia and Estonia rely $100 \%$ on Russian gas and are supporters of the EC's goals of a Single Energy Market and improved security of supply ${ }^{141}$. In the case of the Baltics, the provision of infrastructure to diversify supply away from Russia has a cost /benefit analysis challenged by the distances involved and relatively small markets in terms of gas consumed. After years of debate and positioning, progress is finally being made. There has been discussion of a Baltic regional gas hub but this remains more a vision than an imminent prospect. Should the infrastructure projects planned come to fruition however, there should at least be more cooperation between the countries and improved security of supply.

\footnotetext{
139 National Report of the President of the Energy Regulatory Office: "Promoting competition", pp. 70-77: www.ure.gov.pl/download/2/443/ActivityReport2014.pdf

140 Polish Power Exchange Press Release, $5^{\text {th }}$ February 2015: "Polish Power Exchange achieved record-breaking volumes": http://www.tge.pl/en/27/news/554/in-2014-the-polish-power-exchange-achieved-record-breaking-volumes-on-the-electricityand-natural-gas-markets

${ }^{141}$ They have for many years bemoaned their energy reliance on Russia but only recently strived to improve their position.
} 

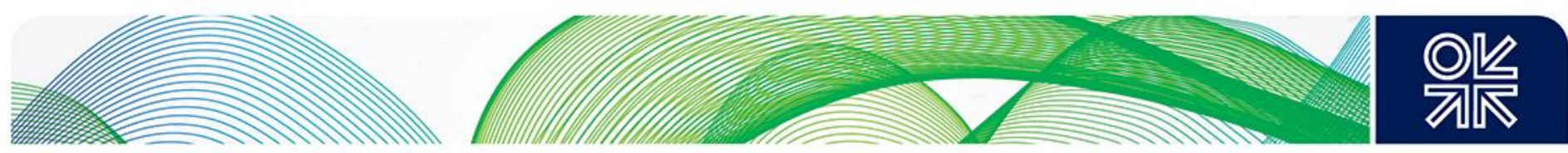

\subsection{Lithuania}

Lithuania relies on Gazprom as its single source of gas supplies, from Soviet era pipelines via Estonia and Latvia, or via Belarus. Diversification of gas supply will be facilitated by the LNG terminal in Klaipeda, which started operating in December 2014. It is important that the planned interconnector with Poland (GIPL) is also constructed in order to further diversify gas supplies to the country and the larger Baltic region.

In an interview, the Lithuanian Ambassador to Sweden ${ }^{142}$ described how his country went through 3 stages of independence: the first in 1991 when the state was liberated from Russian occupation; the second in 2004 when Lithuania joined NATO and the European Union; and the third also in 2004 when the government decided to pursue the goal of energy independence. He went on to say that "although Gazprom had a very large hold on Lithuania, the government had the political will to move on". Looking at the situation ten years later, there is evidence that it is succeeding.

The most impressive project is the Klaipeda LNG terminal, a project that has been hailed as a 'game changer'143 for the whole region. Lithuania has become the first Baltic state capable of buying gas from world markets rather than solely relying on Russian gas via Gazprom pipelines. The terminal opened in 2014 and Lithuania exported natural gas to neighbouring Estonia in 2015.

About $1 \mathrm{bcm}$ of gas was expected to be pumped in the first year of the terminal's operation, with the potential that throughput could grow to 2 or $3 \mathrm{bcma}$ in the future. This capacity could meet Lithuania's annual gas consumption, which in 2014 was $2.6 \mathrm{bcm}$. The terminal would be able to meet roughly $75 \%$ of Lithuania's, Latvia's, and Estonia's total gas demand. For now the five year contract between Lithuania and the Norwegian company Statoil will provide only $0.54 \mathrm{bcm} / \mathrm{year}$ of gas.

The project took less than four years from the first step until the commissioning. The 27th of October 2014 was an important day, both in terms of project execution and symbolically in terms of energy diversification, when the Floating Storage and Regasification Unit (FSRU), (appropriately named Independence), entered Klaipeda port and moored to a jetty. This vessel is chartered for 10 years from Norwegian company Höegh LNG with an option to buy the FSRU at a market price after the end of the lease period.

The additional significance of this terminal is the leverage it provides Lithuania in its LTC price renegotiations with Gazprom. Lithuania will now expect to get Russian gas at the Gazprom Poland/Germany border price.

The process of liberalisation is progressing with the unbundling of the State company completed in 2014. The new entities are Lithuanian Gas and Amber Grid (the TSO). Theoretically, the market is $100 \%$ liberalised and customers are free to choose among gas suppliers but, in reality, the retail market is dominated by just two companies taking $98 \%$ (Lietuvos Dujos $69 \%$ and UAB Dujotekana $29 \%$ ). The remaining $2 \%$ market share is divided between 6 further suppliers. Although consumers can switch suppliers, there is very little switching recorded to date.

\subsection{Latvia}

Latvia is the 'odd one out', of the three Baltic States, in that it has 'stuck' with Russian gas, somewhat to the annoyance of its neighbours. Latvia's state gas company Latvijas Gāze ${ }^{144}$ is not particularly

\footnotetext{
142 Interview with Ambassador Eitvydas Bajarunas, in Stockholm, $21^{\text {st }}$ August 2014.

${ }^{143}$ Natural Gas Europe, $24^{\text {th }}$ September 2014: "Klaipeda's LNG Terminal: A Game Changer": http://www.naturalgaseurope.com/klaipedas-Ing-terminal-a-game-changer

${ }^{144}$ Latvian natural gas company, which deals in the imports, transmission, storage and sales of natural gas. It holds the monopoly of the natural gas market in Latvia. Latvijas Gāze is owned by E.ON Ruhrgas International AG (47.23\%), AAS Gazprom (34\%), SIA "Itera-Latvija" (16\%) and $2.77 \%$ other shareholders.
} 

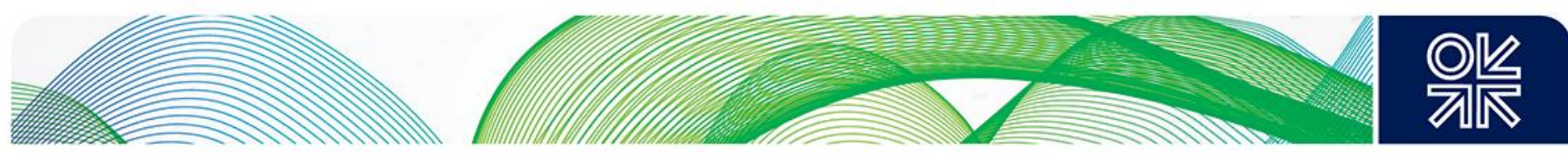

interested in LNG from neighbouring Lithuania's LNG terminal: "Our demand for gas in Latvia is completely satisfied by the long-term contract with Russian Gazprom. The market because of the current (gas) surplus so far is not ready to have an extra quantity of gas added to it," said Mario Nullmeier ${ }^{145}$, deputy chairman of Latvijas Gāze.

This is a remarkable statement given that the country generally wants closer ties with the EU and has been cooperating with its neighbours in the political sphere to promote Baltic unity. It was announced ${ }^{146}$ in September 2015 that the company will work towards a timetable for unbundling, to be achieved by April 2017. This follows the amendments adopted by the Latvian parliament in March 2014 to the emergent market derogations it had been granted by the EU.

Gas imported from Russia during the summer is stored at the Inčukalns underground gas storage (UGS) facility, where $4.47 \mathrm{bcm}$ of gas can be stored (of which $2.32 \mathrm{bcm}$ is 'working' gas). This capacity can be increased to $3.2 \mathrm{bcm}$ of working gas. During the winter Latvia satisfies its additional seasonal natural gas needs from Inčukalns UGS, which also supplies Estonia and to a lesser extent Lithuania. Infrastructure improvements include the enhancement of the Latvian-Lithuanian interconnection, which was realised in early 2013, thereby increasing cross-border capacity to more than 6 millioncm/day in both directions.

As in the wholesale market, Latvijas Gāze is the only player in the gas retail market in Latvia. Switching supplier is therefore not an option. Retail prices are regulated and are indexed to oil derivatives.

\subsection{Estonia}

Estonia's gas grid is connected to Russia at two IPs (Värska in the south and Narva in the north) and has an interconnection with Latvia (Karksi). Estonia's gas market remains isolated from the rest of Europe. Estonia imports all of its natural gas from Gazprom. During the winter months, the Inčukalns gas storage facility in Latvia is also used by Gazprom to supply Estonia. Gas supply is secured by the TSO, Elering Gaas ${ }^{147}$, but the Estonian gas system lacks its own compressor station and the pressure required for transmission is provided by compressor stations that form a part of the Russian transmission system or the compressor station of the underground gas storage facility of Inčukalns in Latvia.

To improve its energy position, Estonia needs to diversify its sources of supply and this is being addressed in several projects. The Lithuanian LNG terminal has brought a new source of supply to the region and the situation will improve further once the pipeline connection between Poland and Lithuania is completed. A third pipeline project, to connect Estonia to Finland, including the building of two LNG terminals may also be pursued.

The Estonian Ministry of Economic Affairs and Communications together with other Baltic countries and Finland have started co-operation to develop a regional gas market. Gas market regulation rules will provide a foundation for a model for multiple suppliers and cross-border trade.

The Estonian Prime Minister Taavi Roivas and Finnish Prime Minister Alexander Stubb reached an agreement ${ }^{148}$ on $1^{\text {st }}$ December 2014 to build an LNG terminal in each country, to be connected by a pipeline across the Gulf of Finland, by 2019. The project ${ }^{149}$, called "Balticconnector", if it succeeds, will

\footnotetext{
145 Natural Gas Europe, $21^{\text {st }}$ May 2015: "Latvia Sticks with Gazprom, Defies Lithuania's Expectations": http://www.naturalgaseurope.com/latvia-latvijas-gaze-gazprom-gas-supply-lithuania-Ing-23690

${ }^{146}$ Nasdaq GlobeNewswire, $16^{\text {th }}$ September 2015: "Latvijas Gāze, JSC: Information on company's unbundling and market liberalisation": http://globenewswire.com/news-release/2015/09/16/768691/0/en/Latvijas-G\%C4\%81ze-JSC-Information-oncompany-s-unbundling-and-market-liberalisation.html

${ }^{147}$ Renamed Elering Gaas on 10 April 2015; previously called EG Võrguteenus.

148 The Baltic Times, $3^{\text {rd }}$ December 2014: "Estonia and Finland agree on construction of two LNG terminals": http://www.baltictimes.com/estonia and finland agree on $999 \quad 9$ construction of two Ing terminals/

${ }^{149}$ Further information available on the TSOs website: http://gaas.elering.ee/en/balticconnector/
} 

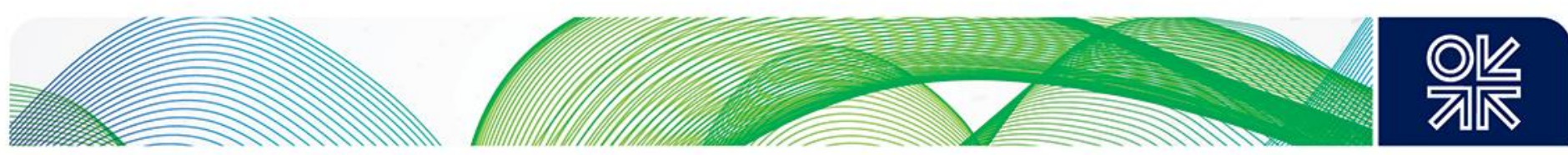

not only increase energy diversification but also help mitigate these two countries' geographical isolation at the northern tip of the European Union. The EU has already approved pre-project funding and the Balticconnector has been included in the Projects of Common Interest (PCl) list of the EU Connecting Europe Facility (CEF) program.

Although the Estonian gas market has been completely open since 2007, the national gas company, Eesti Gaas ${ }^{150}$, is the sole importer of gas and dominates the wholesale and retail markets; there is effectively no competition between gas suppliers. The country's current gas isolation has permitted it to receive an exemption from the EU regarding market liberalisation rules but the government needs to make provision for when this will expire. So far, there have not been any changes to the law.

There is no effective wholesale market and no organised gas hub. As in the wholesale market, Eesti Gaas also has a dominant position in the retail market with a market share in 2012 of $89.0 \%$, while the remaining $11.0 \%$ was sold by another 27 licensed gas sellers. The switching rate is $4.5 \%$ and, interestingly, the retail gas market is assessed ${ }^{151}$ fourth highest in the EU, with the fifth highest score on overall consumer satisfaction; in contrast, consumer assessment of the choice of providers is the lowest in the EU.

\subsubsection{Finland}

In terms of gas grids, Finland is situated at the most northern point within the EU and is not connected to any other EU gas grids. It receives all its gas from Russia through one IP at Imatra. There is only one importer and wholesale supplier, Gasum ${ }^{152}$, which also owns and operates the natural gas transmission network as the TSO.

Gasum buys its natural gas from Gazprom on a 20-year contract signed in 2005. However, in December 2013, it successfully renegotiated the contract ${ }^{153}$ to reduce the amount of oil indexation to $50 \%$. In addition to natural gas imported from Russia, biogas produced in Finland is supplied to the natural gas transmission network.

Because of its isolated gas position within the EU, Finland received a derogation allowed by the Natural Gas Market Directive. Following this, the natural gas market has not been opened in the manner specified in the Directives. This exemption is effective as long as Finland does not have a direct connection to the natural gas network of any other EU Member State and as long as it has only one main natural gas supplier.

Gasum also operates Kaasupörssi Oy, a natural gas exchange, for short term products and a bilateral secondary market where large consumers can make offers. There are 23 natural gas retail suppliers in Finland who have a monopoly within their own distribution network.

More information on the Finnish gas market is available in the Energy Authority's annual report ${ }^{154}$ and the ECs "Energy Markets in the European Union 2014"155.

\footnotetext{
${ }^{150}$ Eesti Gaas is owned by Fortum (51.38\%), Gazprom (37.03\%), and Itera Latvija (10.02\%).

${ }^{151}$ Energy Markets in the European Union 2014, p.56:

http://ec.europa.eu/energy/sites/ener/files/documents/2014 energy market en.pdf

${ }^{2}$ Gasum is owned by the Finnish Government (75\%) and Gazprom (25\%);

[prior to March 2015, the shareholding was: Fortum (31\%), Finnish Government (24\%), E.ON (20\%)]

${ }^{153}$ Reuters, $13^{\text {th }}$ November 2013:" Finland's Russian gas price a dream deal for others":

http://www.reuters.com/article/2013/11/13/finland-gas-idUSL5N0IY2SW20131113

${ }^{154}$ National Report 2014 to the Agency for the Cooperation of Energy Regulators and to the European Commission: http://www.ceer.eu/portal/page/portal/EER HOME/EER PUBLICATIONS/NATIONAL REPORTS/National\%20Reporting\%202 014/NR En/C14 NR Finland-EN.pdf

${ }^{155}$ Finland, pp. 154-156.: http://ec.europa.eu/energy/sites/ener/files/documents/2014 energy market en.pdf
} 

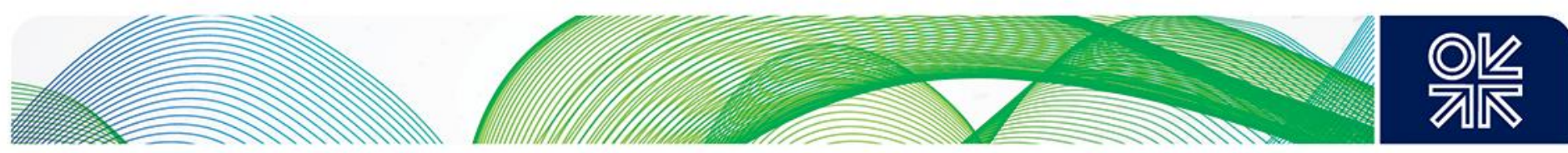

\subsubsection{The Balkans, South East Europe and the Mediterranean}

The Balkan Peninsula, popularly referred to as the Balkans, is the geographical region of south east Europe from Slovenia and Croatia in the west, to Romania and Bulgaria in the east and to Greece in the south. This area of Europe that has rather poor national gas grids, although there are major transit pipelines traversing the region, with the possibility of new pipelines in the future. The aggregate demand for gas in the above 5 countries was $20.2 \mathrm{bcm}$ in 2014 , with Romania accounting for $58 \%$ $(11.7 \mathrm{bcm})$, Croatia, Bulgaria and Greece accounting for $37 \%(2.3 \mathrm{bcm}, 2.6 \mathrm{bcm}$ and $2.7 \mathrm{bcm}$ respectively) and, finally, Slovenia having just a $5 \%$ share $(0.9 \mathrm{bcm})$. Two countries have gas production (Croatia $1.5 \mathrm{bcm}$; Romania $11.7 \mathrm{bcm}$ ) and both have plans for growth in the gas sector. Croatia hopes to substantially increase its domestic production to help turn it into a major gas hub in the region; in January 2015, it awarded 10 licenses for hydrocarbon exploration and drilling in the Adriatic to three consortia ${ }^{156}$. The Croatian Minister of Economy, Ivan Vrdoljak, stated ${ }^{157}$ that "Croatia will surely be an exporter of natural gas".

There has been talk in recent years of a possible Romanian or a South East Europe gas hub, and even a Greek regional gas hub but this section focusses more on the possibility of a Mediterranean hub in line with recent EC intent ${ }^{158}$, clearly expressed in a statement by Maroš Šefčovič ${ }^{159}$ that "in the south [of Europe], the establishment of a Mediterranean gas hub is necessary".

When considering the possibility of a Mediterranean gas hub (MGH), it is necessary to review the gas infrastructure in both the Mediterranean countries (Map 3) and their connectivity with the rest of the $\mathrm{EU}$, as well as the current and future supply/demand situation for gas across all of Europe.

Geographically, there are only a few countries in the EU that are appropriate when considering an MGH: Spain, France, Italy and Greece. There could also be a more regional hub, especially in south east Europe, which might include Greece, Bulgaria and Romania. One should also bear in mind that Turkey, although not in the EU, does border with Greece, exports gas to Europe via Greece, has a large and rising gas demand and could be a transit route for Russian, Caspian and in due course East Mediterranean gas flows.

As has been previously noted, the Iberian Peninsula is a 'separate' gas market from the rest of Europe $^{160}$, relying on LNG and Algerian pipeline gas imports and with relatively poor connectivity with the rest of Europe. Despite recent increase in Spain to France capacity at the Larrau cross-border IP, there remains a serious north/south capacity constraint within France which would limit any onward transportation of gas north or east within the Union.

\footnotetext{
${ }^{156}$ Marathon, OMV and the domestic company, INA.

${ }^{157}$ Natural Gas Europe, 23rd March 2015: "Croatia Plans to Become Gas Giant of the Balkan Region": http://www.naturalgaseurope.com/ivan-vrdoljak-croatia-natural-gas-giant-of-balkans-65874

${ }_{158}$ Communication from the Commission to the European Parliament and the Council, European Energy Security Strategy, SWD(2014) 330 final, p.16: "the EU should engage in intensified political and trade dialogue with Northern African and Eastern Mediterranean partners, in particular with a view to creating a Mediterranean gas hub in the South of Europe". http://eur-lex.europa.eu/legal-content/EN/TXT/PDF/?uri=CELEX:52014DC0330\&from=EN 159 The Parliament Magazine: $21^{\text {st }}$ October 2014: "Šefčovič meets ITRE/ENVI approval": https://www.theparliamentmagazine.eu/articles/eu-monitoring/\%C5\%A1ef\%C4\%8Dovi\%C4\%8D-meets-itreenvi-approval ${ }^{160}$ See Section 5.5.1 for more detail.
} 

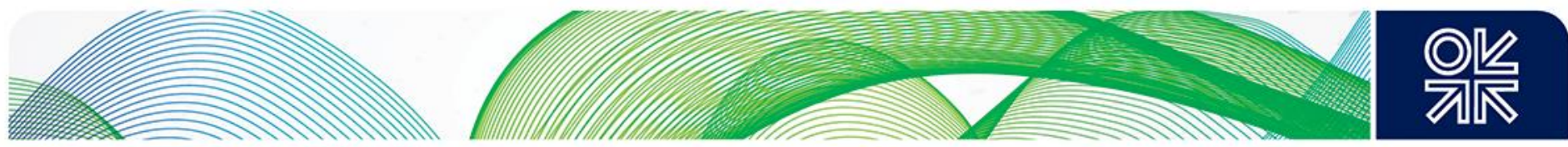

\section{Map 3: Mediterranean Gas Infrastructure}

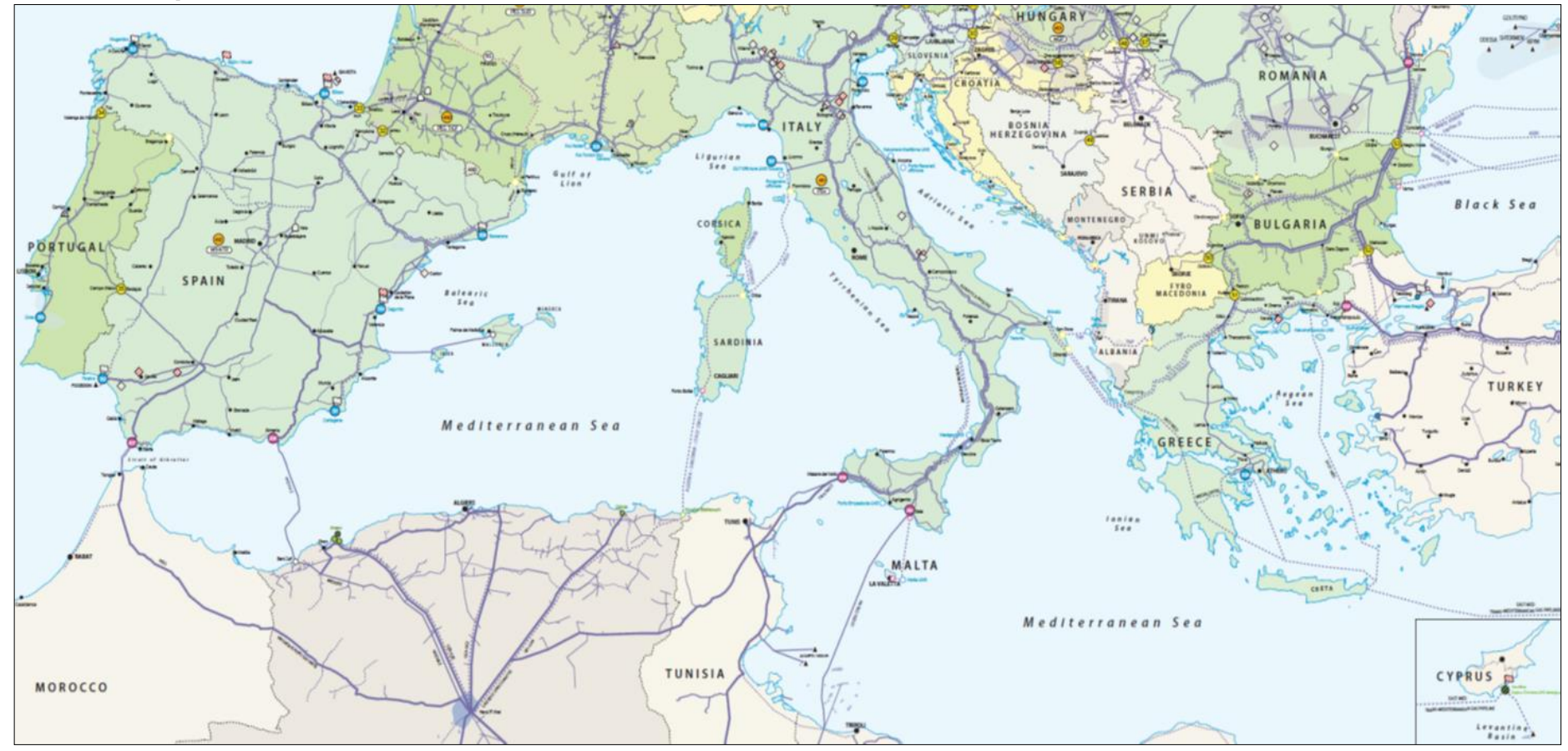

Source: ENTSOG European Natural Gas Network Map

France has a serious north/south transmission grid capacity constraint and its commitment to trading has been disappointing to date. Its southern hub, TRS ${ }^{161}$ is rated as 'inactive' and even the PEG Nord, which represents about $90 \%$ of all French gas trades, is only rated as 'poor' 162 .

Italy has a developed gas grid ${ }^{163}$ and is well connected externally through pipelines and LNG terminals, although there is a need for better south to north capacity, which is being addressed. Italy has Europe's $3^{\text {rd }}$ largest demand for gas and there have been noticeable improvements in recent years in its attitude to trading. Indeed, Italy's total traded volumes in 2014 narrowly exceeded those of France for the first time and the OTC volumes were $86 \%$ greater than in 2013 . The possibility in the future of new pipeline (TAP) gas arriving in the heel of Italy, adding to existing supplies from Algeria (viaTunisia) and Libya, coupled with a strong desire by the regulator and the government to make Italy a southern trading hub in Europe, augurs well for this country to take on that mantle.

The Trans Adriatic Pipeline (TAP) will connect existing and planned natural gas grids in south east Europe with gas systems in western Europe via Greece, Albania, the Adriatic Sea and Italy. The pipeline, which has an initial 10bcma transport capacity, will therefore give Europe better access to the major reserves of natural gas located in the Caspian region.

Greece too has expressed publicly its desire to become a south-east European gas hub, either on its own or as part of a regional hub. This is supported by geopolitical factors, namely the tensions between the EU and Russia over the Ukraine crisis and the Russian desire to bypass Ukraine for its gas exports to Europe. With the Russian announcement to suspend construction of South Stream in favour of a new project, 'Turkish Stream'164, the geographic position of Greece transforms the country into a unique entry point to EU energy markets for all pipeline transit gas coming via Turkey from

\footnotetext{
${ }^{161}$ Prior to $1^{\text {st }}$ April 2015, PEG Sud and PEG TIGF.

162 See Section 6: "Analysis of the European gas hubs" for full details of trading volumes for all the traded gas hubs.

163 See Appendix I for a map of the Italian gas network.

164 See Appendix D for a map of the Turkish Stream project.
} 

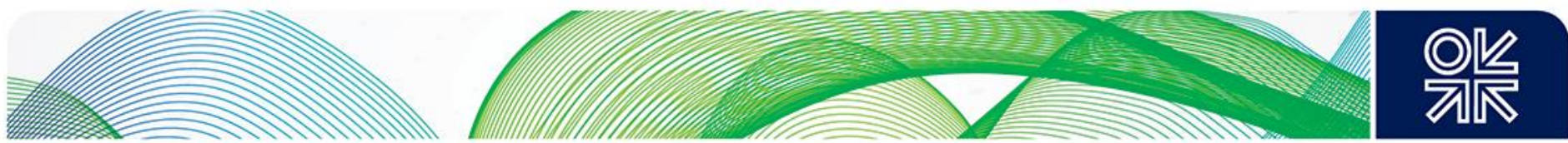

Russia, Azerbaijan and potentially, in a later timeframe, from the East-Mediterranean basin and from the Middle East.

There are many issues with this project, not least the commercial and legal implications for both Russia and its European buyers in relation to the delivery points in long term contracts. EU buyers would perhaps prefer to take delivery on the Russian/Ukraine border rather than on the Greek border and, as a result of any change of delivery point to Greece, could opt to reduce their Take or Pay obligations and buy spot gas on the European hubs instead. The real issue though in practical terms, is how the flows of gas will reach markets in Central and Western Europe.

\section{Map 4: Gas interconnections in SE Europe}

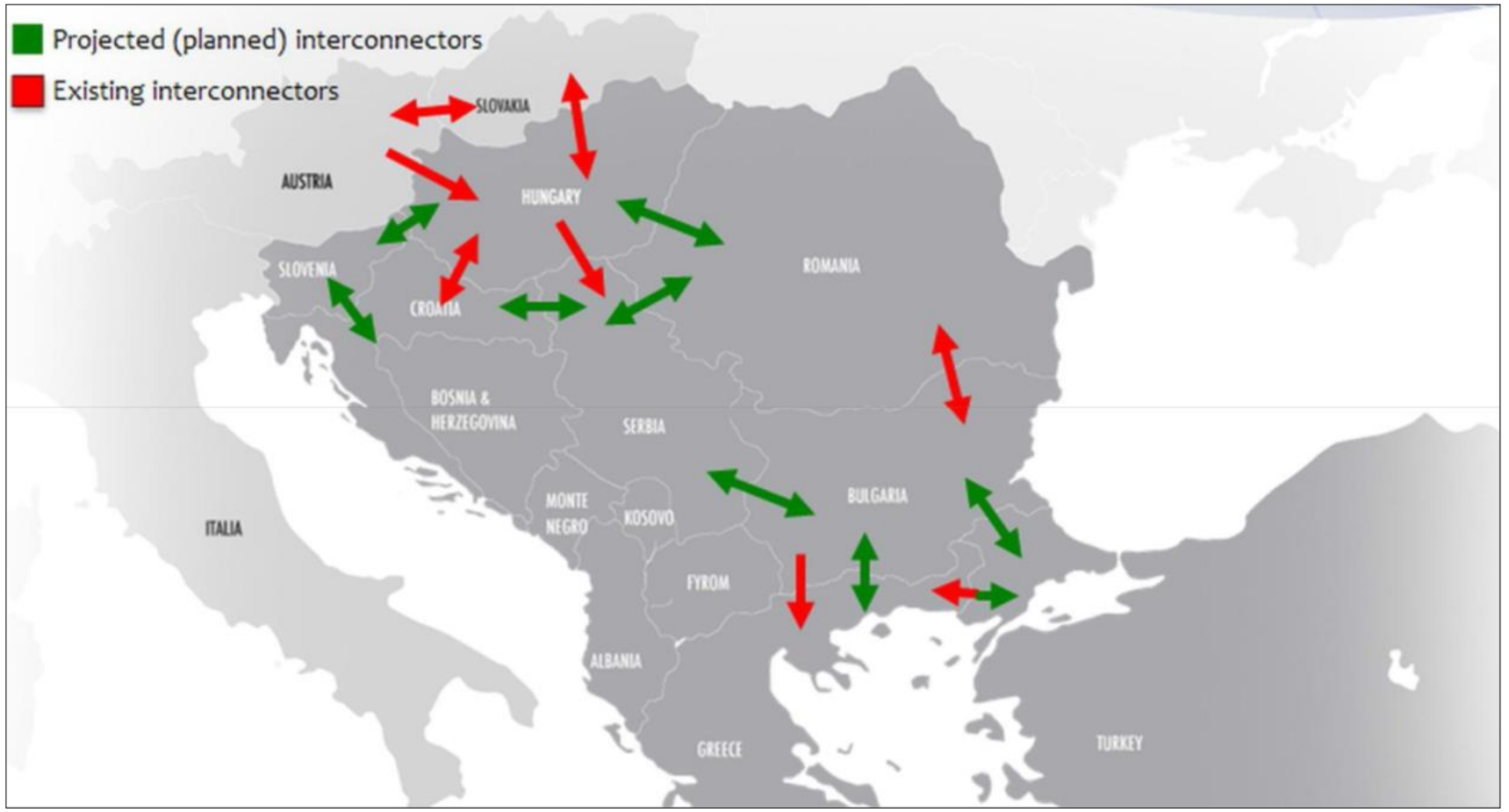

Source: Institute of Energy for S.E. Europe, study project M19 (2014) ${ }^{165}$ : picture 36, p.150

The infrastructure to carry large volumes of transit gas does not exist in Greece or the rest of the Balkans. Indeed, from an infrastructure point of view, there are still many limitations which will need to be overcome. The Greek gas grid ${ }^{166}$ is very limited in its coverage of the country and its capacity: it is essentially a one-pipe network carrying imported gas from the northern borders to the Athens area in the south. Furthermore, the gas interconnections in South East Europe will need reinforcing both in the capacities and the directionality of the flows. Map 4 shows the limited nature of the current connectivity between Turkey, Greece, Bulgaria, Serbia and Romania. It also shows that further reinforcements will need to be made in central Europe between Romania, Hungary, Serbia, Croatia and Slovenia. All of these improvements will in the long run improve the EU's energy security but will be costly and take time ${ }^{167}$.

\footnotetext{
165 "The outlook for a natural gas trading hub in SE Europe": 

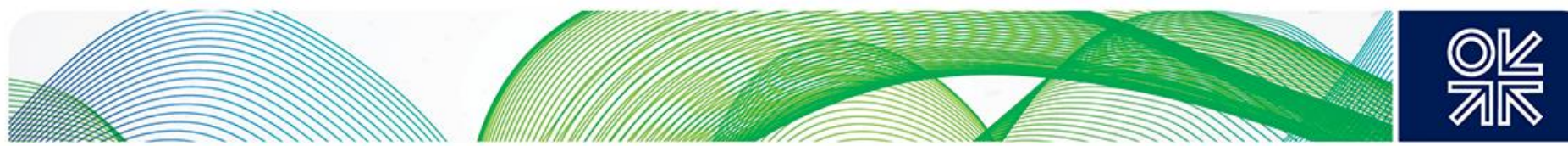

Finally, could Turkey be a gas hub or part of a regional gas hub? Its own gas demand has seen strong growth in recent years and it is already a transit route for gas arriving at the Greek border. It has expressed a desire to become a hub and many commentators have written about this. However, a recent in-depth analysis ${ }^{168}$ has concluded that "Turkey will hardly have the potential to become a regional gas hub in the medium term (up to 2020-2025). However, Turkey could have the potential to play an important role in the regional gas markets in the longer term (after 2025-2030) if a number of structural, commercial and political barriers described in the paper are overcome and, last but not least, if the EU gas demand recovers and the EU market actually needs more natural gas supplies".

\section{Table 2: Mediterranean LNG competitiveness}

\begin{tabular}{|c|c|c|c|c|c|c|c|c|c|c|c|c|c|c|}
\hline \multirow{4}{*}{ Country } & \multicolumn{14}{|c|}{ Mediterranean Gas Competitiveness rating 2014} \\
\hline & \multicolumn{5}{|c|}{ LNG INFRASTRUCTURE } & \multicolumn{5}{|c|}{ PIPELINE INFRASTRUCTURE } & \multicolumn{3}{|c|}{ COMMERCIAL } & \multirow{3}{*}{$\begin{array}{l}\text { OVERALL } \\
\text { RATING } \\
120\end{array}$} \\
\hline & \multicolumn{4}{|c|}{$\begin{array}{l}\text { LNG Terminals \& Send Out } \\
\text { (bcma) }\end{array}$} & \multirow{2}{*}{$\begin{array}{l}\text { LNG } \\
\text { Attract } \\
\text { Rating } \\
16\end{array}$} & \multicolumn{3}{|c|}{$\begin{array}{c}\text { International } \\
\text { Connection Points }\end{array}$} & \multirow{2}{*}{\begin{tabular}{|c} 
National \\
Grid \\
Flex \& \\
constraint
\end{tabular}} & \multirow{2}{*}{$\begin{array}{c}\text { Pipe } \\
\text { Rating } \\
\text { /8 }\end{array}$} & \multirow[b]{2}{*}{$\begin{array}{l}\text { Hub } \\
\text { Trading }\end{array}$} & \multirow[b]{2}{*}{$\begin{array}{c}\text { Cultural } \\
\text { readiness }\end{array}$} & \multirow{2}{*}{$\begin{array}{c}\text { Comm } \\
\text { Rating } \\
16\end{array}$} & \\
\hline & Total & Med & $\begin{array}{c}\text { Capacity } ! \\
\text { Demand }\end{array} \mid$ & $\begin{array}{l}\text { Imports! } \\
\text { Demand }\end{array}$ & & \begin{tabular}{|c|} 
Numb \\
count \\
Import \\
and \\
Export \\
Expote
\end{tabular} & \begin{tabular}{|l|} 
er of \\
tiries \\
$\begin{array}{c}\text { Export } \\
\text { only }\end{array}$ \\
\end{tabular} & $\begin{array}{l}\text { Export } \\
\text { capacitites } \\
\text { (EWh/d) }\end{array}$ & & & & & & \\
\hline Spain & 860.1 & 337. & $7229 \%$ & $39 \%$ & 2 & 4 & 2 & $\sim 340$ & $\begin{array}{l}\text { Fair but } \\
\text { ES/FR }\end{array}$ & 5 & $\begin{array}{l}\text { No } \\
0\end{array}$ & $\begin{array}{c}\text { Poor } \\
0\end{array}$ & 0 & 7 \\
\hline France & 323.8 & 213. & $266 \%$ & $16 \%$ & 3 & 5 & $\begin{array}{l}2+ \\
2 v\end{array}$ & $\begin{array}{l}393+ \\
1138 v\end{array}$ & $\begin{array}{l}\text { Fair } \\
\text { but } \\
\text { N/S }\end{array}$ & 6 & $\begin{array}{c}\text { Yes } \\
3\end{array}$ & $\begin{array}{c}\text { Fair } \\
1\end{array}$ & 4 & 13 \\
\hline Italy & 315.4 & 315. & $427 \%$ & $7 \%$ & 5 & 4 & $\begin{array}{l}1+ \\
1 \mathrm{v}\end{array}$ & $\begin{array}{l}191+ \\
633 v\end{array}$ & $\begin{array}{l}\text { Good } \\
\text { but } N \\
\text { flow }\end{array}$ & 7 & $\begin{array}{c}\text { Yes } \\
3\end{array}$ & $\begin{array}{c}\text { Fair } \\
1\end{array}$ & 4 & 16 \\
\hline Greece & 15 & 15 & $185 \%$ & $18 \%$ & 4 & 2 & 0 & zero & $\begin{array}{l}\text { Poor } \\
\text { and no } \\
\text { export }\end{array}$ & 2 & $\begin{array}{l}\text { No } \\
0\end{array}$ & $\begin{array}{l}\text { Poor } \\
0\end{array}$ & 0 & 6 \\
\hline
\end{tabular}

Sources: GIIGNL 2015; BP 2015; IEA Dec 2014; Honoré (2014).

NOTE: ' $v$ ' = 'virtual'.

In summary, the Mediterranean region (Spain, France, Italy and Greece), imports gas (whether LNG or pipeline gas) from a number of different sources. Their respective 'competitiveness' for attracting additional supplies and therefore the feasibility of them being able to establish a regional gas hub in their country is examined below. Table 2 provides an overview of each country's competitiveness in attracting gas, split between LNG and pipeline supply and the propensity to support commercial gas trading.

The Table assesses and scores:

- the existing capacity compared to overall gas demand;

- the share of LNG in the overall gas demand;

${ }^{168}$ FEEM (2014), p.2, (part of) Summary. 

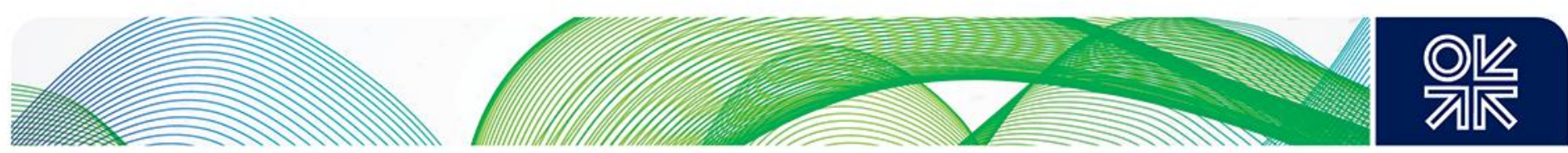

- the number of international import and export pipeline connections;

- the export capacities and the flexibility of the national gas grids and whether there are any major constraints;

- whether there is already gas hub trading;

- $\quad$ and the perceived cultural readiness to trade.

In each LNG and pipeline category we have assigned a value between 0 and 2; in the commercial categories, the score is between 0 and 3 . The maximum score is 20 .

What is immediately apparent from this analysis is that Spain and Greece register a low score, France a mid-ranking score and Italy the highest with 16/20. These results suggest that both France and Italy have the right framework in place to attract additional LNG supplies and Italy could attract more pipeline supplies. However, the overall need for more gas in Europe will be a large determining factor (whether due to demand recovery or continuing decline in domestic production), as well as global supply/demand factors and prices.

The following summarises the prospects for the development of national or regional hubs in central, southern, eastern and south east Europe:

- Central Europe: This region is 'sandwiched' between the 'old' and 'new' worlds in gas trading terms, as well as being a vital transit area into western Europe for Russian gas. If the VTP/CEGH does achieve its goal of truly becoming a Central European gas hub then it is certainly possible that it could represent a benchmark for gas supplies to Austria, Slovakia, Czech Republic, Hungary, Slovenia and, possibly, Italy (but see below).

- Southern Europe: It is very unlikely that Spain and Italy would ever be linked via sufficient pipeline infrastructure to become effectively 'linked' gas markets:

- Spain's gas market is isolated geographically and commercially from the rest of Europe, its traded market is struggling to get started and the country is over-contracted with supplies of LNG and pipeline gas, mainly from North Africa. At present, it could be deemed to be a separate region in the context of the Gas Target Model.

- Italy on the other hand is better connected to the rest of Europe by pipelines as well as having a variety of imported pipeline gas sources from the south and LNG import facilities. It currently meets most of its imported gas requirement through the two major pipelines from the north (the TAG from Baumgarten, today bringing Russian LTC gas (but this could change), and the Transitgas pipeline from Switzerland, bringing North Sea and Dutch gas via the TENP line and the French connection). An important potential development in Italy's development as a benchmark hub are plans to build reverse flow capacity into the Transitgas pipeline ${ }^{169}$ which could see gas imported to Italy from Algeria, Libya, LNG (and possibly Southern Corridor gas) in future flowing to northern Europe. Italy already has a diverse gas supply portfolio and this could become even more flexible in future, putting it in a good position to be a regional hub.

- $\quad$ Eastern Europe: There is still very little trading of gas in Eastern Europe, with the majority of supplies being met from LTCs from Russia. However, there have been important moves to create a more diverse gas supply to Poland, to Lithuania and the region generally, as described in the Baltic Region section above. At present the prospect of a vibrant traded gas market in eastern Europe seems a distant one, but there is certainly scope, in time, for a regional hub here.

- South East Europe: Both Greece and Turkey have expressed interest in developing their gas markets and in providing a gas hub for the region. Until now however, there have been many political, commercial and logistical reasons why this is not really practical. The likelihood of creating trading potential and attracting sufficient interested trading market participants at present

\footnotetext{
${ }^{169}$ Petro Industry News, February 29 2 th 2012 : "Transitgas pipeline could flow south to north": http://www.petroonline.com/news/flow-level-pressure/12/breaking news/transitgas pipeline could flow south to north/18916/
} 

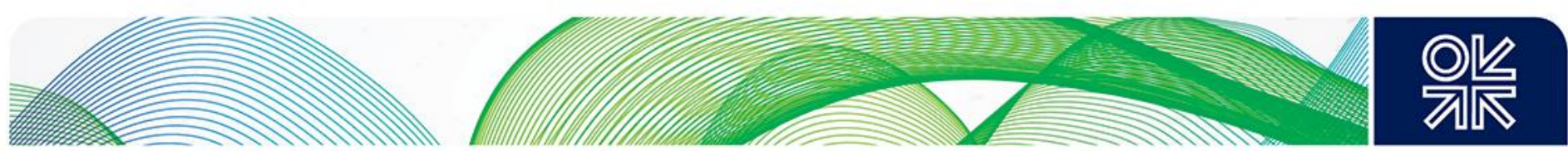

appears low, primarily due to a lack of infrastucture and supply optionality. There are several pipeline connections planned in future which could alter the situation, as well as the prospect of large quantities of Russian gas post 2020, but the formation of a market is still unlikely to happen in the curreny decade. In the meantime, it is more feasible that south eastern Europe will have gas priced at a differential (i.e. higher) to that of the the other regional hubs, such as Italy, central Europe or even eastern Europe, due to lack of competition.

What is clear is that all countries will have at least to establish a 'balancing' hub in order to allow the TSO to balance the gas grid. This however in itself is insufficient to encourage significant trading activity. Whether some of these hubs can transition to become 'marker' hubs (from which physical contracts can be priced), or whether some may merge to form regional Market Areas (which would set prices in their region), is yet to be seen.

The Author believes that there is room in Europe for perhaps two to four such additional hubs, which in turn may provide regional benchmark prices for physical contracts.

This however requires qualification. It is already apparent that the existing North West European hubs are closely correlated in price ${ }^{170}$ which suggests that the industry has already accepted two benchmark hubs (the NBP and TTF), from which contracts can be priced either directly or through basis differentials ${ }^{171}$.

The prospects of a gas hub developing in the Balkans, South East Europe or the Mediterranean region are dependent on two factors:

- $\quad$ That there is a real willingness for it to succeed on the part of key stakeholders ${ }^{172}$

- And that the prospect of significant flows of gas entering the EU through the region creating their own market dynamics, will provide the trading community with the confidence to support and develop such a hub that could in turn provide pricing signals for the underlying physical volumes.

Until this proposition is proved or disproved by events, the possibility of a Mediterranean gas hub is very much alive.

\subsection{Functioning of European gas hubs: surveys and market analyses}

This section will examine external surveys and market analyses concerning the development of the European traded gas hubs. Firstly a questionnaire sent out by $A C E R^{173}$ in early 2014 , along with its published responses. Secondly, the analysis performed on the ACER questionnaire by the Austrian consultancy, Wagner, Elbling and Company. Thirdly, a summary of the findings of the 2015 EFET174 Gas Hub Development Study is assessed. Finally, a review is provided of two pieces of academic analysis: the "Price de-linkages between European gas hubs" by Beatrice Petrovitch; and the "Leaders and Followers: the 'Starlings theory"' by Sybren de Jong.

\footnotetext{
170 See section 5.3.2 and Figure 11.

${ }^{171}$ Basis trading is very common in the oil world where different grades of crude are priced at a differential to one or other of the benchmark crudes, usually Brent or WTI. It is also the way in which the north American gas hubs trade against the Henry Hub. 172 "The EU wants to create a Mediterranean gas hub in the South of Europe to help diversify its energy suppliers and routes": https://ec.europa.eu/energy/en/topics/imports-and-secure-supplies/gas-and-oil-supply-routes

${ }_{173}$ Agency for the Cooperation of Energy Regulators.

${ }^{174}$ European Federation of Energy Traders.
} 

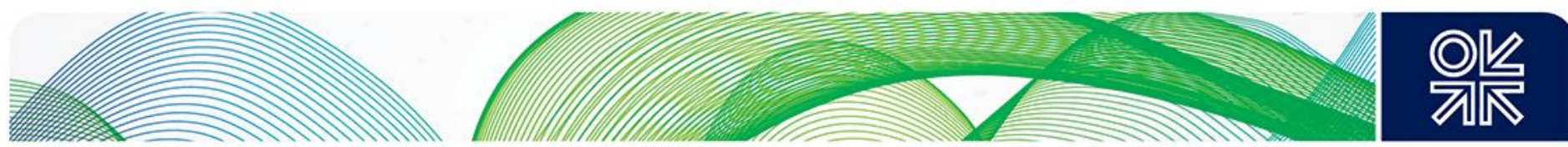

\subsubsection{ACER questionnaire}

In Q1-2014, ACER conducted a survey ${ }^{175}$ amongst European gas market participants on the functioning of European gas wholesale markets. The questionnaire was distributed via various mailing lists (EFET, Eurogas, ACER, FSR) and feedback was received from about twenty respondents with a variety of backgrounds (producers, wholesalers, suppliers, traders, large end users, etc.).

ACER's focus was the brokered OTC markets, due to their overwhelming importance in all markets except the NBP; and covered every European hub in existence at the time: NBP, TTF, NCG, GPL, ZEE, ZTP, PEG N, PEG S, PEG T, VTP, PSV, VOB, AOC (MS-ATR), GTF, as well as the emerging hubs in Slovakia, Poland, Ireland and Hungary.

It posed one simple question: "To what extent are stakeholders' requirements met by today's (2013) traded gas wholesale markets in Europe"? It then analysed the results to examine three important points: Market Access; Ability to Transact; and Traded Market Concentration.

The ACER survey relates to the situation at the end of 2013; however, analysis in this paper suggests that the resulting 'ranking' of the hubs stayed relatively stable during 2014. The results of the survey were wholly as expected: for example, the NBP came 2nd, 3rd, 1st respectively; and the TTF 1st, 1st, $6^{\text {th }}$ on the three questions posed. The graphical results are shown in Figures 23, 24 and 25.

Figure 23: Market access: ease and difficulty of finding trading partners

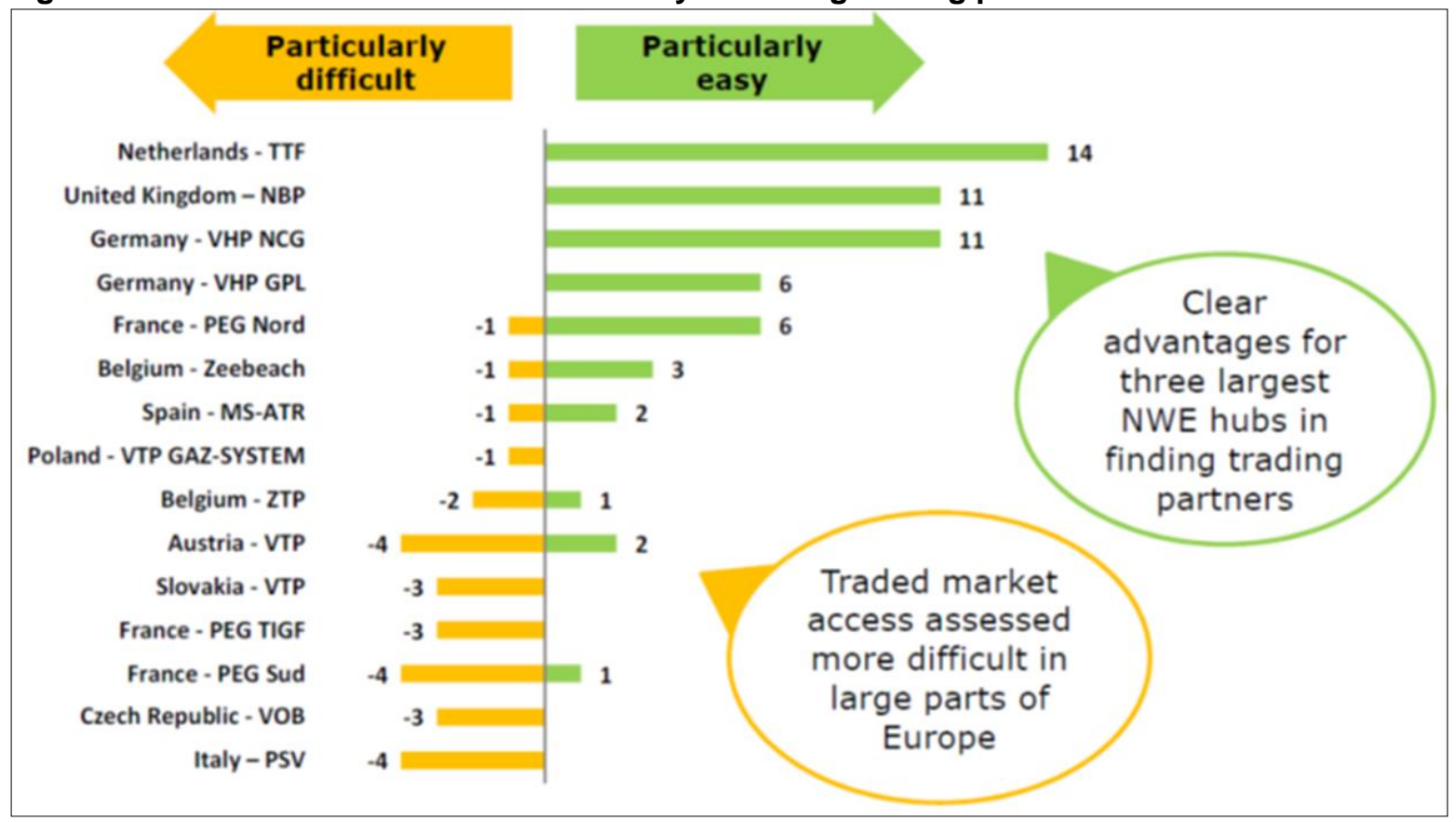

Source: ACER presentation at the $2^{\text {nd }}$ ACER GTM workshop, Ljubljana, 19 March 2014.

The Market Access results (Figure 23) show that the two leading European hubs have the highest score, as would be expected, although it is perhaps surprising that the NBP is second. This is almost certainly due to the way in which OTC gas trades in Britain, where a party must be a Shipper registered with Ofgem to be allowed to transact on the standard NBP'97 Contract. This requirement probably deters a number of participants, especially Continental players who do not want the cost and

\footnotetext{
${ }^{175}$ http://exploredoc.com/doc/1696275/03-boltz-forward-markets-questionnaire-results---acer
} 

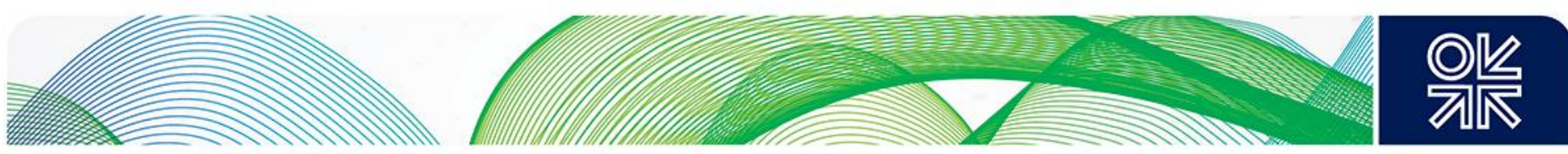

effort of having to go through the registration process. This is also a reason why exchange trading has steadily been rising as a percentage of the total traded volumes since 2010/11 in Britain. The two German hubs have a lower score but no negative points.

The first hubs in the list to have negative (-1) scores attributed to them are the PEG Nord, Zeebrugge, AOC and VPGS, but their final net scores were 5, 2, 1 and -1 respectively. All the remaining hubs had an increasing negative score and only two, VTP and PEG Sud had a small positive score; however, they all had a final net negative score.

The next criterion was the Ability to Transact at fair prices whenever required (Figure 24) and a similar pattern emerges: The Dutch TTF once more is first but the NBP is now 3rd between the two German hubs. This is again probably a reflection that there are many more participants trading on the ICE exchange today than OTC on the NBP hub.

Peg Nord and Zeebrugge are mid-ranking with AOC, VTP, PSV, PEG Sud and ZTP towards the bottom, indicating that they are illiquid markets. All the remaining hubs did not score.

Figure 24: Ability to transact: at fair prices whenever required

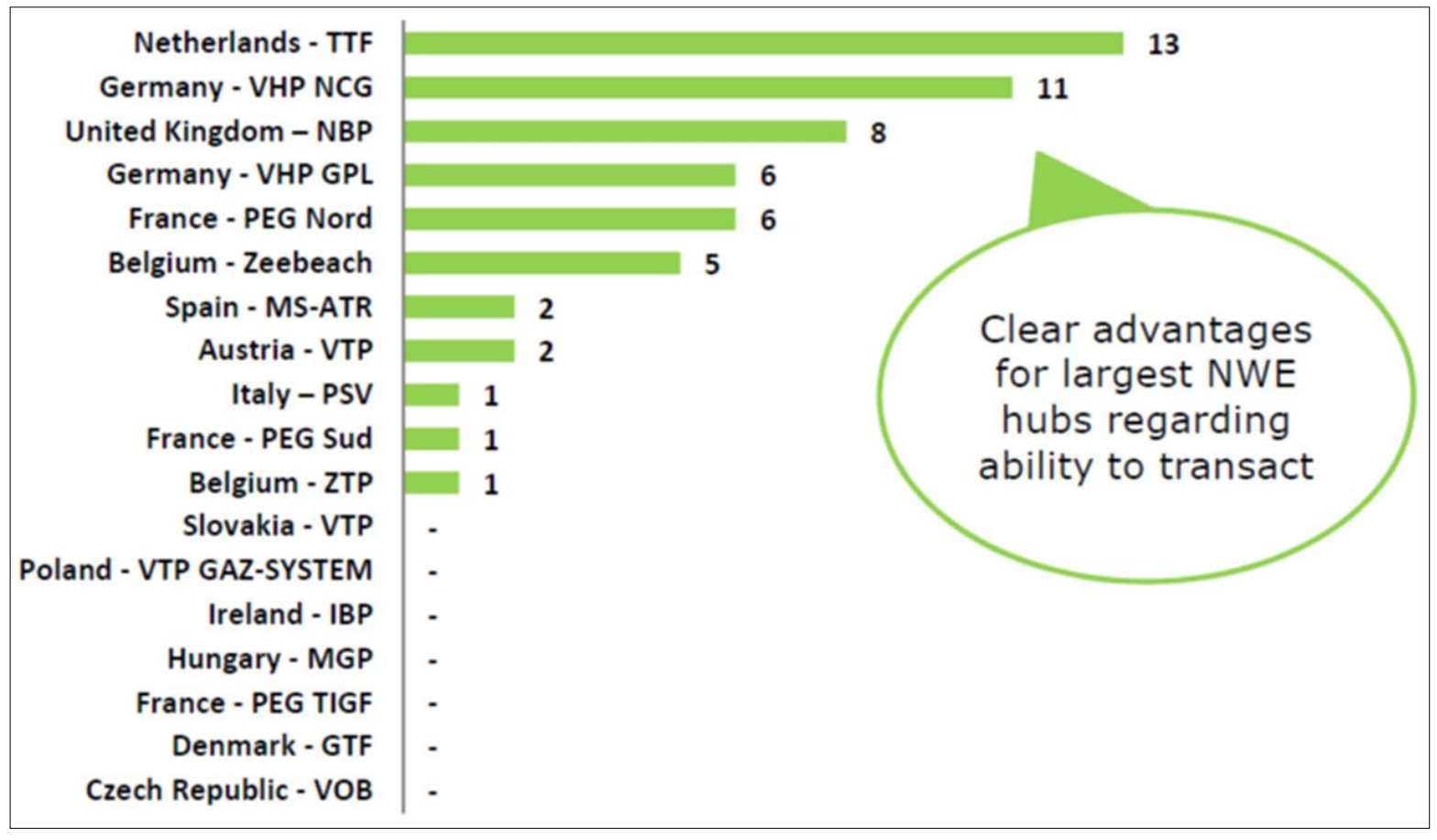

Source: ACER presentation at the $2^{\text {nd }}$ ACER GTM workshop, Ljubljana, 19 March 2014.

The final point surveyed was the Market Concentration (Figure 25) of the top three sellers at each of the hubs. Only the British NBP comes in below $50 \%$ (the criterion set in the Gas Target Model as the benchmark for developing free and competitive gas hubs). The Dutch TTF registers a rather mediocre score of over $65 \%$, mainly due to the dominance of GasTerra's trading at that hub; the PEG Nord is alongside the emerging Slovak hub just within the middle band with $75 \%$.

In the red zone are the PSV, the other two PEGs (both with over $80 \%$ market concentration), the Czech and Polish hubs. This last grouping consists of hubs that are neither liquid nor competitive and are difficult to access. 

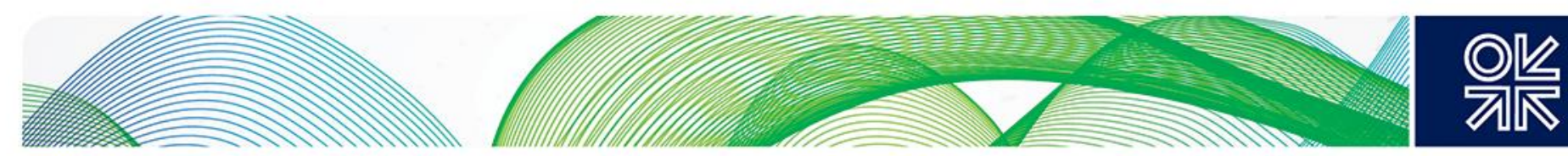

Figure 25: Traded market concentration: of top three sellers in each hub

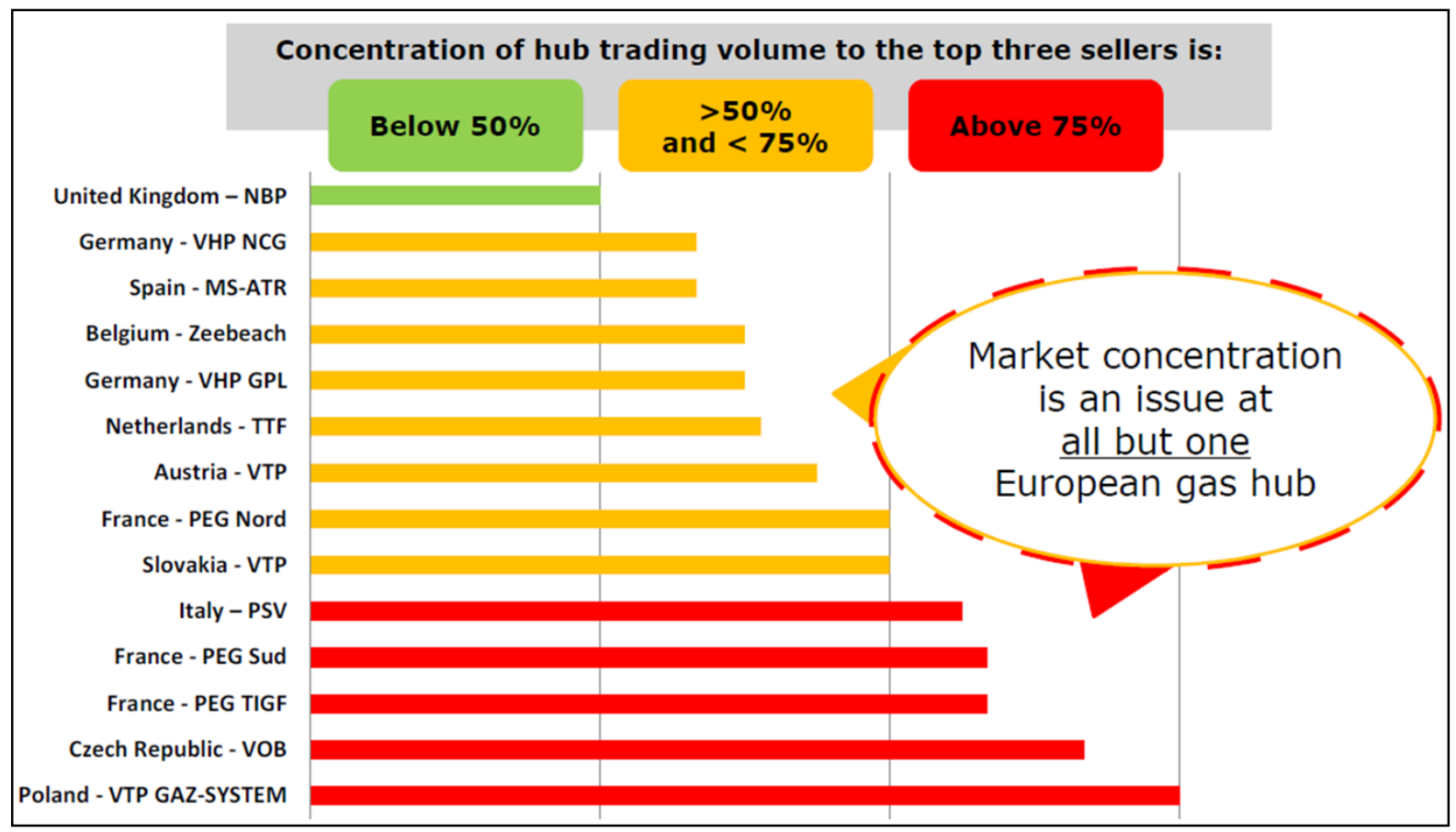

Source: ACER presentation at the $2^{\text {nd }}$ ACER GTM workshop, Ljubljana, 19 March 2014.

Figure 26: Demand of respondents on deal frequency, liquidity and liquid trading horizons

Price relevance threshold:

Minimum number of deals required per product/hub/trading-day so that price signal can be considered trustworthy.

Liquidity threshold:

Minimum amount of gas

simultaneously offered/requested (ask/bid) for a product on a hub so that product is considered "liquid".

\section{Liquid trading horizon:}

Minimum time horizon within which trading in gas standard products should be possible with the market being in a liquid state.

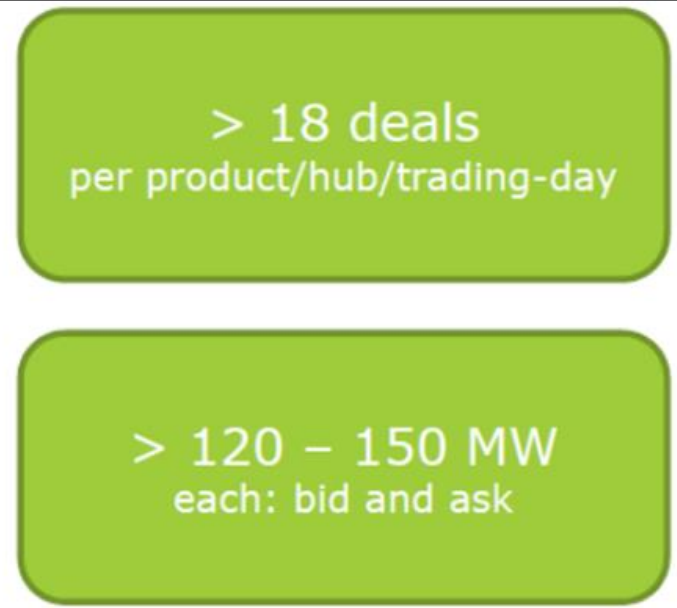

Source: ACER presentation at the $2^{\text {nd }}$ ACER GTM workshop, Ljubljana, 19 March 2014. 

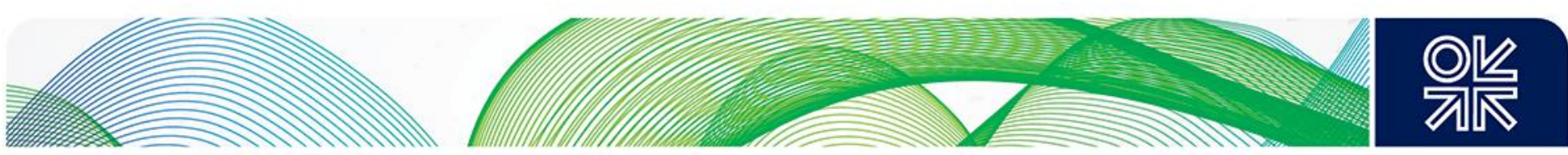

Interestingly, the document then set out three important criteria based on the demands of the respondents on: deal frequency, liquidity and liquid trading horizon. These are shown in Figure 26.

It is interesting to note that respondents have 'wished' for these trading criteria but from the results of the survey are collectively clearly not practising them! This is similar to the situation in Britain in the1996-98 period as NBP developed.

The results of the ACER survey, albeit capturing the views of only about 20 market participants who responded, do show that the NBP, TTF and NCG are the top three hubs in the first two categories, with the NBP being the only hub meeting the market concentration criterion. There are a couple of mid-market hubs, GPL and ZEE and also, very surprisingly, the AOC, but this is most likely due to the very different nature of that market, trading mainly locational and time swaps of gas, often without a price. The PEG Nord fares well in the first two categories due to the very liquid spot and prompt market but its poor score in market concentration refelects the illiquid nature of the forward curve, dominated by the top three participants.

\subsubsection{Wagner, Elbling and Company's analysis}

This Austrian consultancy made a quantitative study of the 2013 hub traded volumes with regard to the demands of respondents cited in the ACER survey results and this was presented in Brussels in May 2014 and published ${ }^{176}$ on the ACER website.

Figure 27: Price discovery: deal count per day vs. trading horizon

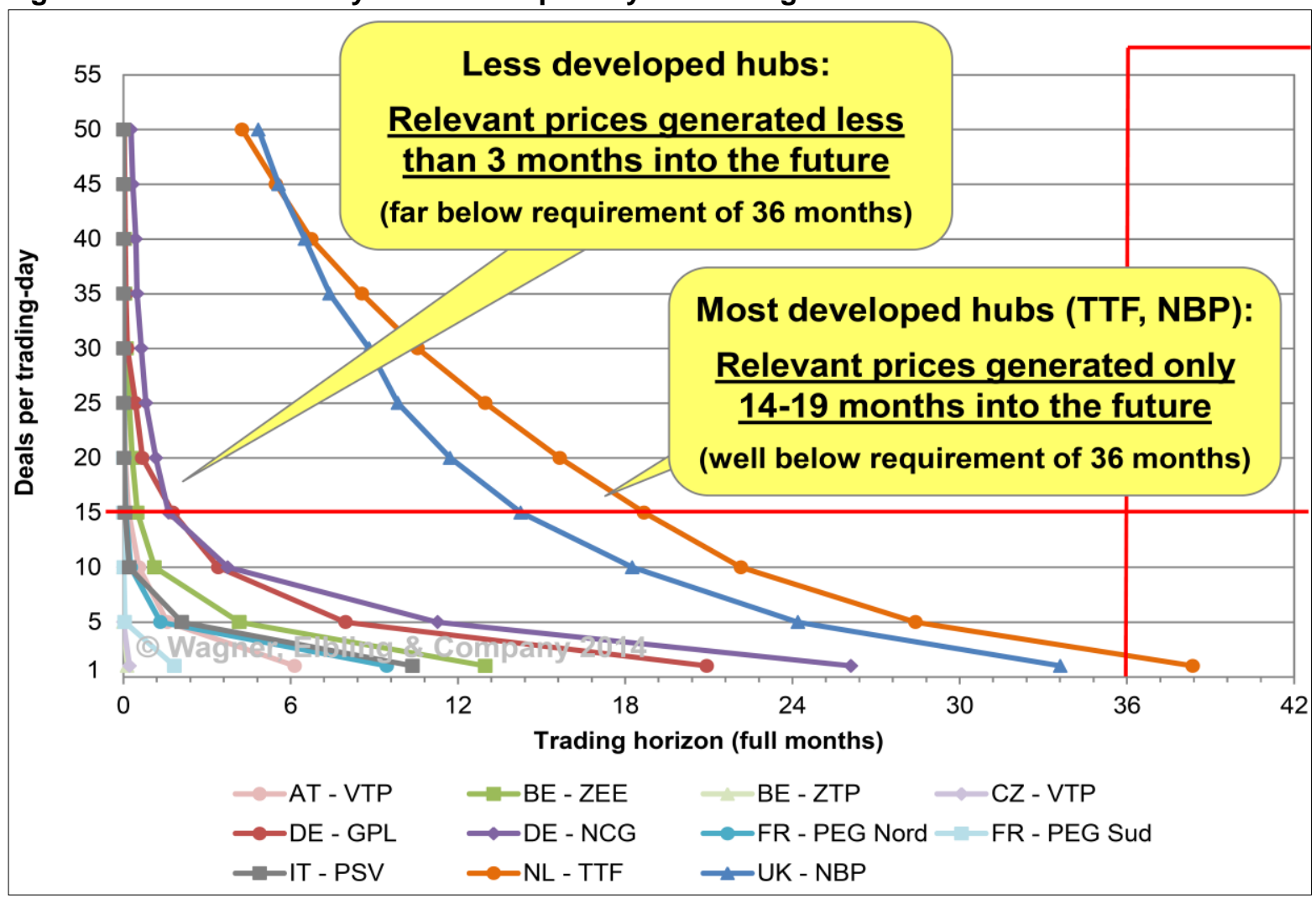

Source: Wagner, Elbling and Company: Functioning of European Gas Wholesale Markets, 15 May 2014.

${ }^{176}$ http://www.acer.europa.eu/Media/Events/3rd-Gas-Target-Model-StakeholdersWorkshop/Documents/04.\%20Wagner\%20WEC\%20-\%20Functioning\%200f\%20Gas\%20Markets\%20\%20Albrecht\%20WAGNER\%20140515.pdf 

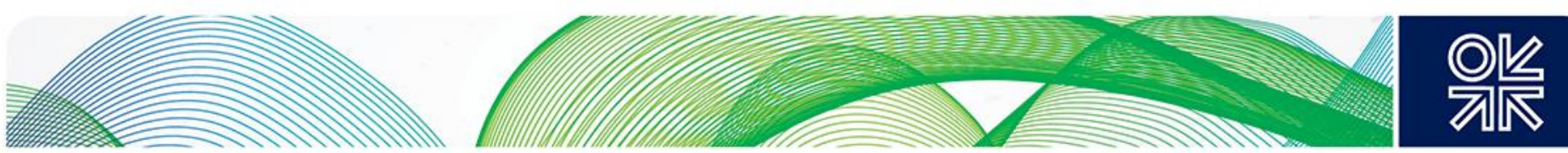

The results in the graphs are plotted using OTC traded data only (not exchange data) which is representative of all but the NBP (as that hub has a very large proportion ${ }^{177}$ of exchange trading). Not only does exchange trading account for a large share of the NBP total but that trading is quite evenly split along the trading curve. Therefore, the results for the NBP would in both cases be higher and more to the right of the graphs in Figures 27 and 28, if exchange volumes were included.

The overall market share of exchange trading at the TTF was $9 \%$ in 2013 and is also spread across the curve; the results for TTF would therefore be slightly higher and more to the right in the same graphs if exchange volumes were included. For the French PEG Nord market, the exchange share was a high $21 \%$ of the total; the major difference compared to NBP and TTF is that most of the PEG Nord exchange trading is in the spot/prompt contracts. Therefore, the results would barely change if the PEG Nord exchange volumes were included.

Figure 27 shows the trading activity set as recorded by the number of deals (rather than the actual volume) against the trading horizon, which would indicate that the price signal for a given contract can be considered trustworthy. The minimum number of deals required per product/per hub/per trading day was given as 18 by the respondents to the survey; this is shown by the horizontal red line. The minimum time horizon within which trading in gas standard products should be possible, with the market being in a liquid state was set at 36 months; this is shown by the vertical red line.

Figure 28: Availability of gas: offered volumes vs. trading horizon

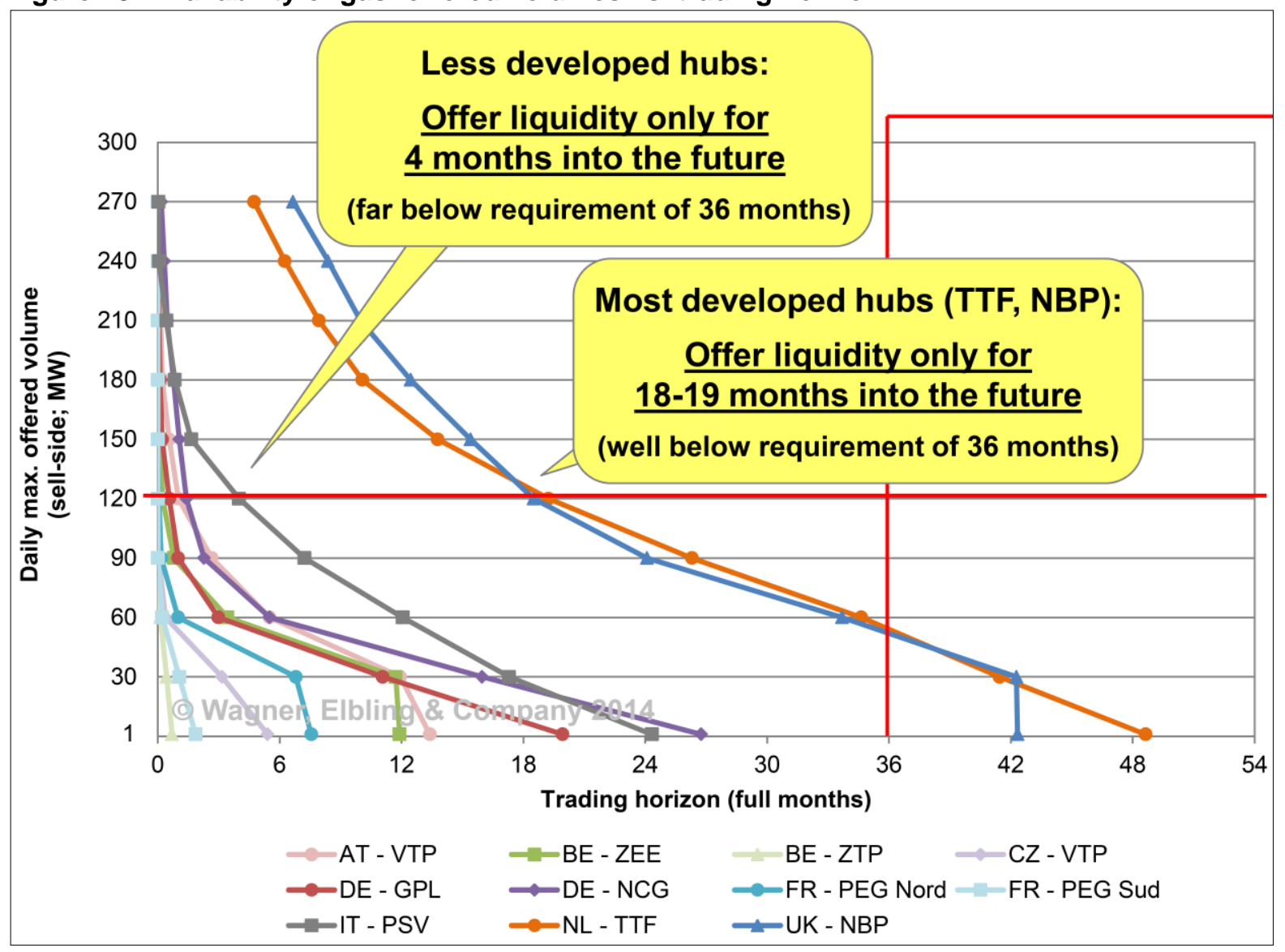

Source: Wagner, Elbling and Company: Functioning of European Gas Wholesale Markets, 15 May 2014. 

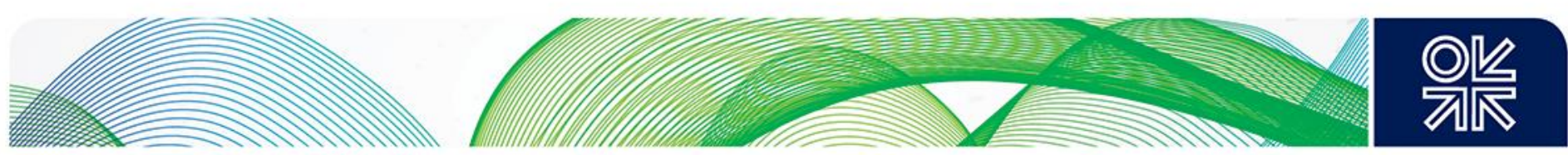

What is clear to see is that the NBP and TTF are far ahead of all the other hubs, but even these two hubs don't quite make the prerequisite threshold. The two German hubs are next, followed by Zeebrugge and, tucked tightly in the bottom left hand corner are the PSV, PEG Nord, VTP, PEG Sud and VOB. These markets have very low trading volumes and what volumes do trade are limited to the spot and prompt. The PEG TIGF is not represented in the results as there is insufficient trading data to analyse: this hub has very few daily trades on just a very limited range of contracts (mainly spot) and does not trade in forward contracts beyond the first month.

Figure 28 shows the market depth set against the trading horizon, a measure of liquidity. The minimum amount of gas simultaneously offered/requested (ask/bid) for a product on a hub was given as $120 \mathrm{MWh}$ by the respondents to the survey; this is shown by the horizontal red line. The minimum time horizon within which trading in gas standard products should be possible, with the market being in a liquid state was set at 36 months; this is shown by the vertical red line.

Once again, NBP and TTF are far ahead of all the other hubs, but even these two hubs don't quite make the prerequisite threshold. Mid-ranking are the PSV, NCG, VTP, GPL and ZEE hubs. In the bottom left hand corner are the PEG Nord, VOB and PEG Sud. These markets are illiquid except PEG Nord in the spot (within-day and day-ahead contracts).

It must be stressed that this analysis was carried out with the 2013 traded volumes and only those traded on the OTC markets. However, the results are very telling: the NBP and TTF hubs are clearly far in front of all the other traded gas hubs and several of the hubs barely feature at all in the context of these findings.

\subsubsection{EFET Gas Hub Development Study}

The European Federation of Energy Traders (EFET) is an organisation that promotes and facilitates European energy trading in open, transparent, sustainable and liquid wholesale markets, unhindered by national borders or other undue obstacles. They have produced ${ }^{178}$ an informative booklet entitled "Towards a single European energy market", in which they describe their statement of activities as being to 'improve the operation of European wholesale energy markets and enhance the performance of traders and their support functions in those markets. We reinforce the markets' functionality and facilitate their liquidity and transparency'.

EFET does this by providing standard solutions to the repetitive aspects of wholesale energy transactions, such as contracting and data exchange; advocating policies and regulatory measures; and encouraging probity, good risk management practices, responsible corporate governance and proper accounting among energy traders.

The standardisation and harmonisation of energy contracts and electronic data exchange are prerequisites for optimising the potential benefits of the liberalisation of the European energy industry.

As part of their activities they have published the EFET European Gas Hub Development Study and the 2015 Review of Gas Hubs Assessments ${ }^{179}$. The Study "emerged from an observation that many new virtual trading points and gas hubs were being implemented across EU and in connected markets, in very different ways. We applaud the development of Entry/Exit systems and hubs as these bring significant benefits to consumers and markets. However, differences in implementation result in increased transaction costs (for both traders and hub operators) and risks, and unnecessary levels of operational complexity, which will ultimately reduce the overall benefits derived from the Internal Energy Market".

\footnotetext{
178 http://www.efet.org/Cms Data/Contents/EFET/Folders/Documents/Home/ contents/GPC2TV6X8L2STWT8/Highlights-IIFinal.pdf

179 "2015 Review of Gas Hubs Assessments": http://www.efet.org/EnergyMarkets/VTP assessment
} 

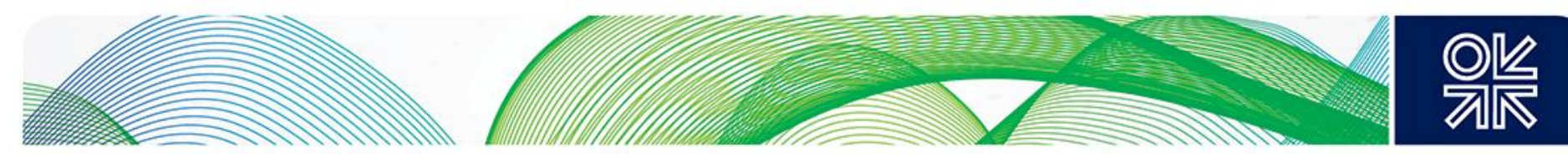

The Review was used to create Table 3, which summarises the scores awarded by EFET to each of the traded gas hubs in Europe, including the emergent hubs. They assess 17 criteria regarding the development of a hub for which they give a score of $0-2^{180}$ out of a possible total of 20 .

The results show that, in line with the other analyses reported in this section and the Author's analysis of the traded hubs in section 6, the two dominant hubs in Europe are the British NBP and the Dutch TTF; but the EFET assessment also gives credence to the two German hubs and to the Belgian Zeebrugge. There are then five more hubs scoring higher than 10/20: the Belgian virtual hub ZTP, French PEGs, Italian PSV, Austrian VTP and Danish GTF; the remaining 11 hubs all score less than 10/20: these are mainly emerging hubs or hubs that have been operational a very short time.

Table 3: EFET Hub Scores H1-2014 and H1-2015

\begin{tabular}{|c|c|c|}
\hline HUB & Score 2014 & Score 2015 \\
\hline NBP & 20 & 20 \\
\hline TTF & 19 & $191 / 2$ \\
\hline NCG & $151 / 2$ & 19 \\
\hline GPL & 16 & 19 \\
\hline ZEE & 18 & 18 \\
\hline ZTP & 16 & $17^{1} / 2$ \\
\hline PEGs & 16 & $16 \frac{1}{2}$ \\
\hline PSV & $101 / 2$ & 15 \\
\hline VTP & 14 & 14 \\
\hline GTF & 9 & $11 \frac{1}{2}$ \\
\hline VOB & 8 & $81 / 2$ \\
\hline$A O C$ & 7 & 7 \\
\hline SK & $31 / 2$ & 7 \\
\hline MGP & 5 & $61 / 2$ \\
\hline GR & 5 & 6 \\
\hline VPGS & $4 \frac{1}{2}$ & $51 / 2$ \\
\hline UDN & $51 / 2$ & 5 \\
\hline RO & $2 \frac{1}{2}$ & $11 / 2$ \\
\hline BG & $11 / 2$ & 1 \\
\hline MIBGAS & 2 & 0 \\
\hline
\end{tabular}

Source: EFET 2015 Review of Gas Hubs Assessments

\subsubsection{Price de-linkages between European gas hubs}

Beatrice Petrovitch published her first in-depth analysis of European gas hubs price correlation in October 2013 ${ }^{181}$, followed by another in September 2014 ${ }^{182}$ and a third in September $2015^{183}$ which

\footnotetext{
${ }^{180}$ See Appendix $\mathrm{K}$ for the assessment table.

181 Petrovitch (2013).

182 Petrovitch (2014).

${ }^{183}$ Petrovitch (2015).
} 

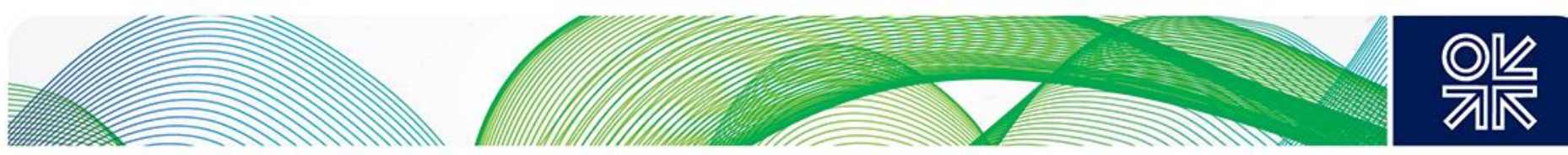

updated the previous two but went into greater detail to provide a more robust analysis of the factors driving price de-linkages between the main European hubs.

For the purposes of this Paper, the important results are those concerning the price correlation between the European traded gas hubs which, along with the other surveys and analyses in this section and the Five Key Elements in section 7, help to give a better overall understanding of the level of development in these hubs.

Figure 29: Cross correlations between OTC day ahead daily prices (Pearson coefficients \%)

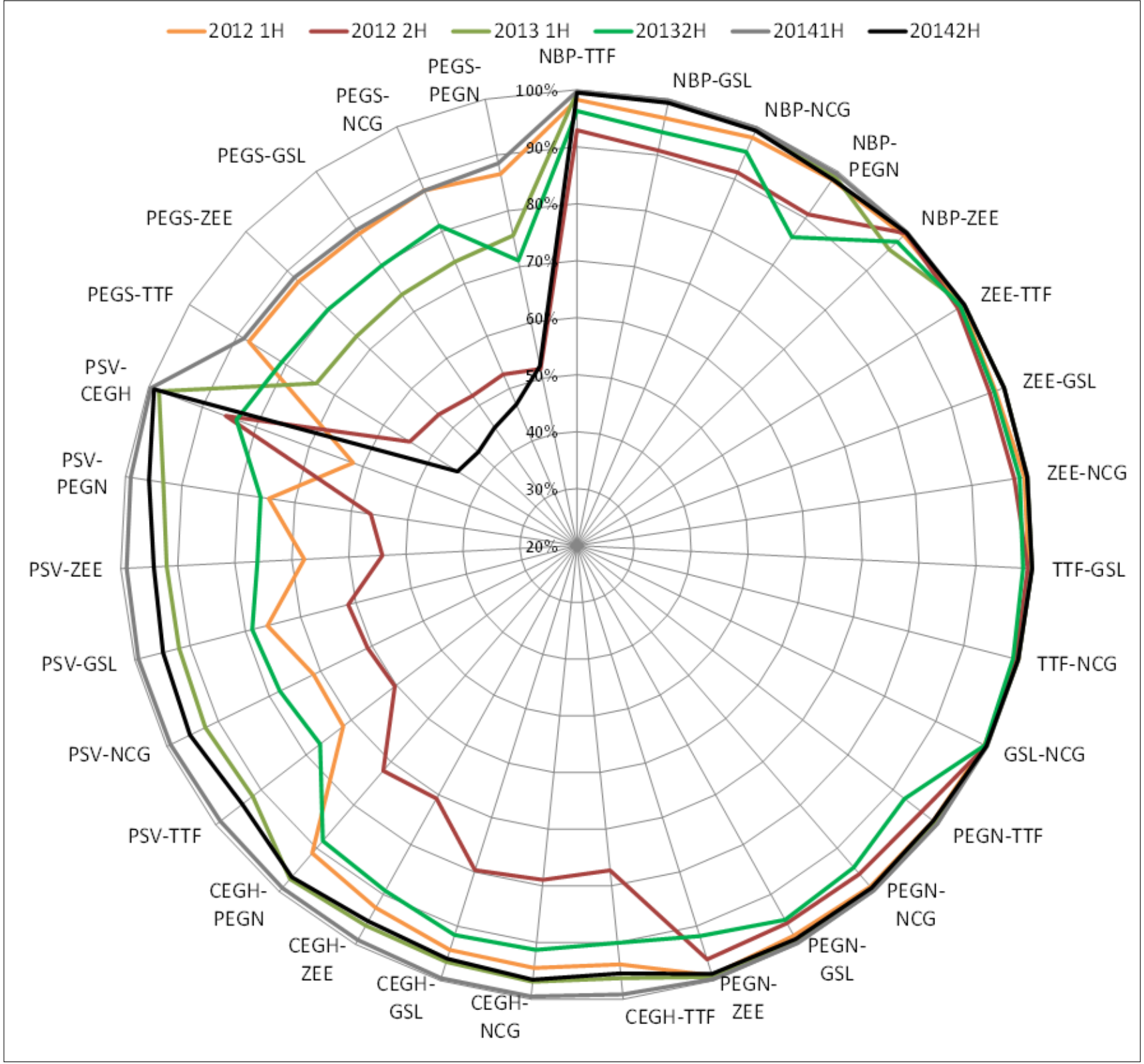

Note: Only correlation coefficients significant at the $5 \%$ level or better are displayed.

Source: Petrovitch (2015)

The methodology she uses is a simple metric to quantify the strength of price alignment (or "linear correlation") between gas hubs: that is the Pearson Product-Moment correlation coefficient. When this score is close to $100 \%$, it indicates the strongest price alignment, meaning that when price in market A goes up by $x \%$, price in market $B$ also goes up by $x \%$, and vice versa. If the Pearson coefficient is 

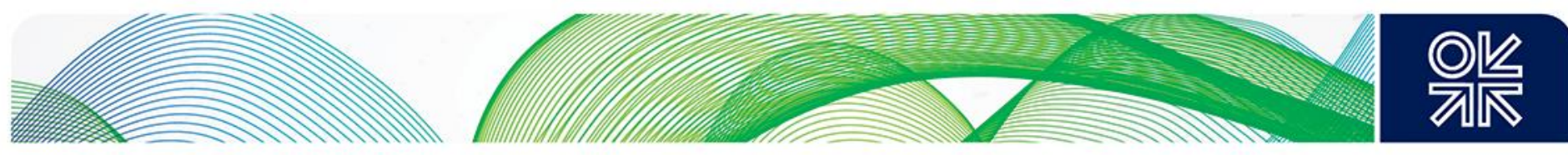

close to zero, the price series are said to be non-correlated. The results are displayed in Figure 29 and show the cross correlations between OTC day ahead daily prices of nine of the traded hubs ${ }^{184}$.

The following are extracts from the conclusions to her paper:

The North West Europe core group (ZEE, TTF, the German hubs and PEGN) stands out as it remains almost perfectly correlated over the whole period (correlation coefficients are stable over time and above 95\%), with these hubs behaving as a single integrated market area. In 2014 the NBP gas prices also moved in tandem with North Western Europe prices.

Periodic de-linkage, however, still occurs at the more peripheral hubs: not just at the PEGS (where the correlation with all the other hubs collapsed in 2014 and in particular in H2-2014 when it was down at 40-50\%), but also, although to a lesser extent, at the Italian and the Austrian hubs. The price disconnection still occurring in the South of France and Austria is due to physical barriers and therefore should be addressed by investing in infrastructure. On the other hand, in the Italian case the policy makers' attention should be on enforcing the rules that optimise the use of existing capacity.

The main gas hubs in Europe are already well integrated but some bottlenecks are still not solved. In order to alleviate such bottlenecks and the related price misalignment, in some parts of Europe investment and new rules on capacity optimization are needed so that transmission capacity is sufficient to allow for the free flow of gas in response to price signals.

As far as the geographical dimension is concerned, it needs to be stressed that this work has focussed on North West, Central Europe and Italy. In Spain and South East Europe hub development is still at an early stage or absent, so that market prices have not developed yet and gas prices in these markets may not be in line with those where gas hubs have already been developed. Once again however, new infrastructure, and especially planned interconnections with markets further north, accompanied by rules for the optimization of the transmission capacity use, can be expected to align these markets with hub prices over the next several years.

It is clear from her analysis that there are four very well correlated hubs: ZEE, TTF, NCG and GPL; then very close to this core can be added the NBP and PEG Nord (in 2014 but less so the previous year). The other pairings are less well correlated with each other and with the 'core' hubs and the PEG Sud has not been correlated with any other hub in the last two years.

\subsubsection{Leaders and Followers: the 'Starlings theory'}

In a forthcoming OIES paper ${ }^{185}$, Sybren de Jong analyses the volume weighted Day Ahead prices of seven European traded gas hubs ${ }^{186}$ for the period January 2011 to December 2014 . He describes a dynamic systems analysis of gas hub prices, in order to quantify the role of gas hubs in the European gas market: as in a swarm of starlings. He asks who is a first mover and who is a follower?

\footnotetext{
${ }^{184}$ For the sake of clarity, some pairs are not included in the graphs, as they refer to less interesting cross correlations: NBPPSV, NBP-CEGH, NBP-PEGS, PEGS-CEGH, PEGS-PSV.

185 deJong $(2015 / 16)$

${ }^{186}$ NBP, TTF, ZEE, PEG Nord, NCG, GPL, CEGH/VTP.
} 

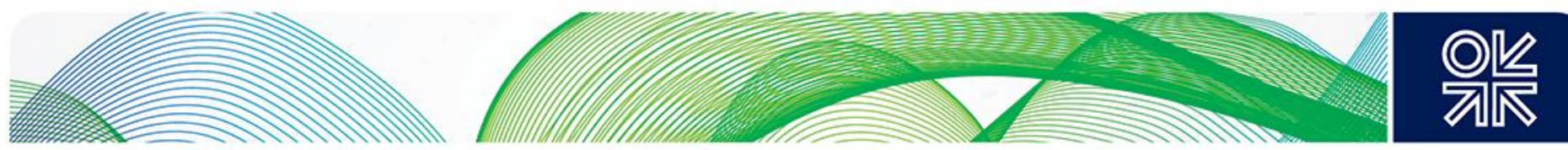

The aim is to categorise neighbouring gas hubs by the role they play in the European gas market, to complement the more traditional indicators such as traded volumes, price volatility, market depth, churn rate, etc., as described in detail in section 7 of this Paper.

The focus of his analysis lies in the dynamics of the gas price, and not on the level of the gas price itself ${ }^{187}$. It can be assumed that all system disturbances, such as maintenance on infrastructure or severe weather conditions, are reflected in the gas price dynamics. Therefore, other input regarding this system information is not required.

The result of the analysis is a matrix with all the parameters that describe the interaction between each of the gas hubs. This matrix is used to determine three parameters: the relative price influence of one gas hub ON other gas hubs; the relative price influence of one gas hub FROM other gas hubs; and the relative price influence of one gas hub from ITSELF.

Figure 30: The influence of one hub on another: graphical representation

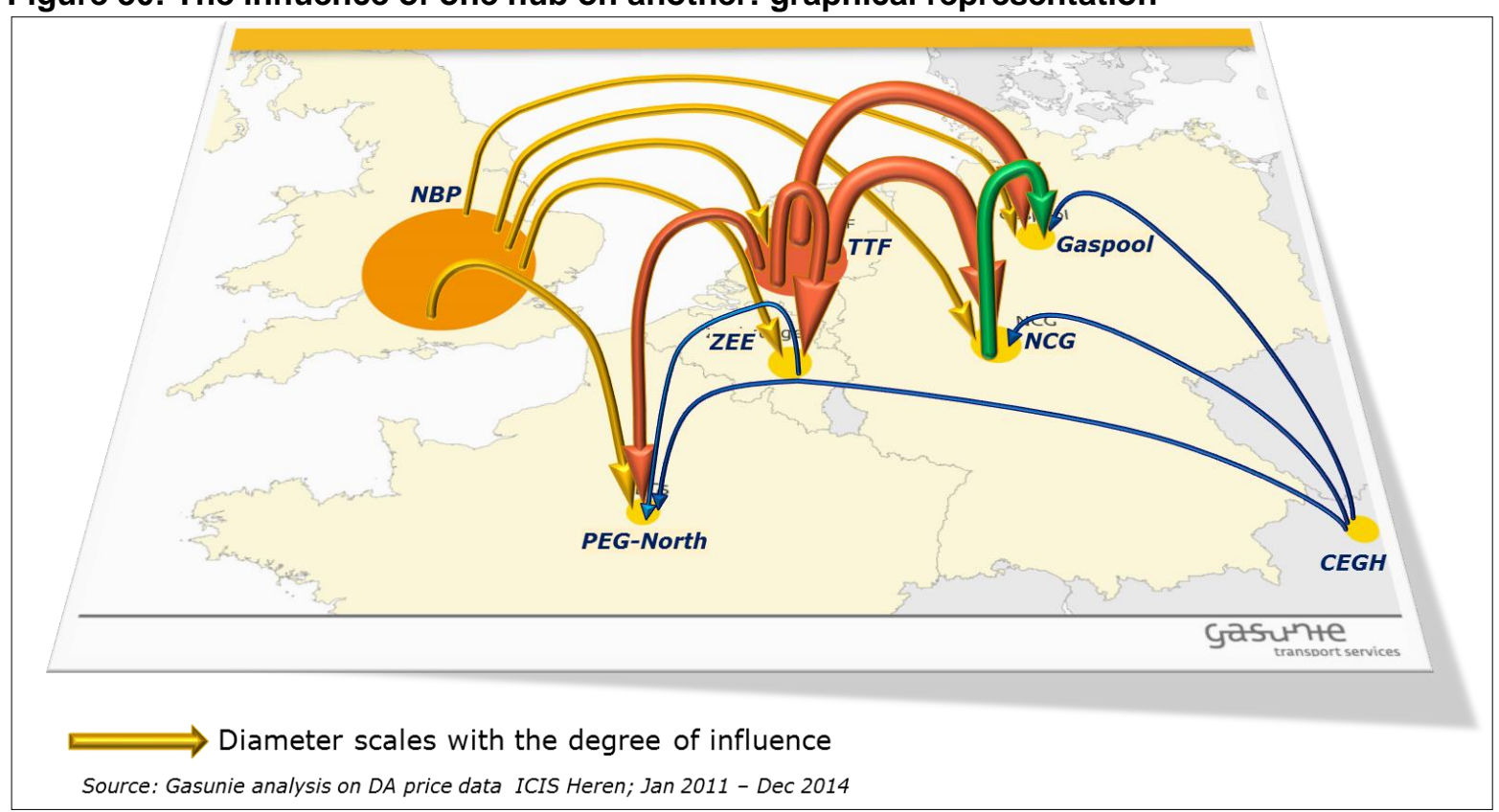

Source: deJong (forthcoming Winter 2015/16)

The influence of one hub on another is clearly shown in the graphical representation in Figure 30, where the direction of the arrows shows which hubs have an influence on another and the size of the arrows scales with the degree of that influence. It can be seen that the NBP and the CEGH/VTP are the only two hubs not influenced by any other and that the PEG Nord and Gaspool are the only two hubs not to have an influence on another.

The numerical results ${ }^{188}$ of the matrix can be displayed in the form of a bar chart (Figure 31), where the green bars show the result of the influence of a hub from itself; the blue bars show the result of the influence on a hub from the others, and the red bars show the result of the influence of a hub on the others. These results are all based on a four-year period of pricing data from January 2011 to December 2014.

\footnotetext{
187 The time series data is described as a Vector Autoregressive model.

188 The precise results and the methodology used are detailed in deJong (2015/16).
} 

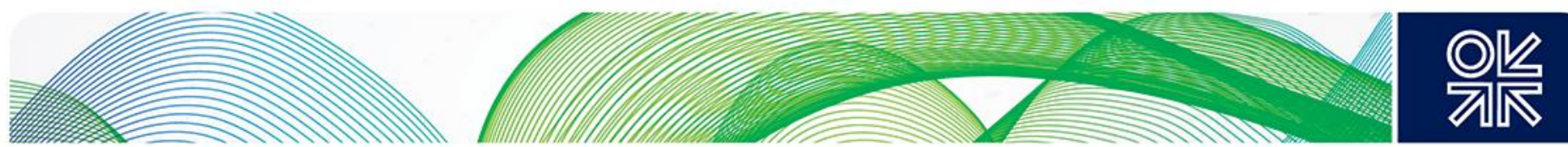

The most pertinent results are:

- That NBP influences itself the most of all hubs with a score very close to '1', or 100\%, closely followed by TTF at about $80 \%$;

- TTF has by far the most influence on the other hubs, around $2 \frac{1}{2}$ more than the second placed hub, NBP, whilst both the PEG Nord and Gaspool have no influence at all on the other hubs;

- Conversely, NBP receives the least influence from the other hubs, closely followed by CEGH/VTP, whilst the two German hubs, NCG and GPL, receive the most influence from the other hubs.

Figure 31: The influence of one hub on another: bar chart

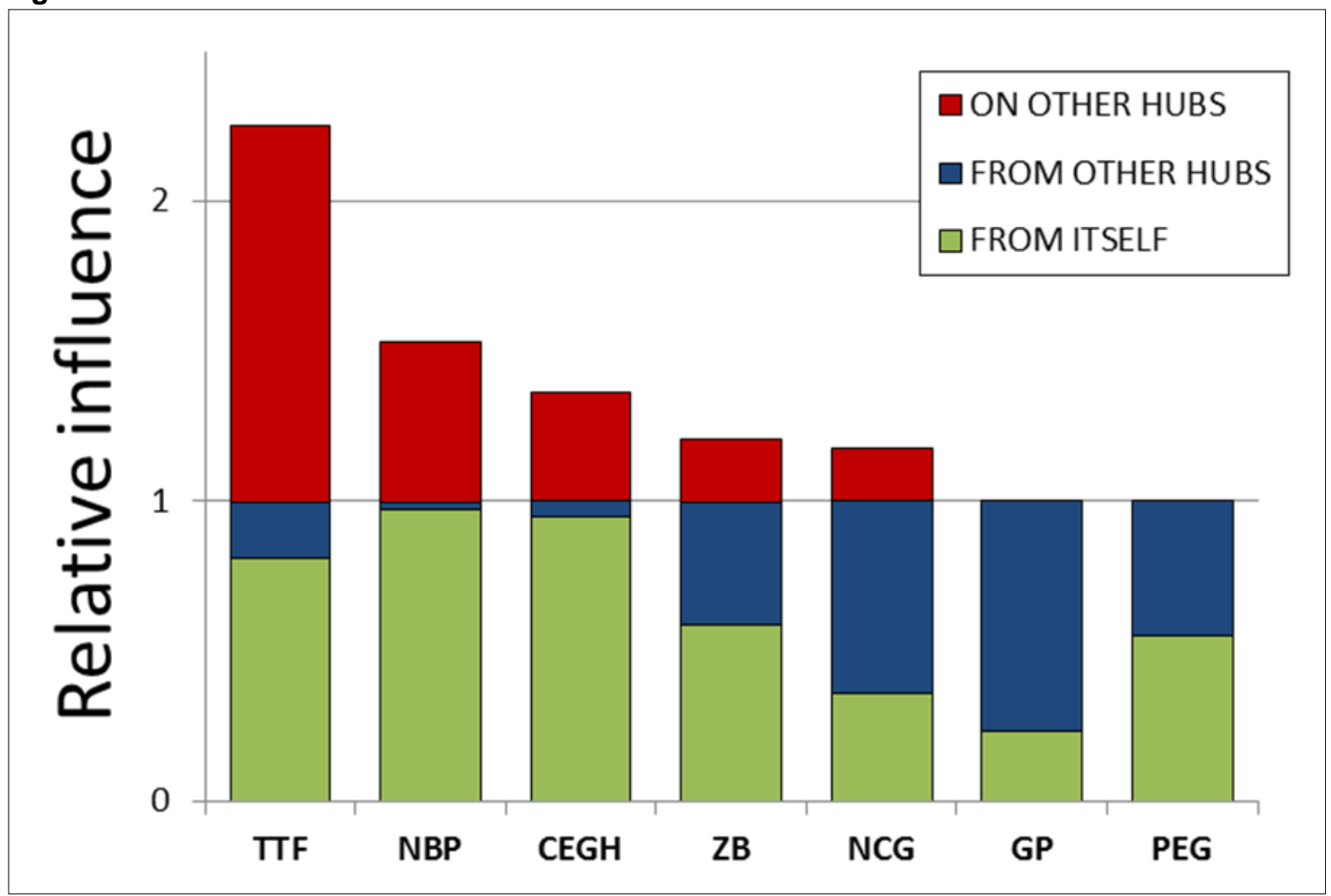

Source: deJong (forthcoming Winter 2015/16)

The results of Sybren's analysis provide a valuable insight into who is influenced by whom, which hub is a 'Leader' and which hub is a 'Follower'?

The final conclusion of his analysis is that there are three 'Leading' gas hubs: the British NBP, the Dutch TTF and the Austrian CEGH/VTP (albeit depending on the physical supply/demand balance). All the other hubs in this analysis are, to a greater or lesser degree, 'Following' gas hubs: the Belgian Zeebrugge, the German NCG and GPL, and the French PEG Nord. 

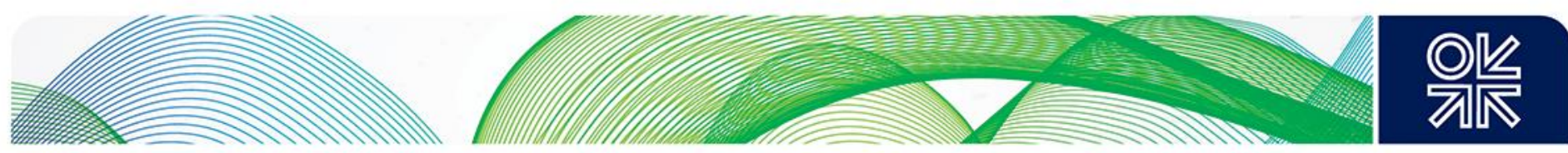

\section{6: Analysis of the European gas hubs}

This section shows two types of analysis used to categorise the European traded gas hubs and to determine their level of development towards fully liberalised, mature, liquid markets. The first is an objective analysis of traded data, for those hubs where such data is available; the second is a more subjective analysis of the development of each hub in relation to the EU's Gas Target Market policies and the Commission's Single Energy Market vision. Of the two types of analysis, the first is more comprehensive, based on 5 Key Elements and easier to make conclusions from. However, it only covers up to 9 out of the 28 Member States, where gas trading is of any recordable significance. The second type of analysis is based on 3 Main Indicators: political will, cultural attitude and commercial acceptance.

Throughout the analyses, a traffic light coding of green, amber and red is used to signify 'good', 'middling' and 'poor'. The methodologies for each Key Element in the relevant section are described and, together, all five elements will make up a final 'total' score for each hub.

\section{1: Objective parameters: The Five Key Elements}

In order to evaluate the depth, liquidity and transparency of the traded gas hubs across Europe, the results of 5 Key Elements are analysed; as far as these are available. The 5 Key Elements analysed are:

- Who trades in each of the hubs;

- What products are traded there;

- How much volume is traded, and over which periods;

- The Tradability Index;

- The churn rates.

They are all important but the churn is possibly the pre-eminent factor. It is essential to review as a minimum these 5 criteria to permit a rigorous analysis; but not all of the elements are consistently available for all of the hubs. From the results it is possible to determine which hubs are 'mature', which are active, which are improving and which are yet to show signs of development.

\subsection{1: Key Element 1: Market participants}

The first Key Element to analyse is the market participants. The number of companies trading at a gas hub is an important indicator driving the development of that market; it not only shows the willingness for traders to 'get involved' but also reflects how easy it is to participate. In addition, importantly, the more participants there are, the less chance (generally) that any one company can dominate that market.

When looking at the number of market participants, there are several things to consider: the total number of companies registered to trade at a given hub, whether that is OTC or on an exchange; how many of those can be considered as 'active' traders; and the different types of participant, whether physical, financial or administrative. Finally, lists of market participants/shippers/exchange members should be scrutinised to eliminate multiple entries by sister companies or companies with a common ownership (in most instances, there will only be one trading arm in a group). 

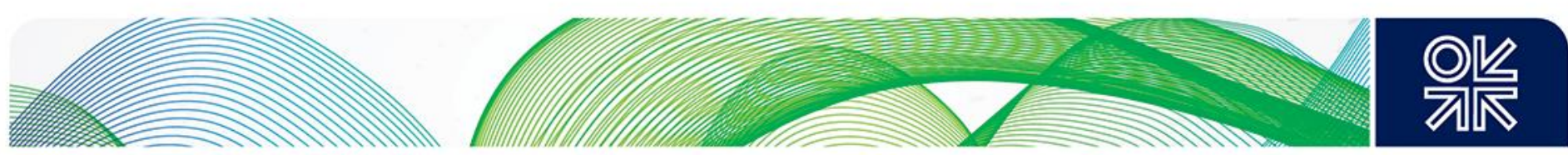

The important criteria are the number of independent participants and how many of them can be considered to be active: the more who regularly trade, the more liquidity there will be. If possible, then the types of participants trading at a given hub should also be noted.

This metric requires an amount of subjective interpretation in order to get a common view across different hubs; this is particularly the case because regulators, TSOs, exchanges, and the trade press, often quote very different numbers depending on their interpretation of who qualifies as a market participant (especially in defining an 'active' participant and determining common ownership).

An example of this from the UK is given in the 'Wholesale Gas Market Working Group report to the All Party Parliamentary Group on Energy Costs', March 2015 189 , which gives the following information on the NBP. On page 5 it states that there are "more than 200 licensees active in the physical over thecounter (OTC) market and over 100 participants registered on the InterContinental Exchange (ICE)"; yet, on page 6 it says that the Ofgem Licence list ${ }^{190}$ includes 227 registered trading participants known as shippers, collectively accounting for 176 distinct companies. In fact, the ICE does not publish lists of market participants nor do companies have to register in order to trade on the exchange. Furthermore, many participants who trade the OTC market also trade on the exchange, so the numbers are not additive. Intelligence gained from talking to brokers and market participants (who cannot disclose their trading parties but who can give an overview of the numbers and types of clients/counterparties), suggests that there are about 40 'active' traders.

A further difficulty is that not all Market Areas have 'registered' traders and currently data is not standardised across Europe in either its definition or its publication, although the introduction of REMIT ${ }^{191}$ should help solve this in time.

Defining an 'active' participant is quite difficult as it is to a certain extent subjective. In European gas markets, a minimum of ten active companies is probably necessary to spur activity and develop liquidity. In this analysis, 'active' participants are defined as those who trade at least once per week. This is in stark contrast with the definition of say the Italian regulator (AEEG ${ }^{192}$ ) who, in its 2014 Annual Report to the EC states: "In 2013, 148 parties conducted trades, sales and purchases of gas on the PSV; around one third of them (48) were pure traders, insofar as they were not users of the transmission system" 193 . This is essentially suggesting that 'active' participants traded at least only once per year.

Even using brokers and market participants has its limitations: OTC brokers will give an accurate indication of the number of 'active' traders but their own individual coverage of a given market may be limited. Market participants may be very active in some hubs but less so in others.

The reason that one should only consider active traders is that it is only they who will improve liquidity, competition to trade and usually create a 'tighter' bid/offer spread, and reduce the chances of market manipulation. If it is possible to obtain information on the type of participants this will be of added benefit.

A basic commodity market will have at its core physical traders, namely producers, wholesalers, and sometimes retailers and consumers. Added to that will be administrative participants such as (in the case of gas) the TSO/balancing agent and storage operators. Finally, as a market develops, financial players (banks and hedge funds/proprietary traders) ${ }^{194}$ will join in, using the OTC and especially the exchange products to hedge and risk manage, as well as speculate. A high proportion of financial players will generally indicate a liquid mature market and is a measure of confidence in that market.

\footnotetext{
189 http://www.lowribeck.eu/media/3510/appgec-wholesale-gas-market-report-final-v3.pdf

190 https://www.ofgem.gov.uk/sites/default/files/docs/2015/08/gas registered or service addresses 0.pdf

191 REMIT is Regulation (EU) No 1227/2011 of the European Parliament and of the Council of 25 October 2011 on wholesale Energy Market Integrity and Transparency

192 L'Autorità per l'Energia Elettrica il Gas e il sistema idrico.

1932014 Annual Report to the EC: p.130: http://www.autorita.energia.it/allegati/relaz ann/14/annualreport 2014.pdf

194 See Heather (2010), pp 20-21 for a full explanation.
} 

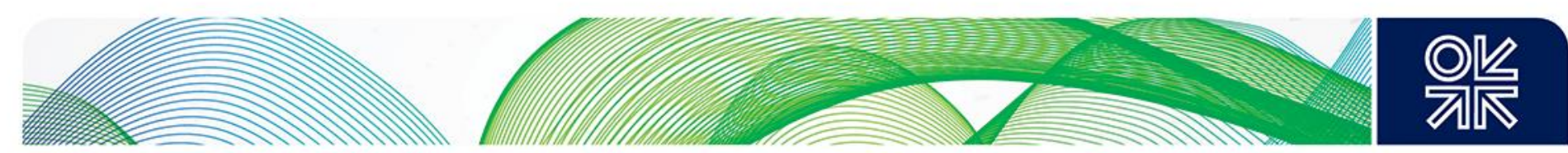

Table 4 shows the estimated number of active participants in twelve European traded gas hubs, as well as the quoted total number of participants ${ }^{195}$. Generally speaking only a small proportion of the total number of participants is 'active' although there are many more active players at the NBP and TTF than at ZEE, PSV, VTP or PEG Nord, with very few at VOB and AOC.

The colour coding methodology used in Table 4 is the following:

For the market participants Green: =/>60; Amber: $<60$; Red: $<25$;

For the number of active participants: Green: =/>20; Amber: $<20$; Red: $<10$.

The number of active players at the NBP has increased slowly from about 20 in the mid-2000s to maybe 40+ in 2014 and includes both OTC and exchange traders. At the TTF there has also been an increase but from say, 10-15 in 2011 to about 30 in 2014 and also includes both OTC and exchange traders. The physical trading point at Zeebrugge has 82 registered ${ }^{196}$ traded companies including 72 separate entities, many of which are also active on the NBP, reflecting the physical connection between the two markets. Here and at PEG Nord there are far fewer financial players, which brings the active number down to about 15 and 10 respectively.

Table 4: European gas hubs market participants: 2005-2014

\begin{tabular}{|c|c|c|c|c|c|c|c|}
\hline \multirow{2}{*}{ HUB } & \multicolumn{4}{|c|}{ Market Participants* } & \multirow{2}{*}{\multicolumn{3}{|c|}{$\begin{array}{c}\text { Active }^{* *} \\
2014\end{array}$}} \\
\hline & 2005 & 2011 & 2013 & 2014 & & & \\
\hline NBP & c. 80 & c. 160 & c. 180 & c. 200 & \multicolumn{3}{|c|}{40} \\
\hline TTF & 37 & 60 & c. 100 & c. 130 & \multicolumn{3}{|c|}{30} \\
\hline NCG+GPL & $\mathrm{n} / \mathrm{a}$ & $\mathrm{n} / \mathrm{a}$ & c. 80 & c.95 & \multicolumn{3}{|c|}{25} \\
\hline ZEE & 53 & 78 & 78 & 82 & \multicolumn{3}{|c|}{15} \\
\hline PSV & $\mathrm{n} / \mathrm{a}$ & 112 & 148 & 118 & \multicolumn{3}{|c|}{12} \\
\hline CEGH/VTP & $\mathrm{n} / \mathrm{a}$ & 40 & 42 & 53 & \multicolumn{3}{|c|}{10} \\
\hline PEG Nord & \multirow{2}{*}{23} & \multirow{2}{*}{26} & \multirow{2}{*}{54} & \multirow{2}{*}{55} & $\mathrm{~N}$ & $S$ & $\mathrm{~T}$ \\
\hline PEG S+T & & & & & 10 & 5 & 0 \\
\hline VOB & $\mathrm{n} / \mathrm{a}$ & $\mathrm{n} / \mathrm{a}$ & $\mathrm{n} / \mathrm{a}$ & 16 & \multicolumn{3}{|c|}{$<10$} \\
\hline $\mathrm{AOC}$ & $\mathrm{n} / \mathrm{a}$ & $\mathrm{n} / \mathrm{a}$ & 43 & 70 & \multicolumn{3}{|c|}{$<5$} \\
\hline
\end{tabular}

Sources: 2005: E-Control; 2011: Heather (2012); Powernext; 2013, 2014: AEEG, CEGH; CNMC; GTS; Huberator; ICE; Ofgem; Parliamentary Wholesale Gas Market Report; Powernext; and from discussions with market participants and brokers.

\footnotetext{
${ }^{195}$ For Germany it is for NCG and GPL grouped; for France, it is for all three PEGs grouped.

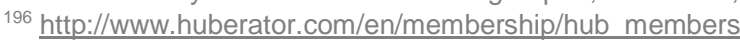



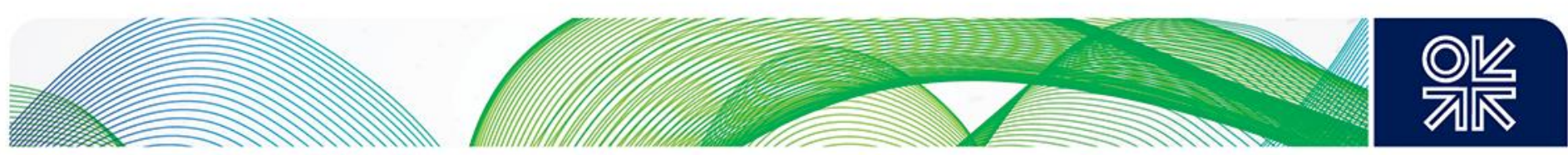

The CEGH exchange lists registered members for both the Austrian VTP ${ }^{197}$ and the Czech VOB ${ }^{198}$ with 53 and 16 separate entities respectively, although the number of active players is probably 10 and 8 respectively. Both PEG Sud and PEG TIGF are very much physical balancing hubs with the occasional added physical bilateral deal. They are dominated by three main players: GDFS, Total and ENI. By contrast, ENI, the largest gas company in Italy, did not trade at the PSV until very recently and even now, only to a limited degree.

At the Italian PSV, trading increased by 84\% from 2013 to 2014 (see Key Element 3 below) but surprisingly the number of registered traders actually fell, according to AEEG ${ }^{199}$, from 148 in 2013 to 118 in 2014, including 48 non-physical 'pure traders'. This is possibly the only country where the total number of participants fell. As with the other hubs the important metric is the number of active traders and this has increased over the past few years from a handful in 2011 to about 12 in 2014 (and there are signs that the trend is continuing into 2015).

In Spain it is very difficult to accurately assess the number of participants at the virtual hub, as opposed to the total, including the LNG terminals and the storage facilities. The information provided by the regulator states ${ }^{200}$ that there are 70 active traders ${ }^{201}$, up from 43 in 2013 . Using the Author's criterion of 'active', the actual number falls to less than 5 .

When considering the results for Key Element 1, there are four hubs clearly in the lead, registering more than 20 active traders: NBP, TTF and the German hubs combined: NCG and GPL. Then there is a middle group of four hubs that do have a reasonable number of active traders, who could in time improve liquidity: ZEE, PSV, VTP and PEG Nord. Finally, the last four hubs really do not yet have enough active traders to provide the liquidity needed to help develop their overall standing. This said, the VOB is improving year on year whereas the three others appear for now to be static.

\subsection{2: Key Element 2: Traded products}

An important consideration when comparing traded markets and evaluating their relative success is to look at the products available to trade (Table 5) and to note where along the traded curve 202 the trades are being effected. This is important as only risk management hubs are likely to become benchmark hubs providing marker prices and only benchmark hubs are likely to be able to provide risk management products - a virtuous circle but one that can be seen in other commodities across the world. Liquidity attracts liquidity which in turn makes a market successful, increases its churn rate and allows it to develop into a 'mature' market able to provide reference prices.

As well as the traded products table, the relative hub versus hub percentage splits of spot/prompt versus curve are shown in Figure 32, detailed product splits for OTC and exchange volumes (Figure 33) and the detailed product splits for the total traded volumes (Figure 34).

These additional tables will give a better understanding of what products along the curve are traded at each of the European hubs and how each of the hubs relates to the others. However, the splits are all percentages of each hub's total traded volume and not absolute volumes.

The traded products table is particularly interesting as it shows the different types of product that are available to be traded and gives a guide as to their 'popularity' in each of the hubs (shown by four colour codes); it is divided between the OTC market to the left and the exchange market to the right.

\footnotetext{
197 http://www.cegh.at/members

198 http://www.cegh.at/trading-participants

199 In the Italian regulator's 2015 annual report, p.147: http://www.autorita.energia.it/allegati/relaz ann/15/RAVolumel 2015.pdf 200 CNMC National Report to the EC, p.61:

http://www.cnmc.es/Portals/0/Ficheros/Energia/Publicaciones Anuales/1509 National Report 2015 final.pdf

${ }^{201}$ A full explanation of the number of market participants in Spain is given in section 5.5.1.

202 Traded Curve refers to the maturity of products available to trade from today to several years forward.
} 

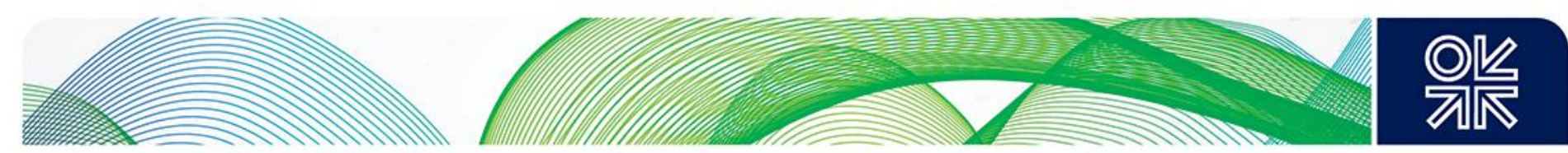

The product categories range from spot and prompt to months, quarters, seasons and both calendar and gas years, plus a column for 'OTC clearing' and one for 'options' (both OTC and exchange).

There are several ways in which to evaluate the relative importance of the traded products but the Author chose to use absolute volumes for each of the products traded in each hub; then a 'score' system to categorise the OTC trading and the exchange trading columns and finally, a 'score' system for the hubs column. For this table, a four colour coding was used to be able to give a more accurate grading across the many products available; however, the overall 'picture' as shown in the 'Hub' column is represented by the usual three colour coding used throughout this section.

Table 5: European gas hubs: traded products in 2014

\begin{tabular}{|c|c|c|c|c|c|c|c|c|c|c|c|c|c|c|c|c|c|c|}
\hline $\begin{array}{l}\text { Product } \\
\text { valuation } \\
\text { based on } \\
\text { absolute } \\
\text { volumes* }\end{array}$ & $\frac{0}{\circ}$ & 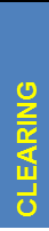 & 号 & 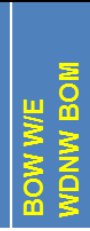 & 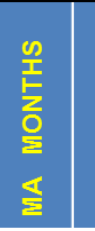 & 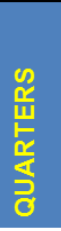 & $\begin{array}{l}\text { 足 } \\
\text { O } \\
\text { 岕 } \\
\text { 山ू }\end{array}$ & 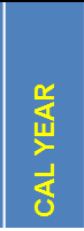 & 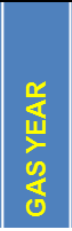 & $\begin{array}{l}\frac{0}{2} \\
\text { O } \\
\frac{5}{5} \\
0\end{array}$ & 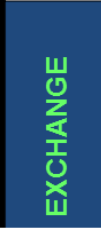 & 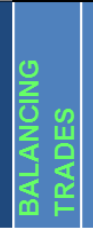 & 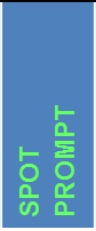 & 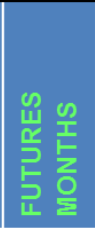 & 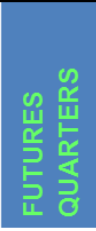 & 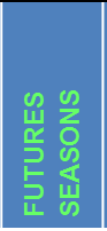 & 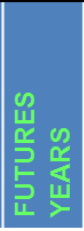 & 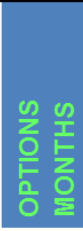 \\
\hline \multirow{3}{*}{ NBP } & \multirow{3}{*}{$\mathbf{Y}$} & \multirow{3}{*}{$Y$} & \multirow{3}{*}{$\mathbf{Y}$} & \multirow{3}{*}{$\mathbf{Y}$} & \multirow{3}{*}{$Y$} & \multirow{3}{*}{$Y$} & \multirow{3}{*}{$\mathbf{Y}$} & \multirow{3}{*}{$Y(<3)$} & \multirow{3}{*}{$Y$} & \multirow{3}{*}{$\mathbf{Y}$} & ICE & N & (Y) & $Y(83)$ & $Y(13)$ & $Y(14)$ & $Y(6)$ & $Y(36)$ \\
\hline & & & & & & & & & & & ICE-En & $Y$ & N & N & N & N & N & N \\
\hline & & & & & & & & & & & EEX & N & N & $Y(6)$ & $Y(7)$ & $Y(6)$ & N & N \\
\hline \multirow{3}{*}{ TTF } & \multirow{3}{*}{ Y } & \multirow{3}{*}{$\mathbf{Y}$} & \multirow{3}{*}{$Y$} & \multirow{3}{*}{$\mathbf{Y}$} & \multirow{3}{*}{$Y$} & \multirow{3}{*}{$Y$} & \multirow{3}{*}{$\mathbf{Y}$} & \multirow{3}{*}{$Y(<5)$} & \multirow{3}{*}{$Y$} & \multirow{3}{*}{$\mathbf{Y}$} & ICE-En & N & $Y$ & $Y(71)$ & $Y(11)$ & $Y(11)$ & $Y(5)$ & $Y(36)$ \\
\hline & & & & & & & & & & & PNXT & N & N & $Y(3)$ & $Y(4)$ & $Y(3)$ & $Y(3)$ & N \\
\hline & & & & & & & & & & & EEX & N & $Y$ & $\mathbf{N}$ & N & $\mathbf{N}$ & $\mathrm{N}$ & $\mathrm{N}$ \\
\hline \multirow{2}{*}{ NCG } & \multirow{2}{*}{$Y$} & \multirow{2}{*}{$Y$} & \multirow{2}{*}{$\mathbf{Y}$} & \multirow{2}{*}{$\mathbf{Y}$} & \multirow{2}{*}{$Y$} & \multirow{2}{*}{$Y$} & & & & & EEX/P & N & $Y$ & $Y(5)$ & $Y(4)$ & $Y(4)$ & $Y(3)$ & N \\
\hline & & & & & & & $\mathrm{Y}$ & $\mathrm{Y}$ & $Y$ & $\mathbf{Y}$ & ICE-En & N & $Y$ & Y (59) & $Y(7)$ & $Y(7)$ & $Y(4)$ & N \\
\hline & & & & & & & & & & & EEX/P & N & $Y$ & $Y(5)$ & $Y(4)$ & $Y(4)$ & $Y(3)$ & N \\
\hline GASPOOL & $Y$ & $\mathrm{Y}$ & $Y$ & $Y$ & Y & $\mathrm{Y}$ & $\mathrm{Y}$ & $Y$ & $Y$ & $\mathrm{Y}$ & ICE-En & N & $Y$ & $Y(59)$ & $Y(7)$ & $Y(7)$ & $Y(4)$ & N \\
\hline ZEE + 7TP & $Y$ & $\mathrm{~N}$ & $Y$ & $Y$ & $Y$ & $Y$ & $Y$ & $Y$ & $Y$ & $\mathrm{~N}$ & ICE-En & $Y$ & $Y$ & N & $\mathbf{N}$ & $\mathbf{N}$ & N & N \\
\hline LLL TLIT & 1 & $\mathbf{W}$ & 1 & 1 & 1 & 1 & 1 & 1 & 1 & $\sqrt{6}$ & PNXT & N & $Y$ & $Y(1)$ & N & N & N & N \\
\hline PEG NORD & $Y$ & $\mathrm{Y}$ & $Y$ & $\mathbf{Y}$ & $\mathrm{Y}$ & $\mathbf{Y}$ & $\mathbf{Y}$ & $Y$ & $\mathrm{Y}$ & $\mathbf{Y}$ & $\begin{array}{l}\text { PNXT/ } \\
\text { PGS }\end{array}$ & $\mathbf{N}$ & $\mathbf{Y}$ & $Y(3)$ & $\mathrm{Y}(3)$ & $Y(3)$ & $\mathrm{Y}(1)$ & $\mathbf{N}$ \\
\hline PSV & $Y$ & $\mathbf{N}$ & $Y$ & $Y$ & $Y$ & $Y$ & $Y$ & $Y$ & $Y$ & $\mathbf{N}$ & GME & $Y$ & $Y$ & $Y(1)$ & $\mathrm{N}$ & $Y(1)$ & $Y(1)$ & N \\
\hline VTP & $Y$ & $\mathbf{N}$ & $Y$ & $Y$ & $Y$ & $Y$ & $\mathbf{Y}$ & $Y$ & $Y$ & N & CEGH & $Y$ & $Y$ & $Y(3)$ & $\mathbf{N}$ & $\mathbf{N}$ & $\mathbf{N}$ & N \\
\hline PEG SUD & $y$ & $N$ & $y$ & y & $\mathbf{y}>-2$ & $Y$ & $Y$ & $Y$ & $Y$ & & & & $Y$ & $Y(1)$ & & & & \\
\hline PEG TIGF & $r$ & $\mathbf{N}$ & $r$ & $r$ & $r$ & $Y$ & $Y$ & $Y$ & $Y$ & $\mathbf{N}$ & PNXT & $\mathbf{N}$ & $Y$ & N & $\mathbf{N}$ & $\mathbf{N}$ & $\mathbf{N}$ & $\mathbf{N}$ \\
\hline${ }^{*} \mathrm{KEY}$ : & GREE & -600 & & AMBER & TWh & BLC & $:<250$ & Wh $R$ & ED: $<5$ & TWh & GREEN: = & : $>500 \mathrm{TWh}$ & AMBE & ER: $<500 T$ & Wh BLC & $<100 \mathrm{TWh}$ & h RED: & $:<30 \mathrm{TWh}$ \\
\hline GREY: & Hubs & Imn & ased & on 0 & Exch & lange & cor & 64 & $\mathrm{rCc}$ & lumn & based & on 'scor & re'/36; & Exchar & ge colu & $\mathrm{nn}$ based & d on 'sc & :ore'/28 \\
\hline No volumes & ICE & $=$ ICE & Endex & PNX & $\mathrm{T}=$ Powern & & & PeGas & & AVAIL & ABLE & $\mathrm{N}=\mathrm{NOT}$ & T AVAILA & BLE & $(-)=A D D$ & ITIONAL IN & NFORMA & ATION \\
\hline
\end{tabular}

Sources: OTC: LEBA; Tankard; ICIS; market participants; Exchange: ICE ; ICE-Endex ; EEX ; Powernext ; CEGH ; GME; P. Heather

NOTE A: Additional Information relates to the number of contracts available in each exchange category / contracts traded in OTC.

NOTE B: GME offer both a trading platform and an exchange: PB-Gas trading platform for balancing trades (good volumes but not strictly speaking "PSV" trades); P-Gas trading platform for bilateral spot and forward trades (trades a little); MT-Gas exchange market for futures trades (does not trade at all).

The colour coding methodology used in Table 5 is the following:

For the OTC products:

Green: =/>600TWh; Amber: <600TWh; Blue: <250TWh; Red: <50TWh;

For the exchange products:

Green: =/>500TWh; Amber: <500TWh; Blue: <100TWh; Red: <30TWh; 

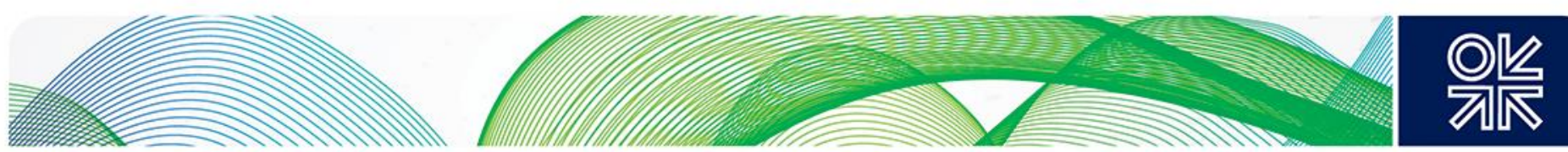

Grey is used where there are no recorded traded volumes or the product is not available.

The product colours are then assigned a points value to calculate the scores ${ }^{203}$ :

Green $=4$ points; Amber $=3$ points; Blue $=2$ points; Red $=1$ point; Grey $=0$ points.

For the OTC column:

There are 9 product columns so the maximum score would be 4 points $\times 9=36$.

Green: =/>24; Amber: <24; Blue: $<14$; Red: $<9$;

For the Exchange column:

There are 7 exchange columns so the maximum score would be 4 points $x 7=24$.

Green: =/>16; Amber: <16; Blue: $<10$; Red: $<6$;

For the Hubs column (three colour coding):

The values of the OTC and Exchange columns are added to give a score/64.

Green: $=/>42 \quad$ (66\%); Amber: $<42$ (66\%); Red: $<16(25 \%)$.

Although it is possible to trade all along the curve in the OTC market in each of the European gas hubs, in reality only the NBP and TTF trade in any quantity beyond the Month Ahead contract and they do so up to about 3 years forward. When looking at the percentage splits, it is the TTF that is slightly ahead of the NBP with a fraction less spot/prompt and an impressive $69 \%$ of the total trading being done in the Quarters, Seasons and Years (with NBP ranked second at 58\%).

Figure 32: Spot/Prompt vs. Curve split ${ }^{204}$ of total volumes (\%): hub vs. hub; 2014

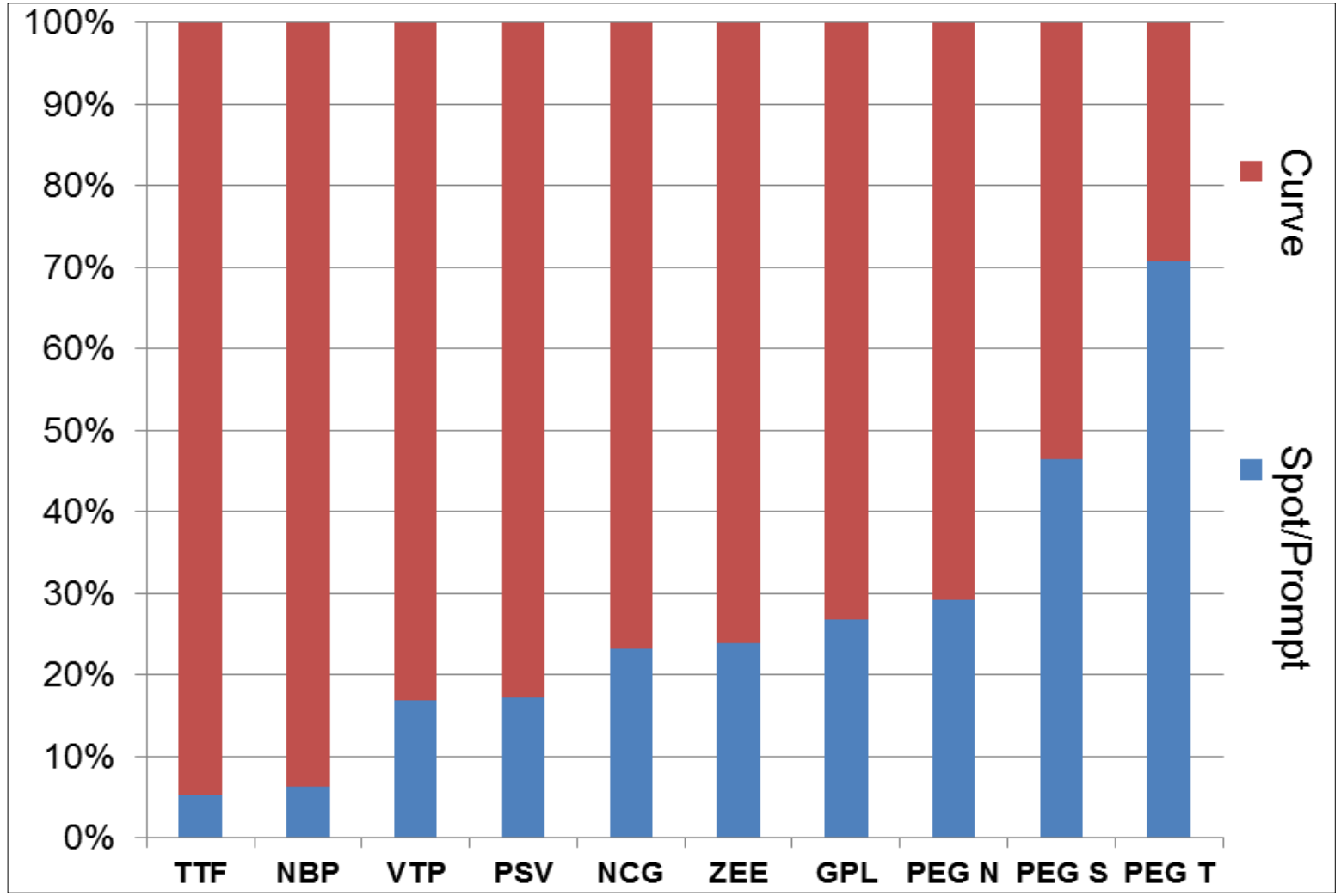

Source: calculated by the author from traded volumes data

\footnotetext{
203 The results of the scoring can be found in the table in Appendix L.

${ }^{204} \mathrm{Spot} /$ Prompt includes all trades with a maturity within 1 month; Curve includes Month Ahead and beyond.
} 

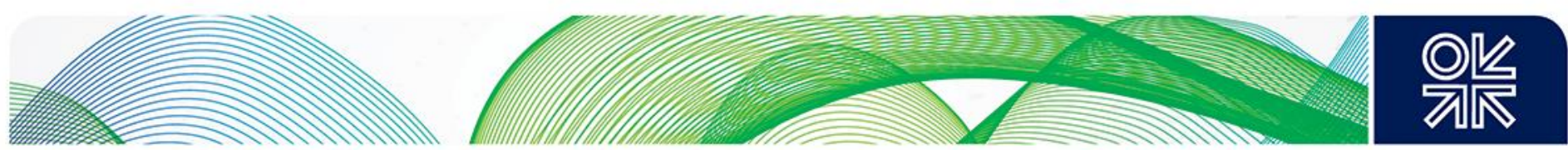

The two German hubs' overall traded volumes are far less than the leading British and Dutch hubs but they still feature in third and fourth place (see Traded volumes below). However, when looking at their rankings in the percentage splits, NCG is $5^{\text {th }}$ and GPL $7^{\text {th }}$ in the spot/prompt vs. curve split. When looking at percentage traded in the Quarters, Seasons and Years, NCG was $47 \%$ and GPL marginally better at $49 \%$.

Figure 33: Product split of OTC and exchange volumes (\%): hub vs. hub; 2014

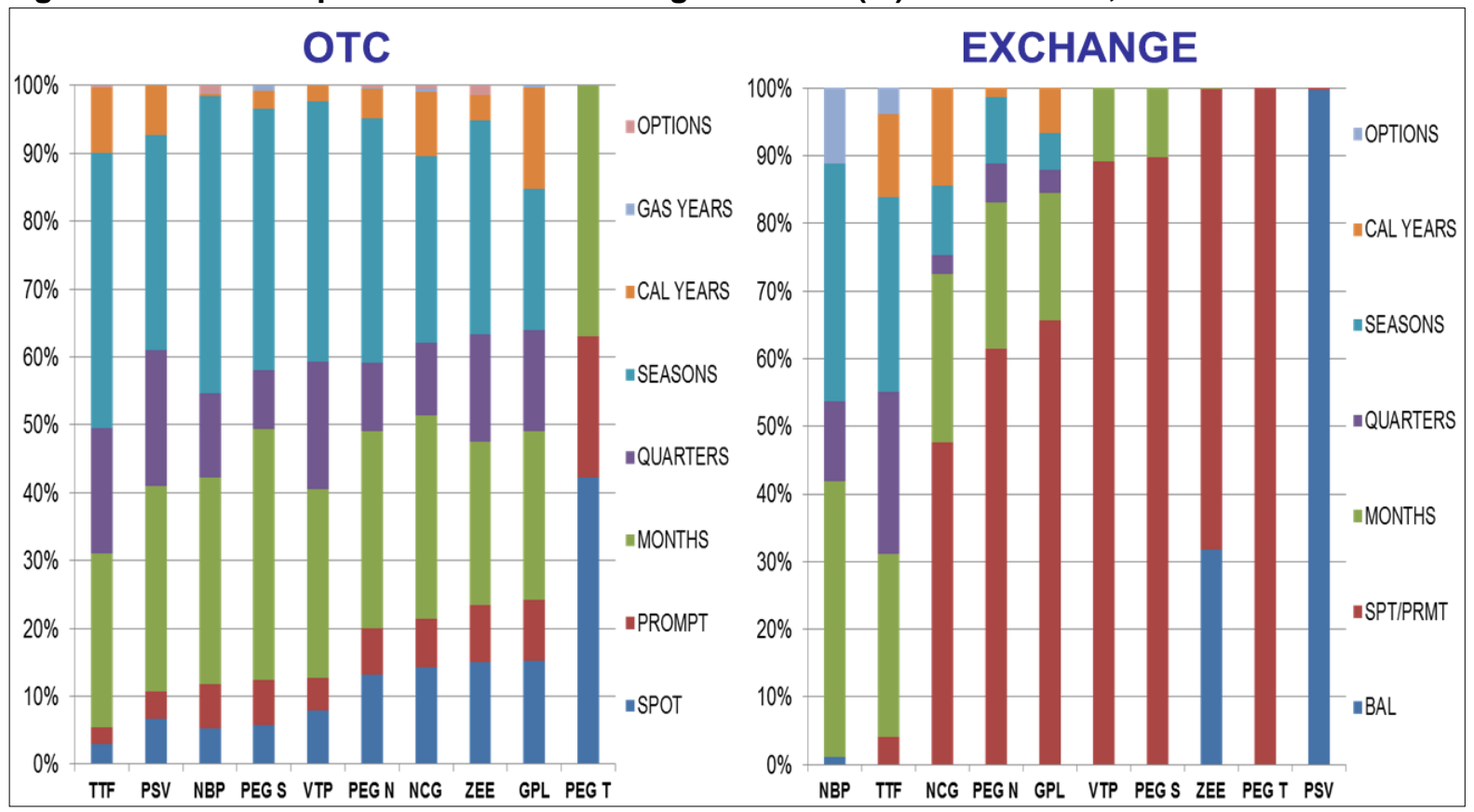

Source: calculated by the author from traded volumes data

The Belgian market is almost exclusively OTC with a small amount of spot exchange trading. Overall, it has reasonable liquidity. The spot/prompt and first month part of the curve accounts for $48 \%$ of the total traded volume; the remaining $52 \%$ is in the near to mid curve, mainly traded in spreads against the NBP with also a limited amount of spreads with TTF and NCG.

When looking at the French hubs, it is useful to look at each one separately as they are very different from each other. PEG Nord is the most active of the three hubs, having seen falling OTC volumes in 2012 and 2013. There seems to have been a small recovery in 2014. The spot/prompt and first month part of the curve accounts for $57 \%$ of the total traded volume (both OTC and exchange combined) and is quite liquid. The remainder of the curve rarely trades except in spreads (OTC and exchange) with PEG Sud, TTF and NCG; curve trading has mixed liquidity with some reasonably good volumes in the front Seasons.

PEG Sud is an illiquid market; any trading that is done is almost exclusively OTC as, on the exchange, there is only very limited Month Ahead trading, usually on spreads with PEG Nord. The spot/prompt and first month part of the curve accounts for over $70 \%$ of the total traded volume; the remainder of trading is made up of near curve spreads with PEG Nord and, especially, structured bilateral deals. PEG TIGF is very illiquid and cannot be described as a 'market' as such. There are no forward exchange products available and only a very limited amount of spot trading. The spot/prompt part of the curve accounts for $70 \%$ of the total traded volume with the remaining $30 \%$ in the first month; there are occasional spreads with PEG Sud and also some structural bilateral deals included in the total. 

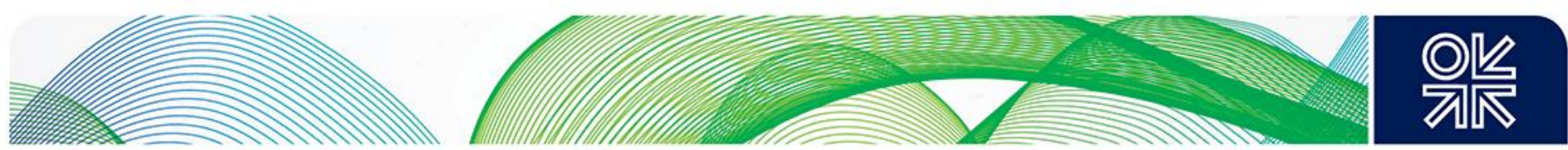

The Austrian and Italian markets have changed in the last few years, with more trading now being done along the curve as the overall volumes have increased. Although these two hubs' total traded volumes are still much lower than the ZEE, GPL and NCG hubs, they actually show that a higher percentage of their traded volumes are curve trading. Indeed, VTP and PSV have now moved to third and fourth, behind NBP and TTF, in the spot/prompt vs. curve ranking, with almost $84 \%$ of their total volumes being curve trading; and with around $55 \%$ being in the Quarters, Seasons and Years.

Figure 34: Product split of total traded volumes (\%): hub vs. hub; 2014

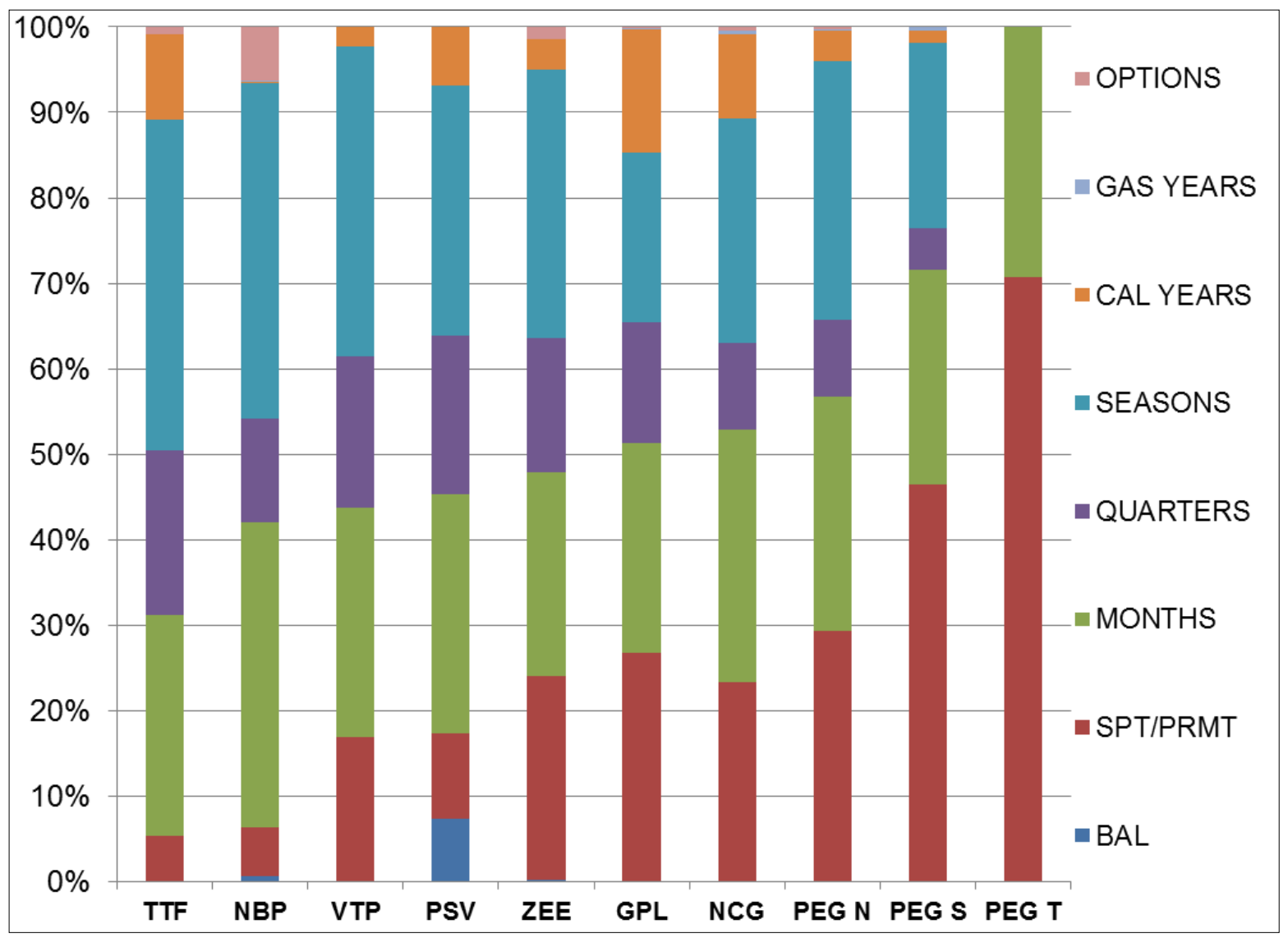

Source: calculated by the author from traded volumes data

On exchange trading, the differences across the hubs is even more stark. Again the NBP and TTF hubs trade regularly across the curve, although in exchange trading the NBP contracts have been a roaring success, attaining $52 \%$ of the total traded volumes in 2014 , with the TTF reaching $15 \%$ and the other hubs' exchange volumes forming just a very small part of the overall total. The exception to this is the French PEG Nord exchange volumes which account for just over $25 \%$ of the total; however those volumes are almost exclusively in the prompt with very little trading along the curve.

Finally, let us look at options trading. These products are favoured by the financial participants, especially the banks and hedge funds and are usually only traded in mature markets that have good liquidity and transparency. Only NBP and TTF recorded exchange options volumes (as well as OTC). The NBP exchange options accounted for $11 \%$ of its total exchange volumes and the TTF $4 \%$ of the total exchange traded volumes. However, when you add the OTC volumes and then look at the share of all traded volume, the NBP options accounted for a reasonable $6.4 \%$ and TTF for just $0.8 \%$. 

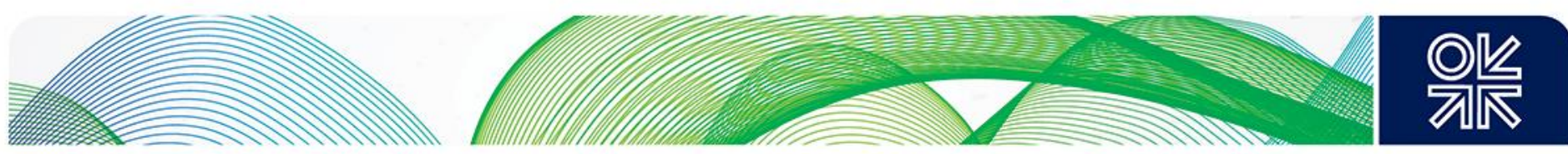

Those two hubs were joined by NCG, GPL, ZEE and PEG Nord, which all recorded small OTC options volumes. The data show that ZEE traded the highest volume (12TWh, 1.4\%), followed by NCG (8TWh, 0.5\%), PEG Nord 1TWh, 0.2\%) and GPL (1TWh, 0.1\%).

When considering the results for Key Element 2, there are two hubs clearly in the lead, NBP and TTF, scoring $46 / 64$ and $45 / 64$ respectively. Then there is a middle group of four hubs that have a reasonable amount of trading in several different products along the curve: NCG, GPL, ZEE, and PEG Nord, but they are some way behind in the scoring (between 24/64 and 17/64). Finally, three hubs, PSV, VTP, and PEG Sud scored poorly (between 13/64 and 11/64), and PEG TIGF scored a very poor $4 / 64$.

\subsection{3: Key element 3: Traded volumes}

The third Key Element is traded volumes, which openly tell the tale of market activity. Whatever the number of participants, whatever the types of product available, the volumes tell a very important story in the analysis of the development of a market, in this case the traded gas hubs. The traded volumes, compared to the overall size of the underlying market determine the churn rate (see 6.1.5 below), which is probably the most important factor in determining the success of a traded market. Generally speaking, markets with very high absolute traded volumes also have a large churn rate, have a large and varied range of participants and are usually free from price manipulation.

Traded volumes are quoted in many reports, from regulators and TSOs to the trade press, brokers and exchanges but, invariably, those reports will focus on just the OTC market or just the exchanges. In this Paper, total traded volumes are quoted, that is to say traded volumes on the OTC and at exchanges, including options and spread trades where applicable, whilst stripping out the potential 'double counting' of OTC 'give ups' 205 to the exchanges. This does not take into account where the trades occurred and for which maturities and those results can be found in the section on Traded products above.

${ }^{205}$ Also known as 'cleared trades': see Glossary. 

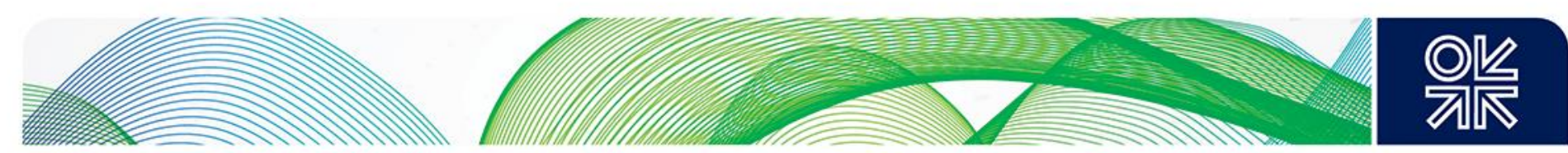

Table 6: Major hubs total traded volumes: annually 2004-2014

\begin{tabular}{|c|c|c|c|c|c|c|c|}
\hline \multirow{2}{*}{ HUB } & \multicolumn{7}{|c|}{ TOTAL TRADED VOLUMES* (TWh) } \\
\hline & 2004 & 2008 & 2011 & $\Delta \%=>$ & 2013 & $\Delta \%=>$ & 2014 \\
\hline NBP & 6100 & 10620 & 18000 & -11 & 16025 & +28 & 20505 \\
\hline TTF & 55 & 560 & 6295 & +32 & 8300 & +63 & 13555 \\
\hline NCG & $\mathrm{n} / \mathrm{a}$ & \multirow{2}{*}{360} & 880 & +59 & 1400 & +25 & 1750 \\
\hline GPL & $\mathrm{n} / \mathrm{a}$ & & 310 & +190 & 900 & +11 & 1000 \\
\hline ZEE & 450 & 500 & 870 & +20 & 1045 & -19 & 850 \\
\hline PSV & $\mathrm{n} / \mathrm{a}$ & 160 & 185 & +54 & 285 & +84 & 525 \\
\hline PEG Nord & 5 & 185 & 430 & -5 & 410 & +6 & 435 \\
\hline CEGH/VTP & $\mathrm{n} / \mathrm{a}$ & 165 & 170 & +47 & 250 & +60 & 400 \\
\hline PEG Sud & $\mathrm{n} / \mathrm{a}$ & $\mathrm{n} / \mathrm{a}$ & 40 & +75 & 70 & +14 & 80 \\
\hline PEG TIGF & $\mathrm{n} / \mathrm{a}$ & $\mathrm{n} / \mathrm{a}$ & 5 & 0 & 5 & 0 & 5 \\
\hline VOB & $\mathrm{n} / \mathrm{a}$ & $\mathrm{n} / \mathrm{a}$ & $\mathrm{n} / \mathrm{a}$ & - & 35 & 0 & 35 \\
\hline
\end{tabular}

Sources: 2004,2008: converted from bcm in IEA 2009 Natural Gas Review, p.30; 2011,2013,2014: LEBA; ICIS; ICE ; ICE-Endex ; EEX ; Powernext, CEGH, GME ; P. Heather

Table 6 shows the total traded volumes for eleven hubs; the colour coding methodology used is the following: Green: =/>5000TWh; Amber: <5000TWh; Red: <1000TWh.

In absolute traded volumes terms, the NBP is approximately $50 \%$ larger than the TTF and the TTF is approximately $3 \frac{1}{2}$ times as large as all the other hubs put together. The OTC markets dominate across the traded hubs overall ${ }^{206}$ but exchange trading is rising fast, especially at the NBP, where it now accounts for $52 \%$ and at the TTF where its share is $15 \% 207$. Another element at both these hubs is the trading of exchange options, which increased further on NBP and TTF to $11 \%$ and $4 \%$ respectively of total exchange trading.

In the last two years NBP has lost market share to Continental hubs, in particular TTF, where Continental players prefer to trade in $€ / M W h$ and where they can now risk manage their physical portfolios, which they used to do at the NBP. After a brief dip in traded volumes in 2013, these rose once more in 2014, thanks in part to a slight increase in volatility, which has attracted more financial players. Total traded volumes managed to increase by $28 \%$, reversing the $11 \%$ fall the previous year and still NBP remains the predominant hub in Europe ${ }^{208}$. The TTF has gained risk management

\footnotetext{
206 Refer to Figure 17.

207 These shares have continued to rise during 2015 at both hubs.

${ }^{208}$ How long it can remain so is in question as, in 2015, the TTF is continuing its rapid increase in traded volumes.
} 

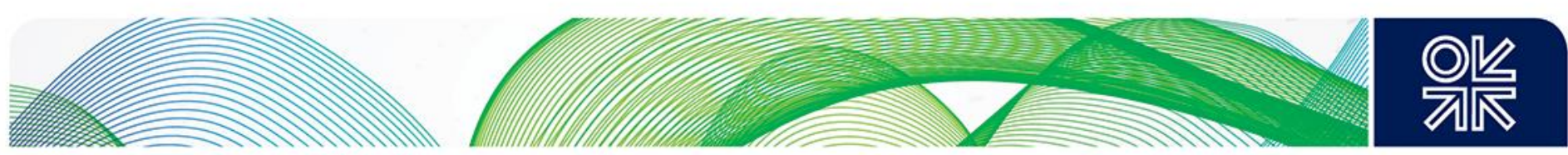

trading from the NBP and also from other Continental hubs. Total traded volumes increased by a huge 63\%, following an already large 32\% increase between 2011 and 2013.

NCG is still the larger of the two German hubs although GPL hub has seen significant increases in trading in the past two years or so, since the Nordstream pipeline started to deliver large quantities of Russian gas into its grid. NCG and GPL had a phenomenal increase from 2012 to 2013, but both hubs still managed to increase by $25 \%$ and $11 \%$ respectively in 2014 and saw a marked increase in 2014 in curve volumes, indicating more risk management trading. Quite a lot of the curve trading is in spreads with TTF or with each other or NCG/VTP.

In France, the PEG Nord dominates total traded volumes ${ }^{209}$ by $84 \%$ to $15 \%$ for PEG Sud and just $1 \%$ for PEG TIGF. PEG Nord has become a primarily 'balancing' hub and much of its traded volumes is in the spot/prompt and first month (see section above on traded products). After two successive years of declining volumes, 2014 saw a modest increase of $6 \%$ on 2013. PEG Sud on the other hand saw large percentage increases for the last three years albeit from a small base and the PEG TIGF saw no change.

The Zeebrugge hub is the only one in 2014 to have had a fall in traded volumes, reversing the increase seen the previous year. PSV turned out to be the 'star' of 2014, increasing its total traded volumes by the most of any hub at $84 \%$, to 525TWh, now slightly ahead of the PEGs combined, with 520TWh. Has PSV finally struck a chord with traders who have embraced the OTC market but almost totally ignored the exchange contracts? We will see if the trend continues in 2015. The Austrian VTP has seen an increase in spread trading with both NCG and PSV, which helped this hub increase its total traded volumes by a large $60 \%$. Finally, the Czech VOB appears to be struggling to gain traction and its total traded volumes remained fairly static at 35TWh. However, with an increase in physical 'backflow' volumes from Germany to the Czech Republic (and beyond), and an open mind on trading helped by the emergence of OTC brokers, trading should increase in the near future.

Figure 35 shows the quarterly development of the total traded volumes over a four year period. Please note the NBP and TTF hubs are represented at $1 / 5^{\text {th }}$ their actual volumes in order to get all the hubs on the same chart: this is to show the development over time and the relationship of the hubs against each other. This figure also shows the individual German and French hubs. In 2011 NCG was about 3 times the size as GPL but this difference has reduced to about double in 2014. The French PEG Sud and PEG TIGF are barely visible at the bottom of the chart, alongside the Czech 'newcomer', VOB. AOC is not included in this chart as there simply is not enough reliable information available as already discussed in section 5.5.1.

\footnotetext{
${ }^{209}$ Rounded figures (OTC+Exch.=Total,.in TWh) for 2014: PEG N: 338+99=437; PEG S: 44+35=79; PEG T: 4+1=5.
} 

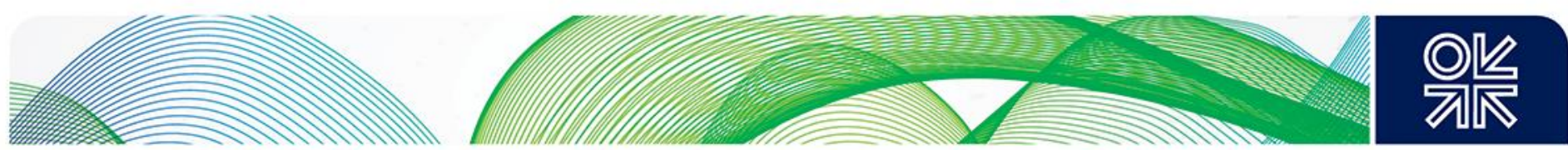

Figure 35: Traded volume development: quarterly 2011-2014

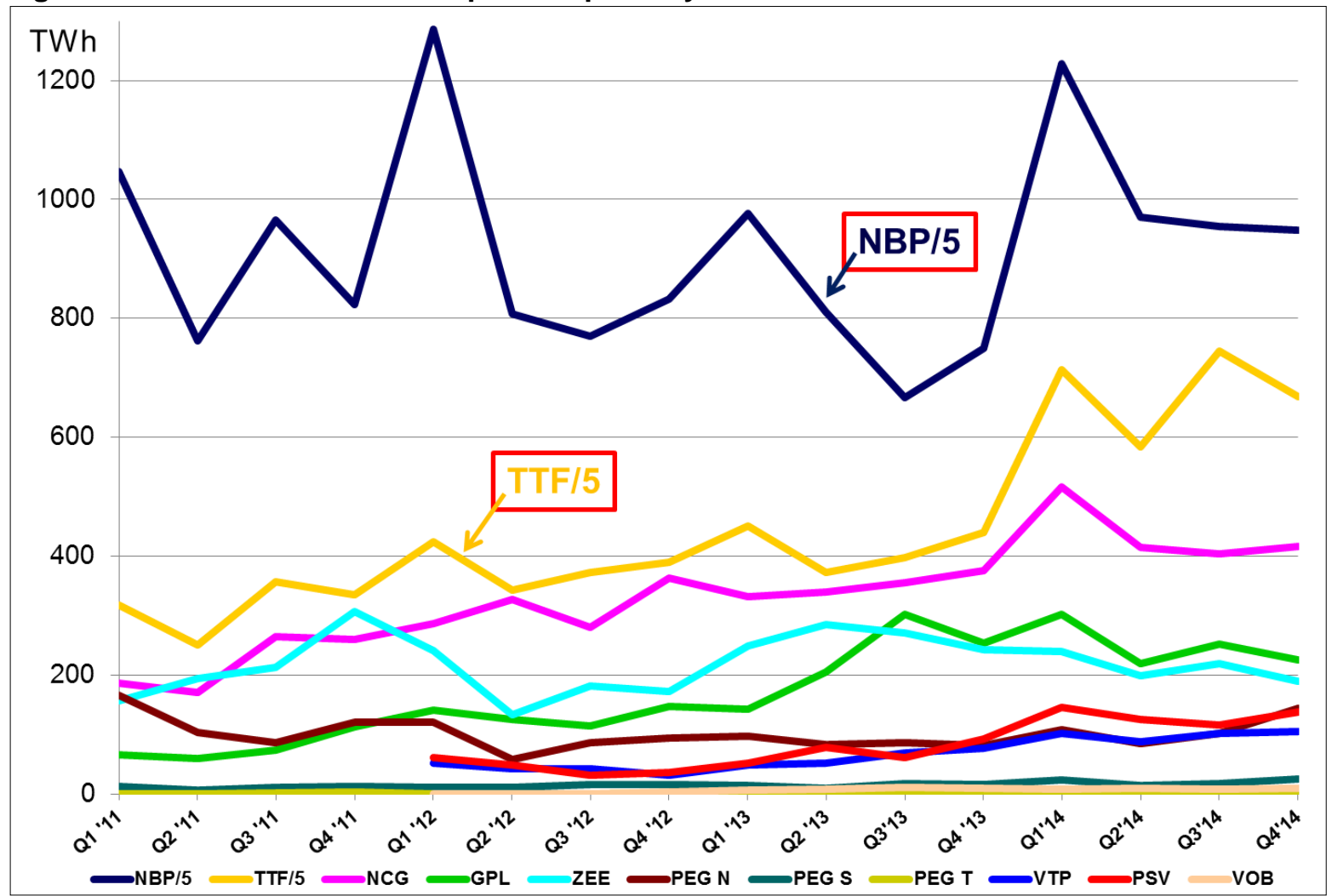

Sources: LEBA; ICIS; ICE ; ICE-Endex ; EEX ; Powernext ; CEGH ; GME; P. Heather

Although NBP has lost volume to the TTF, it does still remain the predominant hub in 2014 but, for how long? The phenomenal pace of growth registered at the Dutch hub appears to be continuing and looks as though TTF might finally overtake NBP during the course of 2015.

When considering the results for Key Element 3 , there are again just two hubs clearly in the lead, NBP and TTF, and by a large margin. The two German hubs are mid-market with the Belgian ZEE not too far behind, and the remaining 6 hubs are fair to poor.

\subsection{4: Key element 4: Tradability Index}

The fourth Key Element is the Tradability Index. Part of the assessment of the development of a traded gas hub is to analyse both the 'tightness' of the bid/offer spreads for all traded products along the curve; and the 'depth' or amount of volume on the bids and the offers. It would also help to know the extent of any additional volumes at the next price after the best bid and offer. The closer the $\mathrm{bid} /$ offer spreads the more liquid a traded market; the further along the curve that there are close $\mathrm{bid} /$ offer spreads, the more mature and developed the market; and, the more volume available to trade on both the bid and the offer at any given time, the more liquid the market.

Although it is possible in some markets to gather this data, from OTC brokers and exchange screens, it is not usually available to everyone and is also not always comparable between hubs, depending on their inherent transparency and liquidity. An alternative, and readily available, metric could be the 'Tradability Index' as calculated and published by ICIS (previously Heren), which is a measure of how narrow the bid/offer spreads are across the trading curve, indicating good liquidity' It reflects the ease with which a market can be traded and therefore is an indication of market confidence and its 

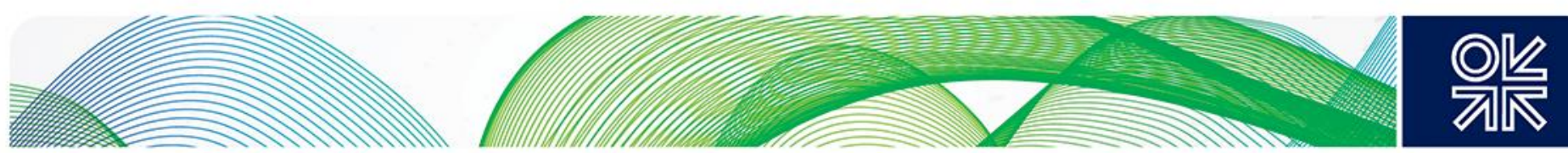

maturity. It is not in itself an indication of a deep, liquid and transparent market but it can assist the analysis of the development of a traded hub, in conjunction with other metrics.

The ICIS 'Tradability Index' is often quoted in gas market presentations and it should therefore be included here also, to complement the other key elements that help to determine the depth, liquidity and transparency of the hubs in question. The Index is calculated by giving one point for each of ten contracts $^{210}$ along the curve at two widths of the bid/ask spread ( $€ 0.5$ and $€ 0.3$ ). The maximum score is 20. The bid/offer spread criteria are in fact quite wide (especially the $€ 0.5 / \mathrm{MWh}$ ) and so the resultant analysis of this metric must be done with care and should really only look at high scoring hubs. Furthermore, the Tradability Index does not show the real depth of the market.

Figure 36: ICIS Tradability Index: 2008-2014

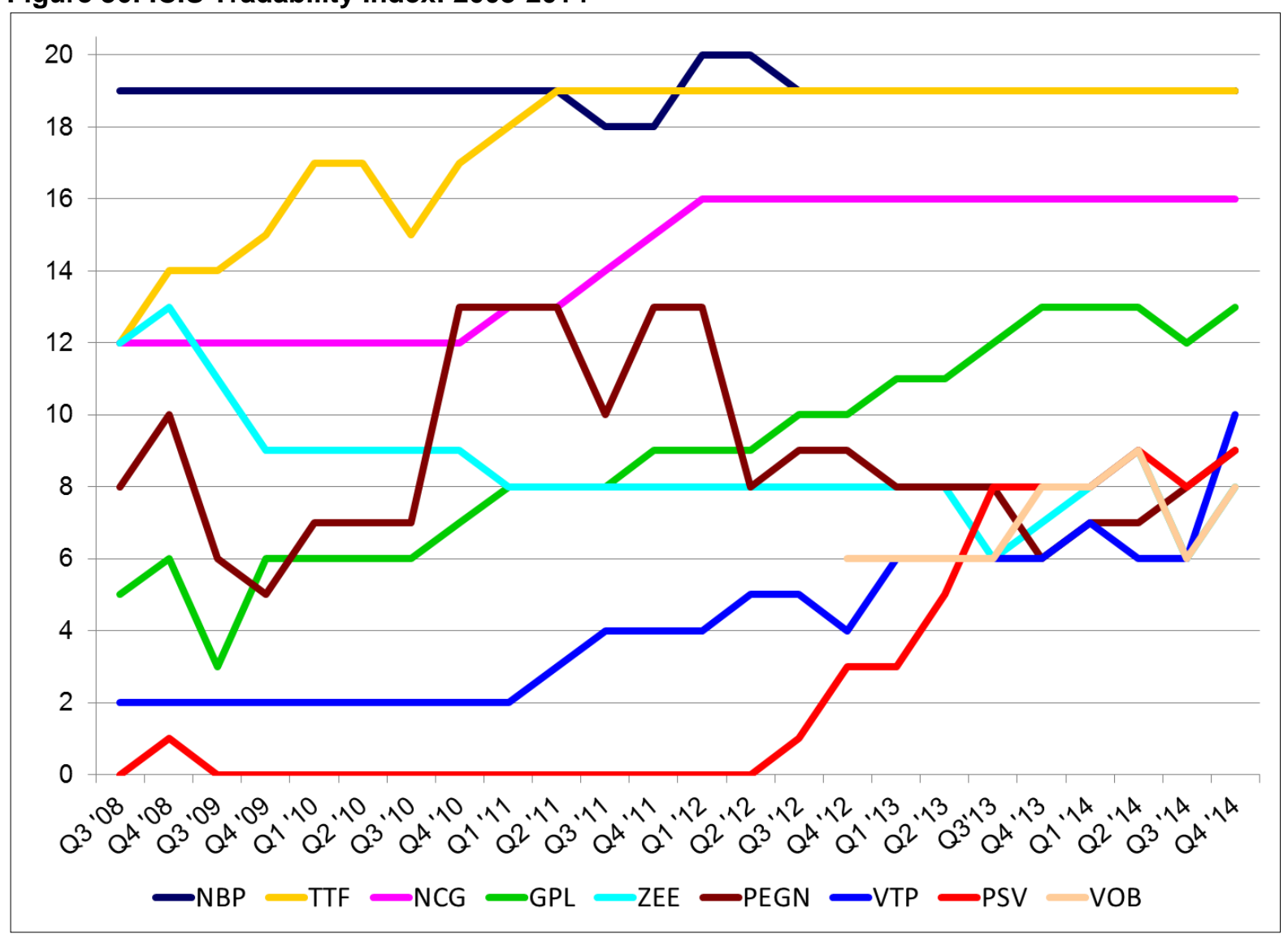

Sources: ICIS European Gas Hub Reports 2008-2014; P. Heather

For the results to have any significance, one first needs to look at the progression of the Index over time, then at the actual number. A result below 16 is not very meaningful, whereas a result of 18 or above does indicate that most of the criteria for arriving at that score have been met and so, by extension, that the hub in question does have reasonable liquidity. The Tradability Index shows (Figure 36) that the NBP has been at the top (19/20) for over 5 years and that the TTF joined it in the last 3 years, and we know that these two hubs are 'mature' so this is not surprising.

The German NCG hub improved up to a score of 16 in Q1-2012 but has since then stayed at that level. This too is not surprising as so much of the traded volume at that hub is in the spot/prompt and near curve. Further out along the curve there is an increase in trading recently but much of that is 

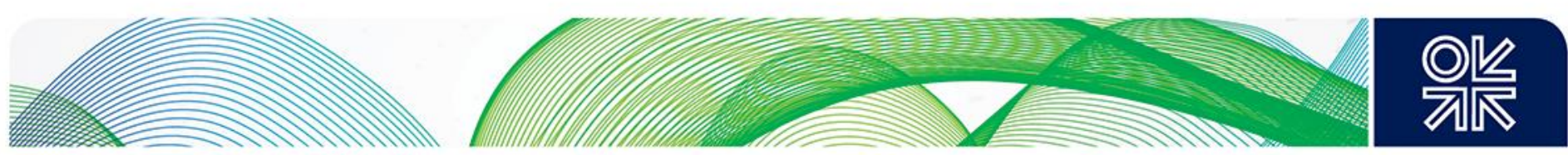

done in spreads with TTF, so the NCG bid/offer spreads are wider. Gaspool has risen steadily since 2009 but now seems to be faltering at 12-13/20.

The PEG Nord result (ICIS does not calculate a score for either PEG Sud or PEG TIGF due to the lack of liquidity) shows us that this hub was improving noticeably in the second half of 2010, extending this move through the following year to a score of $13 / 20$. However, this was its highest score and it has since fallen back to a mediocre 6-9. This reflects the change in trading in PEG Nord, which is now geared to balancing, with hedging and risk management being done essentially at the TTF.

All the other hubs are struggling with a mediocre score of 8-10. Although it should be noted that the PSV, which languished at zero for many years, finally started to improve in 2012 and has reached its best score to date (9/20) at the end of 2014.

Using the Q4-2014 results, the colour coding methodology used in the summary table (Table 9) is the following:

$$
\text { Green: =>18; Amber: }<18 \text {; Red: }<16 \text {. }
$$

When considering the results for Key Element 4, there are again just two hubs firmly in the lead, NBP and TTF. The German NCG is mid-market but, when considering this metric, all the remaining 6 hubs are poor and the PEG Sud and TIGF are not ranked at all.

\subsection{5: Key element 5: Churn rates}

The fifth and last of the Key Elements is the churn rate. The churn rate is the multiple of traded volume to actual physical throughput: a measure of the number of times a 'parcel' of gas is traded and re-traded between its initial sale by the producer and the final purchase by the consumer. Commodity markets are deemed to have reached maturity when the churn is in excess of 10 times.

In this one metric all others are, necessarily, reflected: if there are many participants, trading many different products in large quantities, then the churn rate is likely to be high. The churn rate is used by traders as a 'snapshot' of a market's liquidity; some traders will not participate in markets with a churn of less than 10 and many financial players will only participate when the churn is above 12 times. The churn is probably the most important single factor in determining the success of a traded market.

The churn rates are a much better measure of a hub's real liquidity and success and are a parameter used in most commodity and also financial markets. Gas has a peculiarity in that there is something called 'transit gas' which historically has or has not been included in official statistics, including demand figures and even in some cases physical throughput volumes. (Eurostat did not include transit gas in some countries' physical demand volumes until very recently and there are still statistical anomalies). A further complication is that for some Market Areas, the TSO or Regulator publishes churn figures which do not seem to be comparable to other countries' figures; this is usually because they quote 'trading' volumes obtained from the TSO database as opposed to using market data from brokers or the trade press; this completely distorts the result. 
Table 7: European gas hubs Net and Gross churn rates: 2012, 2013, 2014

\begin{tabular}{|c|c|c|c|c|c|c|c|c|}
\hline $\begin{array}{l}\text { Volumes } \\
\text { in TWh }\end{array}$ & $\begin{array}{c}\Sigma \text { OTC } \\
\text { (less } \\
\text { cleared) }\end{array}$ & $\begin{array}{c}\Sigma \\
\text { Exch. } \\
\text { Fut/Opt } \\
\end{array}$ & $\begin{array}{c}\Sigma \\
\text { Exch. spot }\end{array}$ & $\begin{array}{c}\Sigma \\
\text { Traded }\end{array}$ & $\begin{array}{c}\text { ¿ NET } \\
\text { Physical }\end{array}$ & $\begin{array}{c}\text { Net market } \\
\text { churn }\end{array}$ & $\begin{array}{c}\Sigma \text { GROSS } \\
\text { Physical }\end{array}$ & $\begin{array}{c}\text { Gross } \\
\text { market } \\
\text { churn }\end{array}$ \\
\hline NBP 2012 & $11,624.71$ & $6,724.75$ & 137.36 & $18,486.82$ & 864.52 & 21.4 & 998.07 & 18.52 \\
\hline NBP 2013 & $10,025.72$ & $5,853.01$ & 145.68 & $16,024.42$ & 855.66 & 18.7 & 963.45 & 16.63 \\
\hline NBP 2014 & 9,733.04 & $10,643.20$ & 129.56 & $20,505.79$ & 783.08 & 26.2 & 902.89 & 22.71 \\
\hline$\Delta$ Britain & $-3 \%$ & $82 \%$ & $-11 \%$ & $28.0 \%$ & & & $-6.3 \%$ & \\
\hline TTF 2012 & $7,001.57$ & 624.12 & 23.44 & $7,649.13$ & 419.92 & 18.2 & 973.63 & 7.86 \\
\hline TTF 2013 & $7,700.62$ & 573.40 & 26.18 & $8,300.20$ & 430.94 & 19.3 & $1,048.35$ & 7.92 \\
\hline TTF 2014 & $11,553.82$ & $1,920.76$ & 80.92 & $13,555.49$ & 376.04 & 36.0 & 919.30 & 14.75 \\
\hline$\Delta$ Holland & $50 \%$ & $235 \%$ & $209 \%$ & $63.3 \%$ & & & $-12.3 \%$ & \\
\hline ZEE 2012 & 725.75 & N/A & 1.71 & 727.46 & 220.71 & 3.3 & 431.05 & 1.69 \\
\hline ZEE,ZTP/L'13 & $1,043.62$ & N/A & 3.37 & $1,046.98$ & 191.07 & 5.5 & 463.48 & 2.26 \\
\hline ZTP/L 2014 & 843.39 & 0.01 & 3.94 & 847.33 & 171.95 & 4.9 & 440.76 & 1.92 \\
\hline$\Delta$ Belgium & $-19 \%$ & - & $17 \%$ & $-19.1 \%$ & & & $-4.9 \%$ & \\
\hline $\mathrm{NCG}+\mathrm{GPL}{ }^{\prime} 12$ & $1,600.00$ & 160.53 & 25.82 & $1,786.35$ & 853.20 & 2.1 & $1,042.97$ & 1.71 \\
\hline $\mathrm{NCG}+\mathrm{GPL}{ }^{\prime} 13$ & $2,212.49$ & 29.88 & 59.48 & $2,301.85$ & 901.40 & 2.6 & $1,084.34$ & 2.12 \\
\hline NCG+GPL'14 & $2,558.59$ & 89.70 & 101.46 & $2,749.75$ & 752.70 & 3.7 & $1,140.90$ & 2.41 \\
\hline$\Delta$ Germany & $16 \%$ & $200 \%$ & $71 \%$ & $19.5 \%$ & & & $5.2 \%$ & \\
\hline PEGs 2012 & 291.86 & 41.52 & 43.09 & 376.48 & 460.08 & 0.8 & 497.98 & 0.76 \\
\hline PEGs 2013 & 379.94 & 32.51 & 70.38 & 482.84 & 470.93 & 1.0 & 526.04 & 0.92 \\
\hline PEGs 2014 & 387.10 & 42.12 & 92.83 & 522.04 & 413.93 & 1.3 & 493.24 & 1.06 \\
\hline$\Delta$ France & $2 \%$ & $30 \%$ & $32 \%$ & $8.1 \%$ & & & $-6.2 \%$ & \\
\hline VTP 2013 & 234.59 & 0.30 & 12.97 & 247.86 & 93.98 & 2.6 & 563.60 & 0.44 \\
\hline VTP 2014 & 376.28 & 2.32 & 18.95 & 397.55 & 85.92 & 4.6 & 486.29 & 0.82 \\
\hline$\Delta$ Austria & $60 \%$ & $669 \%$ & $46 \%$ & $60.4 \%$ & & & $-13.7 \%$ & \\
\hline PSV 2013 & 282.05 & 0.62 & 0.02 & 282.69 & 741.39 & 0.4 & 743.78 & 0.38 \\
\hline PSV 2014 & 524.63 & 0.00 & 0.10 & 524.73 & 655.21 & 0.8 & 657.72 & 0.80 \\
\hline$\Delta$ Italy & $86 \%$ & - & $497 \%$ & $85.6 \%$ & & & $-11.6 \%$ & \\
\hline VOB 2013 & 34.18 & 0.00 & 0.00 & 34.18 & 88.88 & 0.4 & 396.23 & 0.09 \\
\hline VOB 2014 & 33.06 & 0.75 & 0.00 & 33.81 & 79.21 & 0.4 & 388.08 & 0.09 \\
\hline$\Delta$ Czech & $-3 \%$ & $-75 \%$ & - & $-1.1 \%$ & & & $-2.1 \%$ & \\
\hline \begin{tabular}{|l} 
NW Europe \\
2013
\end{tabular} & 21913.20 & 6489.73 & 318.08 & $28,721.02$ & $3,774.26$ & 7.6 & $5,789.28$ & 4.96 \\
\hline \begin{tabular}{|l|}
$\Sigma$ NW Europe \\
2014 \\
\end{tabular} & 26009.91 & 12698.84 & 427.76 & $39,136.50$ & 3,318.06 & 11.8 & $5,429.19$ & 7.21 \\
\hline$\Delta$ NW Europe & $19 \%$ & $96 \%$ & $34 \%$ & $36.3 \%$ & -0.12 & & $-6.2 \%$ & \\
\hline
\end{tabular}

Sources: LEBA; IEA; Energy-Flows (TSO data); ICE ; ICE-Endex ; EEX ; Powernext ; CEGH ; GME; P. Heather

December 2015: The evolution of European traded gas hubs 

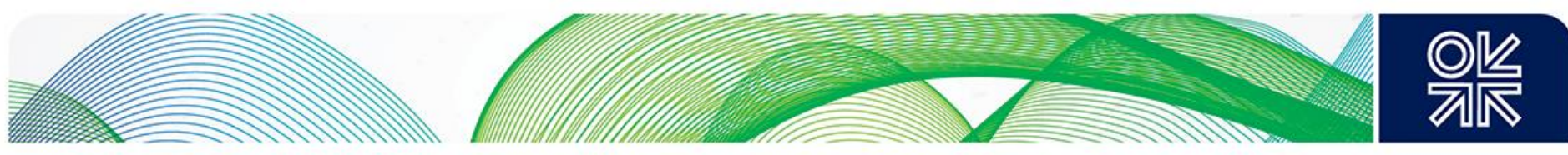

For these reasons two different methodologies for each of the hubs are reflected in this paper. The Net Market Churn is the EU definition ${ }^{211}$ of total trades/physical consumption ${ }^{212}$ at the hub; the Gross Market Churn is total trades/total physical demand ${ }^{213}$ (i.e. throughput including exports). Theoretically, all gas in the system could be traded and so, ultimately, this is a better indication of the trading activity in each Market Area. For some countries like the Netherlands in particular this methodology more than halves the churn rate from 'net' to 'gross' but even so the TTF gross churn stands at a very good 14.75 .

It is also worth mentioning the traded volumes component of the Matrix. The development of the gas hubs throughout Europe can readily be monitored by the ever-growing volumes of gas being traded at the hubs both in the OTC markets and on the exchanges ${ }^{214}$. Generally the OTC markets are still dominant, with the exception of Britain where the exchange element has grown significantly in the past few years. Indeed, all of the European exchanges have been instrumental in helping develop the markets by offering new products on 'easy to trade' electronic platforms.

Table 7 shows all the relevant data over the past three years used to calculate the Net and Gross market churn rates. The total traded ${ }^{215}$ volume is made up of the OTC volumes ${ }^{216}$, the exchange futures and options volumes ${ }^{217}$ and the exchange spot volumes ${ }^{218}$, for each of the hubs; the physical volumes are obtained from official sources ${ }^{219}$ for both the gross and net figures. The first column shows the amount of OTC trading at each of the hubs, although any 'cleared' element is left out as the true total cleared volumes ${ }^{220221}$ will be shown with the Exchange figures. The next column shows the total futures and options volumes as reported by the various exchanges; these totals will also include any intra- and inter-market spreads as appropriate; the volumes relate to all trades of a maturity including and beyond the Month Ahead contracts. Options are only available to trade at the NBP and the TTF, on the ICE and ICE-Endex platforms respectively. The exchange spot volumes column contains all the trades at each of the hubs ${ }^{222}$ for maturities of less than one month (such as Within Day, Day Ahead, Weekend, Working Days Next Week, Balance of Month, etc.).

The results for 2012-2014 are very interesting and clearly show the rankings of the traded gas hubs in Europe. When ordered by Gross Market Churn, the NBP is significantly in front in the low twenties, followed by the TTF at just under 15. From there it is a big drop to the next hubs, Zeebrugge with a Gross Churn of just 1.92 and the German hubs together showing 2.41. The French PEGs have just passed 1 in 2014 for the first time and the last three European hubs have a Gross Churn of less than 1.

The results using the EU definition of total traded volume against the consumption in the hub area, or Net Market Churn, show that in 2014 the TTF at 36 times was actually higher than the NBP (26x). Both markets are at more than two to three times the recognised level at which a hub is deemed

\footnotetext{
${ }^{211}$ EU Energy Sector Enquiry 2007, p.34, para.70, note 52: “'Churn' here means the ratio between total volume of trades and the physical volume of gas consumed in the area served by the hub".

212 Consumption = Production + Imports $-\Delta$ Storage - Exports.

${ }^{213}$ Demand = Total Physical Throughput = Consumption + Exports.

${ }^{214}$ For a description of different methods of trading, see "Routes to Market" section p.24, in Heather (2010).

215 These are the volumes that are traded at each hub as recorded by brokers (OTC) or exchanges (Exchange) and do not include 'contracted' (LTC or other bilateral deals) volumes which are conducted 'off market' (unless they are 'given up' for exchange clearing) and are usually private.

216 See Appendix $M$ for a full break down of the OTC volume figures.

217 See Appendix $\mathrm{N}$ for a full break down of the exchange futures and options volume figures.

218 See Appendix $\mathrm{O}$ for a full break down of the exchange spot volume figures.

219 See Appendix $\mathrm{P}$ for a table showing the full calculations.

220 See Glossary for definition of Cleared Trades (Give ups).

${ }^{221}$ Which may include both trades given up from the brokers as well as any bilateral trades.

222 In the sole case of the Italian market, the PB-Gas trades are not included in these calculations as they are not effected at the PSV hub but are traded 'in storage'; however, it is possible to note those balancing volumes in the "Italian spot total" column of the table in Appendix $\mathrm{O}$.
} 

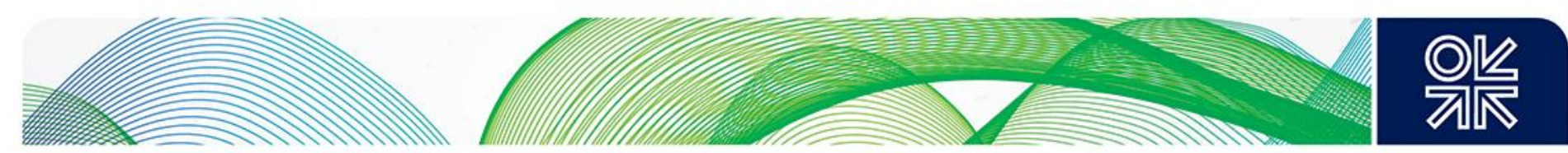

mature and way above the minimum of 15 quoted by Gazprom at industry conferences as being the level they recognise.

Table 8 shows the net market churn rates for 9 individual hubs, plus the two German hubs combined ${ }^{223}$; the colour coding methodology used is the following:

Green: =/>10; Amber: $<10 ;$ Red: $<5$.

Table 8: European gas hubs Net churn rates development: 2004-2014

\begin{tabular}{|l|c|c|c|c|c|}
\hline \multirow{2}{*}{ HUB } & \multicolumn{5}{|c|}{ Gas traded hubs churn rates* } \\
\hline NBP & 2004 & 2008 & 2011 & 2013 & 2014 \\
\hline TTF & 7 & 14.4 & 19.8 & 18.7 & 26.2 \\
\hline ZEE & 0.2 & 3.3 & 13.9 & 19.3 & 36.0 \\
\hline CEGH/VTP & n/a & 2.4 & 2.2 & 2.6 & 4.6 \\
\hline NCG+GPL & n/a & 0.4 & 1.4 & 2.6 & 3.7 \\
\hline PEG Nord & n/a & & & 1.4 & 1.6 \\
\hline PEG Sud & n/a & 0.4 & 1.0 & 0.7 & 1.0 \\
\hline PEG TIGF & n/a & & & 0.3 & 0.1 \\
\hline PSV & n/a & 0.2 & 0.2 & 0.4 & 0.8 \\
\hline VOB & n/a & n/a & n/a & 0.4 & 0.4 \\
\hline *Calculated on a Net Market Churn basis; not the same methodology in all years. & & \\
\hline
\end{tabular}

Sources: 2004: NBP: Heather (2010), p.35; TTF, ZEE: calculated from BP and IEA;

2008: Heather (2010), Table 6, p.19; Komlev ${ }^{224}$ presentation 2011; calculated from BP and IEA; 2011,2013,2014: LEBA; ICE ; ICE-Endex ; EEX ; Powernext ; CEGH; GME; P. Heather.

In this table we can see the development of the traded hubs through the progression of their churn rates over the past 10 years. The NBP's trading liquidity had suffered in the mid-2000's, falling back below 10x churn for a few years but that turned around from 2007-2008 and has continued to strengthen since. The TTF only passed the 10x threshold in 2011 but it too has continued to strengthen and has now overtaken NBP. Zeebrugge has for most of its life been around $5 x$ churn and has now been joined by the other major European physical import location, Austria, whose VTP reached a churn of 4.6 in 2014 . The German hubs, taken together, have improved over time,

\footnotetext{
${ }^{223}$ The Author was able to calculate the PEG Sud and PEG TIGF churn as physical data was available; however, getting reliable individual physical data for NCG and GPL has proved difficult.

224 "The European Gas Pricing Model", Amsterdam, $8^{\text {th }}$ November 2011, slide 4: http://www.gazpromexport.ru/files/European Gas Pricing Model Final Nov 201184.pdf
} 

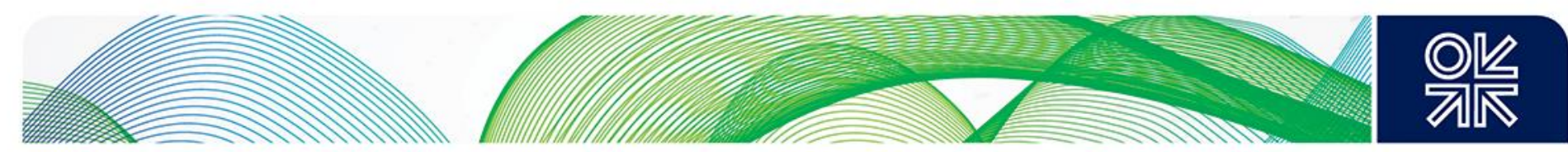

particularly in the last three years but, despite the overall size of the physical market are still only at 3.7.

This table shows the individual figures that have been calculated for each of the three French hubs: the PEG Nord did improve very slightly in 2014 to a still very poor 1.6 and its southern counterpart, PEG Sud, just passed 1 in 2014 for the first time; PEG TIGF actually went even lower to register a mere 0.1. Finally, the Italian PSV did improve, doubling its relative trading activity in 2014 but is still trading less than its consumption and registers a churn of 0.8 .

When considering the results for Key Element 5, from all the results, whichever methodology is used, it is clear that there are only two 'mature' hubs in Europe in 2014 the NBP and the TTF; all the other hubs are poor.

The British NBP and the Dutch TTF dominance has continued and strengthened in 2015. These are likely to remain leading benchmark hubs in Europe, the NBP a Sterling contract used to price all the gas for the British Isles and some LNG supplies; the TTF a Euro contract used to price gas for delivery to north-west Europe and for LNG supplies.

Further down the line another European hub is feasible to price gas delivered to southern and/or eastern Europe, although this could still be done ${ }^{225}$ using either the NBP or the TTF, with price adjustments to allow for transportation and other factors. European gas hubs already do and will continue to provide a reliable reference price for contract gas deliveries and risk management purposes.

\subsection{6: Summary of the Five Key Elements}

Table 9: European traded gas hubs development based on the 5 Key Elements

\begin{tabular}{|c|c|c|c|c|c|c|}
\hline 2014 & \multicolumn{5}{|c|}{5 KEY ELEMENTS } & \multirow[b]{2}{*}{$\begin{array}{l}\text { Score } \\
/ 15^{\star *}\end{array}$} \\
\hline HUB & $\begin{array}{l}\text { Active Market } \\
\text { Participants }\end{array}$ & $\begin{array}{l}\text { Traded } \\
\text { Products* }\end{array}$ & $\begin{array}{c}\text { Traded } \\
\text { Volumes }\end{array}$ & $\begin{array}{l}\text { Tradability } \\
\text { Index (Q4) }\end{array}$ & $\begin{array}{c}\text { Churn } \\
\text { Rate }\end{array}$ & \\
\hline NBP & 40 & 46 & 20505 & 19 & 26.2 & 15 \\
\hline TTF & 30 & 45 & 13555 & 19 & 36.0 & 15 \\
\hline NCG & \multirow{2}{*}{25} & 24 & 1750 & 16 & \multirow{2}{*}{3.7} & 10 \\
\hline GPL & & 21 & 1000 & 13 & & 9 \\
\hline ZEE & 15 & 17 & 850 & 7 & 4.9 & 7 \\
\hline PEG Nord & 10 & 17 & 435 & 9 & 1.6 & 7 \\
\hline CEGH/VTP & 10 & 11 & 400 & 10 & 4.6 & 6 \\
\hline PSV & 12 & 11 & 525 & 9 & 0.8 & 6 \\
\hline PEG Sud & 5 & 13 & 80 & $\mathrm{n} / \mathrm{a}$ & 1.0 & 4 \\
\hline VOB & $<10$ & $\mathrm{n} / \mathrm{a}$ & 35 & 8 & 0.4 & 4 \\
\hline PEG TIGF & 0 & 4 & 5 & $\mathrm{n} / \mathrm{a}$ & 0.1 & 3 \\
\hline AOC & $<5$ & $\mathrm{n} / \mathrm{a}$ & (165) & $\mathrm{n} / \mathrm{a}$ & $(0.6)$ & $2 / 3$ \\
\hline
\end{tabular}
${ }^{225}$ Indeed, TTF is already being used to price contracts in Austria, Italy, the Czech Republic and possibly further afield also;
TTF is also being used as a reference price for regulators in France (to set part of the regulated tariffs), Spain and Italy. 

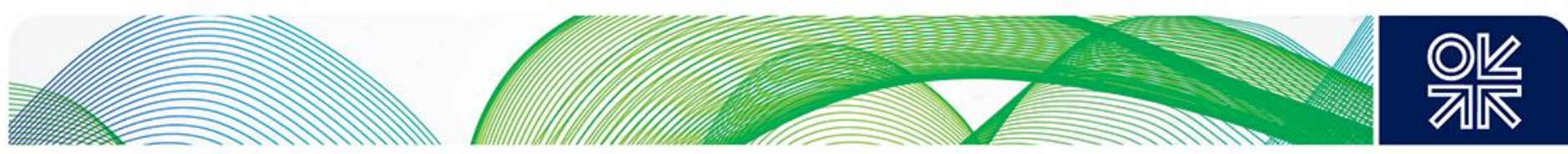

The 2014 results from each of the 5 Key Element tables have been recorded in this summary table (Table 9). The Author has then used a simple scoring methodology to derive the final ordering of the hubs, to reflect their level of development: mature, active, poor and inactive as indicated in the map of the European gas regions, markets and hubs in section 6.2 (Map 5). The points system is indicated at the bottom of the table and, adding up each of the constituent Key Elements will give a hub score out of 15 . A hub is classified ${ }^{226}$ as being 'mature' if the score is $12-15$; 'active' if the score is $9-11$; 'poor' if the score is 6-8; and 'inactive' if the score is 1-5.

Once again, it is clear to see that the NBP and the TTF stand out in front as the only two 'mature' hubs, scoring a maximum 15/15; followed by the two 'active' German hubs at 10/15 and 9/15; next the Zeebrugge, PEG Nord, VTP and PSV as 'poor'; and the VOB, PEG Sud, PEG TIGF as 'inactive'. The $A O C$ is also included in this table using the figures given in the CNMC annual report for total hub trades and the net gas consumption; this gives a churn of just 0.6 and a total score of 2-3/15 due to the uncertain definition 227 of 'traded volume' in its report. The remaining hubs shown on the map are classified as 'inactive' also as they simply do not have any or enough data to analyse properly.

\section{2: Subjective parameters: The Three Main Indicators}

In order to evaluate the path to liberalisation and market development, the political willingness and cultural attitudes to trading are assessed that are also key to the development of successful gas trading hubs; in turn these often dictate the level of commercial acceptance in a given country. The EFET Review of Gas Hubs Assessments is also referred to as this quantifies 5 regulatory conditions, 6 TSO conditions and 6 market conditions; these broadly follow the Three Main Indicators.

\subsection{1: Main Indicator 1: Political will}

The importance of creating a Single Internal Energy Market within the EU is paramount to the European Commission and it has strived to achieve this goal. In a Progress Report published 228 in October 2014, the Commission stated:229 "In 2011 the Heads of State or Government recognised the importance of having an internal energy market in place and set a clear deadline for its completion by 2014, underlining that no EU Member State should remain isolated from the European gas and electricity networks after 2015. These targets have often been repeated ever since and explicitly endorsed by all the main stakeholders, from industry associations to consumer organizations. The enormous importance of the energy sector to Europe's competitiveness, welfare and independence means that the EU cannot afford failure". Unfortunately, the results have so far been patchy at best and non-existent in some countries.

It is apparent that each Member State sees the implementation of this goal very differently and this is often from both an ideological standpoint, as well as a financial one, as many countries will need to improve or build new infrastructure. The Romanian energy shadow minister, Catlin Predoin, stated:230 " $70 \%$ of the gas infrastructure needs renewal requiring an investment of $€ 30-35 \mathrm{bn}$ in Romania alone". Many of the smaller (in particular south east European) countries have big ambitions and this is just one example of countries wanting to feel privileged as being part of the 'European Club'. This

\footnotetext{
226 In Map 1: "European gas regions, markets and hubs".

227 The Author was told by a market participant and a broker that this figure is the 'nominated' volume to the TSO and that a more realistic figure for total traded volumes at the AOC in 2014 would be c.30TWh, making the churn just 0.1 .

${ }^{228}$ EC Communication to the European Parliament,13 ${ }^{\text {th }}$ October 2014 (COM(2014) 634 final): "Progress towards completing the Internal Energy Market": https://ec.europa.eu/energy/sites/ener/files/documents/2014 iem communication 0.pdf

${ }^{229}$ Introduction, p.2.

${ }^{230}$ Bucharest Energy Forum, 25 ${ }^{\text {th }}$ June 2015.
} 

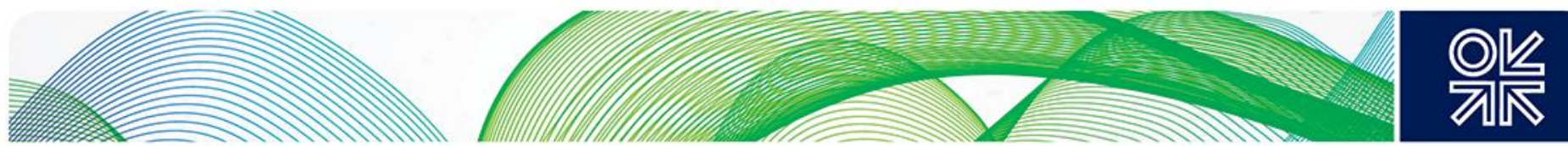

suggests that the role of the EU should be one of catalyst to bring all the different countries together, a role that it has found difficult to achieve.

The Gas Target Model (GTM) 1 had an aim of all Member States complying with the Network Codes by the end of 2014; this deadline passed with just two countries having reached full implementation of the Balancing Network Code (BAL NC, see Map 5) and, in early 2015, a revised GTM 2 was published, allowing more time for compliance.

There has been a lacklustre uptake of the Directives and Codes in certain countries and the published timetables by some Member States show that they may not be able to comply by even the end of this decade. Indeed there are still many countries with regulated prices and many of these are resisting liberalisation of wholesale markets. Retail price controls must be removed if competition is to thrive. Some progress is evident is some countries, for example in Romania which has allowed regulated prices to rise, but there remains inherent cross-subsidisation and a fear that the government will 'lose control' if it removes regulated prices altogether. In some countries, the outlook is even bleaker.

\section{Map 5: Expected implementation of the BAL NC}

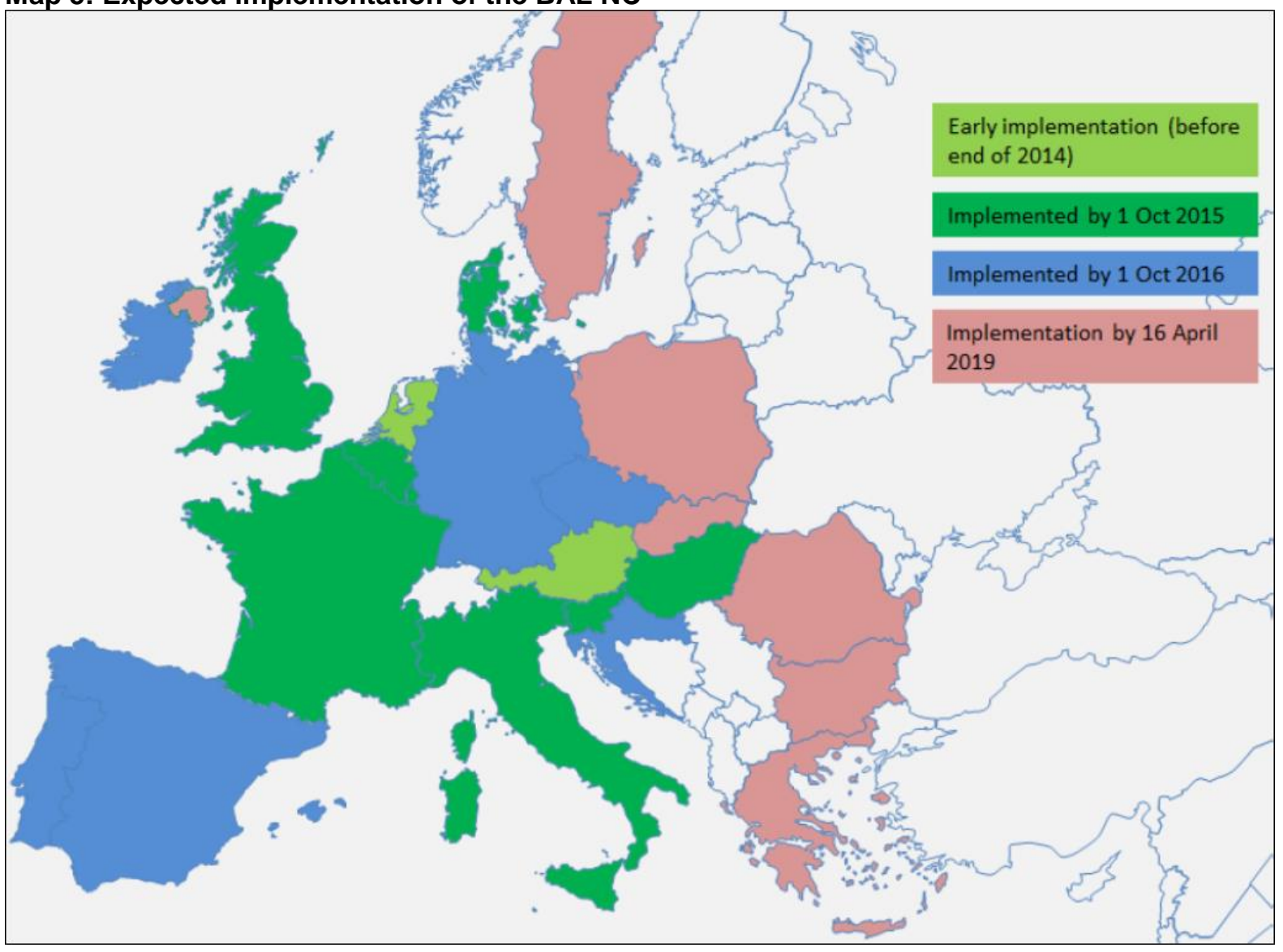

Source: ACER-ENTSOG Report on the early implementation of the Balancing Network Code (BAL NC), p.6

The political signals from Hungary in particular, have been very negative towards market liberalisation and trading. The Hungarian government of Viktor Orbán (or the Government of National Cooperation) is attempting to restore large enterprises to Hungarian state ownership ${ }^{231}$, including energy assets

231 BUDAPEST TELEGRAPH, 22nd September 2015: "Hungary seeks to restore domestic ownership of major enterprises": http://www.budapesttelegraph.com/news/819/hungary seeks to restore domestic ownership of major enterprises 

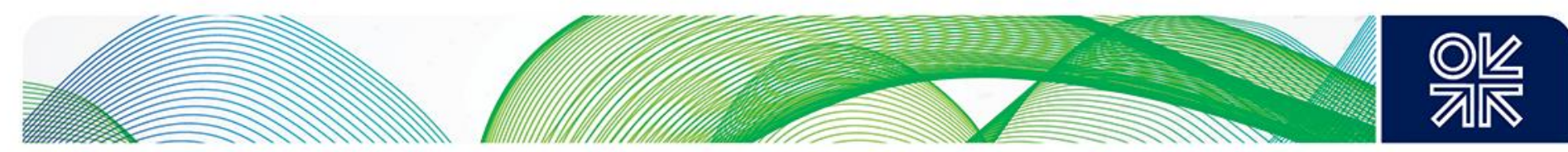

and has already spent HUF1000 billion to re-purchase energy firms, which had been privatized in the 1990s.

It is important to stress that the 2014 deadline set in the GTM was always a political target determined at the Community level. However forceful they may have been, these 'top down' rules were often resented in many countries. National sovereignty therefore acts as a break on progress and the interpretations of the codes have been as varied as the number of different countries. Worst of all is the apparent lack of enforcement from the Commission itself, which has allowed a wide variance in the adoption of the rules and regulations, leading to the current situation in GTM 2 that does not include a fixed final implementation deadline.

A joint ACER-Entsog report published 232 in October 2014 concluded $^{233}$ that only "two Member States have already implemented the BAL NC by end of 2014" and that a further "13 Member States expect to be fully compliant with the code on either 1 October $2015^{234}$ or 1 October 2016 ". It reported on the situation in the European Member States with regards to the implementation of the BAL NC and discovered that significant differences existed between the various regions in Europe. Most Member States in North West and Southern Europe have already implemented or are clearly aiming for implementation in either 2015 or 2016 at the latest, whereas most Member States in Central and Eastern Europe are opting for the 5 year implementation period which allows for the use of interim measures. Table 10 shows their findings.

Table 10: Implementation timelines of the BAL NC

\section{Member State}

\section{2 countries:}

Austria, the Netherlands*

8 countries:

Belgium, Denmark, France, Great Britain, Hungary,

Italy, Luxembourg, Slovenia

5 countries:

Czech Republic ${ }^{\star *}$, Germany ${ }^{\star * *}$, Hungary, Ireland,

Spain

8 countries:

Bulgaria, Greece, Northern Ireland, Poland, Romania,

Slovakia, Sweden, Portugal ${ }^{* * *}$

\section{Expected implementation date}

Up to 31 December 2014

Up to 1 October 2015

Up to 1 October 2016

Up to 16 April 2019 (interim measures)

* The Netherlands implemented the BAL NC on 1 July 2014, whereas Austria reported to be already compliant.

** Czech Republic will implement the BAL NC by 1 July 2016

*** Germany will implement the NC by 1 October 2016 except for the use of a balancing platform as an interim measure for 5 years.

**** Still undecided if Portugal will implement in 2016 or will go for interim measures until 2019.

Source: ACER-ENTSOG Report on the early implementation of the Balancing Network Code (BAL NC):

Annex III, p.53

The reasons given as 'barriers' to implementation ${ }^{235}$ are equally varied and sometimes surprising; of the 23 countries surveyed, 12 declared to have identified various issues, risks or barriers to the

\footnotetext{
232 http://www.entsog.eu/public/uploads/files/publications/Balancing/2013/ACER-

ENTSOG Report BAL NC Early Implementation-Final 22-Oct-2014.pdf

233 Executive summary, p.3.

234 See section 7: Developments in 2015 for the updated situation.

${ }^{235}$ ACER-ENTSOG Report on the early implementation of the Balancing Network Code (BAL NC): p.6.
} 

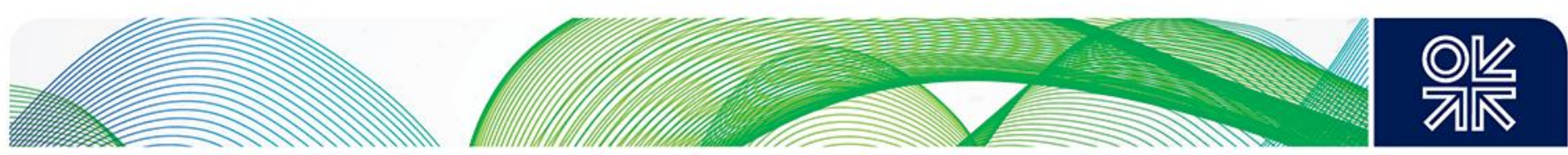

implementation of all or at least parts of the BAL NC. The specific areas of concern reported are a mixture of real tangible implementation problems and many 'excuses' that can be broadly divided in the three categories of political will, cultural attitude and commercial acceptance:

\section{Real physical issues:}

The presence of one main source and one main route for gas supplies and the low level of the local production (BG);

Considerable improvements required in the TSO's IT system to manage the new business processes (IT);

\section{Political will:}

Challenging implementation timescales (GB, PT, SI);

Concomitant changes in the system and industry developments (GB);

\section{Cultural attitude:}

$\mathrm{DSO}^{236}$ data provision towards the TSO, allocation rules on DSO networks and the profiled (non-daily metered) customers' forecasting methodology (HU);

\section{Commercial acceptance:}

Potential lack of market liquidity (IT, PL, PT, SK, SE, UKNI);

Readiness of market participants to adapt to the new regime and to assume a central role in balancing activities (IT).

What is interesting is that even in countries like Britain and the Netherlands, which already have 'mature' traded gas markets, there can be a reluctance to change the existing system (which is proven to work) to step in line with the EU-wide Network Code.

\subsection{2: Main Indicator 2: Cultural attitude}

This is no doubt a very subjective issue and one that is presented here from the Author's point of view. To a large extent this is really about the historical attitude of nations to trading in general and their approach to it. Countries such as Great Britain, the Netherlands and the Nordic countries have traditionally been 'trading nations' and have both disseminated their knowledge and accepted foreign influences equally, to develop very efficient market places. Others such as the Germanic countries have developed their own trading systems and have often stuck quite rigidly to them, knowing that 'they work'. Yet others such as France, Italy and other southern European countries have traditionally been more defensive of their trading environments including, in more recent times, espousing the virtues of 'national champions' over the actual performances of those companies.

Therefore, in the Author's opinion, Europe comprises a multitude of peoples all with very noble histories which combine to make this continent culturally diverse. But this has the downside of making Europe-wide implementation of standardised trading rules very difficult.

Cultural attitude alone is quite difficult to pin down as very often it forms part of an overall approach alongside political will and commercial acceptance. However, I will now illustrate with two examples: the German grid structure and the Within Day markets.

There are big cultural issues in Germany, a country that (it could be argued) is not really gas market friendly. Many of the market development initiatives and the accompanying rules are undermined by the very complicated grid structure of two Market Areas, each with multiple owners and TSOs; with

${ }^{236}$ Distribution System Operator. 

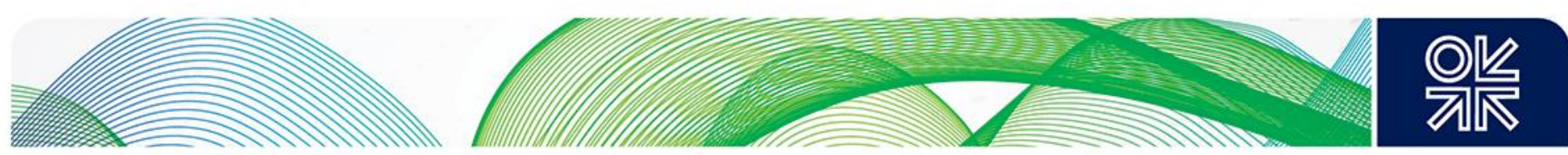

the parallel running of both high and low calorific gas networks without cost socialisation (as was effected some time ago in the Netherlands); and by the myriad municipal utilities, the Stadtwerke.

According to the Verband Kommunaler Unternehmen ${ }^{237}$ (VKU), the German Association of Local Utilities, there are 1,420 Stadtwerke in total (although they do not necessarily all supply gas). They were originally set up as local monopolies to ensure water supply, treat waste water and provide public transport and energy. When Germany liberalised its energy sector in 1998, allowing competition to hitherto regulated monopolies, many predicted local companies were doomed because they were too small, yet almost 20 years later, most Stadtwerke are alive and well and many are even in a better position than the Big Four ${ }^{238}$.

Today, there are hundreds of tiny Stadtwerke with only a few dozen employees as well as a few very large concerns that can rival the large utilities. (In particular the Stadtwerke München for example had a turnover of 6.3 billion euros in 2013.) As a group, in the German gas market, they account for $59 \%$ of retail sales compared to RWE, the largest single retailer, with a share of just $10 \%$. The Stadtwerke are able to keep this very strong position mainly because of the cultural attitude of the German people who trust them and like the fact that profits stay in the local community.

Turning to gas market balancing and Within Day (WD) trading: balancing is a safety issue and WD trading is an efficient market-led way of carrying this out, as prescribed by the European Network Code. Germany is still reluctant to adopt a proper within-day market; preferring the command and control associated with letting TSOs do short term balancing via its appointed agents in the Market Operators (NCG and Gaspool). German grid balancing is effectively done at the Day-Ahead stage, so there is very little WD trading and a large volume of DA trading; this is the same method used in Austria.

France does balance WD but does not have an equivalent to the OCM and, there too, many shippers will balance at the DA stage as substantial flows of physical gas come into France from Germany and Belgium/Netherlands. Italy primarily uses storage to balance WD so, there too, there is little need for shippers to trade WD gas (certainly not OTC, although, there is a very large volume traded on the 'PB-Gas' platform).

In Britain there is a very large volume of gas traded on the WD market, including on the OCM, the balancing platform set up to allow the TSO and shippers to trade with each other to help keep the system in balance. The amount of WD trading at the European hubs varies greatly, with that done at the NBP being by far the largest. The reason is that the NBP is balanced within day by the TSO (National Grid Gas), just like other hubs, but in Britain the TSO uses a prescribed method determined in the original Network Code of 1996. This was called the Flexibility Mechanism, which then became Open Link and finally, the On-the-day Commodity Market (OCM). This is a market styled trading platform which went through various incarnations but is now operated by ICE-Endex.

On the OCM, shippers and NGG can trade gas for delivery on D, from the afternoon of D-1 until 15:00 on $D$ itself. During this initial period it is possible that shippers might be matched with each other or with NGG; after 15:00 on D until 05:00, any shipper trading on the OCM will always have NGG as counterparty. The traded volume weighted average price for all trades done for D becomes the SAP (System Average Price). The lowest traded price becomes the SMPs (System Marginal Price Sell) and the highest traded price becomes the SMPb (System Marginal Price Buy).These prices are what are used by NGG to set the official gas price for D (SAP), along with the two punitive prices to penalise shippers who are out of balance (SMPs and SMPb).

\footnotetext{
237 "The 1,420 member companies organized within the VKU are primarily active in the fields of energy supply, water supply and sewage, waste management and municipal cleaning": http://www.vku.de/en/ueber-uns.html

238 Clean Energy Wire, $18^{\text {th }}$ February 2015: Factsheet "Small, but powerful - Germany's municipal utilities": https://www.cleanenergywire.org/factsheets/small-powerful-germanys-municipal-utilities

The Big Four German utilities are: RWE, EnBW, E.ON and Vattenfall.
} 

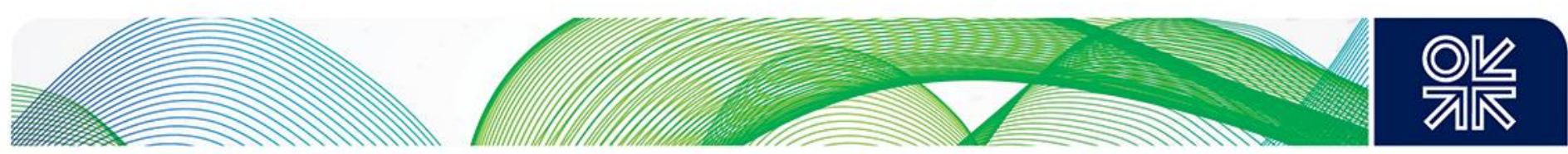

Britain's is the only European market with a fully functioning WD market and with a WD trading platform. No other country currently has within day balancing as set out in the NC and even the Netherlands which created a system of 'real time' balancing in April 2012, has not strictly followed the Network Code; its position is still under review by the TSO, Gas Transport Services.

Germany has 13 TSOs and an NC compliant balancing system and WD trading platform is unlikely to be introduced any time soon (as indicated in the notes in Table 10). Most other countries are either happy with what they currently are doing or do not yet have an established mechanism for shippers to 'trade' to balance (i.e.: those countries have very rigid 'delivery' mechanisms - 'Old World' style).

The engrained cultural attitudes across the Member States are causing a block to the efficient introduction of the Network Codes and, even in countries such as Germany that do have an 'active' gas market, the EU's vision of a Single energy Market is being held back.

\subsection{3: Main Indicator 3: Commercial acceptance}

Commercial acceptance is very much an element that goes hand in glove with cultural attitudes and political will. However, we can distinguish in this category certain elements that pertain especially to the commercial aspect of gas trading: in particular, the historical nature of gas contracts in Europe.

The current EU-led process of transformation in the gas (and electricity) markets towards competitive markets supplied with market priced gas is in contrast to the historical model of dominant incumbents and long term (oil-indexed) contracts. In order to achieve this process there needs to be companies all along the value chain that 'want to make the change'. It is perfectly understandable that a national incumbent will want to protect its 'cash cow' profit margins and future revenue flows. These are often nationalised companies (or only recently privatised) with strong ties to governments and so are able to successfully lobby for delays in the implementation of European law, even if they cannot stop it completely.

The roles therefore of the regulatory authorities and the TSOs are key to effecting change, but only if the political will is present in the first place to order that change to happen. In Britain, the process of change was led by the strong political will to 'privatise' the nationalised British Gas ${ }^{239}$ and there was then a strong alignment of interest from all the key market players to make the new market work. British Gas was forced to accept change following political and competition law intervention. Ofgas 240 set out how the market would be regulated in an open transparent way; Transco as TSO actively promoted the move believing that in the face of the inevitable, shaping the future was a better way forward; and the market participants were keen to see a viable market established quickly within a commercially friendly environment.

The Netherlands came next following the politically led initiative of the Gas Roundabout strategy. ${ }^{241}$ By this stage they realised that a full and clear move to an open and transparent commercial gas market was to be an advantage to the country. There too, full commitment came from the incumbent producer, GasTerra (after some political pressure to 'use the hub'), from the TSO and from market participants. Once the change had been effected, the TTF hub has not looked back and will probably supersede the NBP in 2015 as Europe's premier gas hub.

The question is, is there really sufficient commercial acceptance across the other European countries to enable a successful change towards fully liberalised gas markets?

\footnotetext{
${ }^{239}$ For a full account of this process, see Heather (2010).

240 The precursor to the current Ofgem.

${ }^{241}$ For a full account of this process, see Heather (2012).
} 

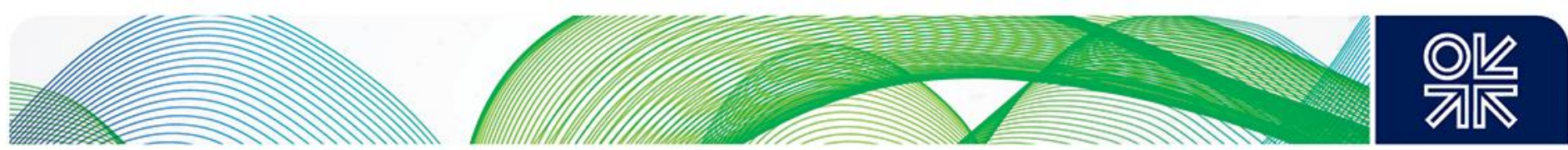

\subsection{4: Summary of the Three Main Indicators}

These three Main Indicators are most certainly inter-dependent in enabling the move towards fully liberalised gas markets across the entire EU. There must be the political will to get the process off the ground; there must be the cultural attitude to want to succeed in a trading environment; and there has to be the right commercial appetite to see all the changes followed though.

We have seen that the European Commission is very keen to see the process completed across all of the Member States so that there will be, one day, a Single Energy Market. Thus far though it is also evident that in many countries there is not the political will to carry out this vision. There are also in many cases strong cultural attitudes that hinder the development of liberalised markets; and finally, there are still too many incumbent or dominant companies that want to protect their current revenue streams.

Therefore, we will only see the emergence of liberalised, open, transparent and efficient traded gas markets in those countries where all three indicators can positively be aligned to fulfil the EU's vision. The level of progress is patchy across the Union and it is probably best to look at any observable results.

The European Commission published a report 242 in October 2014 on the progress in the energy markets of the EU. After evaluating the commercial progress of the gas hubs and their traded volumes, it then focuses on the wholesale price of gas ${ }^{243}$ across the Member States. The results show that it is the two countries that have the only mature hubs, Britain and the Netherlands that have the lowest wholesale gas prices in H1-2014: $€ 21.62 / \mathrm{MWh}$ and $€ 21.58 / \mathrm{MWh}$ respectively. They are joined by Denmark, Austria, Belgium and Germany in the lowest price group ( $<€ 25 / \mathrm{MWh}$ ) of four categories.

The second tier group (€25/MWh - €27.50/MWh) comprises Poland, Romania and Hungary, where all three countries have regulated prices and both Poland and Romania have domestic production. The third tier group (€27.51/MWh - €30/MWh) comprises, in ascending price order: Spain, Czech Republic, France, Italy, Slovakia, Finland, Latvia, Slovenia, and Bulgaria. Finally, the dearest price group (>30€/MWh) comprises Greece, Estonia, Sweden and Lithuania with the highest wholesale gas price in Europe of $€ 35.20 / \mathrm{MWh}$.

The report concludes that "as illustrated by the map 244 , [ ] Member States with few supply choices were facing a tougher bargain and higher prices." However, what this report also shows is that there are still very wide discrepancies in the wholesale prices of gas across Europe, taking into account all sources. Even in those countries that have progressed towards liberalisation, prices are not necessarily competitive. It also shows that even in some countries with a good choice of supply, such as France, Spain and Italy, there is not yet a truly competitive market to help bring prices lower.

The EFET Gas Hub Development Study, mentioned in section 6.6.3 is a good proxy for evaluating the three Main Indicators across all countries, including those that do not yet have an operational traded gas hub, as it assesses 5 regulatory conditions, 6 TSO conditions and 6 market conditions.

The results, already shown in Table 3 , are enhanced by a 'traffic light' methodology as follows: Green: =>18; Amber: <18; Red: <12; this then produces the 'mature/active', 'poor' and 'inactive' rankings in Table 11.

\footnotetext{
242 EU Energy Markets in 2014: http://ec.europa.eu/energy/sites/ener/files/documents/2014 energy market en.pdf

${ }^{243}$ Competitive energy markets being one main reason for the European Union to pursue market liberalisation.

${ }^{244}$ See Appendix Q for the map of the comparison of EU28 average wholesale gas prices: $\mathrm{H} 1-2014$.
} 

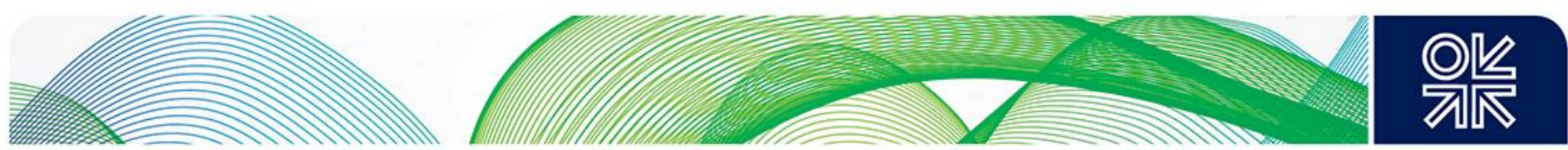

Table 11: EFET Hub Scores categorised as mature/active, poor and inactive

\begin{tabular}{|l|c|c|}
\hline HUB & Score 2014 & Score 2015 \\
\hline NBP & 20 & 20 \\
\hline TTF & 19 & $191 / 2$ \\
\hline NCG & $151 / 2$ & 19 \\
\hline GPL & 16 & 19 \\
\hline ZEE & 18 & 18 \\
\hline ZTP & 16 & $171 / 2$ \\
\hline PEGs & 16 & $161 / 2$ \\
\hline PSV & $101 / 2$ & 15 \\
\hline VTP & 14 & 14 \\
\hline GTF & 9 & $11 \frac{1}{2} 2$ \\
\hline VOB & 8 & $81 / 2$ \\
\hline AOC & 7 & 7 \\
\hline SK & $31 / 2$ & 7 \\
\hline MGP & 5 & $61 / 2$ \\
\hline GR & 5 & 6 \\
\hline VPGS & $41 / 2$ & $51 / 2$ \\
\hline UDN & $51 / 2$ & 5 \\
\hline RO & $21 / 2$ & $11 / 2$ \\
\hline BG & $11 \frac{2}{2}$ & 1 \\
\hline MIBGAS & 2 & 0 \\
\hline
\end{tabular}

Source: EFET 2015 Review of Gas Hubs Assessments; P. Heather

Not surprisingly, the order of the hubs is almost identical to that in Table 9, except that EFET does not distinguish between the three PEGs and that the VTP and PSV rankings are reversed. Of course, it does assess 10 further hubs, of which 8 are ranked lower; the two that are not, are the Belgian virtual hub, ZTP, which is ranked $1 / 2$ a point below ZEE, and the Danish GTF, which very narrowly misses being in the mid-market band. I did not assess these two hubs.

This independent analysis, using very different criteria to the Author's, arrives at the same conclusions as to the European hubs' stages of development. 

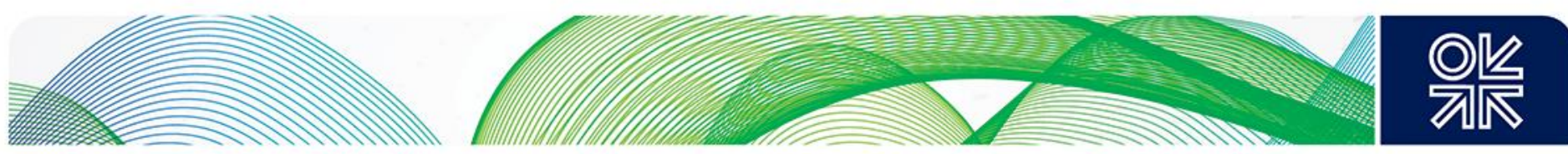

\section{7: Developments in 2015}

European demand could rise slightly in 2015 after 4 consecutive years of decline; the latest estimate from Eurogas ${ }^{245}$ predicts a $7 \%$ increase for the full year, after a $9 \%$ increase in $\mathrm{H} 1$ year on year. This is attributed to average weather conditions compared to the warmer years of 2013 and 2014 . However, in each of the last 4 years, predicted demand levels have proved to be optimistic when the final volumes were known.

European production will fall more in 2015 than the recent trend due to the cap on Dutch production imposed by the Dutch government after earth tremors that occurred in the Groningen area. In January 2014, the government imposed a cap for 2014 and 2015 of $42.5 \mathrm{bcma}$; it also said that this would reduce to $40 \mathrm{bcm}$ for 2016. Then, in December 2014, it revised the production levels for 2015 and 2016 to $39.4 \mathrm{bcma}$.

After further consultation with interested parties, the Government decided ${ }^{246}$ in June 2015 that production in $\mathrm{H} 2-2015$ would be capped at $13.5 \mathrm{bcm}$, making a total for the full year of just $30 \mathrm{bcm}$. It was further announced that the limit for 2016 and beyond would be at a maximum of $33 \mathrm{bcma}$. The Minister of Economic Affairs, Henk Kamp, stated: "The safety of the people of Groningen must come first. We are reducing gas extraction in Groningen as far as feasibly possible at the present time. The Government has therefore decided on a maximum of 30 billion cubic metres in 2015." According to the operator, NAM, Groningen output for the first nine months of 2015 was down $25 \%$ year on year at $22.22 \mathrm{bcm}$.

In September 2015, Gazprom Export conducted its first ever gas auctions ${ }^{247}$, declaring its intention to partially move away from the traditional long-term contracts system based on oil-indexed prices towards new flexible market-driven tools. Gazprom sold just under $40 \%$ of the $3.34 \mathrm{bcm}$ offered during the auctions on $7^{\text {th }}-10^{\text {th }}$ September, for delivery in winter 2015/16 in Germany. The company awarded lots to 16 buyers (half of them were new partners) while 39 companies were initially qualified to take part.

Announcing the results on $10^{\text {th }}$ September, Alexander Medvedev, the deputy chairman of Gazprom's management committee said: "We are satisfied with the process and the results of the auction. We managed to effectively sell additional gas volumes on our most important German direction, to earn additional revenues, and to gain valuable experience."

Although the volumes offered for auction were a small fraction of the contract gas sales to Europe, this does signify an important move away from rigid oil-indexed pricing for the company and could, in time, bring greater activity and liquidity to German and other north west European gas hubs.

The European traded gas hubs have continued to develop and grow during 2015, especially the Dutch TTF which, at the time of writing, equals the British NBP and could very well surpass it by the end of the year in terms of trading activity. Other hubs are also showing signs of further growth such as PEG Nord and, especially, the Italian PSV.

\footnotetext{
245 Platts, 23 ${ }^{\text {rd }}$ October 2015: "Eurogas sees EU 2015 gas demand increasing 7\% on year".

${ }^{246}$ Netherland government website, $23^{\text {rd }}$ June 2015: "Groningen gas extraction further reduced to 30 billion cubic metres in 2015": https://www.government.nl/latest/news/2015/06/23/groningen-gas-extraction-further-reduced-to-30-billion-cubic-metresin-2015

${ }^{247}$ Platts, $16^{\text {th }}$ September 2015: "Russia's Gazprom edges towards flexible gas market-driven auctions": http://www.platts.com/latest-news/natural-gas/london/russias-gazprom-edges-towards-flexible-gas-market-26210724
} 

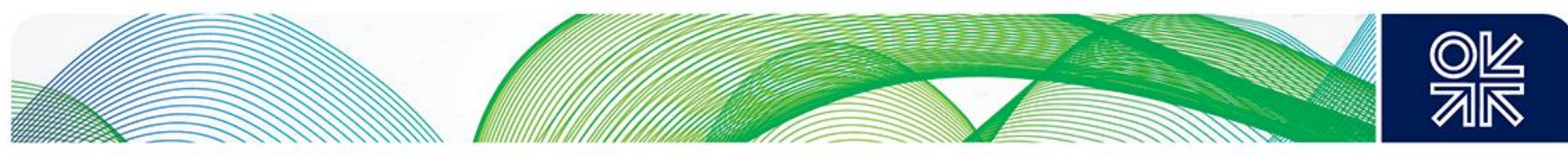

The total trading activity over the first nine months to the end of September, was actually fairly static year-on-year but there were some wide variations. The total OTC volumes as reported by LEBA ${ }^{248}$ were up $0.2 \%$, although this included a large rise in cleared volumes (given up to the exchanges, and in particular on the NBP, TTF and PEG Nord hubs); the net bilaterally settled volumes actually fell $3.3 \%$. When comparing hub to hub, five saw a fall in traded volumes: ZEE $(-0.3 \%)$, NCG $(-5.2 \%)$, NBP $(-9.6 \%)$, GPL $(-12.9 \%)$ and VTP $(-13.4 \%)$; the remaining three hubs increased their traded volumes: TTF $(+11 \%)$, the PEGs $(+28 \%)$ and PSV $(+37 \%)$. The trend at the NBP of volumes going from OTC to exchange has continued and the TTF also had higher exchange volumes.

The ICIS Tradability Index, which refers to OTC trading, echoed the LEBA statistics, especially for the TTF, PEG Nord and PSV hubs. The NBP, NCG, GPL, ZEE and VTP hubs had the same TI result in Q3-2015 as they had at the end of 2014; however, the TTF increased from 19 to 20, the VOB from 8 to 10, the PEG Nord from 9 to 12 (although for the first time ICIS has started to report PEG Sud separately), and the greatest increase was the PSV, from 9 to 13. These results confirm TTF's position at the top of the $€$ denominated hubs and that a few of the 'middling' hubs are slowly improving, although this would not change their ratings in the summary table (Table 9).

The Gas Target Model 2 (more properly called the "European Gas Target Model - review and update") was published by ACER in January 2015. Disappointingly, it was a case of 'lowest common denominator' as it dropped two important criteria from the original Model: the market zone size needing to be over $20 \mathrm{bcm}$; and the churn rate needing to be over 8 times. Not only was its threshold for the churn lower than the commonly held level for maturity, but both criteria were almost certainly dropped as it was realised that they simply were not realistically achievable across all of Europe.

There will be a further review in 2017 to assess each Member State's ability to meet the GTM2 criteria and, if there are still outstanding issues, more structural changes might be considered. The goal of the $\mathrm{EU}$ is that a single energy market will be realised and I think that they will make every effort to get all Member States to adhere to the requisite Directives and to the Network Codes, even if that means changing some of the rules, regulations and targets.

On $1^{\text {st }}$ October 2015 , the EU officially started its push towards more within-day gas balancing with the formal application 249 of the EU gas balancing network code (BAL NC). This is the first of the EU gas network codes to apply and follows years of work by the European Commission, EU energy regulatory agency ACER, grid operators and users as part of efforts to integrate the EU's national gas markets and increase cross-border trading. Full gas balancing harmonisation is still some years off however, according to ACER's latest available data.

Table 10 showed the expected implementation timetable as it stood in October 2014. One year on and most of that information is still correct with one major exception: Italy has not managed to apply the BAL NC this October and even says that it may delay its implementation until October 2017.

During 2015 a new hydrocarbons law (amendment) was passed in the Spanish parliament which lays down the framework for that country's adherence to the GTM2. The first evidence should be the start of operations on the new Spanish gas hub; however, there has already been a delay: according to one source, "The operator of the so-called MIBGAS initiative, OMIE, which operates co-ordinated Iberian energy markets and coordinates the related auctions, is still awaiting the necessary Royal Decree which will allow the market to commence operations"250.

Spain has other gas legislation still pending approval this year, including a possible tax on upstream production and a decree governing the mothballing of gas-fired plants.

\footnotetext{
${ }^{248}$ London Energy Brokers' Association.

${ }^{249}$ Platts, $2^{\text {nd }}$ October 2015: "EU starts within-day gas balancing push with network code application".

250 Platts, $21^{\text {st }}$ September 2015: "Iberian MIBGAS hub to likely miss Sep 23 start".
} 

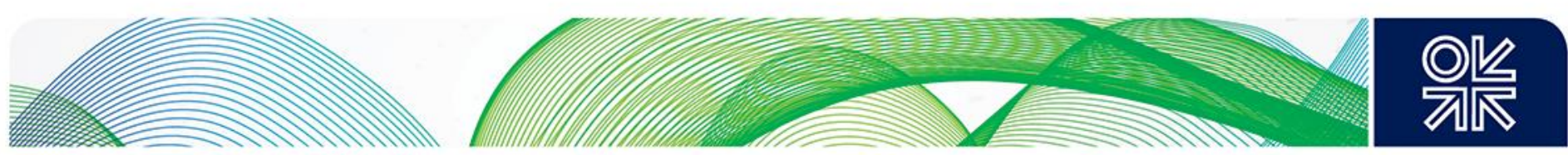

Poland has a new draft energy bill, which was revealed in August 2015, although it does not sound too positive for gas. ${ }^{251}$ The Polish Ministry of Economy revealed a new draft Polish Energy Policy to 2050, showing that the government is determined to reduce the country's dependence on coal. It includes one 'basic' scenario and two alternative ones. All the scenarios lead to reduced use of brown and black coal and more nuclear power and renewables; gas use would increase slightly to $18 \%$ of primary energy and $9 \%$ of power generation. It also signals the possible end of shale gas development in Poland.

\section{8: Summary and Conclusions}

Much has happened in the development of gas hubs in the past 30 years; the process was started in North America, followed by Britain and then by Continental Europe. In all cases, it has taken many years to complete the transition from the 'old' world to the 'new' and it has been a very costly process for many participants. In particular, the incumbent monopolistic companies had to give up market share and the large utilities who wanted to renegotiate their supply contracts often incurred very large financial 'write offs' to bring those contracts back to market value.

Britain's gas markets started their journey of transformation in the mid-1990s, a process that took about 14 years to complete but one that has delivered a fully liberalised market. The NBP hub reached maturity within 10 years, although it has now become a successful liquid benchmark NBP hub.

West European gas markets really started the liberalisation process, following the First and Second Gas Directives, in the mid-2000s and, despite a successful Dutch TTF hub, are still some way from being fully liberalised across all countries. The added complication of reviewing and adapting the Long Term Gas Contracts to the new market model has added time and cost to the transformation; however, the evidence shows that the transformation is happening and will probably take as long as it did in North America or Britain. This means that the markets could be fully liberalised by the end of this decade.

East European gas markets have barely started their evolution towards liberalised, competitive markets but, through EU Directives and commercial pressure, will change in time, but the end date could be as far away as 2025 .

Although every EU member state will have, in time, its own gas hub into which and from which physical volumes of gas will be traded, only a few of these hubs will likely emerge as price reference hubs. It is clear that the British NBP the Dutch TTF are now established as benchmark hubs; it is likely that there will be between one and three further hubs developing into marker hubs, possibly in one or other of: Southern Europe, North Eastern Europe, Central Europe or South Eastern Europe. It is certainly the European Commission's wish ${ }^{252}$ that the Eastern and Southern European gas markets develop to the same extent as in the north-west. However, there must be a commercial imperative for such hubs to develop, usually driven by the diverse, sizeable import flows into a market of material scale giving rise to different dynamics to those in the other already liquid hubs, thereby creating the possibility of arbitrage in response to price signals having, at their root, different causes.

\footnotetext{
251 Defence24.com, 25 ${ }^{\text {th }}$ August 2015: "Polish Energy Policy Until 2050 - Nuclear Energy Replaces Coal; End Of The Shale Revolution": http://www.defence24.com/248097,polish-energy-policy-until-2050-nuclear-energy-replaces-coal-end-of-the-shalerevolution

252 ENERGY UNION PACKAGE (Brussels, 25.2.2015, COM(2015) 80 final): "In Northern Europe, the establishment of liquid gas hubs with multiple suppliers is greatly enhancing supply security. This example should be followed in Central and Eastern Europe, and in the Mediterranean area, where a Mediterranean gas hub is in the making."
} 

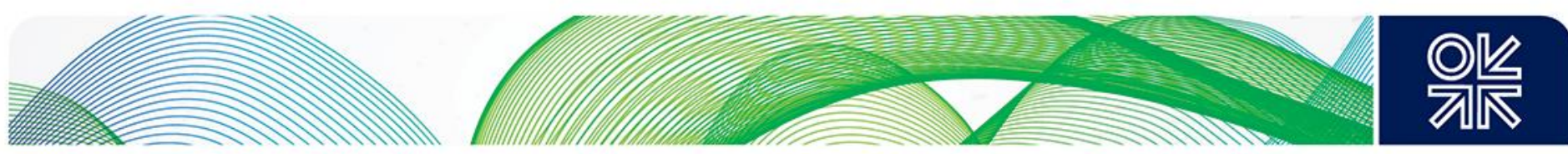

In the meantime, further market interaction within the southern and eastern regions of Europe, both north-south, east-west and vice versa, should be envisaged in order to strengthen EU energy security. These must include the adoption of the GTM and the Network Codes, thereby increasing transparency, flexibility of supply, fair and easy access to cross border trade, all within a stable and effective regulatory framework. In parallel to this, the development of the Gas Regional Infrastructure Plans (especially the Southern Corridor GRIP) with appropriate planning and investment must continue in order to improve the gas infrastructure networks and so facilitate the transportation of gas across the Union.

It may be obvious, but significant trading will only occur when certain prerequisites are in place:

- If there are a number of sellers and buyers at each hub;

- If the infrastructure is able to flow physical gas to where it's needed, when it's needed;

- If cross-border arrangements are in place and without constraints; and,

- If there is then a 'reason' for trading.

The legislative and commercial environment must be attractive for traders to even contemplate entering a market, and if all these prerequisites are in place, then it is likely that a virtuous circle will be started thereby helping a particular hub to develop and succeed.

From a legislative point of view, although having taken a long time to write and get ratified, the process of implementing the Network Codes is underway and will continue, albeit at a rather slow pace. Overall, the European gas market is perhaps not in quite such a bad state as many make out. There are functioning markets that operate in both the short and the longer term. However, efforts need to be made to make sure that interconnection capacity is created and appropriately used when needed, even if that means that it is not always used to its full capacity. What is important in the near term is the implementation of the balancing code, which will fully enable the realisation of a short-term balancing market.

There have been some important moves to developing a more cohesive wholesale gas market in Europe and there have been signs that trading is picking up slightly overall, with some notable exceptions. It remains to be seen whether the positive trend can continue forward, hopefully at a faster pace!

The reality at the end of 2014 is that Europe does have two leading, mature, benchmark hubs, a few 'active' hubs and several mid-market hubs that do trade, especially in the spot/prompt and near curve and that are primarily 'balancing' hubs. This trading model could have a third market hub in due course but realism must prevail. The model of concentrating liquidity on one benchmark hub has served the North American market well, where trading and liquidity is focussed on a single hub (Henry Hub) and each of the other 32 hubs trades at a 'basis' to the benchmark.

This is a system that is beginning to develop in Europe and one that should provide the required physical flexibility as well as the financial risk management tools. The emerging hubs will need to adopt the BAL NC and should then be in a position to become efficient balancing hubs; but, as we have seen, this process has already taken a long time and the end point is not clearly determined yet. To return to the question posed in the introduction: the European Union's vision for a Single Energy Market is still many years off. 

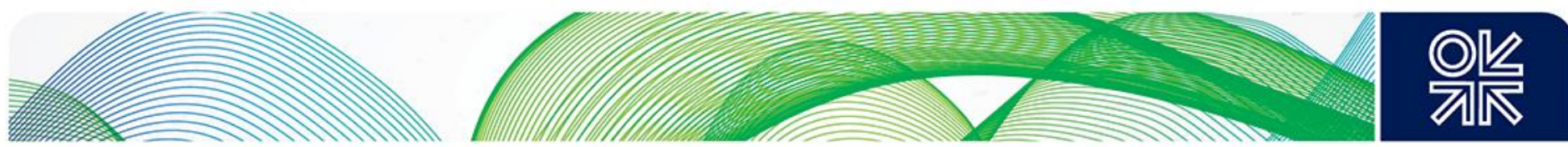

\title{
9: Appendices
}

\section{A) Balancing Network Code, Article 45}

CHAPTER X

\section{INTERIM MEASURES}

Article 45

\author{
Interim measures: general provisions
}

1) In the absence of sufficient liquidity of the short term wholesale gas market, suitable interim measures referred to in Articles 47 to 50 shall be implemented by the transmission system operators. Balancing actions undertaken by the transmission system operator in case of interim measures shall foster the liquidity of the short term wholesale gas market to the extent possible.

2) The resort to an interim measure is without prejudice to the implementation of any other interim measure(s) as an alternative or additionally, provided that such measures aim at promoting competition and liquidity of the short term wholesale gas market and are consistent with the general principles set out in this Regulation.

3) The interim measures referred to in paragraph 1 and 2 shall be developed and implemented by each transmission system operator, in accordance with the report, referred to in Article 46(1), approved by the national regulatory authority in accordance with the procedure set out in Article 46.

4) The report shall foresee the termination of the interim measures no later than five years as from the entry into force of this Regulation.

\section{B) Balancing Network Code, Article 47}

CHAPTER X

\section{INTERIM MEASURES}

Article 47

Balancing platform

1) Where the short term wholesale gas market has or is anticipated to have insufficient liquidity or where temporal products and locational products required by the transmission system operator cannot reasonably be procured on this market, a balancing platform shall be established for the purpose of transmission system operator balancing.

2) The transmission system operators shall consider whether a joint balancing platform may be implemented for adjacent balancing zones in the framework of cooperation between the transmission system operators or where there is sufficient interconnection capacity and such joint balancing platform is deemed efficient to be implemented. If a joint balancing platform is established, it shall be operated by the transmission system operators concerned.

3) In case the situation described under paragraph 1 has not fundamentally changed after five years the national regulatory authority may, without prejudice to Article 45(4) and after submitting the appropriate amendment of the report, decide to continue the operation of the balancing platform for another period of no more than five years. 
C) North American gas regions, markets and hubs

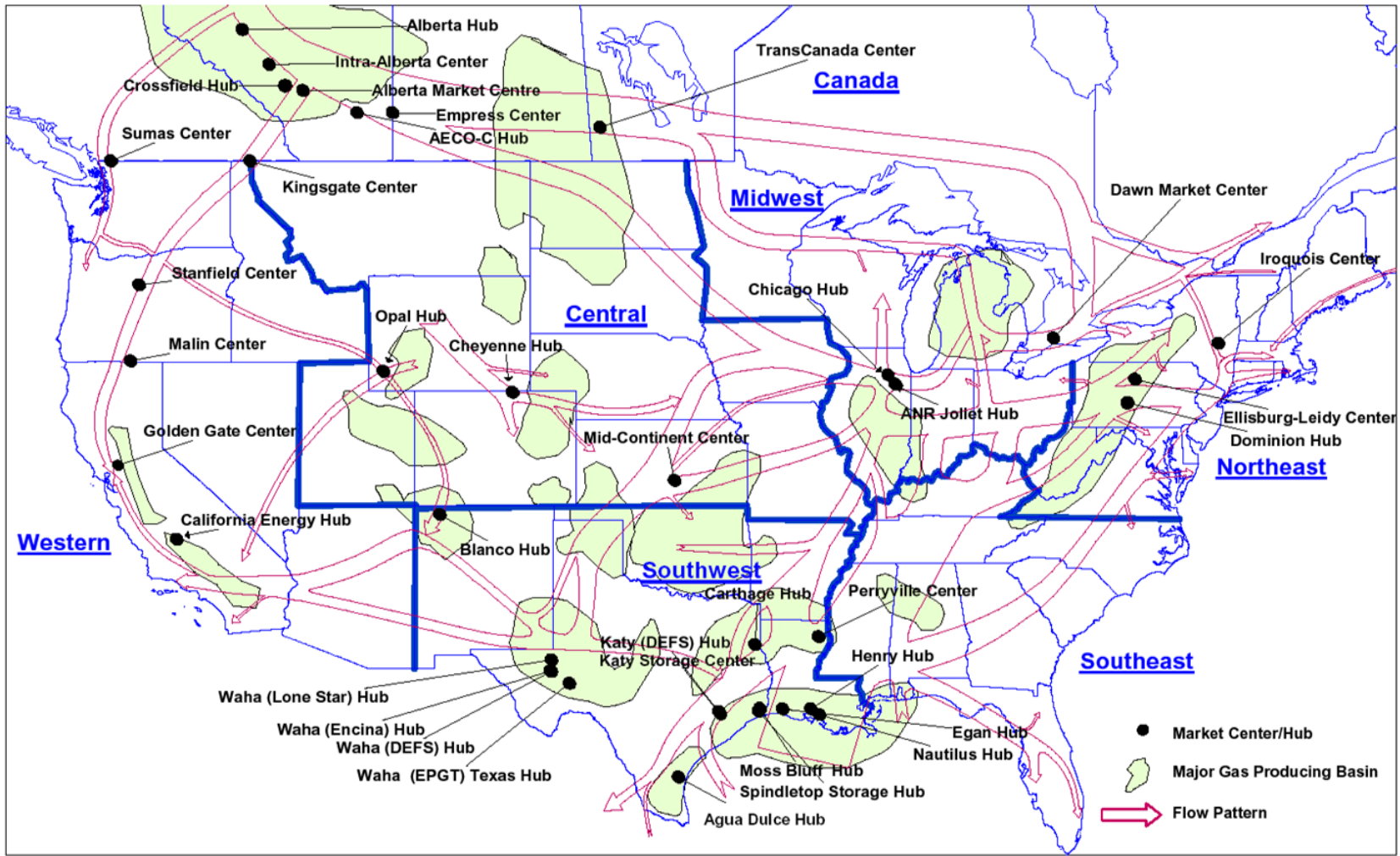

Source: Katy (DEFS) Hub, from EIA

D) Map of the Turkish Stream project

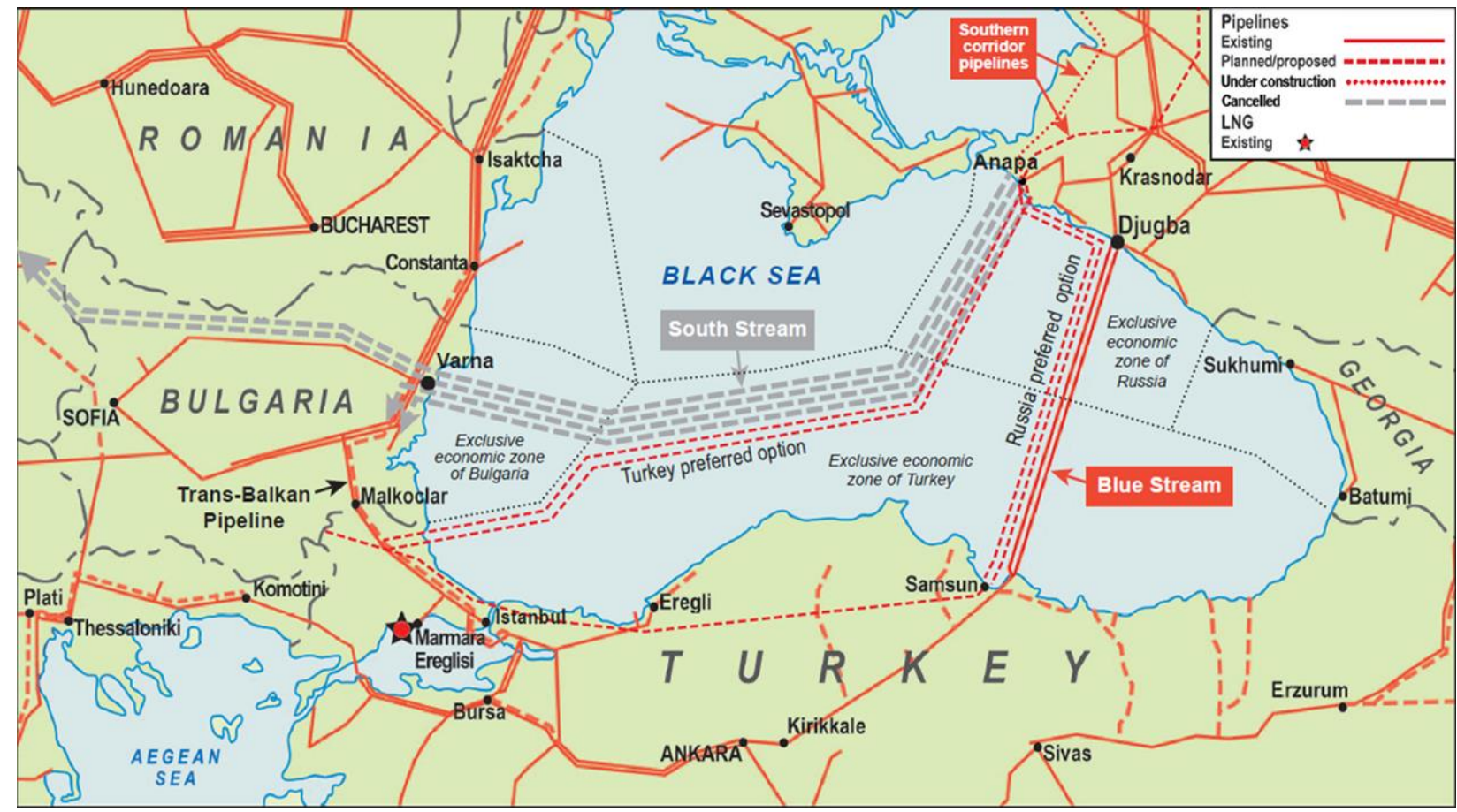

Source: OIES 

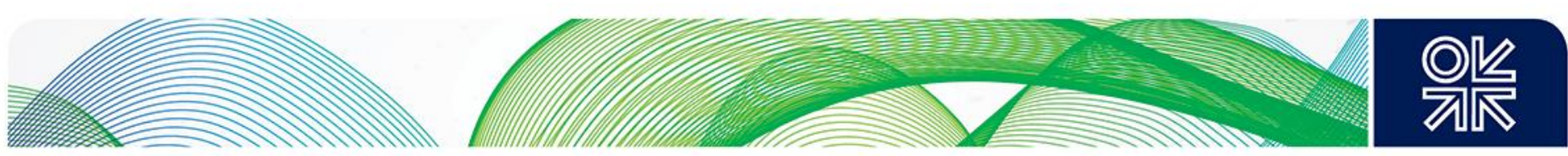

E) European traded gas hubs in 2014

\section{NBP}

National Balancing Point; Great Britain; 1996

\section{ZEE/ZTP}

Zeebrugge Hub / Zeebrugge Trading Point; Belgium; 2000/2012

TTF

Title Transfer Facility; Netherlands; 2003

PSV

Punto di Scambio Virtuale; Italy; 2003

PEG (N,S,T)/TRS

Point d'Echange de Gaz (Nord, Sud, TIGF)/Trading Region South; France; 2004/2015

AOC

Almacenamiento Operativo Comercial; Spain; 2004

GTF

GasTransfer Facility; Denmark; 2004

\section{CEGH/VTP}

Central European Gas Hub / Virtual Trading Point; Austria; 2005/2013

GPL

Gaspool; Germany; 2009

NCG

NetConnect Germany; Germany; 2009

\section{VOB}

Virtuální Obchodní Bod; Czech Republic; 2011

VPGS

Virtual Point Gaz-System; Poland; 2014 

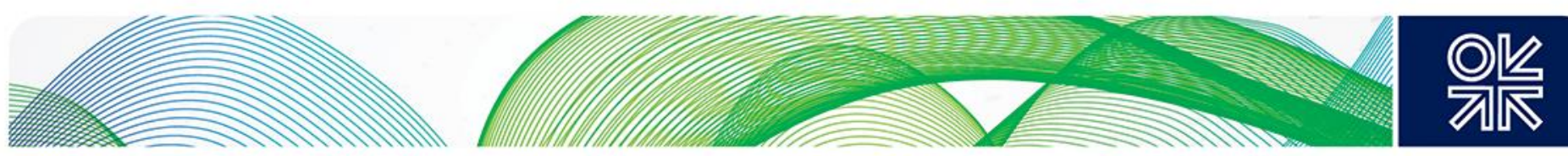

F) Main exchanges offering gas contracts in 2014

\section{The ICE}

NBP futures and options contracts

NCG, GPL, ZTP futures contracts

Months, Quarters, Seasons, Years

Month Ahead to 6 Years forward

\section{ICE-Endex}

TTF futures and options contracts

Months Quarters, Seasons, Years

Month Ahead to 5 Years forward

NBP, TTF, ZTP spot contracts

NBP: OCM; TTF/ZTP: Within Day and Day Ahead

\section{EEX}

NCG, GPL futures contracts (+NBP clearing: zero volume)

Months, Quarters, Seasons, Years

Month Ahead to 3 Years forward

NCG, GPL, TTF spot contracts

Within Day and Day Ahead

\section{Powernext}

PEG N, PEG S, TTF, futures contracts

3 Months (N,S,TTF), 3 Quarters(N,TTF), 3 Seasons(N,TTF), 1 Year(N)

5 spread futures contracts

PEG N, PEG S, PEG T, ZTP spot contracts

Within Day, Day Ahead, WeekEnd, Individual Days

\section{CEGH}

VTP, VOB futures contracts

VTP spot contracts (WD, DA, WE)

\section{GME}

PSV futures contracts (P-Gas: no volumes)

PSV spot contracts (MI-Gas + MGP-Gas: very little volume)

GME "balancing" market: (PB-Gas: not PSV but good volumes) 

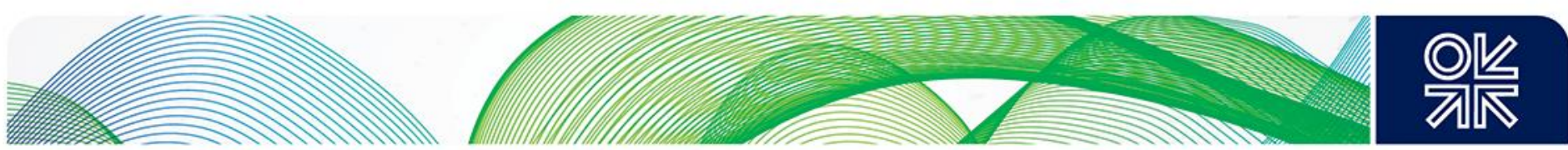

G) Spanish Gas Network System

\section{Spanish Gas Network System Infrastructures at January $31^{\text {st }} 2015$ (in operation)}

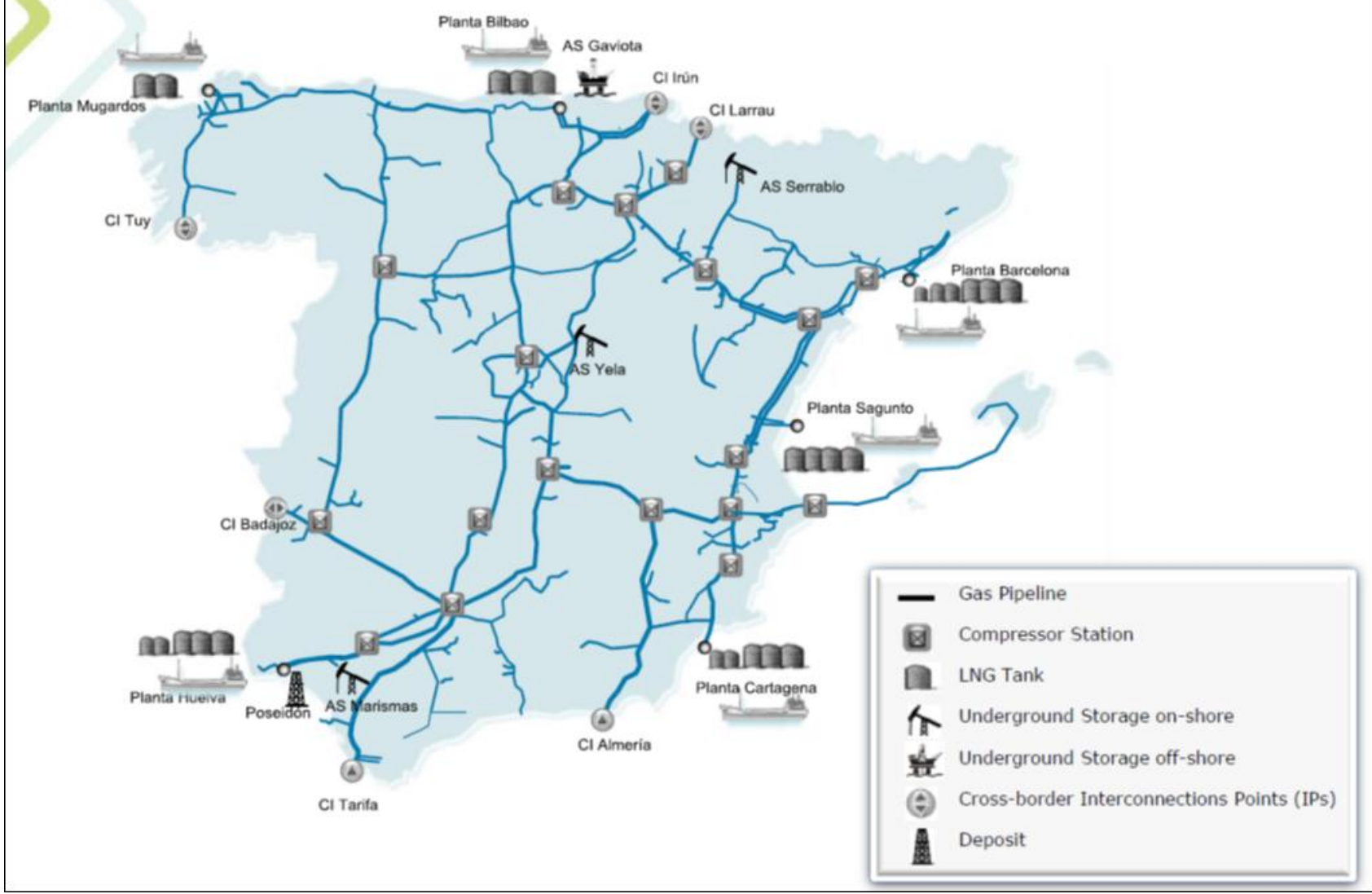

Source: Enagas 


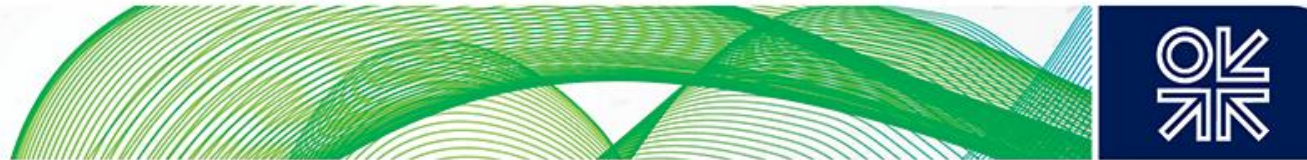

\section{H) Portuguese Gas Network System}

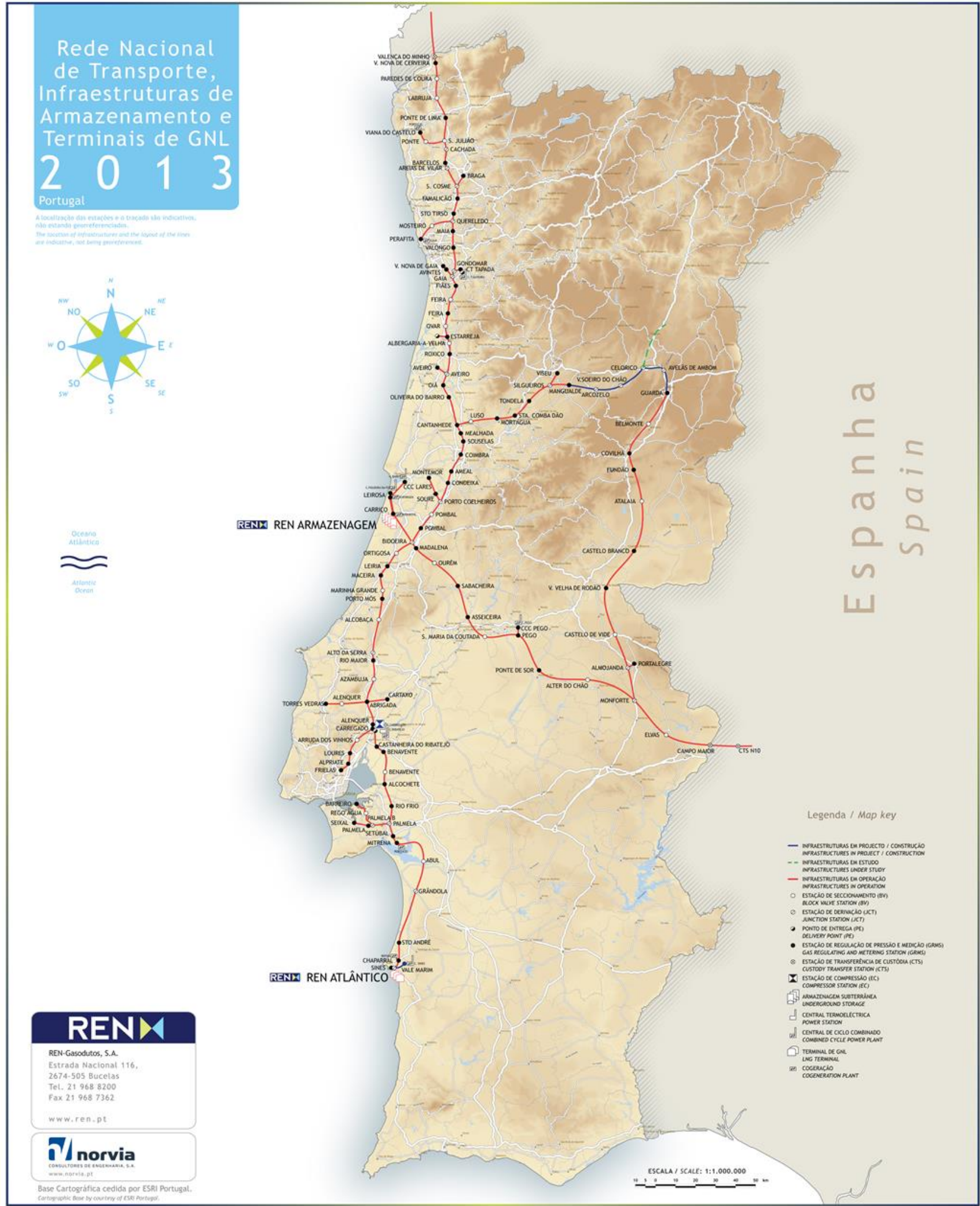

Source: REN 

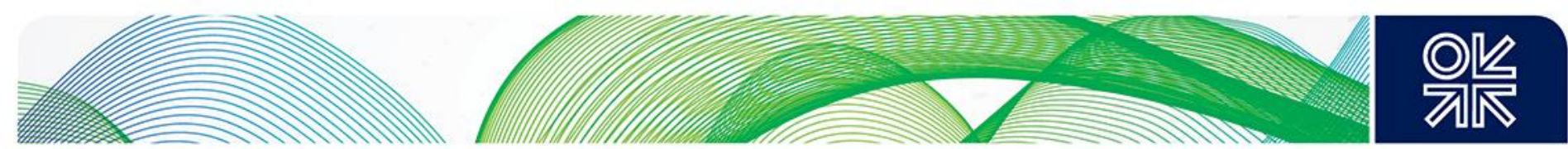

I) Italian Gas Network System

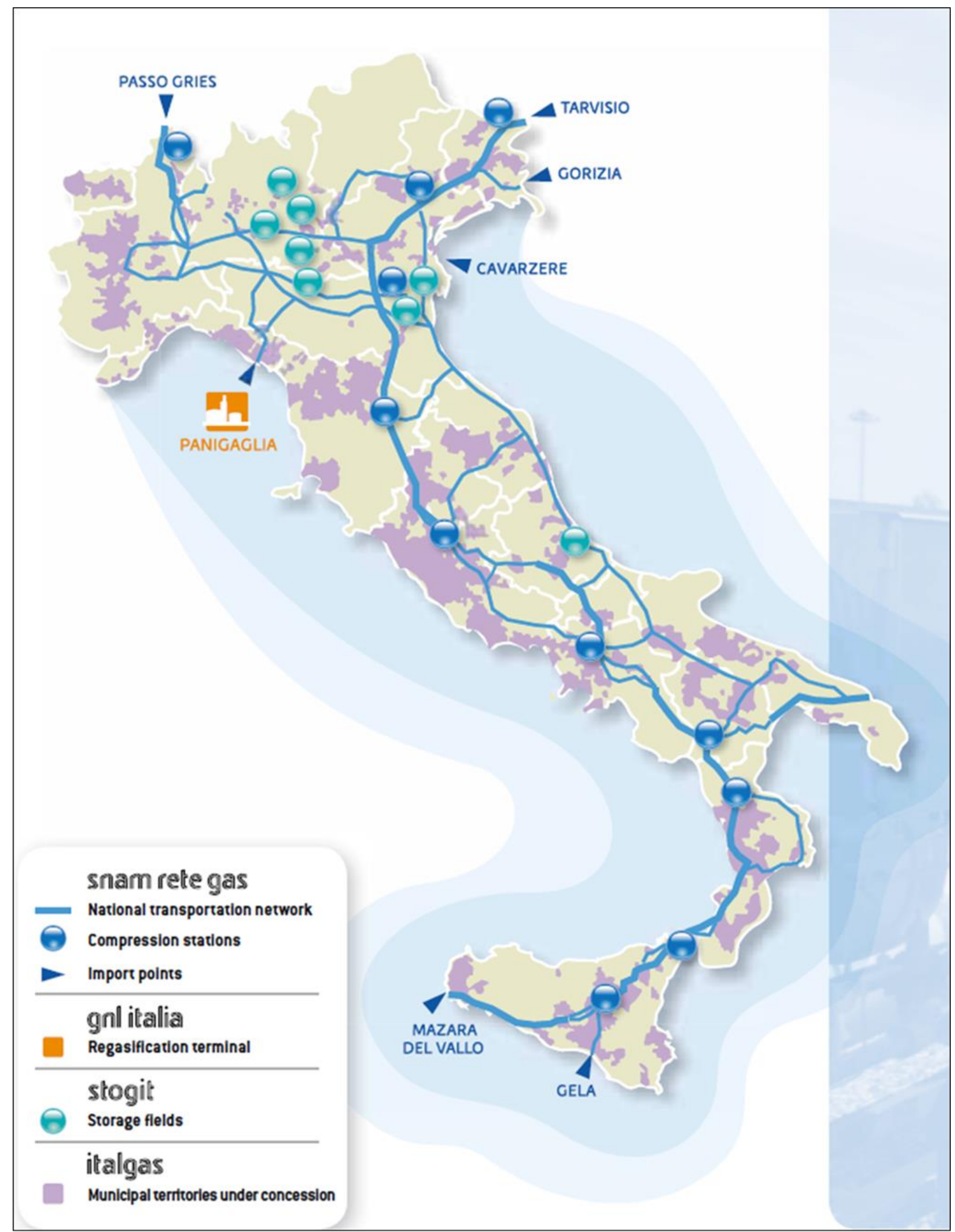

Source: SNAM Rete Gas 

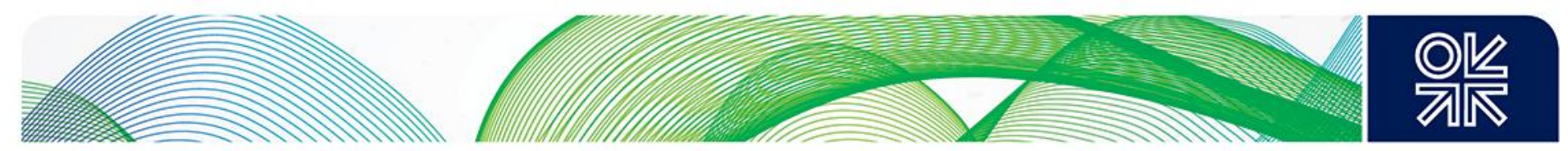

J) Greek Gas Network System

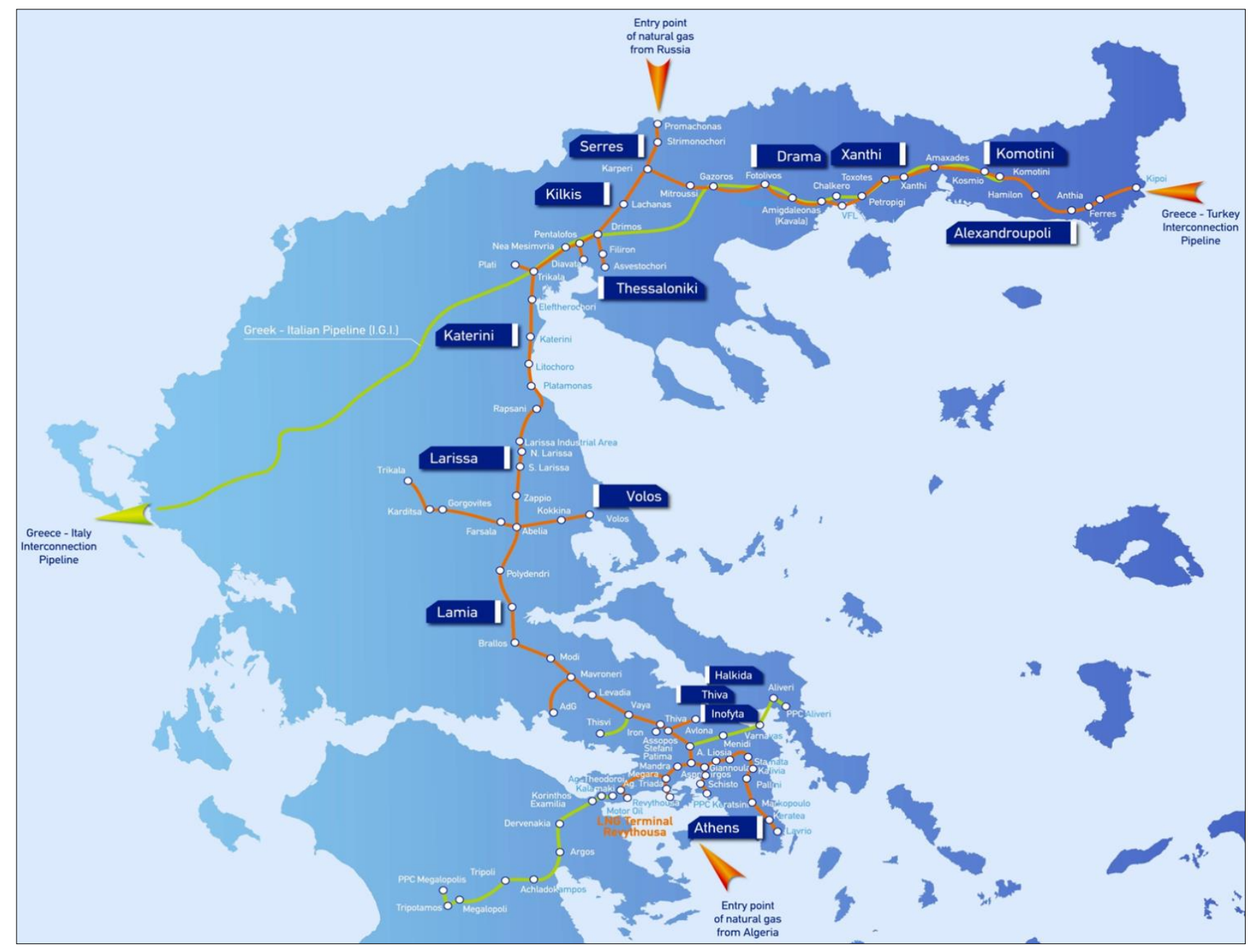

Source: DESFA 

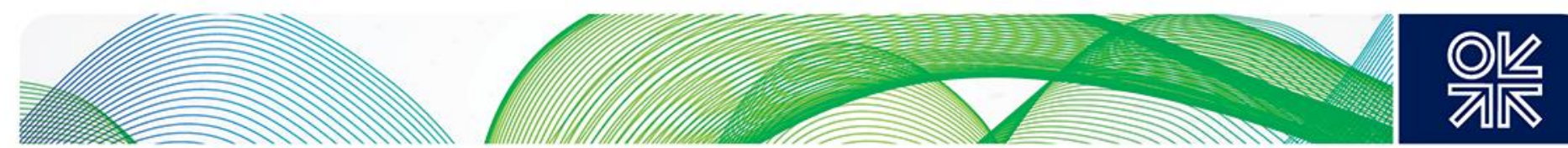

\section{K) EFET European Gas Hubs Assessment Table}

\begin{tabular}{|c|c|c|c|c|c|c|}
\hline $\begin{array}{l}\text { Responsible } \\
\text { party }\end{array}$ & What should be done & Guideline for assessment & $\begin{array}{l}\text { Score } \\
2014\end{array}$ & $\begin{array}{c}\text { Comments } \\
2014\end{array}$ & $\begin{array}{l}\text { Score } \\
2015\end{array}$ & $\begin{array}{l}\text { Comments } \\
2015\end{array}$ \\
\hline NRA & Establish a consultation mechanism & 1 if set up and English language & 0 & & 1 & \\
\hline TSO & Entry-exit system established & 1 for Entry Exit; 2 if a single VTP & 0 & & 1 & \\
\hline TSO & $\begin{array}{l}\text { Title Transfer (gas can be traded without } \\
\text { physical delivery, usually by transfer between } \\
\text { balancing groups) }\end{array}$ & & 0 & & 1 & \\
\hline TSO & $\begin{array}{l}\text { Cashout rules (long short positions set to zero at } \\
\text { the end of the balancing period against payment } \\
\text { of penalty in } \in / M W h \text { ) }\end{array}$ & & 0 & & 1 & \\
\hline TSO & $\begin{array}{l}\text { Accessible to non-physical traders (to trade gas } \\
\text { you do not require to flow gas physically from } \\
\text { entry to exit) }\end{array}$ & 1 if trade without signup to physical rules & 0 & & 1 & \\
\hline TSO & $\begin{array}{l}\text { Firmness of hub (cash out rules instead of pro } \\
\text { rata curtailment of flows in case not enough gas } \\
\text { is traded at the hub) }\end{array}$ & $\begin{array}{l}0 \text { if not firm; } 1 / 2 \text { if firmness "managed" by } \\
\text { TSO; } 1 \text { if Back-up-Back-down; } 2 \text { if fully } \\
\text { market-based }\end{array}$ & 0 & & 2 & \\
\hline TSO & Credit arrangements non punitive & & 0 & & 1 & \\
\hline NRA & $\begin{array}{l}\text { Resolve market structural issues (defined role } \\
\text { for historical player: gas release programs, } \\
\text { transport capacity release programs, market } \\
\text { maker obligations, etc.) }\end{array}$ & $1 / 2$ for release etc; 1 if market maker & 0 & & 1 & \\
\hline NRA & $\begin{array}{l}\text { defined Role of Hub operator (what are its } \\
\text { responsibilities in comparison with the TSO) }\end{array}$ & 1 - role defined; 2 -gov'nce addressed & 0 & & 2 & \\
\hline NRA & Agree regulatory jurisdiction if cross border & $\begin{array}{l}0 \text { if cross border and no agreement; } 1 \text { if not } \\
\text { cross border or does have agreement }\end{array}$ & 0 & & 1 & \\
\hline Market & $\begin{array}{l}\text { Establish a reference price at the hub for } \\
\text { contract settlement }\end{array}$ & 1 if price always available; $1 / 2$ if deemed & 0 & & 1 & \\
\hline Market & $\begin{array}{l}\text { Standardised contract (e.g. EFET Master } \\
\text { Contract) }\end{array}$ & $\begin{array}{l}1 \text { if specialised contract - EFET or equivalent } \\
\text { (or standard is sufficient) }\end{array}$ & 0 & & 1 & \\
\hline Market & Price Reporting Agencies active at the hub & 2 if several, 1 if only one PRA & 0 & & 2 & \\
\hline Market & Market makers & & 0 & & 1 & \\
\hline Market & Brokers & $1 / 2$ if voice or few ; 1 if systems and many & 0 & & 1 & \\
\hline NRA & Establishment of exchange & $\begin{array}{l}1 \text { if exchange appointed and hub is liquid; } 1 / 2 \text { if } \\
\text { exchange appointed and hub illiquid }\end{array}$ & 0 & & 1 & \\
\hline Market & Index becomes reliable and used as benchmark & 1 if Market parties frequently requested & 0 & & 1 & \\
\hline Total & & & 0 & & 20 & \\
\hline
\end{tabular}

Source: EFET 

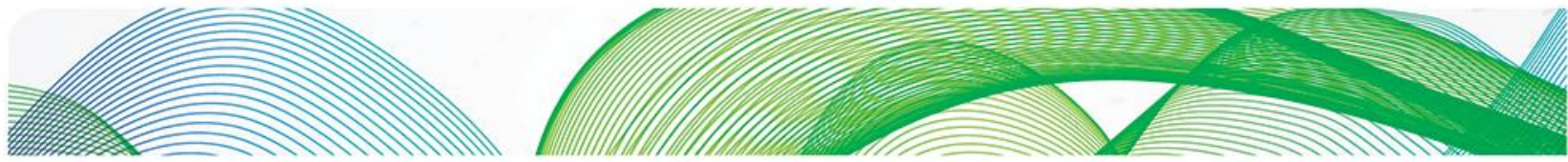

O倸

L) Traded products table methodology scoring results

\begin{tabular}{|c|c|c|c|}
\hline HUB & $\begin{array}{c}\text { OTC } \\
\text { SCORE } \\
\text { /36 }\end{array}$ & $\begin{array}{c}\text { EXCH } \\
\text { SCORE } \\
\text { /28 }\end{array}$ & $\begin{array}{c}\text { HUB } \\
\text { SCORE } \\
\text { /64 }\end{array}$ \\
\hline NBP & 27 & 19 & 46 \\
\hline TTF & 27 & 18 & 45 \\
\hline NCG & 17 & 7 & 24 \\
\hline GPL & 15 & 6 & 21 \\
\hline ZEE & 14 & 3 & 17 \\
\hline PEG N & 11 & 6 & 17 \\
\hline PSV & 10 & 3 & 13 \\
\hline VTP & 9 & 2 & 11 \\
\hline PEG $S$ & 8 & 3 & 11 \\
\hline PEG $T$ & 3 & 1 & 4 \\
\hline
\end{tabular}



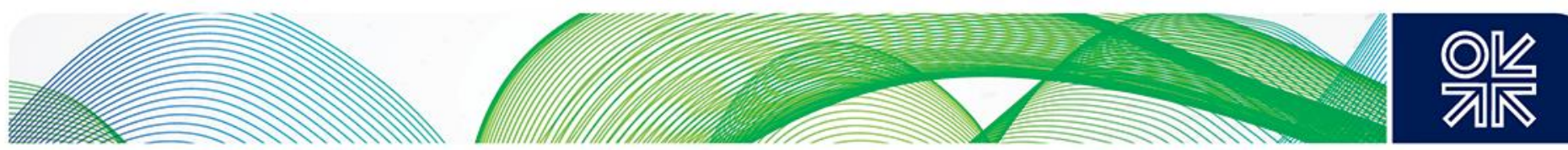

\section{M) OTC volume figures for Churn matrix}

European gas hubs OTC net traded volumes - 2012 to 2014 (TWh)

Aggregated volume totals from all the gas hubs

\begin{tabular}{|c|c|c|c|c|c|c|c|c|c|c|}
\hline Date & BRITAIN & HOLLAND & NCG & GPL & GERMANY & FRANCE & BELGIUM & AUSTRIA & ITALY & CZECH \\
\hline & OTC & OTC & OTC & OTC & OTC & OTC & OTC & OTC & OTC & OTC \\
\hline & TOTAL & TOTAL & TOTAL & TOTAL & TOTAL & TOTAL & TOTAL & TOTAL & TOTAL & TOTAL \\
\hline \multirow{2}{*}{\multicolumn{11}{|c|}{2012}} \\
\hline & & & & & & & & & & \\
\hline \multirow{3}{*}{$\begin{array}{l}\text { JANUARY TOTALS } \\
\text { FEBRUARY TOTALS } \\
\text { MARCH TOTALS }\end{array}$} & $1,387.054$ & 676.886 & 83.793 & 44.056 & 127.849 & 25.974 & 81.776 & 17.704 & 20.655 & 0.005 \\
\hline & $1,532.658$ & 746.601 & 78.233 & 44.935 & 123.168 & 22.395 & 87.866 & 19.023 & 22.193 & 0.010 \\
\hline & $1,310.217$ & 550.707 & 88.154 & 47.617 & 135.771 & 23.118 & 71.163 & 15.406 & 17.974 & 0.020 \\
\hline Q1 TOTALS & $4,229.929$ & $1,974.194$ & 250.180 & 136.608 & 386.788 & 71.487 & 240.806 & 52.133 & 60.822 & 0.035 \\
\hline APRIL TOTALS & 873.072 & 472.347 & 73.228 & 36.017 & 109.244 & 15.941 & 49.738 & 10.768 & 12.563 & 0.090 \\
\hline MAY TOTALS & 928.381 & 567.791 & 144.877 & 50.154 & 195.031 & 24.475 & 27.216 & 19.090 & 21.480 & 0.070 \\
\hline JUNE TOTALS & 780.359 & 541.782 & 83.068 & 37.795 & 120.863 & 17.463 & 55.299 & 11.732 & 15.034 & 0.160 \\
\hline Q2 TOTALS & $2,581.812$ & $1,581.920$ & 301.173 & 123.965 & 425.138 & 57.880 & 132.253 & 41.590 & 49.077 & 0.320 \\
\hline H1 TOTALS & $6,811.742$ & $3,556.114$ & 551.353 & 260.573 & 811.926 & 129.367 & 373.059 & 93.723 & 109.899 & 0.355 \\
\hline \multirow{2}{*}{$\begin{array}{l}\text { JULY TOTALS } \\
\text { AUGUST TOTALS }\end{array}$} & 849.568 & 619.652 & 87.209 & 34.486 & 121.694 & 25.895 & 55.391 & 15.238 & 10.296 & 0.110 \\
\hline & 825.380 & 567.514 & 66.167 & 37.749 & 103.916 & 19.462 & 59.641 & 9.960 & 5.761 & 0.250 \\
\hline SEPTEMBER TOTALS & 760.935 & 529.772 & 92.111 & 39.850 & 131.961 & 25.920 & 66.050 & 16.153 & 14.032 & 0.130 \\
\hline Q3 TOTALS & $2,435.883$ & $1,716.938$ & 245.487 & 112.084 & 357.571 & 71.278 & 181.081 & 41.351 & 30.089 & 0.490 \\
\hline OCTOBER TOTALS & 965.486 & 669.267 & 102.822 & 42.391 & 145.213 & 27.202 & 55.684 & 15.798 & 12.631 & 0.580 \\
\hline NOVEMBER TOTALS & 798.197 & 639.785 & 90.607 & 51.924 & 142.531 & 32.360 & 61.930 & 10.202 & 12.412 & 0.810 \\
\hline DECEMBER TOTALS & 613.406 & 419.461 & 93.995 & 48.762 & 142.757 & 31.658 & 53.990 & 3.528 & 9.802 & 2.200 \\
\hline Q4 TOTALS & $2,377.089$ & $1,728.514$ & 287.424 & 143.078 & 430.502 & 91.220 & 171.605 & 29.528 & 34.845 & 3.590 \\
\hline H2 TOTALS & $4,812.972$ & $3,445.452$ & 532.911 & 255.162 & 788.073 & 162.498 & 352.686 & 70.879 & 64.934 & 4.080 \\
\hline 2012 TOTALS & $11,624.713$ & $7,001.566$ & $1,084.264$ & 515.735 & 1,599.999 & 291.864 & 725.745 & 164.602 & 174.833 & 4.435 \\
\hline & & & & & & & & & & \\
\hline 2013 & & & & & & & & & & \\
\hline JANUARY TOTALS & 968.616 & 747.310 & 112.230 & 49.916 & 162.146 & 39.467 & 87.716 & 15.504 & 19.497 & 2.840 \\
\hline FEBRUARY TOTALS & $1,079.583$ & 633.993 & 88.287 & 45.771 & 134.058 & 27.601 & 85.336 & 18.042 & 17.457 & 1.410 \\
\hline MARCH TOTALS & 967.510 & 660.569 & 112.223 & 40.088 & 152.311 & 40.801 & 73.983 & 13.096 & 14.839 & 1.280 \\
\hline Q1 TOTALS & $3,015.709$ & $2,041.873$ & 312.740 & 135.775 & 448.515 & 107.868 & 247.035 & 46.642 & 51.792 & 5.530 \\
\hline APRIL TOTALS & 827.186 & 641.213 & 112.594 & 65.294 & 177.887 & 27.436 & 79.933 & 11.362 & 21.731 & 2.900 \\
\hline MAY TOTALS & 825.539 & 526.511 & 97.126 & 48.132 & 145.258 & 25.545 & 115.053 & 15.883 & 32.856 & 2.570 \\
\hline JUNE TOTALS & 870.145 & 610.051 & 116.134 & 87.304 & 203.438 & 36.632 & 89.680 & 21.683 & 23.142 & 2.910 \\
\hline Q2 TOTALS & $2,522.870$ & $1,777.774$ & 325.854 & 200.730 & 526.584 & 89.613 & 284.666 & 48.928 & 77.730 & 8.380 \\
\hline H1 TOTALS & $5,538.579$ & $3,819.647$ & 638.594 & 336.505 & 975.099 & 197.482 & 531.701 & 95.570 & 129.522 & 13.910 \\
\hline JULY TOTALS & 635.123 & 548.026 & 110.027 & 69.992 & 180.019 & 35.806 & 91.402 & 23.877 & 25.987 & 5.790 \\
\hline AUGUST TOTALS & 711.365 & 614.374 & 110.130 & 102.081 & 212.211 & 30.210 & 97.546 & 16.349 & 13.303 & 2.380 \\
\hline SEPTEMBER TOTALS & 861.959 & 666.273 & 125.615 & 122.538 & 248.153 & 26.686 & 81.122 & 26.982 & 21.144 & 3.010 \\
\hline Q3 TOTALS & $2,208.447$ & $1,828.673$ & 345.772 & 294.611 & 640.383 & 92.702 & 270.070 & 67.208 & 60.435 & 11.180 \\
\hline OCTOBER TOTALS & 942.059 & 738.065 & 118.127 & 90.501 & 208.628 & 34.121 & 89.164 & 25.722 & 35.678 & 4.240 \\
\hline NOVEMBER TOTALS & 817.289 & 773.191 & 133.310 & 96.568 & 229.879 & 33.539 & 80.467 & 25.763 & 23.090 & 2.780 \\
\hline DECEMBER TOTALS & 519.346 & 541.044 & 103.831 & 54.669 & 158.500 & 22.099 & 72.215 & 20.324 & 33.325 & 2.070 \\
\hline Q4 TOTALS & $2,278.694$ & $2,052.300$ & 355.268 & 241.738 & 597.007 & 89.758 & 241.846 & 71.809 & 92.093 & 9.090 \\
\hline H2 TOTALS & $4,487.141$ & $3,880.974$ & 701.040 & 536.350 & $1,237.390$ & 182.460 & 511.915 & 139.017 & 152.528 & 20.270 \\
\hline 2013 TOTALS & $10,025.721$ & $7,700.620$ & $1,339.634$ & 872.855 & $2,212.489$ & 379.942 & $1,043.616$ & 234.587 & 282.050 & 34.180 \\
\hline & & & & & & & & & & \\
\hline 2014 & & & & & & & & & & \\
\hline JANUARY TOTALS & $1,056.475$ & $1,026.797$ & 157.734 & 84.363 & 242.096 & 29.810 & 106.530 & 27.037 & 54.127 & 3.180 \\
\hline FEBRUARY TOTALS & $1,090.215$ & $1,097.503$ & 177.595 & 104.145 & 281.740 & 23.303 & 71.111 & 38.459 & 45.810 & 2.890 \\
\hline MARCH TOTALS & $1,082.373$ & $1,097.163$ & 143.127 & 96.812 & 239.938 & 41.275 & 61.443 & 32.199 & 45.839 & 2.200 \\
\hline Q1 TOTALS & $3,229.064$ & $3,221.463$ & 478.455 & 285.320 & 763.774 & 94.388 & 239.084 & 97.694 & 145.776 & 8.270 \\
\hline APRIL TOTALS & 879.089 & 925.482 & 157.495 & 82.789 & 240.284 & 32.536 & 57.194 & 25.075 & 44.512 & 3.660 \\
\hline MAY TOTALS & 685.928 & 705.760 & 104.757 & 63.862 & 168.620 & 19.032 & 55.993 & 35.292 & 36.847 & 3.170 \\
\hline JUNE TOTALS & 746.345 & 867.857 & 126.733 & 60.382 & 187.115 & 21.921 & 84.285 & 23.530 & 43.964 & 1.770 \\
\hline Q2 TOTALS & $2,311.361$ & $2,499.100$ & 388.986 & 207.034 & 596.019 & 73.489 & 197.472 & 83.897 & 125.323 & 8.600 \\
\hline H1 TOTALS & $5,540.426$ & $5,720.563$ & 867.440 & 492.353 & $1,359.794$ & 167.876 & 436.555 & 181.591 & 271.099 & 16.870 \\
\hline JULY TOTALS & 771.930 & $1,115.387$ & 140.404 & 88.066 & 228.470 & 32.363 & 68.603 & 31.406 & 43.238 & 3.260 \\
\hline AUGUST TOTALS & 549.821 & $1,009.020$ & 103.859 & 68.819 & 172.679 & 18.396 & 73.299 & 34.408 & 23.710 & 2.020 \\
\hline SEPTEMBER TOTALS & 698.465 & $1,055.531$ & 131.149 & 82.132 & 213.281 & 37.481 & 76.433 & 30.775 & 48.306 & 2.090 \\
\hline Q3 TOTALS & $2,020.217$ & $3,179.937$ & 375.412 & 239.017 & 614.429 & 88.240 & 218.336 & 96.589 & 115.254 & 7.370 \\
\hline OCTOBER TOTALS & 838.163 & 958.280 & 152.465 & 73.424 & 225.890 & 37.039 & 58.131 & 36.963 & 49.810 & 3.360 \\
\hline NOVEMBER TOTALS & 722.947 & 875.628 & 117.977 & 75.911 & 193.889 & 47.100 & 86.272 & 31.251 & 52.424 & 2.980 \\
\hline DECEMBER TOTALS & 611.288 & 819.408 & 108.390 & 56.201 & 164.591 & 46.840 & 44.098 & 29.888 & 36.043 & 2.480 \\
\hline Q4 TOTALS & $2,172.398$ & $2,653.316$ & 378.832 & 205.537 & 584.369 & 130.979 & 188.501 & 98.102 & 138.277 & 8.820 \\
\hline H2 TOTALS & $4,192.615$ & $5,833.254$ & 754.244 & 444.554 & $1,198.798$ & 219.219 & 406.837 & 194.692 & 253.531 & 16.190 \\
\hline 2014 TOTALS & $9,733.041$ & $11,553.817$ & $1,621.684$ & 936.907 & $2,558.592$ & 387.095 & 843.392 & 376.283 & 524.630 & 33.060 \\
\hline
\end{tabular}

Source: LEBA; ICIS; P. Heather 

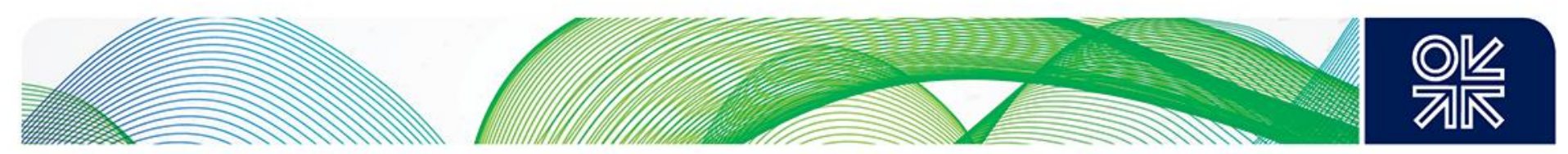

\section{N) Exchange futures and options volume figures for Churn matrix}

European gas hubs futures traded volumes - 2012 to 2014 (TWh)

Aggregated volume totals from all the gas exchanges

\begin{tabular}{|c|c|c|c|c|c|c|c|c|c|c|c|c|c|c|c|c|}
\hline Date & NBP & NBP & NBP & $\pi F$ & $\pi F$ & $\pi F$ & ZTP & NCG & GPL & NCG+GPL & PEG NORD & PEG SUD & NORD+SUD & VTP & PSV & VOB \\
\hline & FUTURES & OPTIONS & EXCHANGE & FUTURES & OPTIONS & EXCHANGE & FUTURES & FUTURES & FUTURES & FUTURES & FUTURES & FUTURES & FUTURES & FUTURES & FUTURES & FUTURES \\
\hline & TOTAL & TOTAL & TOTAL & TOTAL & TOTAL & TOTAL & TOTAL & TOTAL & TOTAL & TOTAL & TOTAL & TOTAL & TOTAL & TOTAL & TOTAL & TOTAL \\
\hline \multirow{2}{*}{\multicolumn{17}{|c|}{2012}} \\
\hline JUNU & & & & & & & & & & & & & & & & \\
\hline JANUARY TOTALS & 629.279 & 35.574 & 664.853 & 49.383 & & 49.383 & & 17.085 & 0.187 & 17.273 & 10.891 & & 10.891 & 0.000 & 0.527 & \\
\hline FEBRUARY TOTALS & 817.277 & 56.196 & 873.473 & 56.963 & & 56.963 & & 8.407 & 0.382 & 8.789 & 4.258 & & 4.258 & 0.000 & 0.000 & \\
\hline MARCH TOTALS & 593.920 & 38.237 & 632.157 & 36.058 & & 36.058 & & 6.195 & 0.248 & 6.443 & 4.814 & & 4.814 & 0.000 & 0.000 & \\
\hline Q1 TOTALS & $2,040.477$ & 130.007 & $2,170.484$ & 142.405 & & 142.405 & & 31.688 & 0.817 & 32.505 & 19.963 & & 19.963 & 0.000 & 0.527 & \\
\hline APRIL TOTALS & 450.903 & 19.546 & 470.449 & 25.174 & & 25.174 & & 4.967 & 0.060 & 5.027 & 1.625 & & 1.625 & 0.022 & 0.000 & \\
\hline MAY TOTALS & 497.787 & 23.937 & 521.724 & 44.902 & & 44.902 & & 13.076 & 0.029 & 13.105 & 1.652 & & 1.652 & 0.000 & 0.000 & \\
\hline JUNE TOTALS & 396.396 & 31.803 & 428.198 & 57.876 & & 57.876 & & 4.584 & 0.042 & 4.627 & 1.219 & & 1.219 & 0.000 & 0.000 & \\
\hline Q2 TOTALS & $1,345.086$ & 75.286 & ; $1,420.372$ & 127.952 & & 127.952 & & 22.628 & 0.131 & 22.759 & 4.495 & & 4.495 & 0.022 & 0.000 & \\
\hline H1 TOTALS & $3,385.563$ & 205.293 & $3,590.856$ & 270.357 & & 270.357 & & 54.316 & 0.948 & 55.264 & 24.459 & & 24.459 & 0.022 & 0.527 & \\
\hline JULY TOTALS & 436.178 & 36.475 & 472.652 & 42.874 & 0 & 42.874 & & 7.187 & 0.088 & 7.275 & 4.501 & & 4.501 & 0.134 & 0.000 & \\
\hline AUGUST TOTALS & 426.339 & 39.937 & 466.276 & 46.497 & 1.836 & 48.333 & & 11.055 & 0.065 & 11.120 & 2.145 & & 2.145 & 0.022 & 0.391 & \\
\hline SEPTEMBER TOTALS & 428.763 & 12.639 & 441.402 & 47.037 & 0 & 47.037 & & 13.671 & 0.030 & 13.700 & 1.338 & & 1.338 & 0.045 & 0.378 & \\
\hline Q3 TOTALS & $1,291.280$ & 89.050 & $1,380.330$ & 136.408 & 1.836 & 138.244 & & 31.913 & 0.183 & 32.095 & 7.984 & & 7.984 & 0.200 & 0.769 & \\
\hline OCTOBER TOTALS & 661.045 & 27.857 & 688.901 & 96.494 & 0 & 96.494 & & 39.244 & 0.000 & 39.244 & 2.613 & & 2.613 & 0.000 & 0.391 & \\
\hline NOVEMBER TOTALS & 607.553 & 22.489 & 630.042 & 76.921 & 0.777 & 77.699 & & 21.338 & 0.015 & 21.353 & 1.717 & & 1.717 & 0.045 & 0.620 & \\
\hline DECEMBER TOTALS & 334.475 & 100.147 & 434.622 & 41.330 & 0 & 41.330 & & 9.995 & 2.577 & 12.571 & 4.750 & & 4.750 & 0.030 & 0.560 & \\
\hline Q4 TOTALS & $1,603.073$ & 150.492 & $1,753.565$ & 214.745 & 0.777 & 215.522 & & 70.577 & 2.591 & 73.169 & 9.080 & & 9.080 & 0.074 & 1.571 & \\
\hline H2 TOTALS & $2,894.353$ & 239.543 & $3,133.896$ & 351.153 & 2.613 & 353.766 & & 102.490 & 2.774 & 105.264 & 17.064 & & 17.064 & 0.275 & 2.340 & \\
\hline 2012 TOTALS & $6,279.916$ & 444.835 & $6,724.751$ & 621.510 & 2.613 & 624.123 & & 156.806 & 3.722 & 160.528 & 41.523 & & 41.523 & 0.297 & 2.868 & \\
\hline
\end{tabular}

\begin{tabular}{|c|c|c|c|c|c|c|c|c|c|c|c|c|c|c|c|c|}
\hline \multicolumn{17}{|l|}{2013} \\
\hline JANUARY TOTALS & 508.118 & 30.459 & 538.577 & 66.561 & 0 & 66.561 & & 2.651 & 0.007 & 2.657 & 3.774 & & 3.774 & 0.020 & 0.620 & \\
\hline FEBRUARY TOTALS & 584.897 & 46.601 & 631.498 & 72.220 & 1.581 & 73.801 & & 1.921 & 0.030 & 1.951 & 2.946 & & 2.946 & 0.201 & 0.000 & \\
\hline MARCH TOTALS & 601.796 & 59.909 & 661.705 & 57.878 & 2.933 & 60.812 & & 2.962 & 0.000 & 2.962 & 1.498 & & 1.498 & 0.000 & 0.000 & \\
\hline Q1 TOTALS & $1,694.811$ & 136.969 & $1,831.780$ & 196.659 & 4.514 & 201.173 & & 7.534 & 0.036 & 7.570 & 8.218 & & 8.218 & 0.221 & 0.620 & \\
\hline APRIL TOTALS & 461.127 & 58.166 & 519.292 & 59.134 & 1.051 & 60.185 & & 2.342 & 0.044 & 2.386 & 1.403 & & 1.403 & 0.000 & 0.000 & \\
\hline MAY TOTALS & 441.966 & 41.578 & 483.544 & 46.192 & 0 & 46.192 & & 1.707 & 0.000 & 1.707 & 2.304 & & 2.304 & 0.000 & 0.000 & \\
\hline JUNE TOTALS & 447.078 & 44.786 & 491.864 & 42.494 & 0.262 & 42.756 & & 2.228 & 0.832 & 3.060 & 2.256 & & 2.256 & 0.007 & 0.000 & \\
\hline Q2 TOTALS & $1,350.171$ & 144.529 & $1,494.700$ & 79.265 & 1.313 & 80.578 & & 6.277 & 0.876 & 7.153 & 5.963 & & 5.963 & 0.007 & 0.000 & \\
\hline H1 TOTALS & $3,044.981$ & 281.499 & $3,326.480$ & 275.923 & 5.828 & 281.751 & & 13.811 & 0.913 & 14.723 & 14.181 & & 14.181 & 0.228 & 0.620 & \\
\hline JULY TOTALS & 266.820 & 49.696 & 316.516 & 35.156 & 2.202 & 37.358 & & 1.041 & 0.836 & 1.877 & 2.404 & & 2.404 & 0.000 & 0.000 & \\
\hline AUGUST TOTALS & 329.585 & 22.713 & 352.299 & 40.168 & 0.389 & 40.556 & & 1.661 & 0.742 & 2.404 & 2.942 & & 2.942 & 0.000 & 0.000 & \\
\hline SEPTEMBER TOTALS & 416.424 & 6.899 & 423.323 & 71.946 & 1.441 & 73.388 & & 1.222 & 0.772 & 1.993 & 2.378 & & 2.378 & 0.000 & 0.000 & \\
\hline Q3 TOTALS & $1,012.829$ & 79.309 & $1,092.138$ & 147.269 & 4.032 & 151.302 & & 3.924 & 2.350 & 6.274 & 7.724 & & 7.724 & 0.000 & 0.000 & \\
\hline OCTOBER TOTALS & 387.125 & 13.650 & 400.775 & 32.063 & 0 & 32.063 & & 1.653 & 1.380 & 3.033 & 2.557 & 0.199 & 2.757 & 0.000 & 0.000 & \\
\hline NOVEMBER TOTALS & 503.066 & 84.226 & 587.291 & 58.748 & 0.524 & 59.272 & & 2.375 & 1.587 & 3.962 & 4.645 & 0.216 & 4.861 & 0.060 & 0.000 & \\
\hline DECEMBER TOTALS & 421.153 & 25.176 & 446.329 & 46.776 & 2.241 & 49.017 & & 0.763 & 1.127 & 1.890 & 2.760 & 0.231 & 2.991 & 0.013 & 0.000 & 0.000 \\
\hline Q4 TOTALS & $1,311.344$ & 123.052 & $1,434.395$ & 137.587 & 2.765 & 140.351 & & 4.791 & 4.094 & 8.885 & 9.962 & 0.646 & 10.609 & 0.073 & 0.000 & 0.000 \\
\hline H2 TOTALS & 2,324.173 & 202.360 & $2,526.533$ & 284.856 & 6.797 & 291.653 & & 8.715 & 6.443 & 15.159 & 17.686 & 0.646 & 18.333 & 0.073 & 0.000 & 0.000 \\
\hline 2013 TOTALS & $5,369.155$ & 483.859 & $5,853.014$ & 560.779 & 12.625 & 573.404 & & 22.526 & 7.356 & 29.882 & 31.868 & 0.646 & 32.514 & 0.301 & 0.620 & 0.000 \\
\hline & & & & & & & & & & & & & & & & \\
\hline \multicolumn{17}{|l|}{2014} \\
\hline JANUARY TOTALS & 871.384 & 107.545 & 978.929 & 93.826 & 2.503 & 96.329 & 0.000 & 9.631 & 3.038 & 12.669 & 4.631 & 0.196 & 4.827 & 0.028 & 0.000 & 0.000 \\
\hline FEBRUARY TOTALS & 813.162 & 55.013 & 868.175 & 118.902 & 2.848 & 121.750 & 0.000 & 5.894 & 1.938 & 7.832 & 2.327 & 0.564 & 2.891 & 0.045 & 0.000 & 0.022 \\
\hline MARCH TOTALS & 959.430 & 79.097 & $1,038.527$ & 111.651 & 3.745 & 115.396 & 0.000 & 10.195 & 2.688 & 12.883 & 3.424 & 0.679 & 4.104 & 0.043 & 0.000 & 0.000 \\
\hline Q1 TOTALS & $2,643.975$ & 241.655 & $2,885.631$ & 324.379 & 9.097 & 333.475 & 0.000 & 25.720 & 7.664 & 33.384 & 10.382 & 1.439 & 11.821 & 0.115 & 0.000 & 0.022 \\
\hline APRIL TOTALS & 837.159 & 93.234 & 930.392 & 127.563 & 2.555 & 130.117 & 0.000 & 2.769 & 1.895 & 4.664 & 2.827 & 0.323 & 3.150 & 0.037 & 0.000 & 0.000 \\
\hline MAY TOTALS & 647.919 & 56.844 & 704.763 & 88.005 & 3.537 & 91.542 & 0.000 & 5.284 & 0.964 & 6.248 & 1.147 & 0.176 & 1.322 & 0.194 & 0.000 & 0.000 \\
\hline JUNE TOTALS & 784.849 & 81.623 & 866.472 & 177.857 & 3.939 & 181.795 & 0.000 & 4.575 & 0.840 & 5.415 & 3.575 & 0.370 & 3.946 & 0.022 & 0.000 & 0.044 \\
\hline Q2 TOTALS & $2,269.928$ & 231.700 & $2,501.627$ & 393.425 & 10.030 & 403.454 & 0.000 & 12.628 & 3.698 & 16.326 & 7.549 & 0.870 & 8.418 & 0.254 & 0.000 & 0.044 \\
\hline H1 TOTALS & $4,913.903$ & 473.355 & $5,387.258$ & 717.803 & 19.126 & 736.930 & 0.000 & 38.348 & 11.363 & 49.710 & 17.931 & 2.309 & 20.240 & 0.369 & 0.000 & 0.066 \\
\hline JULY TOTALS & 889.662 & 117.661 & $1,007.323$ & 150.104 & 7.045 & 157.149 & 0.007 & 5.063 & 1.707 & 6.771 & 3.598 & 0.149 & 3.748 & 0.536 & 0.000 & 0.080 \\
\hline AUGUST TOTALS & 721.598 & 69.990 & 791.588 & 150.575 & 3.536 & 154.111 & 0.000 & 4.920 & 0.713 & 5.634 & 2.894 & 0.119 & 3.012 & 0.454 & 0.000 & 0.062 \\
\hline SEPTEMBER TOTALS & 800.749 & 119.484 & 920.234 & 199.705 & 8.808 & 208.513 & 0.000 & 5.011 & 2.252 & 7.263 & 4.519 & 0.060 & 4.579 & 0.127 & 0.000 & 0.015 \\
\hline Q3 TOTALS & $2,412.009$ & 307.136 & $2,719.145$ & 500.384 & 19.389 & 519.773 & 0.007 & 14.994 & 4.673 & 19.667 & 11.011 & 0.328 & 11.339 & 1.116 & 0.000 & 0.157 \\
\hline OCTOBER TOTALS & 754.296 & 100.320 & 854.616 & 222.269 & 22.863 & 245.132 & 0.000 & 3.564 & 2.038 & 5.602 & 4.795 & 0.538 & 5.334 & 0.230 & 0.000 & 0.094 \\
\hline NOVEMBER TOTALS & 725.229 & 133.850 & 859.079 & 233.433 & 8.152 & 241.585 & 0.000 & 4.970 & 2.257 & 7.227 & 3.338 & 0.336 & 3.674 & 0.317 & 0.000 & 0.111 \\
\hline DECEMBER TOTALS & 645.068 & 178.029 & 823.098 & 170.302 & 7.036 & 177.338 & 0.000 & 5.583 & 1.909 & 7.492 & 1.448 & 0.084 & 1.533 & 0.285 & 0.000 & 0.318 \\
\hline Q4 TOTALS & $2,124.593$ & 412.199 & $2,536.793$ & 626.004 & 38.050 & 664.055 & 0.000 & 14.118 & 6.204 & 20.322 & 9.582 & 0.958 & 10.540 & 0.832 & 0.000 & 0.522 \\
\hline H2 TOTALS & $4,536.603$ & 719.335 & $5,255.938$ & $1,126.388$ & 57.440 & $1,183.828$ & 0.007 & 29.112 & 10.877 & 39.989 & 20.593 & 1.286 & 21.879 & 1.948 & 0.000 & 0.679 \\
\hline 2014 TOTALS & $9,450.506$ & $1,192.690$ & 10,643.196 & $1,844.191$ & 76.566 & $1,920.757$ & 0.007 & 67.460 & 22.240 & 89.699 & 38.524 & 3.595 & 42.119 & 2.317 & 0.000 & 0.745 \\
\hline
\end{tabular}

Source: ICE; ICE-Endex; EEX; Powernext, CEGH, GME; P. Heather 

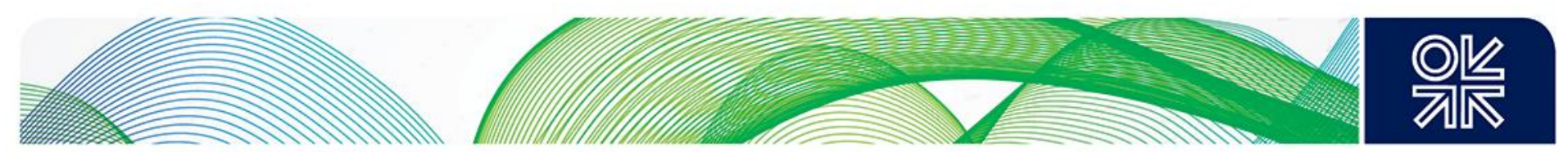

\section{O) Exchange spot volume figures for Churn matrix}

European gas hubs spot traded volumes - 2012 to 2014 (TWh)

Aggregated volume totals from all the gas exchanges

\begin{tabular}{|c|c|c|c|c|c|c|c|c|c|c|c|c|c|c|c|c|}
\hline Date & NBP & $\pi F$ & NCG & GPL & NCG+GPL & PEG NORD & PEG SUD & PEG TIGF & PEGs & ZEE & ZTP/L & ZEE+ZTP/L & CEGH/VTP & PSV & ITALIAN & VOB \\
\hline & SPOT & SPOT & SPOT & SPOT & SPOT & SPOT & SPOT & SPOT & SPOT & SPOT & SPOT & SPOT & SPOT & SPOT & SPOT & SPOT \\
\hline & TOTAL & TOTAL & TOTAL & TOTAL & TOTAL & TOTAL & TOTAL & TOTAL & TOTAL & TOTAL & TOTAL & TOTAL & TOTAL & TOTAL & TOTAL & TOTAL \\
\hline \multirow{2}{*}{\multicolumn{17}{|c|}{2012}} \\
\hline & & & & & & & & & & & & & & & & \\
\hline JANUARY TOTALS & 12.515 & 2.444 & 1.547 & 0.684 & 2.231 & 2.240 & 0.746 & 0.015 & 3.001 & 0.049 & & 0.049 & 0.020 & 0.000 & 2.673 & \\
\hline FEBRUARY TOTALS & 8.792 & 2.561 & 1.781 & 1.533 & 3.314 & 3.059 & 0.889 & 0.068 & 4.016 & 0.088 & & 0.088 & 0.027 & 0.015 & 6.102 & \\
\hline MARCH TOTALS & 11.537 & 2.464 & 1.802 & 0.622 & 2.424 & 2.977 & 0.785 & 0.010 & 3.772 & 0.056 & & 0.056 & 0.005 & 0.010 & 3.861 & \\
\hline Q1 TOTALS & 32.844 & 7.469 & 5.131 & 2.839 & 7.970 & 8.275 & 2.421 & 0.093 & 10.789 & 0.193 & & 0.193 & 0.053 & 0.024 & 12.635 & \\
\hline APRIL TOTALS & 10.999 & 2.315 & 1.388 & 0.414 & 1.802 & 1.952 & 0.736 & 0.023 & 2.711 & 0.066 & & 0.066 & 0.045 & 0.013 & 2.154 & \\
\hline MAY TOTALS & 14.101 & 1.889 & 1.156 & 0.368 & 1.524 & 1.778 & 0.913 & 0.011 & 2.703 & 0.113 & & 0.113 & 0.195 & 0.020 & 2.080 & \\
\hline JUNE TOTALS & 11.358 & 1.252 & 0.821 & 0.468 & 1.289 & 1.786 & 0.822 & 0.009 & 2.616 & 0.318 & & 0.318 & 0.105 & 0.045 & 2.148 & \\
\hline Q2 TOTALS & 36.458 & 5.456 & 3.365 & 1.250 & 4.615 & 5.516 & 2.471 & 0.043 & 8.031 & 0.496 & & 0.496 & 0.345 & 0.079 & 6.382 & \\
\hline H1 TOTALS & 69.302 & 12.925 & 8.495 & 4.089 & 12.584 & 13.791 & 4.892 & 0.136 & 18.819 & 0.690 & & 0.690 & 0.397 & 0.103 & 19.017 & \\
\hline JULY TOTALS & 10.171 & 1.273 & 0.975 & 0.391 & 1.366 & 1.889 & 0.997 & 0.012 & 2.898 & 0.166 & & 0.166 & 0.084 & 0.010 & 2.957 & \\
\hline AUGUST TOTALS & 12.213 & 1.596 & 0.807 & 0.631 & 1.438 & 2.906 & 1.220 & 0.023 & 4.149 & 0.072 & & 0.072 & 0.392 & 0.031 & 1.868 & \\
\hline SEPTEMBER TOTALS & 10.214 & 2.305 & 1.548 & 1.056 & 2.604 & 2.883 & 1.478 & 0.011 & 4.371 & 0.023 & & 0.023 & 0.324 & 0.027 & 2.731 & \\
\hline Q3 TOTALS & 32.598 & 5.174 & 3.330 & 2.078 & 5.408 & 7.678 & 3.695 & 0.045 & 11.418 & 0.261 & & 0.261 & 0.800 & 0.068 & 7.556 & \\
\hline OCTOBER TOTALS & 13.393 & 1.892 & 1.878 & 0.621 & 2.498 & 3.961 & 1.497 & 0.051 & 5.509 & & 0.180 & 0.180 & 0.601 & 0.000 & 2.945 & \\
\hline NOVEMBER TOTALS & 10.979 & 1.846 & 1.556 & 0.601 & 2.156 & 2.772 & 0.955 & 0.016 & 3.742 & & 0.216 & 0.216 & 0.527 & 0.000 & 2.509 & \\
\hline DECEMBER TOTALS & 11.083 & 1.602 & 2.193 & 0.980 & 3.172 & 2.375 & 1.196 & 0.032 & 3.603 & & 0.367 & 0.367 & 0.436 & 0.000 & 2.965 & \\
\hline Q4 TOTALS & 35.456 & 5.340 & 5.626 & 2.201 & 7.827 & 9.108 & 3.647 & 0.099 & 12.854 & & 0.764 & 0.764 & 1.564 & 0.000 & 8.419 & \\
\hline H2 TOTALS & 68.054 & 10.514 & 8.956 & 4.279 & 13.235 & 16.786 & 7.342 & 0.145 & 24.272 & 0.261 & 0.764 & 1.025 & 2.364 & 0.068 & 15.976 & \\
\hline 2012 TOTALS & 137.356 & 23.439 & 17.452 & 8.368 & 25.820 & 30.577 & 12.234 & 0.281 & 43.092 & 0.951 & 0.764 & 1.715 & 2.761 & 0.171 & 34.992 & \\
\hline
\end{tabular}

\begin{tabular}{|c|c|c|c|c|c|c|c|c|c|c|c|c|c|c|}
\hline \multicolumn{15}{|l|}{2013} \\
\hline JANUARY TOTALS & 11.561 & 2.991 & 2.861 & 2.370 & 5.231 & 3.689 & 1.711 & 0.038 & 5.439 & 0.408 & 0.408 & 0.747 & 0.008 & 2.894 \\
\hline FEBRUARY TOTALS & 10.867 & 2.811 & 3.695 & 1.164 & 4.859 & 3.239 & 1.575 & 0.015 & 4.828 & 0.396 & 0.396 & 0.910 & 0.003 & 3.686 \\
\hline MARCH TOTALS & 16.419 & 2.725 & 4.803 & 2.487 & 7.290 & 4.378 & 1.671 & 0.026 & 6.075 & 0.661 & 0.661 & 0.793 & 0.006 & 5.096 \\
\hline Q1 TOTALS & 38.847 & 8.527 & 11.359 & 6.021 & 17.380 & 11.306 & 4.957 & 0.079 & 16.342 & 1.465 & 1.465 & 2.450 & 0.016 & 11.675 \\
\hline APRIL TOTALS & 11.897 & 1.952 & 3.382 & 1.519 & 4.900 & 3.404 & 1.509 & 0.025 & 4.937 & 0.186 & 0.186 & 1.628 & 0.001 & 3.756 \\
\hline MAY TOTALS & 11.657 & 2.093 & 2.278 & 1.372 & 3.651 & 3.661 & 1.482 & 0.033 & 5.176 & 0.174 & 0.174 & 0.605 & 0.000 & 1.906 \\
\hline JUNE TOTALS & 13.032 & 1.986 & 2.027 & 1.027 & 3.054 & 3.081 & 1.723 & 0.047 & 4.851 & 0.144 & 0.144 & 0.861 & 0.000 & 2.326 \\
\hline Q2 TOTALS & 36.586 & 6.030 & 7.687 & 3.918 & 11.605 & 10.147 & 4.713 & 0.105 & 14.965 & 0.504 & 0.504 & 3.094 & 0.001 & 7.987 \\
\hline H1 TOTALS & 75.433 & 14.557 & 19.046 & 9.939 & 28.985 & 21.453 & 9.670 & 0.184 & 31.306 & 1.969 & 1.969 & 5.544 & 0.017 & 19.662 \\
\hline JULY TOTALS & 11.362 & 1.170 & 1.316 & 1.362 & 2.678 & 3.924 & 2.215 & 0.031 & 6.171 & 0.279 & 0.279 & 0.870 & 0.000 & 2.405 \\
\hline AUGUST TOTALS & 11.827 & 1.895 & 2.138 & 1.508 & 3.646 & 3.513 & 1.727 & 0.009 & 5.249 & 0.107 & 0.107 & 0.908 & 0.000 & 2.381 \\
\hline SEPTEMBER TOTALS & 12.303 & 2.812 & 2.338 & 1.629 & 3.967 & 2.561 & 1.528 & 0.029 & 4.117 & 0.176 & 0.176 & 0.517 & 0.000 & 3.086 \\
\hline Q3 TOTALS & 35.493 & 5.877 & 5.792 & 4.499 & 10.291 & 9.998 & 5.470 & 0.068 & 15.537 & 0.562 & 0.562 & 2.295 & 0.000 & 7.872 \\
\hline OCTOBER TOTALS & 11.509 & 1.912 & 3.436 & 2.162 & 5.599 & 4.609 & 3.068 & 0.025 & 7.702 & 0.265 & 0.265 & 2.087 & 0.000 & 3.668 \\
\hline NOVEMBER TOTALS & 11.315 & 2.146 & 5.004 & 2.799 & 7.803 & 5.759 & 3.046 & 0.026 & 8.831 & 0.239 & 0.239 & 1.266 & 0.000 & 5.096 \\
\hline DECEMBER TOTALS & 11.934 & 1.687 & 4.084 & 2.716 & 6.800 & 4.244 & 2.731 & 0.030 & 7.005 & 0.332 & 0.332 & 1.780 & 0.000 & 4.599 \\
\hline Q4 TOTALS & 34.759 & 5.745 & 12.524 & 7.677 & 20.202 & 14.612 & 8.844 & 0.081 & 23.538 & 0.836 & 0.836 & 5.134 & 0.000 & 13.364 \\
\hline H2 TOTALS & 70.252 & 11.622 & 18.316 & 12.176 & 30.493 & 24.610 & 14.314 & 0.150 & 39.074 & 1.399 & 1.399 & 7.430 & 0.000 & 21.235 \\
\hline 2013 TOTALS & 145.685 & 26.179 & 37.362 & 22.115 & 59.478 & 46.063 & 23.984 & 0.334 & 70.381 & 3.367 & 3.367 & 12.973 & 0.017 & 40.897 \\
\hline
\end{tabular}

\begin{tabular}{|c|c|c|c|c|c|c|c|c|c|c|c|c|c|c|}
\hline \multicolumn{15}{|l|}{2014} \\
\hline JANUARY TOTALS & 9.776 & 5.122 & 4.370 & 4.012 & 8.383 & 5.597 & 3.964 & 0.015 & 9.577 & 0.204 & 0.204 & 0.834 & 0.000 & 2.456 \\
\hline FEBRUARY TOTALS & 10.644 & 3.349 & 3.843 & 2.482 & 6.326 & 4.935 & 3.944 & 0.137 & 9.015 & 0.185 & 0.185 & 1.095 & 0.000 & 1.816 \\
\hline MARCH TOTALS & 11.057 & 3.540 & 4.234 & 2.430 & 6.664 & 4.249 & 3.198 & 0.119 & 7.566 & 0.308 & 0.308 & 2.670 & 0.000 & 4.582 \\
\hline Q1 TOTALS & 31.478 & 12.010 & 12.448 & 8.925 & 21.373 & 14.781 & 11.106 & 0.271 & 26.158 & 0.698 & 0.698 & 4.599 & 0.000 & 8.854 \\
\hline APRIL TOTALS & 12.382 & 5.088 & 4.164 & 3.032 & 7.195 & 4.201 & 1.725 & 0.048 & 5.974 & 0.350 & 0.350 & 2.172 & 0.000 & 3.808 \\
\hline MAY TOTALS & 11.949 & 5.878 & 4.180 & 3.405 & 7.585 & 4.555 & 1.963 & 0.040 & 6.558 & 0.303 & 0.303 & 0.669 & 0.000 & 2.652 \\
\hline JUNE TOTALS & 10.118 & 7.897 & 4.429 & 2.644 & 7.072 & 4.049 & 1.665 & 0.039 & 5.752 & 0.281 & 0.281 & 0.401 & 0.000 & 2.881 \\
\hline Q2 TOTALS & 34.449 & 18.863 & 12.773 & 9.080 & 21.853 & 12.805 & 5.352 & 0.127 & 18.284 & 0.935 & 0.935 & 3.241 & 0.000 & 9.340 \\
\hline H1 TOTALS & 65.927 & 30.873 & 25.221 & 18.005 & 43.226 & 27.586 & 16.458 & 0.398 & 44.442 & 1.632 & 1.632 & 7.840 & 0.000 & 18.194 \\
\hline JULY TOTALS & 10.184 & 6.670 & 3.829 & 2.247 & 6.075 & 5.025 & 2.177 & 0.054 & 7.257 & 0.349 & 0.349 & 1.110 & 0.000 & 3.175 \\
\hline AUGUST TOTALS & 10.427 & 7.543 & 4.670 & 2.827 & 7.496 & 3.861 & 2.312 & 0.125 & 6.298 & 0.243 & 0.243 & 1.238 & 0.000 & 3.507 \\
\hline SEPTEMBER TOTALS & 10.207 & 8.278 & 4.446 & 3.332 & 7.778 & 4.804 & 2.091 & 0.158 & 7.052 & 0.374 & 0.374 & 2.085 & 0.000 & 3.926 \\
\hline Q3 TOTALS & 30.818 & 22.490 & 12.944 & 8.405 & 21.349 & 13.690 & 6.580 & 0.336 & 20.606 & 0.966 & 0.966 & 4.434 & 0.000 & 10.608 \\
\hline OCTOBER TOTALS & 11.989 & 8.341 & 8.923 & 5.347 & 14.269 & 6.740 & 2.916 & 0.017 & 9.673 & 0.427 & 0.427 & 2.600 & 0.000 & 4.270 \\
\hline NOVEMBER TOTALS & 10.640 & 9.079 & 6.555 & 4.099 & 10.654 & 5.181 & 2.291 & 0.064 & 7.536 & 0.410 & 0.410 & 1.840 & 0.000 & 3.524 \\
\hline DECEMBER TOTALS & 10.183 & 10.134 & 7.388 & 4.572 & 11.959 & 7.244 & 3.189 & 0.140 & 10.574 & 0.500 & 0.500 & 2.239 & 0.102 & 4.961 \\
\hline Q4 TOTALS & 32.813 & 27.555 & 22.865 & 14.017 & 36.883 & 19.164 & 8.396 & 0.222 & 27.783 & 1.337 & 1.337 & 6.680 & 0.102 & 12.755 \\
\hline H2 TOTALS & 63.631 & 50.045 & 35.810 & 22.423 & 58.232 & 32.855 & 14.976 & 0.558 & 48.389 & 2.303 & 2.303 & 11.113 & 0.102 & 23.363 \\
\hline 2014 TOTALS & 129.558 & 80.918 & 61.030 & 40.428 & 101.458 & 60.441 & 31.435 & 0.956 & 92.831 & 3.935 & 3.935 & 18.953 & 0.102 & 41.557 \\
\hline
\end{tabular}

Source: ICE-Endex; EEX; Powernext, CEGH, GME; P. Heather 
P) Calculation of the physical demand figures for Churn matrix

\begin{tabular}{|c|c|c|c|c|c|c|c|c|}
\hline Country & Hub & $\begin{array}{c}\text { Data } \\
\text { source }^{1}\end{array}$ & Period & $\begin{array}{l}\text { TWh } \\
\text { consumption }^{2} \\
\text { NET Physical }\end{array}$ & $\begin{array}{c}\text { TWh demand }^{3} \\
\text { GROSS } \\
\text { Physical }\end{array}$ & $\begin{array}{l}\text { Conversion }^{4} \\
\text { TWh/1 bcm }\end{array}$ & $\begin{array}{c}\text { bcm } \\
\text { GROSS } \\
\text { Physical }\end{array}$ & $\begin{array}{r}\% \Delta \\
y r / y r\end{array}$ \\
\hline Britain & NBP & IEA & 2012 & 864.52 & 998.07 & 11.051 & 90.32 & \\
\hline Britain & NBP & IEA & 2013 & 855.66 & 963.45 & 11.051 & 87.18 & -3.5 \\
\hline Britain & NBP & IEA & 2014 & 783.08 & 902.89 & 11.051 & 81.70 & -6.3 \\
\hline Holland & TTF & IEA & 2012 & 419.92 & 973.63 & 9.261 & 105.13 & \\
\hline Holland & TTF & IEA & 2013 & 430.94 & $1,048.35$ & 9.261 & 113.20 & 7.7 \\
\hline Holland & TTF & IEA & 2014 & 376.04 & 919.30 & 9.261 & 99.27 & -12.3 \\
\hline Germany & NCG +GPL & IEA & 2012 & 853.20 & $1,042.97$ & 10.325 & 101.01 & \\
\hline Germany & NCG +GPL & IEA & 2013 & 901.40 & $1,084.34$ & 10.325 & 105.02 & 4.0 \\
\hline Germany & NCG + GPL & IEA & 2014 & 752.70 & 1140.90 & 10.325 & 110.50 & 5.2 \\
\hline France & PEGs & IEA & 2012 & 460.08 & 497.98 & 11.206 & 44.44 & \\
\hline France & PEGs & IEA & 2013 & 470.93 & 526.04 & 11.206 & 46.94 & 5.6 \\
\hline France & PEGs & IEA & 2014 & 413.93 & 493.24 & 11.206 & 44.02 & -6.2 \\
\hline Belgium & ZEE & IEA & 2012 & 220.71 & 431.05 & 11.024 & 39.10 & \\
\hline Belgium & $\mathrm{ZEE}+\mathrm{ZTP} / \mathrm{L}$ & IEA & 2013 & 191.07 & 463.48 & 11.024 & 42.04 & 7.5 \\
\hline Belgium & ZTP/L & IEA & 2014 & 171.95 & 440.76 & 11.024 & 39.98 & -4.9 \\
\hline Austria & BAUM & IEA & 2012 & 98.09 & 424.41 & 11.051 & 38.41 & \\
\hline Austria & BAUM & IEA & 2013 & 93.98 & 563.60 & 11.051 & 51.00 & 32.8 \\
\hline Austria & VTP & IEA & 2014 & 85.92 & 486.29 & 11.051 & 44.00 & -13.7 \\
\hline Italy & PSV & IEA & 2012 & 791.22 & 792.69 & 10.583 & 74.90 & \\
\hline Italy & PSV & IEA & 2013 & 741.39 & 743.78 & 10.583 & 70.28 & -6.2 \\
\hline Italy & PSV & IEA & 2014 & 655.21 & 657.72 & 10.583 & 62.15 & -11.6 \\
\hline Czech $^{5}$ & VOB & IEA & 2012 & 86.35 & 105.08 & 10.545 & 9.97 & \\
\hline Czech & VOB & IEA & 2013 & 88.88 & 396.23 & 10.545 & 37.58 & 277.1 \\
\hline Czech & VOB & IEA & 2014 & 79.21 & 388.08 & 10.545 & 36.80 & -2.1 \\
\hline
\end{tabular}

1: Data source:

IEA = International Energy Agency Monthly Gas Data Survey: http://www.iea.org/statistics/relatedsurveys/monthlygasdatasurvey/

2: Cons umption $=$ Production + Imports $-\Delta$ Storage - Exports

3: Demand $=$ Total Physical Throughput $=$ Consumption + Exports

4: Gross Calorific Values (GCV): IEA Average Consumption vahes in $\mathrm{TWh} / \mathrm{bcm}$ :

UK: 11.051; NL: 9.261; DE: 10.325; FR: 11.206; BE: 11.024; AT: 11.051; IT: 10.583; CZ: 10.545

5: Czech 2012 Gross Physical volumes: do not include 'Transit' gas 

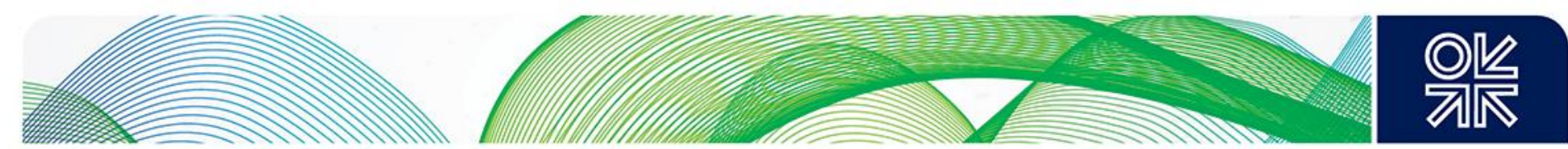

Q) Comparison of EU28 average wholesale gas prices: H1-2014

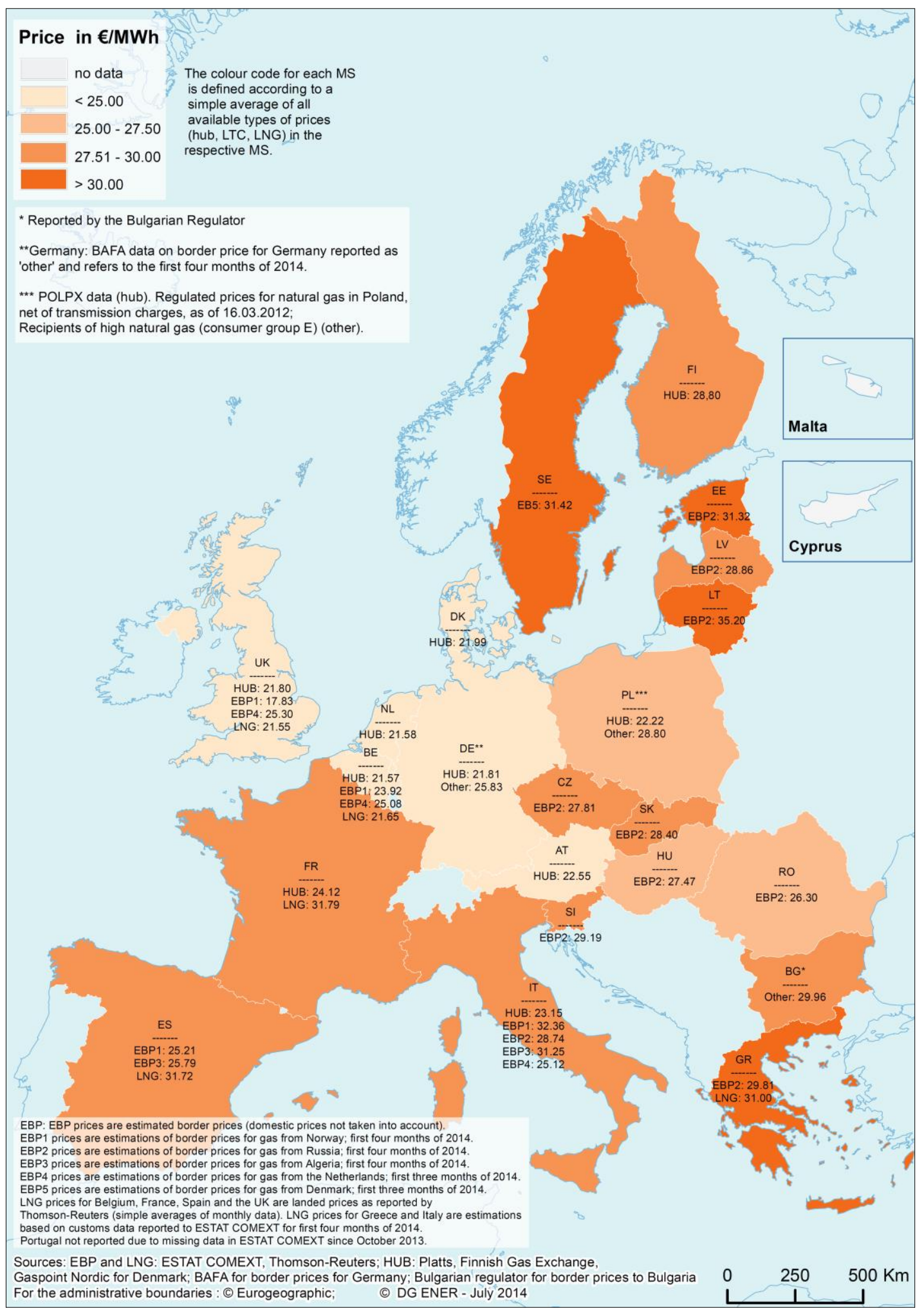

Source: EU Energy Markets in 2014: Figure 20, p.17 

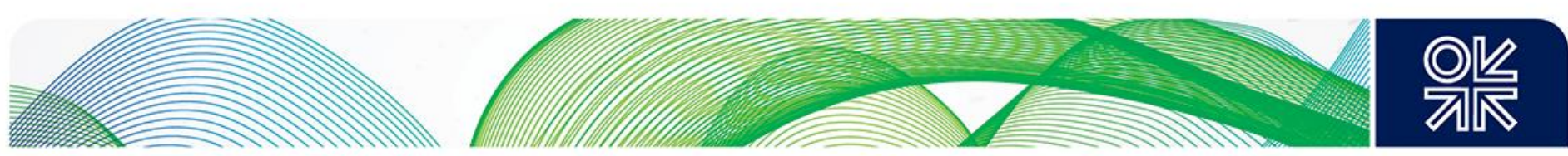

\section{0: Glossary}

\begin{tabular}{|c|c|c|}
\hline Term & Definition & Comment \\
\hline $\begin{array}{l}\mathrm{BCM} / \mathrm{bcm} \\
\mathrm{bcma} \\
\mathrm{bcm} / \mathrm{mth}\end{array}$ & $\begin{array}{l}\text { Billion cubic metres } \\
\text { Billion cubic metres per annum } \\
\text { Billion cubic metres per month }\end{array}$ & \\
\hline Capacity & $\begin{array}{l}\text { A measure of the amount of gas that a } \\
\text { pipeline is rated to transport. This will } \\
\text { usually be quoted as a flow rate. }\end{array}$ & \\
\hline $\begin{array}{l}\text { Cleared trades } \\
\text { (Give ups) }\end{array}$ & $\begin{array}{l}\text { Term used to indicate OTC bilateral } \\
\text { trades that are 'given up' to the } \\
\text { exchange for clearing. The counterparty } \\
\text { risk is then transferred to the Clearing } \\
\text { House. }\end{array}$ & $\begin{array}{l}\text { When two bilateral counterparties do not want to accept } \\
\text { the financial risk between them, inherent in an OTC } \\
\text { trade, they can choose to transfer their trades to an } \\
\text { exchange through the Clearing process and so end up } \\
\text { with a futures product. }\end{array}$ \\
\hline Clearing & $\begin{array}{l}\text { Strictly speaking, the processing of all } \\
\text { purchase and sale contracts traded on a } \\
\text { futures exchange. }\end{array}$ & $\begin{array}{l}\text { Term used in the futures markets to describe the } \\
\text { process of anonymously matching buyers and sellers } \\
\text { who traded on the Exchange. }\end{array}$ \\
\hline $\begin{array}{l}\text { EEX } \\
\text { (European } \\
\text { Energy } \\
\text { Exchange) }\end{array}$ & $\begin{array}{l}\text { The German energy exchange, } \\
\text { providing a market platform for trading in } \\
\text { power, natural gas, CO2 emission } \\
\text { allowances and coal. }\end{array}$ & $\begin{array}{l}\text { EEX's main contracts are German Power and the NCG } \\
\text { and Gaspool gas futures contracts. It self-clears all of its } \\
\text { contracts. } \\
\text { http://www.eex.com }\end{array}$ \\
\hline $\begin{array}{l}\text { EU Natural Gas } \\
\text { Directives }\end{array}$ & $\begin{array}{l}\text { The European Parliament and Council } \\
\text { Directive } 98 / 30 / E C \text { concerning common } \\
\text { rules for the internal market in natural } \\
\text { gas was ratified by Member States and } \\
\text { became law in } 2000 \text {. There followed the } \\
\text { second Gas Directive ( } 2003 / 55 / E C) \text { in } \\
2003 \text { and the third Gas Directive } \\
(2009 / 73 / E C) \text { in } 2009 \text {. }\end{array}$ & $\begin{array}{l}\text { The purpose of these directives was to create a single } \\
\text { Europe-wide gas market by reducing barriers to trade } \\
\text { and encouraging new entrants into the market. The text } \\
\text { of the three gas Directives can be found by searching } \\
\text { the EU archive at: http://old.eur- } \\
\text { lex.europa.eu/RECH_naturel.do?ihmlang=en }\end{array}$ \\
\hline $\begin{array}{l}\text { EU Energy } \\
\text { Packages }\end{array}$ & $\begin{array}{l}\text { There have been } 3 \text { energy packages, } \\
\text { although the 'first' was actually electricity } \\
\text { market and gas market Directives, } \\
\text { published in } 1996 \text { and } 1998 \text { respectively } \\
\text { and becoming effective in } 1997 \text { and } \\
2000 \text { respectively. The second became } \\
\text { effective in } 2003 \text { and the third in } 2009 \text {. }\end{array}$ & $\begin{array}{l}\text { These Packages contain Directives and regulations for } \\
\text { both the electricity and gas markets. }\end{array}$ \\
\hline Forwards & $\begin{array}{l}\text { OTC contracts to trade a commodity for } \\
\text { delivery in the future. } \\
\text { A forwards contract is a bilateral } \\
\text { contract, whether traded directly } \\
\text { between two parties, or through the } \\
\text { intermediary of a broker, or on an } \\
\text { electronic trading platform. }\end{array}$ & $\begin{array}{l}\text { The cash flow of trading forwards is very different to } \\
\text { trading futures: forwards contracts are settled after the } \\
\text { delivery of the traded commodity, when the buyer will } \\
\text { pay the seller's invoice. However, there is full } \\
\text { counterparty risk until the payment has been made. }\end{array}$ \\
\hline
\end{tabular}



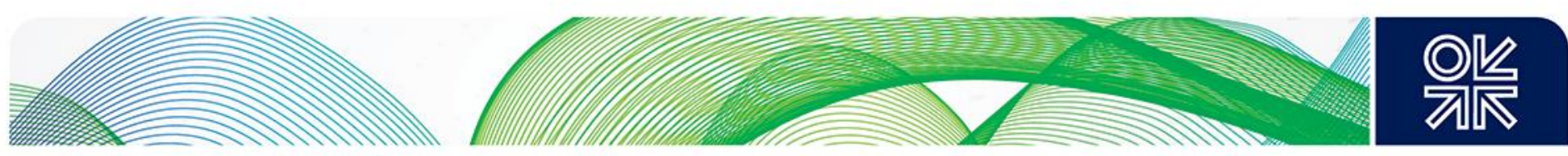

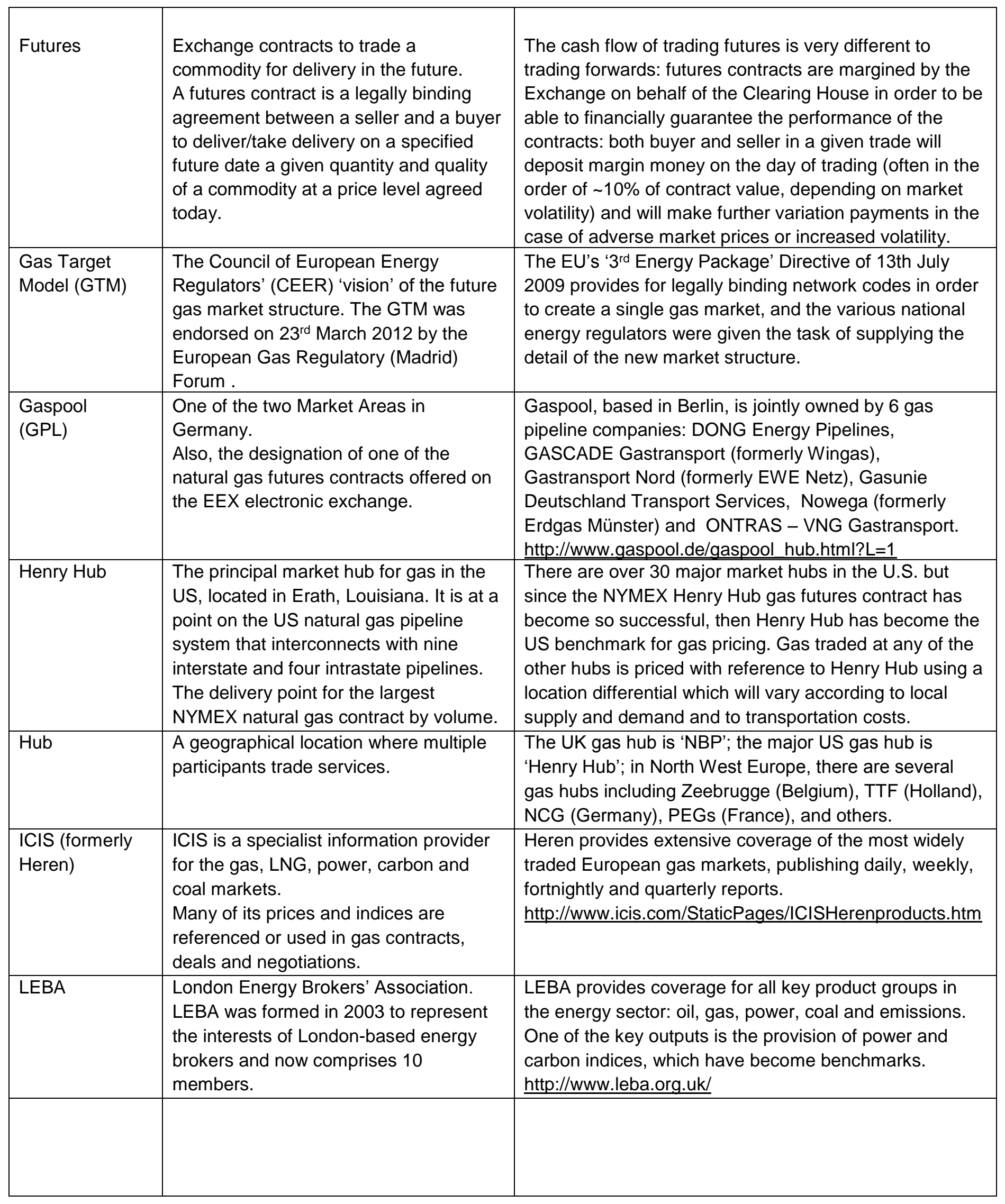



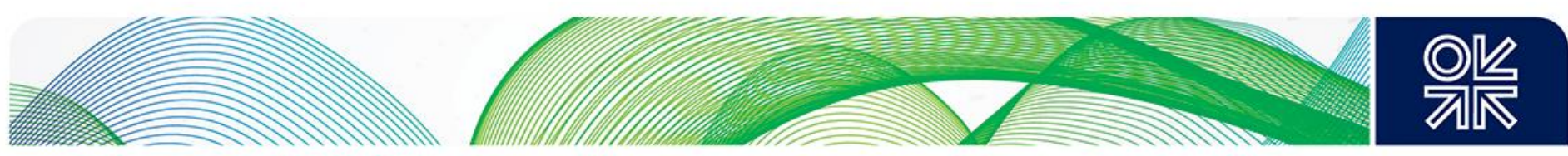

\begin{tabular}{|c|c|c|}
\hline $\begin{array}{l}\text { Liquefied } \\
\text { Natural Gas } \\
\text { (LNG) }\end{array}$ & $\begin{array}{l}\text { Liquefied natural gas or LNG is natural } \\
\text { gas that has been converted to liquid } \\
\text { form for ease of storage or } \\
\text { transportation. } \\
\text { Liquefied natural gas takes up about } \\
1 / 600 \text { th the volume of natural gas in the } \\
\text { gaseous state. It is odorless, colorless, } \\
\text { non-toxic and non-corrosive. } \\
\text { LNG is principally used for transporting } \\
\text { natural gas to markets, where it is } \\
\text { regasified and distributed as pipeline } \\
\text { natural gas. }\end{array}$ & $\begin{array}{l}\text { The liquefication process involves removal of certain } \\
\text { components, such as dust, acid gases, helium, water, } \\
\text { and heavy hydrocarbons, which could cause difficulty } \\
\text { downstream. The natural gas is then condensed into a } \\
\text { liquid at close to atmospheric pressure (maximum } \\
\text { transport pressure set at around } 25 \mathrm{kPa} / 3.6 \mathrm{psi}) \text { by } \\
\text { cooling it to approximately }-162{ }^{\circ} \mathrm{C}\left(-260^{\circ} \mathrm{F}\right) \text {. LNG } \\
\text { typically contains more than } 90 \% \text { methane. }\end{array}$ \\
\hline LNG Terminal & See Regasification Terminal & \\
\hline $\begin{array}{l}\text { Term gas } \\
\text { Contacts } \\
\text { (LTCs) }\end{array}$ & $\begin{array}{l}\text { In Continental Europe, Long Term } \\
\text { Contracts are traditionally the way in } \\
\text { which large volumes of gas are sold by } \\
\text { producers to the importing wholesalers. }\end{array}$ & $\begin{array}{l}\text { These contracts have been for a duration of } 20-30 \text { years } \\
\text { and the prices are determined by formulae containing } \\
\text { rolling averages of crude oil or defined oil product prices. }\end{array}$ \\
\hline $\begin{array}{l}\text { Market Area } \\
\text { (MA) }\end{array}$ & $\begin{array}{l}\text { A gas balancing zone. } \\
\text { A market area is a network, or an } \\
\text { alliance of several networks or sub- } \\
\text { networks connected by interconnection } \\
\text { points, in which a transmission customer } \\
\text { may use booked capacities at entry and } \\
\text { exit points in a flexible manner. }\end{array}$ & $\begin{array}{l}\text { For example, Britain has one MA, the NTS. Germany } \\
\text { has two MAs, Gaspool and NCG. Austria is proposing to } \\
\text { have three MAs from 1st January 2013, Eastern, Tyrol } \\
\text { and Voralberg and possibly, later this decade, have one } \\
\text { Regional MA, to include the existing grids of Slovakia, } \\
\text { Czech Republic and Hungary. }\end{array}$ \\
\hline $\mathrm{Mt} / \mathrm{mtpa}$ & $\begin{array}{l}\text { (For LNG) = Million tonnes / million } \\
\text { tonnes per year. }\end{array}$ & \\
\hline $\begin{array}{l}\text { NBP (National } \\
\text { Balancing } \\
\text { Point) }\end{array}$ & $\begin{array}{l}\text { The National Balancing Point or NBP is } \\
\text { a virtual point or location created by the } \\
\text { Network Code in order to promote the } \\
\text { balancing mechanism detailed in the } \\
\text { Code. In effect, it is the whole of the } \\
\text { NTS. }\end{array}$ & $\begin{array}{l}\text { Established in 1996, it is where shippers nominate their } \\
\text { buys and sells and where National Grid Gas balances } \\
\text { the system on a daily basis. } \\
\text { The NBP also rapidly evolved as a trading point too and } \\
\text { is the UK gas hub. }\end{array}$ \\
\hline $\begin{array}{l}\text { NCG } \\
\text { (NetConnect } \\
\text { Germany) }\end{array}$ & $\begin{array}{l}\text { One of the two Market Areas in } \\
\text { Germany. } \\
\text { Also, the designation of one of the } \\
\text { natural gas futures contracts offered on } \\
\text { the EEX electronic exchange. }\end{array}$ & $\begin{array}{l}\text { NCG, based in Ratingen, is jointly owned by } 6 \text { gas } \\
\text { pipeline companies: Bayernets, Fluxys TENP TSO, } \\
\text { GRTgaz Deutschland, Open Grid Europe, Terranets bw } \\
\text { (formerly GVS Netz) and Thyssengas. } \\
\text { http://www.net-connect- } \\
\text { germany.de/cps/rde/xchg/ncg/hs.xsl/index.htm }\end{array}$ \\
\hline $\begin{array}{l}\text { OTC } \\
\text { (Over-The- } \\
\text { Counter) }\end{array}$ & $\begin{array}{l}\text { The most common form of trading today, } \\
\text { OTC contracts are bilateral, dealt direct } \\
\text { or through brokers, by voice or } \\
\text { electronic media. } \\
\text { See "forwards" above. }\end{array}$ & $\begin{array}{l}\text { The duration can be from spot and prompt to several } \\
\text { years forward, in the form of physical or financial deals. } \\
\text { Unlike Exchange trading, OTC trading carries counter- } \\
\text { party credit and performance risk. }\end{array}$ \\
\hline $\begin{array}{l}\text { PEG } \\
\text { (Point } \\
\text { d'Echange de } \\
\text { Gaz) }\end{array}$ & $\begin{array}{l}\text { There are } 2 \text { French balancing zones } \\
\text { known as Points d'Echange de Gaz and } \\
\text { each is also a traded hub. PEG Nord } \\
\text { and TRS (Trading Region South) }\end{array}$ & $\begin{array}{l}\text { Also, the designations of the natural gas spot contracts } \\
\text { offered on the Powernext electronic exchange. } \\
\text { Powernext also offer a PEG Nord futures contract. }\end{array}$ \\
\hline
\end{tabular}



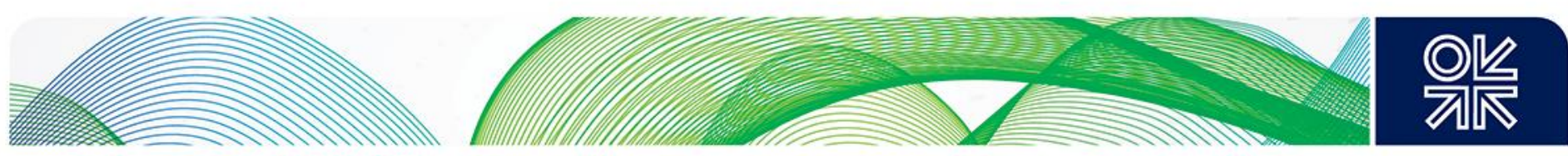

\begin{tabular}{|c|c|c|}
\hline $\begin{array}{l}\text { PSV } \\
\text { (Punto di } \\
\text { Scambio } \\
\text { Virtuale) }\end{array}$ & $\begin{array}{l}\text { The Italian gas trading hub, a virtual } \\
\text { point located between the national } \\
\text { network Entry and Exit Points at which } \\
\text { the subscriber can trade/sell gas } \\
\text { injected into the national network. }\end{array}$ & $\begin{array}{l}\text { The PSV System is the IT platform for trading and } \\
\text { selling gas at the Virtual Trading Point and which } \\
\text { enables transactions to be registered. }\end{array}$ \\
\hline $\begin{array}{l}\text { Regasification } \\
\text { Terminal }\end{array}$ & $\begin{array}{l}\text { Where LNG vessels are received and } \\
\text { their shipment transferred to holding } \\
\text { tanks before being reheated and } \\
\text { reconverted into pipeline gas. }\end{array}$ & $\begin{array}{l}\text { Usually connected to a storage and pipeline distribution } \\
\text { network to distribute natural gas to local distribution } \\
\text { companies. In some cases they may directly feed a } \\
\text { power station or industrial plant. }\end{array}$ \\
\hline $\begin{array}{l}\text { TSO } \\
\text { (Transmission } \\
\text { System } \\
\text { Operator) }\end{array}$ & $\begin{array}{l}\text { The company(ies) responsible for a gas } \\
\text { pipeline system and its safe operation. } \\
\text { Some countries have one TSO, others } \\
\text { have multiple TSOs. }\end{array}$ & $\begin{array}{l}\text { Some European TSOs are: Austria, BOG/OMV/TAG; } \\
\text { Belgium, Fluxys; Britain, NGG/IUK; France, } \\
\text { GRTgaz/TIGF; Holland, Gas Transport Services; Italy, } \\
\text { Edison Stoccaggio/Snam Rete Gas. }\end{array}$ \\
\hline $\begin{array}{l}\text { TTF } \\
\text { (Title Transfer } \\
\text { Facility) }\end{array}$ & $\begin{array}{l}\text { The Dutch gas trading hub, TTF, is a } \\
\text { virtual market place where the Dutch } \\
\text { TSO, Gas Trading Services (GTS), } \\
\text { offers market participants the } \\
\text { opportunity to transfer gas that is } \\
\text { already present in the GTS system } \\
\text { ('entry-paid gas') to another party. Can } \\
\text { also be traded as futures contracts on } \\
\text { ICE-Endex. }\end{array}$ & $\begin{array}{l}\text { TTF was established in 2003; it can serve as a virtual } \\
\text { entry point in the portfolio of a shipper or trader who } \\
\text { buys gas on TTF, or as a virtual exit point in the portfolio } \\
\text { of a shipper or trader who sells gas on TTF. GTS } \\
\text { registers the title transfers of gas via TTF by means of a } \\
\text { 'nomination'. This is an electronic message stating the } \\
\text { volumes of gas transferred, and the purchasing and } \\
\text { selling parties. }\end{array}$ \\
\hline $\begin{array}{l}\text { VTP } \\
\text { (Virtual Trading } \\
\text { Point) }\end{array}$ & $\begin{array}{l}\text { The virtual location in a Market Area } \\
\text { where quantities of gas may be traded } \\
\text { after entry and before exit. }\end{array}$ & $\begin{array}{l}\text { The Virtual Trading Point enables the purchase or sale } \\
\text { of gas quantities without booked capacities, as well as } \\
\text { the transfer of gas quantities between balancing groups. } \\
\text { It is not allocated to a physical entry or exit point. }\end{array}$ \\
\hline $\begin{array}{l}\text { Zeebrugge } \\
\text { (ZEE) }\end{array}$ & $\begin{array}{l}\text { A Belgian port and the generic term } \\
\text { used for the market hub of the same } \\
\text { name. The Zeebrugge Hub is a so- } \\
\text { called physical hub, with natural gas } \\
\text { made available from neighbouring } \\
\text { countries, the nearby LNG terminal or } \\
\text { the Belgian market. Connecting to a } \\
\text { variety of pipeline gas and LNG sources, } \\
\text { the Zeebrugge area has an overall } \\
\text { throughput capacity of about 48Bcma. }\end{array}$ & $\begin{array}{l}\text { The Zeebrugge area is considered to be one of the most } \\
\text { important natural gas landing points in the EU27. The } \\
\text { Interconnector Zeebrugge Terminal (IZT) connects the } \\
\text { Belgian grid (operated by Fluxys) to the underwater } \\
\text { Interconnector pipeline which runs to Bacton in England. } \\
\text { Gassco's Zeepipe Terminal (ZPT) connects Norway's } \\
\text { Troll and Sleipner offshore gas fields to the Fluxys grid } \\
\text { via the underwater Zeepipe pipeline. The Zeebrugge } \\
\text { LNG Terminal serves as a gateway to supply LNG into } \\
\text { North West Europe. }\end{array}$ \\
\hline ZTP & $\begin{array}{l}\text { Zeebrugge Trading Point. } \\
\text { The Belgian entry-exit transmission } \\
\text { model offering title trading. }\end{array}$ & $\begin{array}{l}\text { Belgian TSO Fluxys and energy exchange ICE-ENDEX } \\
\text { cooperated to create the new Zeebrugge Trading Point } \\
\text { which started when Fluxys switched to a new Entry/Exit } \\
\text { model for its transmission grid at the end of } 2012 \text {. ICE- } \\
\text { ENDEX provides exchange services for the new } \\
\text { Zeebrugge Trading Point. }\end{array}$ \\
\hline
\end{tabular}



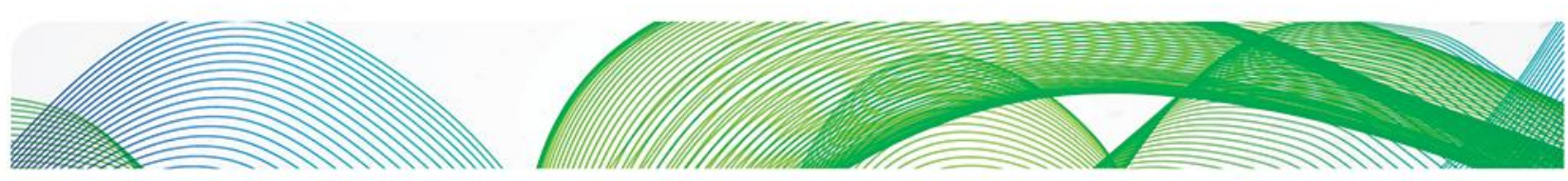

\section{1: Bibliography}

BP (2015): "BP Statistical Review of World Energy June 2015"

http://www.bp.com/content/dam/bp/pdf/energy-economics/statistical-review-2015/bp-

statistical-review-of-world-energy-2015-full-report.pdf

deJong (2015/16): Sybren de Jong: "European Gas Hubs Behaviour - the 'Starlings' theory";

OIES Paper (forthcoming Winter 2015/16)

FEEM (2014): Fondazione Eni Enrico Mattei: "Turkey as a Regional Natural Gas Hub: Myth or Reality?"; Nota di Lavoro 2.2014, February 2014

http://www.feem.it/getpage.aspx?id=6055\&sez=Publications\&padre $=73$

Floreest (2010): Floris van Foreest: "The Role of Natural Gas in the Dutch Energy Transition: Towards low-carbon electricity supply"; OIES Paper NG39, January 2010 http://www.oxfordenergy.org/2010/01/the-role-of-natural-gas-in-the-dutch-energy-transitiontowards-low-carbon-electricity-supply/

GIIGNL (2015): Groupe International des Importateurs de Gaz Naturel Liquéfié: "The LNG Industry in 2014" (March 2015)

http://www.giignl.org/sites/default/files/PUBLIC AREA/Publications/giignl 2015 annual report .pdf

Heather (2010): Patrick Heather: "The Evolution and Functioning of the Traded Gas Market in Britain"; OIES Paper NG44, August 2010

http://www.oxfordenergy.org/wpcms/wp-content/uploads/2010/11/NG44-

TheEvolutionandFunctioningOfTheTradedGasMarketInBritain-PatrickHeather-2010.pdf

Heather (2012): Patrick Heather: "Continental European Gas Hubs: are they fit for purpose?"; OIES Paper NG63, June 2012

http://www.oxfordenergy.org/wpcms/wp-content/uploads/2012/06/NG-63.pdf

Honoré (2010): "European Natural Gas Demand, Supply \& Pricing, cycles, seasons and the impact of LNG price arbitrage", Oxford University Press, December 2010

http://www.oxfordenergy.org/shop/european-natural-gas-demand-supply-pricing-cyclesseasons-and-the-impact-of-Ing-price-arbitrage/

Honoré (2014): Anouk Honoré: "The Outlook for Natural Gas Demand in Europe"; OIES Paper NG87, June 2014 http://www.oxfordenergy.org/2014/06/the-outlook-for-natural-gas-demand-in-europe-2/

IEA (2014): IEA Monthly Natural Gas Surveys http://www.iea.org/statistics/monthlystatistics/monthlygasstatistics/ 

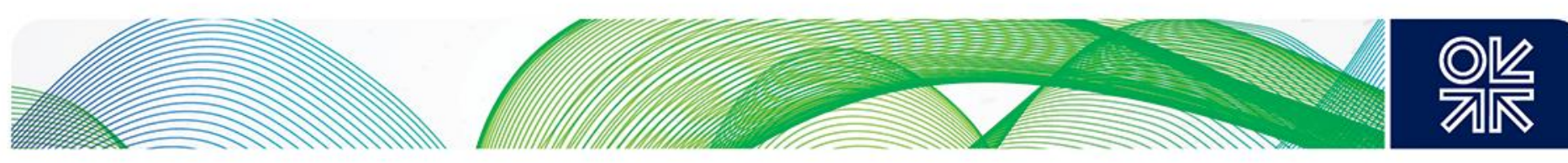

Petrovitch (2013): Beatrice Petrovitch: "European gas hubs: how strong is price correlation?"; OIES Paper NG79, October 2013

http://www.oxfordenergy.org/wpcms/wp-content/uploads/2013/10/NG-79.pdf

Petrovitch (2014): Beatrice Petrovitch: "European gas hubs price correlation - barriers to convergence"; OIES Paper NG91, September 2014

http://www.oxfordenergy.org/2014/09/european-gas-hubs-price-correlation-barriers-toconvergence/

Petrovitch (2015): Beatrice Petrovitch: "The cost of price de-linkages between European gas hubs"; OIES Paper NG101, September 2015

http://www.oxfordenergy.org/2015/09/the-cost-of-price-de-linkages-between-european-gashubs-2/

Pirani/Yafimava (2015/16): Simon Pirani and Katja Yafimava: "Russian gas transit across Ukraine post 2019”; OIES Paper (forthcoming Winter 2015/16)

Stern (2007): Jonathan Stern: "Is There a Rationale for the Continuing Link to Oil Product Prices in Continental European Long Term Gas Contracts?"

http://www.oxfordenergy.org/?s=NG19

Stern et al (2014): Jonathan Stern ed.: "Reducing European Dependence on Russian Gas"; OIES Paper NG92, October 2014

http://www.oxfordenergy.org/2014/10/reducing-european-dependence-on-russian-gas-

distinguishing-natural-gas-security-from-geopolitics/

Yafimava (2013): Katja Yafimava: "The EU Third Energy Package for Gas and the Gas Target Model: major contentious issues inside and outside the EU"; OIES Paper NG75, April 2013 http://www.oxfordenergy.org/2013/04/the-eu-third-package-for-gas-and-the-gas-target-modelmajor-contentious-issues-inside-and-outside-the-eu-2/ 